\title{
The value of optical coherence tomography in anterior segment surgery
}

Citation for published version (APA):

Doors, M. (2014). The value of optical coherence tomography in anterior segment surgery. [Doctoral Thesis, Maastricht University]. Maastricht University. https://doi.org/10.26481/dis.20140221md

Document status and date:

Published: 01/01/2014

DOI:

10.26481/dis.20140221 md

Document Version:

Publisher's PDF, also known as Version of record

\section{Please check the document version of this publication:}

- A submitted manuscript is the version of the article upon submission and before peer-review. There can be important differences between the submitted version and the official published version of record.

People interested in the research are advised to contact the author for the final version of the publication, or visit the DOI to the publisher's website.

- The final author version and the galley proof are versions of the publication after peer review.

- The final published version features the final layout of the paper including the volume, issue and page numbers.

Link to publication

\footnotetext{
General rights rights.

- You may freely distribute the URL identifying the publication in the public portal. please follow below link for the End User Agreement:

www.umlib.nl/taverne-license

Take down policy

If you believe that this document breaches copyright please contact us at:

repository@maastrichtuniversity.nl

providing details and we will investigate your claim.
}

Copyright and moral rights for the publications made accessible in the public portal are retained by the authors and/or other copyright owners and it is a condition of accessing publications that users recognise and abide by the legal requirements associated with these

- Users may download and print one copy of any publication from the public portal for the purpose of private study or research.

- You may not further distribute the material or use it for any profit-making activity or commercial gain

If the publication is distributed under the terms of Article $25 \mathrm{fa}$ of the Dutch Copyright Act, indicated by the "Taverne" license above, 
The Value of Optical Coherence Tomography in Anterior Segment Surgery

Muriël Doors 
Financial support for the publication of this thesis was provided by:

Rotterdamse Stichting Blindenbelangen, Stichting Blindenhulp, Ophtec BV, Hoornvlies patienten vereniging, Allergan BV, Ursapharm Benelux BV, Rockmed BV, Thea Pharma NV, Alcon BV, Carl Zeiss BV, ABN Amro Bank

Printed by Drukwerkconsultancy

C Copyright M Doors, Maastricht 2014

ISBN 978-90-9028036-3

All rights reserved. No part of this publication may be reproduced in any form or by any means, electronically, mechanically, by print or otherwise without written permission of the copyright owner. 


\title{
The Value of Optical Coherence Tomography in Anterior Segment Surgery
}

\author{
PROEFSCHRIFT \\ ter verkrijging van de graad van doctor \\ aan de Universiteit Maastricht \\ op gezag van de Rector Magnificus \\ Prof. dr. L.L.G. Soete, \\ volgens het besluit van het College van Decanen \\ in het openbaar te verdedigen \\ op vrijdag 21 februari 2014 om 12:00 uur
}

door

Muriël Doors 


\section{Promotores}

Prof. dr. R.M.M.A. Nuijts

Prof. dr. C.A.B. Webers

\section{Copromotor}

Dr. T.T.J.M. Berendschot

\section{Beoordelingscommissie}

Prof. dr. H.W.M. Steinbusch, voorzitter

Dr. C.J. Budo

Prof. dr. R.R.W.J. van der Hulst

Prof. dr. N.M. Jansonius (Universitair Medisch Centrum Groningen)

Prof. dr. G.P.M. Luyten (Leids Universitair Medisch Centrum) 
voor Hanna 


\section{Contents}

List of Abbreviations $\quad 8$

Chapter 1 Introduction: 11

The value of optical coherence tomography for anterior seg-

ment surgery

J Cataract Refract Surg. 2010 Jul;36(7):1213-29

Chapter 2 Comparison of central corneal thickness and anterior chamber depth measurements using three imaging technologies in normal eyes and after phakic intraocular lens implantation Graefes Arch Clin Exp Ophthalmol. 2009 Aug;247(8):1139-46

Chapter 3 Influence of anterior chamber morphometrics on endothelial 55 cell changes after phakic intraocular lens implantation J Cataract Refract Surg. 2008 Dec;34(12):2110-8

Chapter 4 The value of preoperative phakic intraocular lens simulation 73 using optical coherence tomography J Cataract Refract Surg. 2009 Mar;35(3):438-43

Chapter 5 Model to predict endothelial cell loss after iris-fixated phakic 85 intraocular lens implantation Invest Ophthalmol Vis Sci. 2010 Feb;51(2):811-5

Chapter 6 Late-onset decentration of iris-fixated phakic intraocular 99 lenses: a case series Am J Ophthalmol. 2009 Jun;147(6):997-1003

Chapter 7 Artiflex toric foldable phakic intraocular lens: short term re- 113 sults of a prospective european multicenter study Am J Ophthalmol. 2012 Oct;154(4):730-9

Chapter 8 Use of anterior segment optical coherence tomography to 135 study corneal changes after collagen cross-linking Am J Ophthalmol. 2009 Dec;148(6):844-51 
Chapter 9 Phacopower modulation and the risk for postoperative corneal

151 decompensation: a randomized trial of cataract surgery in Fuchs' endothelial dystrophy

JAMA Ophthalmol. 2013 Nov;131(11):1443-50

Chapter 10 General discussion

Summary / samenvatting

Dankwoord

Curriculum Vitae

List of publications 


\section{List of Abbreviations}

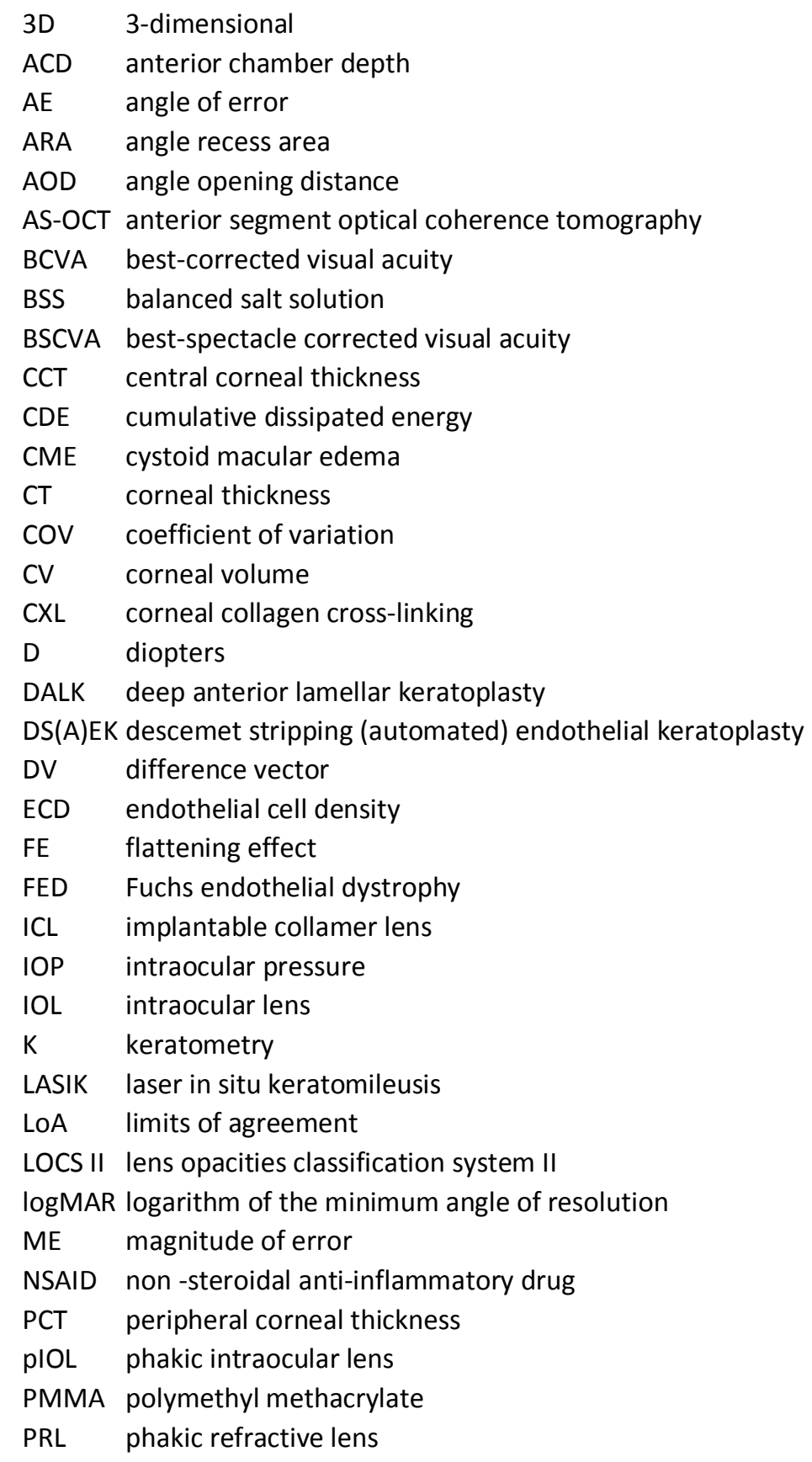


PRK photorefractive keratectomy

PK penetrating keratoplasties

$R \quad$ Pearson's correlation coefficient

SD standard deviation

SE spherical equivalent

SIA surgically induced astigmatism

SL-OCT slit-lamp-OCT

TIA target induced astigmatism

TISA trabecular-iris space area

UBM ultrasound biomicroscopy

UCVA uncorrected visual acuity

UVA ultraviolet-A

US ultrasound 



\section{Chapter 1}

\section{Introduction}

The value of optical coherence tomography for anterior segment surgery: a review

Muriël Doors, Tos T. J. M. Berendschot, John de Brabander, Carroll A. B. Webers, Rudy M. M. A. Nuijts

Partly published as review:

J Cataract Refract Surg. 2010 Jul;36(7):1213-29 


\section{INTRODUCTION}

Assessment of the anterior segment of the eye is an important part of ophthalmic examination. There are numerous ways to investigate the anterior segment, including traditional slit-lamp examination, rotating Scheimpflug photography, and ultrasound biomicroscopy (UBM). In contrast to Scheimpflug imaging, UBM is a contact method, which caries the risk of corneal abrasions and infections due to corneal contact, as well as discomfort experienced by the patient. Corneal contact is also necessary to assess the iridocorneal angle during slit-lamp biomicroscopy and is a highly subjective examination, depending on experience of the examiner and light conditions. Due to the mentioned disadvantages of contact methods, non-contact imaging devices have become increasingly popular.

After the initial development of optical coherence tomography for imaging of the posterior segment of the eye in $1991^{1}$, anterior segment optical coherence tomography (AS-OCT) recently became available. ${ }^{2}$ This new non-contact technology has had a significant impact on ophthalmic practise and research. It allows highresolution, cross-sectional images of the anterior segment of the eye and can be used in various clinical situations, such as the investigation of pathological processes in the anterior segment (e.g. uveitis, tumor), the evaluation of chamber angle configurations, and the measurement of anterior chamber dimensions. Furthermore, there is an increasing popularity of the device for follow-up purposes after corneal refractive surgery, phakic intraocular lens (pIOL) implantation, corneal collagen cross-linking (CXL), intracorneal ring segment implantation and glaucoma filtering surgery.

\section{PRINCIPLES OF OPTICAL COHERENCE TOMOGRAPHY}

The technique of AS-OCT is based on low coherence interferometry, which measures the delay and intensity of backscattered infrared light, using a super luminescent diode with a wavelength of approximately $1310 \mathrm{~nm}$. Low coherence interferometry measures the interference of two light beams that come from the same light source, by comparing the backscattering of tissue to light that travels a known reference path with a reference mirror. ${ }^{1}$ (Figure 1 ) Both paths are combined at a detector, then modulated and finally send to a computer. Multiple longitudinal scans are performed at a series of lateral locations to form a two-dimensional image, which is similar to B-scan ultrasonography, except AS-OCT uses light rather than sound waves. AS-OCT has a 10-25 times (approximately $10 \mu \mathrm{m}$ ) higher resolution than high resolution ultrasound imaging and a faster image acquisition time. However, the penetration depth is smaller with optical coherence tomography when compared to ultrasound. ${ }^{3}$ 
Retinal OCT uses light with a wavelength of $830 \mathrm{~nm}$. The wavelength used in ASOCT results in less scattering in tissues such as sclera and limbus, which increases the penetration through these tissues and allows the visualization of cornea, iris, anterior chamber angle and anterior portion of the lens through the pupil. This longer wavelength of light is absorbed by water in the ocular media, and therefore only $10 \%$ of the laser light reaches the retina. ${ }^{4}$ Unfortunately, AS-OCT can not pass through the pigmentation on the posterior side of the iris, which limits the visualization of the ciliary body. The transmitted light is absorbed by the pigment epithelium of the iris.

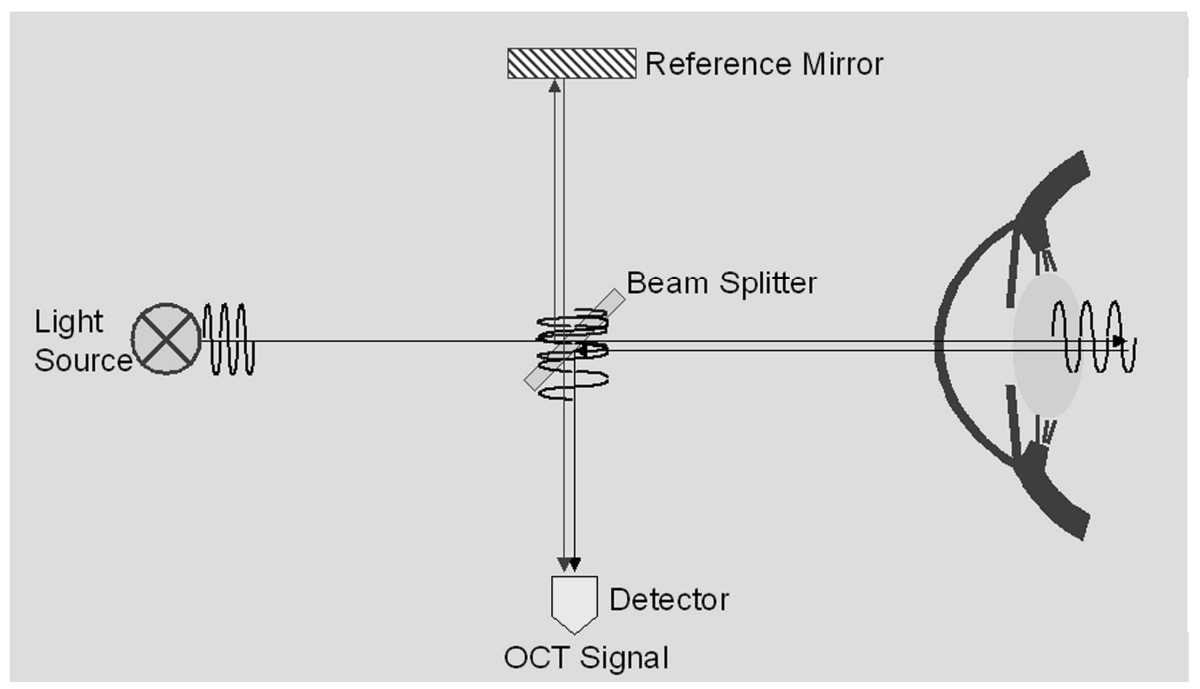

Figure 1. Basic principle of optical coherence tomography: Light beams are directed into tissue and reflections coming from different layers are received by a detector and then processed to generate a two-dimensional image.

\section{Visante OCT versus Slit-lamp-OCT}

Currently, two types of time-domain AS-OCT are commercially available for application in anterior segment imaging; the Visante OCT and Slit-Lamp-OCT (SL-OCT; Heidelberg Engineering $\mathrm{GmbH}$, Heidelberg, Germany). Both imaging systems use low coherence interferometry to scan the anterior segment of the eye. However, there are some differences in acquiring and processing the images. The SL-OCT is incorporated into a modified slit-lamp biomicroscopy system, to save time and space in the clinic. However, the image acquisition is 10 times faster with the Visante OCT compared to the SL-OCT, and the transverse and axial resolutions are 60 and $18 \mu \mathrm{m}$, respectively, for the Visante OCT compared to 75 and $25 \mu \mathrm{m}$, respectively, for the SL-OCT (Table 1). Furthermore, when imaging the anterior segment using the Visante OCT, the device automatically repositions the head of the patient in the 
chinrest, which can be followed by the examiner on a live video screen. The SL-OCT uses a low-intensity narrow light beam from the slit-lamp, which has to be manually positioned by the examiner. Hence, greater operator skills are necessary to acquire the images with SL-OCT. However, this position behind the slit-lamp has one major advantage; the inferior and superior eyelids are easily held open by the examiner, whereas with the Visante OCT this is much more difficult, especially when scanning the left eye. The Visante OCT is capable of scanning up to 4 meridians simultaneously. After the images have been captured and saved to the computer, both OCT devices can measure distances between two points on the acquired scans as well as perform a quantitative analysis of the chamber angle. Various parameters can be measured including corneal thickness (CT), anterior chamber depth (ACD), anterior chamber angle, and angle-to-angle distance. Furthermore, additional software can analyse and calculate other useful parameters, such as angle opening distance (AOD), trabecular-iris space area (TISA), angle recess area (ARA), scleral spur angle, and lens rise.

Table 1. Slit-lamp Optical Coherence Tomography (OCT) versus Visante OCT

\begin{tabular}{lll}
\hline & Slit-lamp OCT & Visante OCT \\
\hline Device & Incorporated in slit-lamp & Separate device \\
Transverse resolution & $75 \mu \mathrm{m}$ & $60 \mu \mathrm{m}$ \\
Axial resolution & $25 \mu \mathrm{m}$ & $18 \mu \mathrm{m}$ \\
Scanning & Manual repositioning of patient & Automatic repositioning of patient \\
Opening eyelids & Easily held open & Difficult when scanning left eye \\
Meridians & 1 meridian at a time & $4-16$ meridians at a time \\
\hline
\end{tabular}

A recent study compared the diagnostic performance of the Visante OCT in angle measurements to the SL-OCT. ${ }^{5}$ In detecting irido-trabecular contact, the Visante OCT detected significantly more eyes than SL-OCT. A possible explanation for the reported difference might be that the SL-OCT needs a narrow light beam from the slit-lamp to capture the OCT image, whereas the Visante OCT can capture images in total darkness. This light difference resulted in a larger pupil diameter when using the Visante OCT. The overall agreement with gonioscopy was better for the SL-OCT than the Visante-OCT, most likely because the lighting circumstances were the same for gonioscopy and SL-OCT. The latest version of the SL-OCT tackles this problem, as it has a video monitor, which allows scanning in the dark.

The repeatability for central corneal thickness (CCT) measurements was high for both devices (Visante OCT and SL-OCT). ${ }^{6}$ However, the automated as well as the manual CCT measurements were significantly higher with the SL-OCT compared to CCT measurements using the Visante OCT, despite the identical working principle.

The Visante OCT has a built-in fixation target, which can be adjusted by adding positive and negative lenses to compensate for the patient's spherical ametropia. 
Due to these possibilities, the Visante OCT is able to investigate patients in accommodated and unaccommodated states, which can be useful to evaluate the movement of the crystalline lens and changes in pupil size in vivo during accommodation. $^{7}$

\section{BIOMETRY MEASUREMENTS}

\section{Corneal Thickness}

CCT is a useful measurement in the diagnosis of certain corneal diseases, for preoperative screening of refractive surgery candidates, and accurate interpretation of intraocular pressure measurements. The most commonly used technique and current 'gold standard' for CCT assessment is a spot measurement by ultrasound pachymetry. However, this technique is of limited use, for example in donor corneas, because of the contact required during measurements. Contact with donor corneas during storage should ideally be avoided to preserve tissue sterility. Light microscopy and slit-lamp examinations are currently used to investigate these donor corneas in storage medium. However, AS-OCT has been proposed as a method for donor cornea screening, since it can perform non-contact measurements through the donor corneal chamber. 8

Several studies demonstrated a good correlation between CCT measurements by AS-OCT and ultrasound pachymetry. ${ }^{6,10-12}$ However, most reports do show a significant smaller measurement by AS-OCT when compared to ultrasound pachymetry, ${ }^{6,11,12}$ whereas other show no significant difference, ${ }^{10}$ or even larger measurements. ${ }^{13}$ To our knowledge, only one study compared CCT measurements by Scheimpflug imaging to AS-OCT. This study showed a significant difference between these two devices, with smaller CCTs measured using AS-OCT compared to Scheimpflug imaging. ${ }^{14}$ Overall, it should be noted that CCT measurements can not be used interchangeably between the mentioned devices.

Recent studies show an excellent repeatability and reproducibility for CCT measurements using AS-OCT. ${ }^{6,11,15}$ Furthermore, the Visante OCT is capable of producing reproducible pachymetry maps after scanning the cornea on 8 or 16 different meridians (Figure 2). ${ }^{16}$ Corneal mapping can reveal abnormal patterns characteristic for keratoconus or pellucid marginal degeneration, and can also be useful in the preoperative evaluation of patients seeking refractive surgery or before intracorneal ring segment implantation. Corneal thinning is an important feature of keratoconus, and therefore pachymetry mapping may offer useful additional information besides corneal topography maps, especially in cases where topography maps are unreliable due to poor corneal reflexes in advanced keratoconus or tear film disturbances. Mohamed et al. showed that these pachymetry maps for central 
and peripheral corneal thickness measurements, are repeatable and reproducible in healthy eyes as well as in patients with keratoconus, which was also confirmed by Li et al. $^{17,18}$

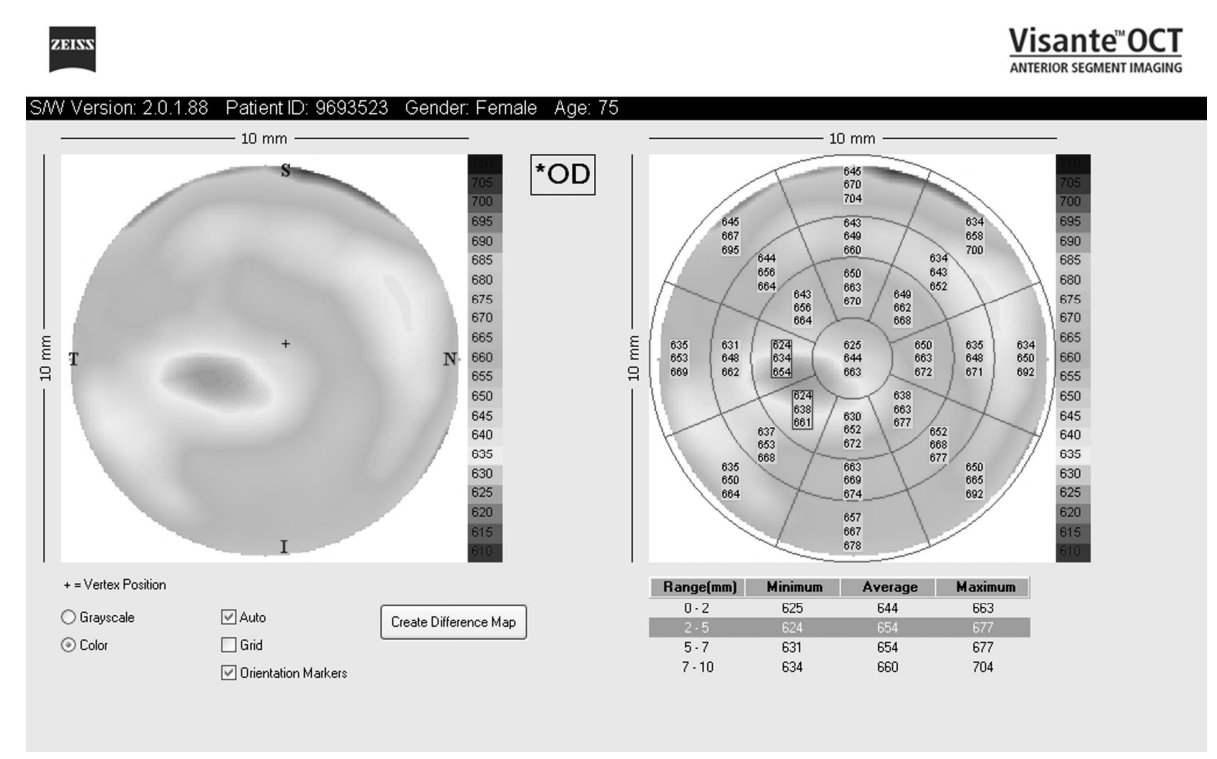

Figure 2. Visante pachymetry map of patient with Fuchs endothelial dystrophy.

\section{Anterior Chamber Biometry}

Measurements of anterior chamber dimensions are important for IOL calculations prior to cataract surgery and for safe implantation of pIOLs. UBM and AS-OCT can both measure ACD. Recent studies showed high correlations between ACD measurements by AS-OCT and UBM, with only a small variability between measurements, with the advantage of AS-OCT being a non-contact technique. ${ }^{10,19,20}$

AS-OCT can also be used for research purposes, e.g. to study changes in ACD before and after phacoemulsification. ${ }^{21}$ It is able to easily visualize the IOL, which is important for postoperative ACD assessment.

Another anterior chamber measurement which can be assessed by AS-OCT is angle-to-angle distance. This distance is especially important prior to implantation of angle-supported pIOLs, to guarantee adequate sizing and hence avoid postoperative complications. ${ }^{22,23}$ In the past, size was determined by measuring white-towhite diameter. A recent study by Kohnen et al. showed that estimated white-towhite measurements (horizontal corneal diameter) performed by IOLMaster (Carl Zeiss Meditec, Jena, Germany) were significantly smaller than AS-OCT angle-toangle distances, with more accurate 'real' angle-to-angle distances using AS-OCT. ${ }^{24}$ Furthermore, AS-OCT can measure angle-to-angle distance in all meridians. ${ }^{25}$ Pinero 
et al. reported no significant differences between UBM and AS-OCT angle-to-angle measurements, with excellent intrasession repeatability for both devices. ${ }^{20}$

Other important measurements in the preoperative assessment of patients wanting iris-fixated plOL implantations include iris profile/configuration and crystalline lens rise (distance between the angle-to-angle reference line and the anterior pole of the crystalline lens), which can both be assessed using AS-OCT (Figure 3). A lens rise larger than 600 microns and a convex iris shape results in an increased risk for pigment dispersion on the plOLs, due to sandwiching of the iris between the pIOL and the crystalline lens. ${ }^{26}$

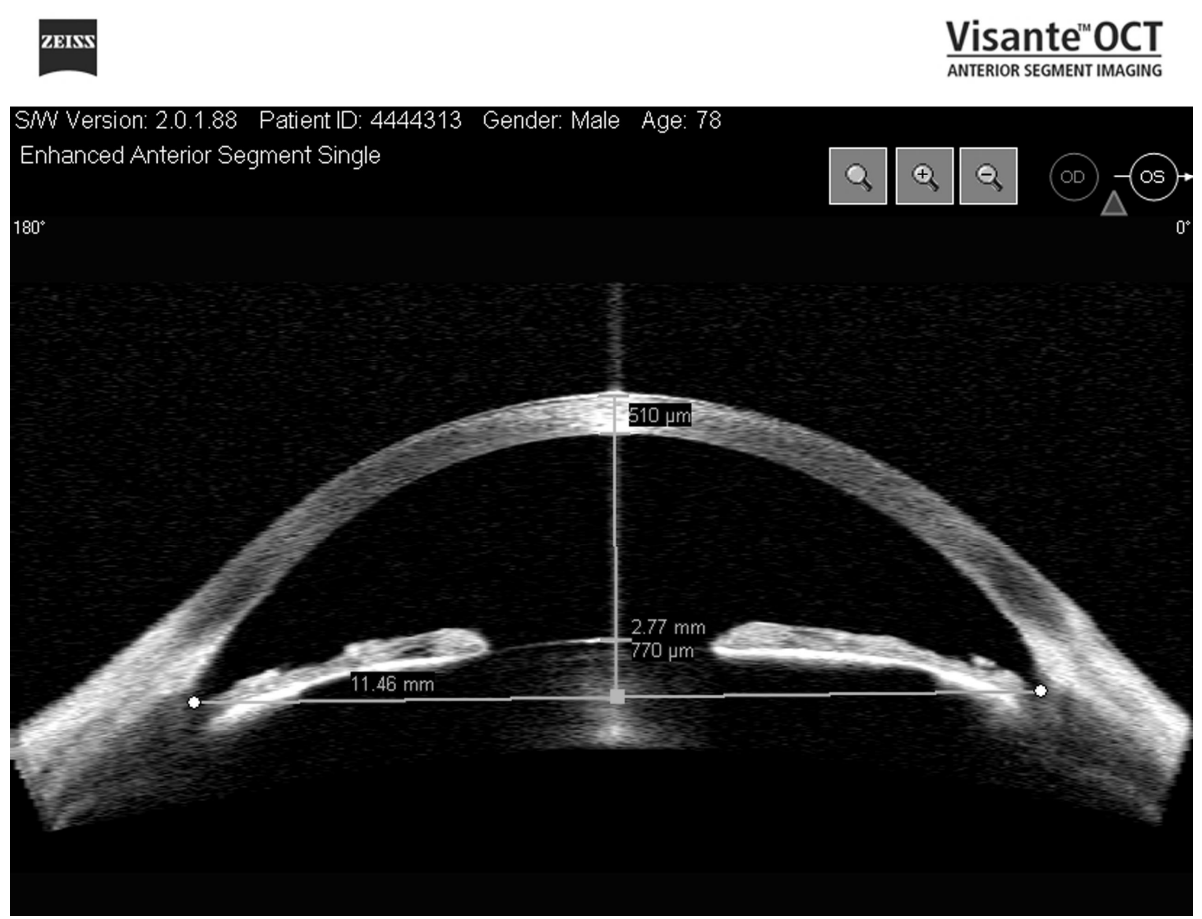

Figure 3. Visante anterior segment scan of phakic eye, with measured central corneal thickness $(510 \mu \mathrm{m})$, anterior chamber depth $(2.77 \mathrm{~mm})$, angle-to-angle distance $(11.46 \mathrm{~mm})$, and lens rise $(770 \mu \mathrm{m})$.

\section{Angle Measurements}

Although angle closure glaucoma represents only $25 \%$ of all glaucoma cases, it causes a great amount of visual morbidity. Therefore, early detection of this type of glaucoma is of great importance and significantly improves visual prognosis. AS-OCT provides cross-sectional images of the anterior chamber angle, which makes it potentially useful in glaucoma research and the detection and management of primary angle closure. ${ }^{27}$ It is capable of a qualitative (angle open or closed) and quantitative 
analyses, with measurements including AOD, ARA and TISA (Figure 4). These angle measurements can be done over 360 degrees (in all quadrants). Furthermore, ASOCT is able to image and analyse the dynamic light and dark changes in angle configuration, whereas the 'gold standard' gonioscopy always needs a small slit-beam illumination. Gonioscopy might be less accurate in detecting closed angles, because the measurements are never in total darkness and it is a contact technique, which might indentate and open the angle. ${ }^{28}$ Studying the light and dark changes in angle configuration may provide an assessment of the risks for developing primary angle closure. $^{29}$

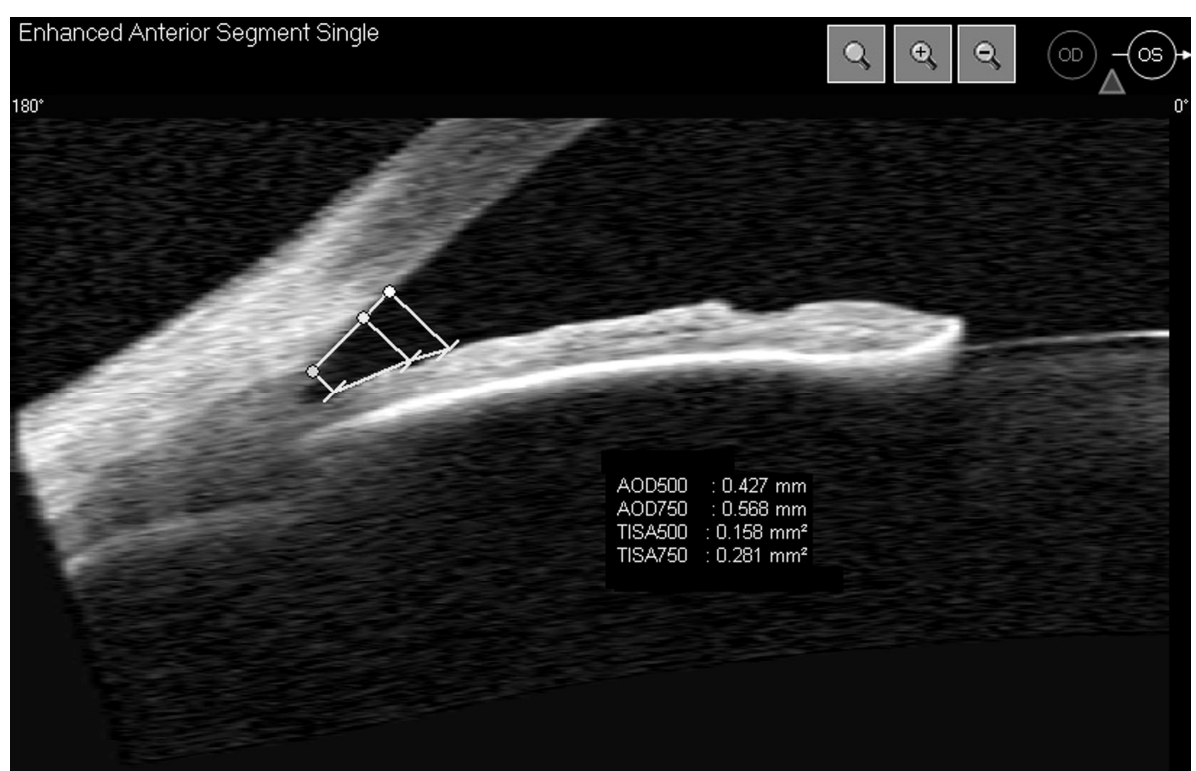

Figure 4. Visante optical coherence tomography angle measurements, including angle opening distance (AOD; $0.427 \mathrm{~mm}, 0.568 \mathrm{~mm}$ ) and trabecular-iris space area (TISA; $0.158 \mathrm{~mm}^{2}, 0.281 \mathrm{~mm}^{2}$ ).

Overall, more closed angles are being reported with AS-OCT. Besides the issues mentioned before, another explanation for detecting more closed angles might be the difference in definition. With gonioscopy it is possible to visualize Schwalbe's line and posterior area of the trabecular meshwork, which can not be seen with ASOCT. In AS-OCT only the position of the scleral spur can be detected, which anatomically represents the junction between the inner wall of the trabecular meshwork and the sclera. The AS-OCT definition of a closed angle is contact between the iris and angle structures anterior to the scleral spur. $^{30} \mathrm{~A}$ recent study showed that AOD750 is the most useful AS-OCT angle measurement for detecting narrow angles. $^{31}$

To perform reliable angle measurements, a good visualization of the scleral spur is extremely important. However, many studies show that this localization can be 
difficult. $^{5,31-33}$ Sakata et al. showed that identification of the scleral spur was possible in $72 \%$ of cases. It was less detectable in patients with closed angles (assessed by gonioscopy) and in the superior and inferior quadrant. ${ }^{33} \mathrm{~A}$ recent study by Li et al. showed good intra- and inter-session repeatability and reproducibility for AS-OCT (Visante OCT) angle measurements (AOD and TIA). ${ }^{34}$ However, they only included healthy subjects, with open angles and they suggest that it would be extremely helpful to develop customized software for semi-automatic angle measurements in stead of the simple and often imprecise caliper tools. The main reason for differences between observers is the variability in identifying the scleral spur. Improved imaging resolution may overcome these differences in the future. ${ }^{35}$

High-frequency UBM is the most established imaging device for visualization of the chamber angles and posterior segment. However, there is one disadvantage of UBM; it has no fixed reference point and therefore the location of the angle measurement is subjective (nasal, temporal, superior or inferior). With AS-OCT the exact location of the measured angle can be located. ${ }^{10}$

In short, AS-OCT can rapidly visualize the anterior chamber angle in a noncontact manner and appears to be promising in angle assessment. Overall, it detects more closed angles than gonioscopy, which might be explained by the difference in illumination. In the future, AS-OCT could be used as a screening device for primary angle glaucoma, but further research is needed to investigate this possibility.

\section{Iris Measurements}

Several recent studies describe the possibility of AS-OCT to measure iris parameters. One study by Aptel et al. measured iris volume changes before and after pupil dilation. ${ }^{36}$ They showed that eyes with a narrow chamber angle demonstrated an increase of iris volume after pharmacological pupil dilation, whereas normal eyes showed a decrease in iris volume. This biometric change was associated with angle closure in narrow angle patients despite the presence of a patent laser iridotomy. They also compared iridolenticular contact in eyes with pigment dispersion syndrome to normal control eyes, and found a larger contact area in pigment dispersion eyes. ${ }^{37}$ Several other studies investigated the relationship between iris parameters and the presence of narrow angles. ${ }^{38,39}$ A thicker iris, larger iris volume and an increased forward bowing of the iris were associated with narrow angles. These iris parameters provide new evidence on the importance of iris dynamics in patients with narrow angles and pigment dispersion syndrome. More research will be necessary to evaluate their relevance in the identification and treatment of patient with narrow angles. 


\section{Lens Thickness}

After some adjustments have been made in the standard refractive indices incorporated in the software of the Visante $\mathrm{OCT}$, valid lens thickness measurements can be performed after pupil dilation, with an excellent repeatability. ${ }^{40}$ Richdale et al. demonstrated an increase in lens thickness of $21 \mu \mathrm{m} /$ year with increasing age, ${ }^{41}$ which is comparable to other studies using different imaging devices. ${ }^{42}$ Furthermore, they found an increase in lens thickness of $51 \mu \mathrm{m}$ for each dioptre of accommodation, which can be established using the built-in fixation target in the Visante OCT.

Wong et al. evaluated the reliability of lens density measurements with AS-OCT and compared them to the LOCS III classification system, which scores nucleus opalescence and nuclear color. ${ }^{43}$ They found that AS-OCT lens density measurements were significantly correlated with the nucleus opacity scores by LOCS III, with high repeatability.

Overall, AS-OCT is a useful tool to examine the crystalline lens in vivo in a noninvasive way and could provide reliable measurements of lens density, which might be useful for research purposes.

\section{Insertion of Rectus Muscles}

One study by Liu et al. showed the possibility of the Visante OCT to measure the limbus-insertion distances of the horizontal rectus muscles. ${ }^{44}$ They compared the measurements to actual intraoperative measurements and found a good agreement using Bland-Altman plots, Pearson correlation coefficients and intraclass correlation coefficient analysis. The ability to visualize the rectus muscles might be useful in the diagnosis of extraocular muscle diseases. Furthermore, limbus-insertion distances can be used during the preoperative assessment of patients with strabismus. The accuracy of these measurement should be subject to further investigation.

\section{PATHOLOGIES OF THE ANTERIOR SEGMENT}

\section{Corneal Abnormalities}

Microbial keratitis can lead to severe corneal ulcers and significant visual loss. The depth of infiltration is usually subjectively assessed at the slit-lamp. However, ASOCT is capable of visualizing the cornea in great detail, and objectively assess microbial keratitis, which can be used to monitor the disease process in addition to slit-lamp examination. ${ }^{45}$ Slit-scanning devices, such as Orbscan II (Bausch \& Lomb Inc., Rochester, NY), tend to underestimate corneal thickness in corneal opacities or haze due to scattering, which causes an incorrect identification of the corneal sur- 
face reflections. Corneal opacities, such as scars, and opacities due to corneal degeneration or dystrophies, can be precisely mapped using AS-OCT, providing depth of the opacity and corneal thickness (Figure 5). ${ }^{46}$ This can be useful in the preoperative assessment of phototherapeutic keratectomy and lamellar keratoplasty patients.
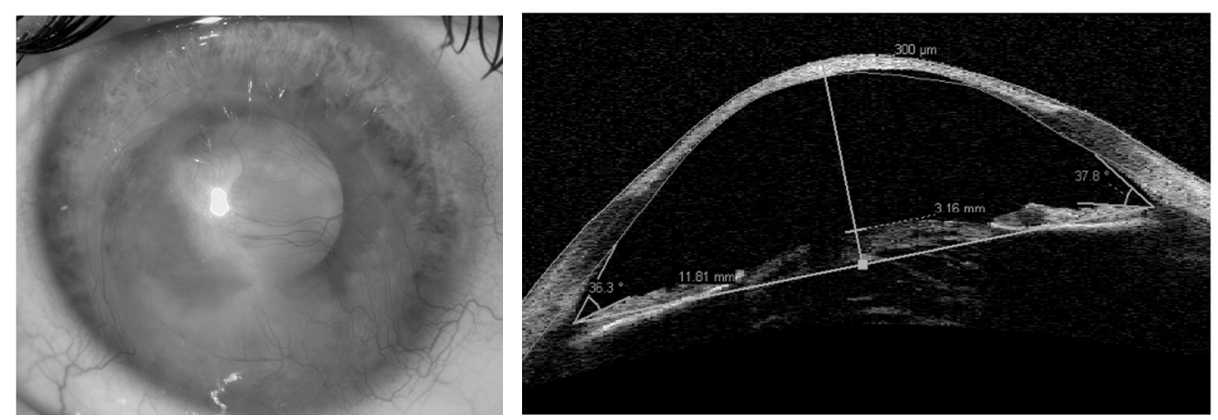

Figure 5. Slit-lamp photograph and anterior segment optical coherence tomography image of patient after corneal ulcer.

\section{Anterior Segment Tumours}

UBM is a useful tool in the investigation of anterior segment masses, such as iris cysts and uveal tumors. AS-OCT can also visualize the anterior chamber with a higher spatial resolution than UBM, and has the advantage of being a non-contact technique (Figure 6). Pavlin et al. investigated the use of AS-OCT in imaging anterior segment tumors. ${ }^{47}$ They found that AS-OCT could completely penetrate small hypopigmented iris tumors. UBM showed similar images of the tumors. However, in pigmented tumors of the iris, penetration was poor with AS-OCT, leading to a well visualized anterior margin and an invisible posterior margin. UBM showed a complete penetration of tumor with clearly visualized margins, both anteriorly and posteriorly. In large hypopigmentated tumor, the same problem arises: AS-OCT can not penetrate the whole tumor, with a fading out of the tumor in the deeper portions, whereas UBM could visualize the entire tumor with the possibility of measuring its diameter. In irido-ciliary tumors, only the iris portion of the tumor can be seen by AS-OCT, due to increased pigmentation in the ciliary body part. Another example of the superiority of UBM was described by Pong et al. ${ }^{48}$ They investigated an iris cyst arising from the iris pigment epithelium using AS-OCT and UBM. UBM was able to show the whole cystic lesion and could measure the internal dimension using calipers. AS-OCT did detect an iris hump, but the lesion itself could not be visualized. These above mentioned findings were confirmed in a recent large case series, with better visualization of the posterior margin with UBM and overall better images of the entire tumor configuration. ${ }^{49}$ 


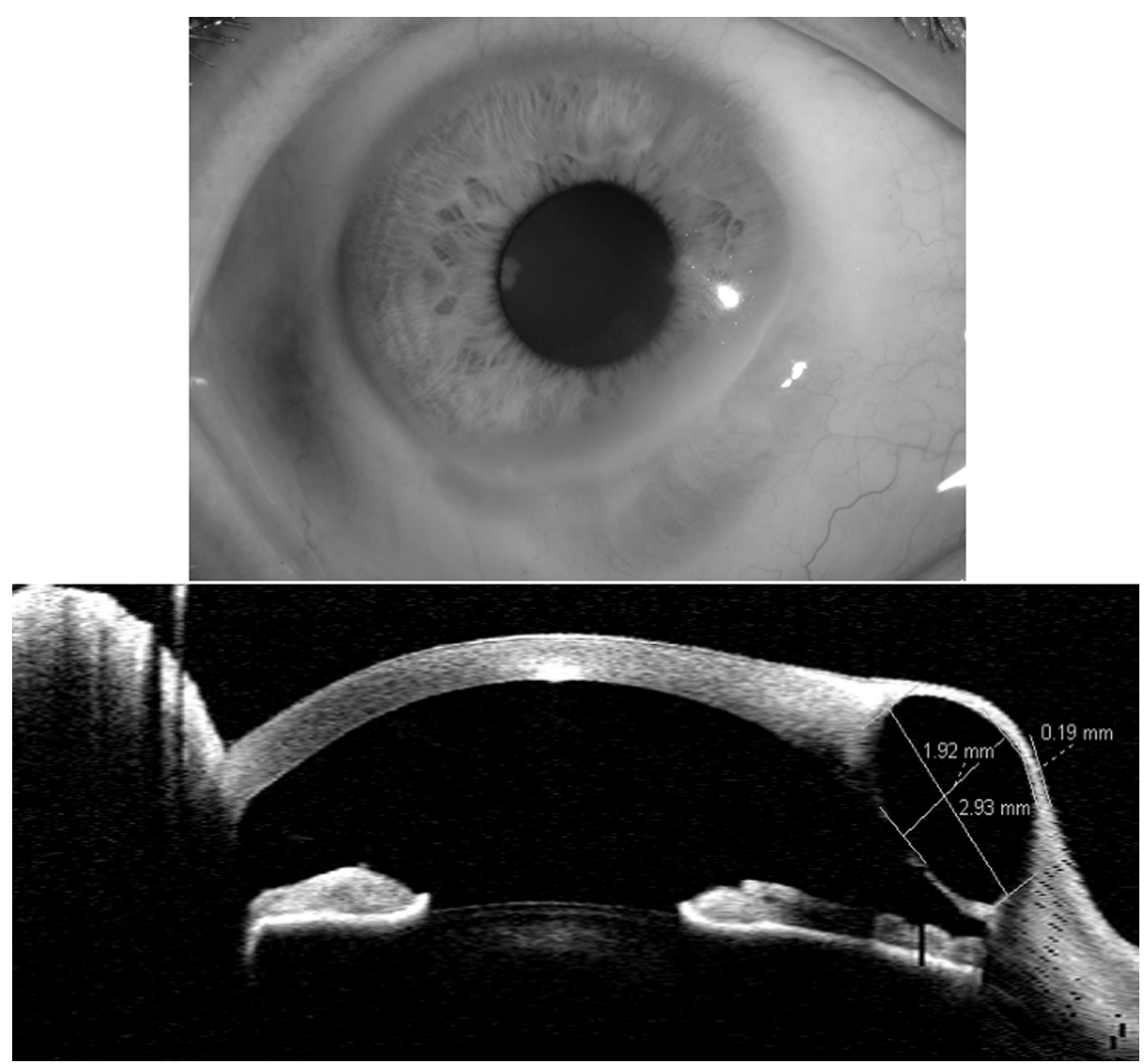

Figure 6. Slit-lamp photograph and anterior segment optical coherence tomography of patient with corneal cyst secondary to pellucid marginal degeneration.

AS-OCT may have a role in differentiating solid and cystic lesions of the iris, as long as the lesion is localized in front of the pigment epithelium at the posterior side of the iris. Furthermore, its use is confined to small, hypopigmented iris tumors.

\section{Conjunctival Nevus}

A recent study by Shields et al. demonstrated that conjunctival nevi can be evaluated using AS-OCT. ${ }^{50}$ They described that all margins of the nevus could be visualized, even the deeper margins in most cases, which is in contrast to the evaluation of iris tumours. One of the typical clinical features of conjunctival nevi is the presence of intralesional cysts, which is important since this almost always represent a benign lesion. AS-OCT can provide data about the configuration, tumour boundaries, and internal structures, such as cysts, which will help the ophthalmologist in diagnosing the lesion. 


\section{Uveitis}

AS-OCT can be used to detect an anterior chamber inflammatory reaction in uveitis patients. Two recent studies demonstrated that inflammatory cells can be seen as hyperreflective spots. ${ }^{51,52}$ Inflammatory cells, such as neutrophils and monocytes, are very small in size, ranging between 10-20 microns. Since the axial resolution of the Visante OCT is 18 microns, cells smaller than 18 microns will not be detected by the machine. However, inflammatory cells usually clump together due to cell-cell adhesions, increasing the size of the total particle, and thereby increasing its detection rate. This method is especially useful in patients with corneal edema, in which there is a limitation of visualization of the anterior chamber during conventional slitlamp examination.

\section{Trauma}

Because of its non-contact technique, AS-OCT is very valuable in fragile traumatic eyes. Classification of the ocular trauma is essential to evaluate the severity and provide adequate management. In a recently published case report, occult scleral perforation (scleral lesions with intact overlying conjunctiva) and displacement of the crystalline lens were detected by AS-OCT. ${ }^{53}$

Gonioscopy is the most common method to investigate iridocorneal angle abnormalities, such as cyclodialysis cleft. However, in some cases gonioscopy is contraindicated or can not be used, for example in corneal opacities, hypotonia after trauma or surgery, and hyphema. In these cases non-contact AS-OCT allows for adequate observation of the iridocorneal angle. ${ }^{54}$

Furthermore, in patients after blunt eye trauma with opaque corneas either due to edema or blood, AS-OCT can reveal unexpected lesions that are difficult to visualize with routine slit-lamp examination, including angle closure, dislocation of the lens, or foreign body. ${ }^{55}$

\section{AS-OCT in Children}

One of the advantages of AS-OCT is the minimal light intensity necessary during the investigation. This makes the device especially useful in photophobic children. Sometimes AS-OCT can even be of more use than slit-lamp examination in those cases. However, some cooperation will be required to obtain meaningful images; the recommended age is above 5 years old. ${ }^{56}$ 


\section{POSTOPERATIVE POSSIBILITIES}

\section{LASIK flap Thickness}

Laser in situ keratomileusis (LASIK) is one of the most frequently performed corneal refractive procedures. Assessment of LASIK flap and residual stromal thickness are extremely important in re-treatment procedures, to ensure an adequate postoperative residual stromal bed and avoid post-LASIK ectasia. Cheng et al. showed a good intra- and inter-observer reproducibility for flap thickness measurements after LASIK using the flap tool as provided by the manufacturer of the Visante OCT. ${ }^{57}$ The interface between the stroma of the flap and the residual stromal bed is visualized by increased internal reflectivity. Li et al. detected the LASIK-flap 1 day and 1 week after the laser treatment in all eyes, which decreased to $61 \%$ of eyes at 3 months and $42 \%$ at 6 months postoperatively. ${ }^{58}$ They reported best repeatability in the pericentral zone and worst in the central zone, which can be explained by the white corneal reflex in the center of the cornea inhibiting an accurate measurement.

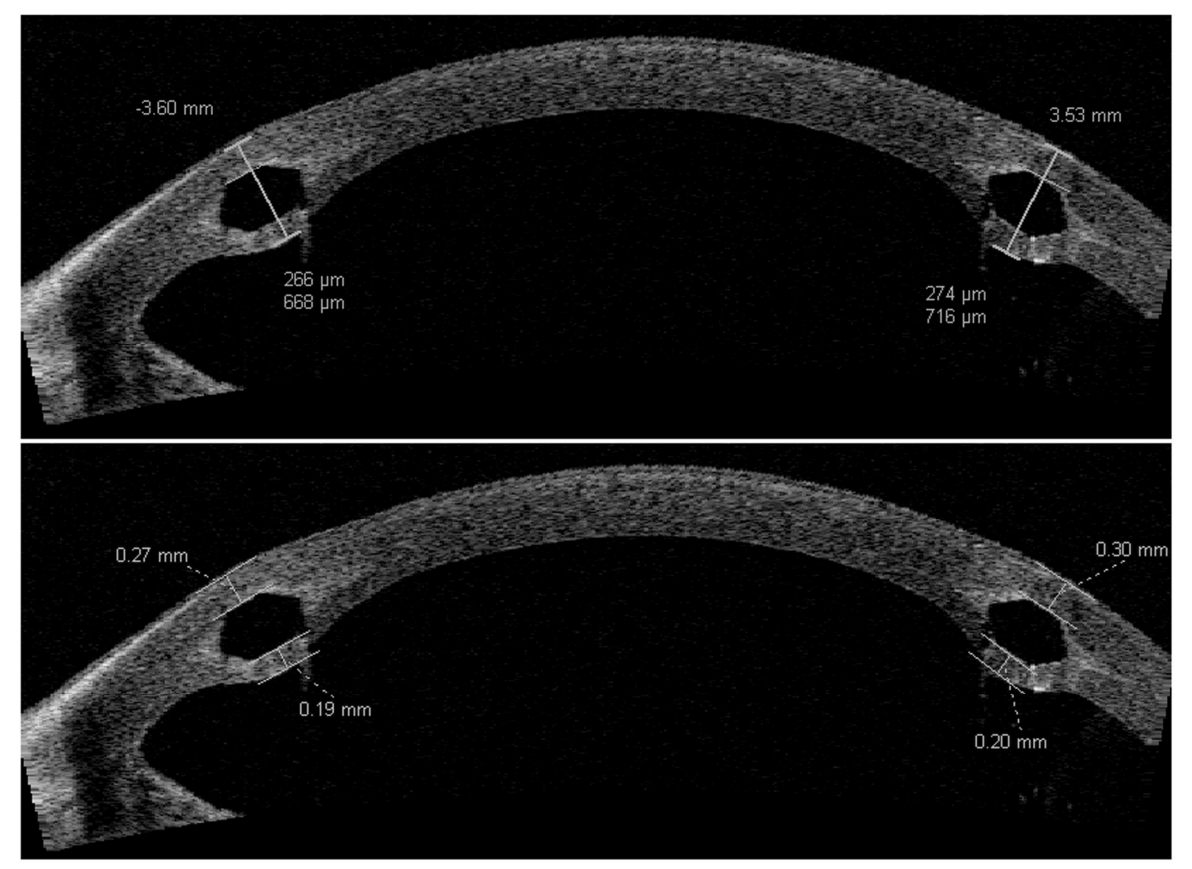

Figure 7. Visante high resolution corneal scan of patient with keratoconus and intracorneal ring segments.

Using the flap thickness on different locations, can give an impression about regularity, reproducibility, and accuracy of the creation of the LASIK flap. A recent 
study demonstrated that femtosecond laser flaps were more regular, had a more accurate mean flap thickness, and showed more precision in the periphery than microkeratome flaps. 59

\section{Intracorneal Ring Segments and Corneal Cross-linking}

Keratoconus is a bilateral, progressive corneal disease, which is characterized by corneal collagen structure changes, decreased corneal rigidity, and corneal thinning, leading to a progressive corneal deformation, and decreased vision. ${ }^{60}$ Early treatment options are correction of the refractive error by spectacles or contact lenses. In contact lens intolerant patients with mild to moderate keratoconus, the implantation of intracorneal ring segments can be considered, since they lead to a flattening-effect of the cornea and can increase contact lens tolerance. ${ }^{61}$ Evaluation of the depth of intrastromal corneal rings can be done by subjective slit-lamp examination. However, AS-OCT is capable of measuring the precise depth of implantation (Figure 7), and may identify patients at risk for depth-related complications, such as too shallow placement of the segments. ${ }^{62}$

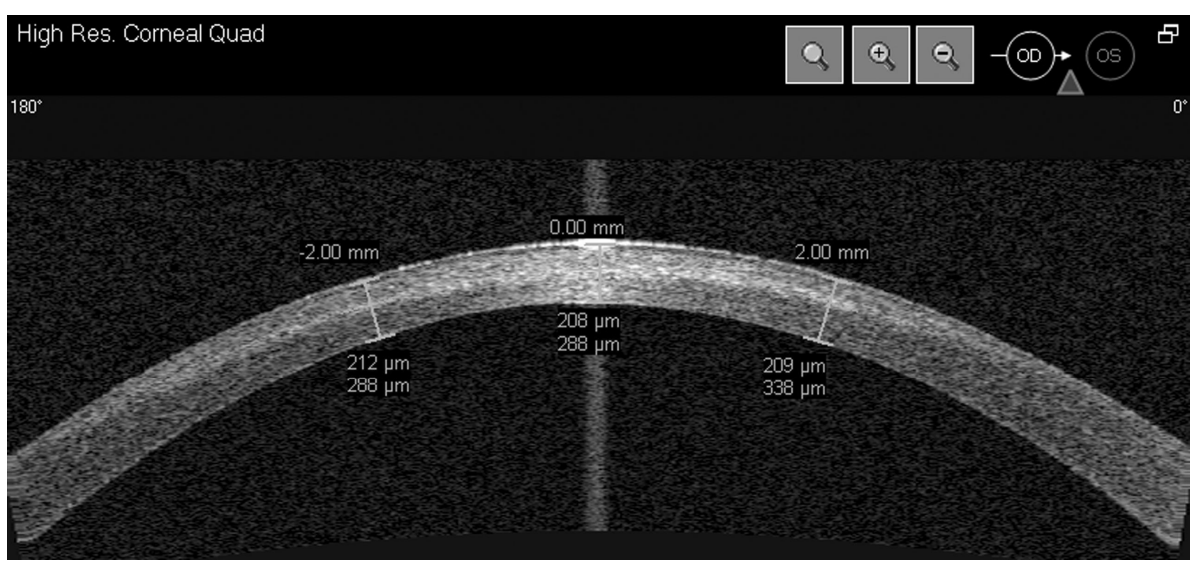

Figure 8. Visante high resolution corneal scan of patient with progressive keratoconus, one months after corneal cross-linking. Demarcation line depth is measured using the flap-tool.

For patients with progressive keratoconus a new treatment modality has become available, known as corneal cross-linking (CXL). CXL combines riboflavin eyedrops and ultraviolet-A radiation which generates reactive oxygen species, leading to the formation of cross-links between the corneal collagen fibers, with the primary goal to increase corneal rigidity by increasing the mechanical stability of the corneal stroma. The first reports on the appearance of a stromal demarcation line 2 weeks after corneal cross-linking were published in 2006 using slit lamp analysis and confocal microscopy. ${ }^{63,64}$ It has been postulated that this demarcation line indicates 
the transition zone between the crosslinked anterior corneal stroma and the untreated posterior corneal stroma and may result from the difference in refractive indices or reflection properties of crosslinked versus untreated corneal stroma. This demarcation line can also be visualized using AS-OCT (Figure 8). A recent study showed that it can be detected within the first month after the treatment, being most clearly visible 1 month after CXL. ${ }^{65}$ The depth of the line can be accurately measured and perhaps in the future can be correlated to the effectiveness of the treatment.

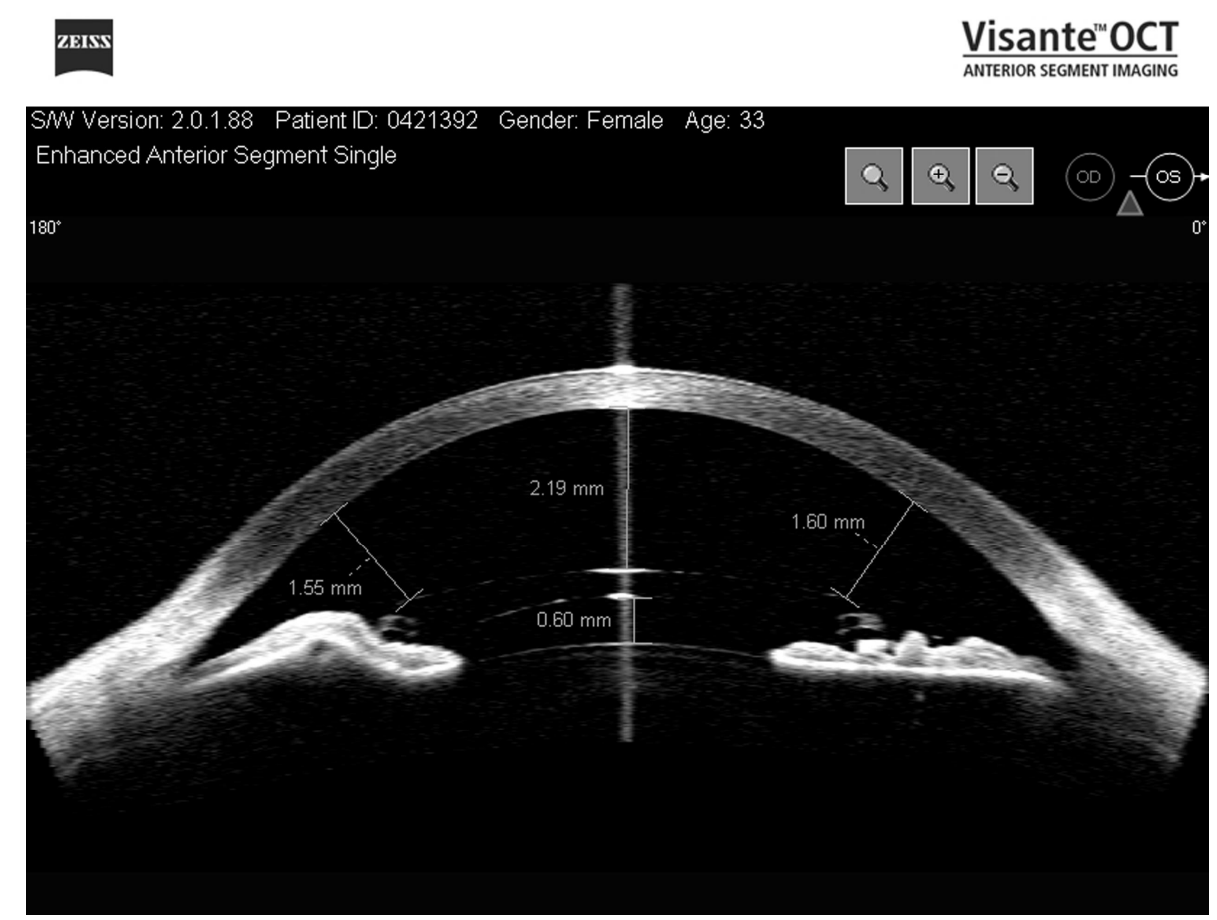

Figure 9. Visante anterior segment scan of patient after iris-fixated phakic intraocular lens (plOL) implantation. Distances from pIOL to endothelium and crystalline lens are measured using refractive tools.

\section{Phakic Intraocular Lenses}

In the last decade, a variety of plOLs have been developed to correct myopia, hyperopia and astigmatism. It is important for the long-term safety of these plOLs that they remain within a safe distance from the corneal endothelium and crystalline lens, to prevent corneal decompensation or cataract formation. The main concern after implantation of a pIOL is how the lens interacts with other anterior segment structures, e.g. the crystalline lens, chamber angle and corneal endothelium. ASOCT provides high-resolution images and is capable of visualizing the plOL in the 
anterior chamber. A recent update of the software includes some refractive tools, which can easily measure the distance between the anterior surface of the plOL to the corneal endothelium and the crystalline lens (Figure 9).

AS-OCT has shown to be of tremendous value in the research of safety of pIOLs. A study by Guell et al. investigated the movement of iris-fixated plOLs during accommodation. ${ }^{66}$ With accommodation the pIOL moves slightly forward, significantly reducing the distance between the anterior surface of the pIOL and the endothelium. In contrast, there was no change in the distance between the posterior surface of the pIOL and the crystalline lens. This suggests that the iris, pIOL and crystalline lens act as a combined unit.

Some new safety criteria have been developed since the introduction of AS$\mathrm{OCT}$, to guarantee the long-term safety of iris-fixated pIOLs, such as the previously mentioned lens rise smaller than 600 microns, to prevent pigment dispersion. ${ }^{26}$ Furthermore, a safety distance of $1.50 \mathrm{~mm}$ between the edge of the $\mathrm{plOL}$ and the endothelium (the smallest distance between the plOL and the corneal endothelium) is suggested. ${ }^{25}$ All these safety parameters can now be preoperatively assessed, especially since the introduction of the pIOL simulation program in the Visante OCT (Figure 10). A recent study showed good agreement between the preoperative distance measurements and the actual postoperative measurements. ${ }^{67}$

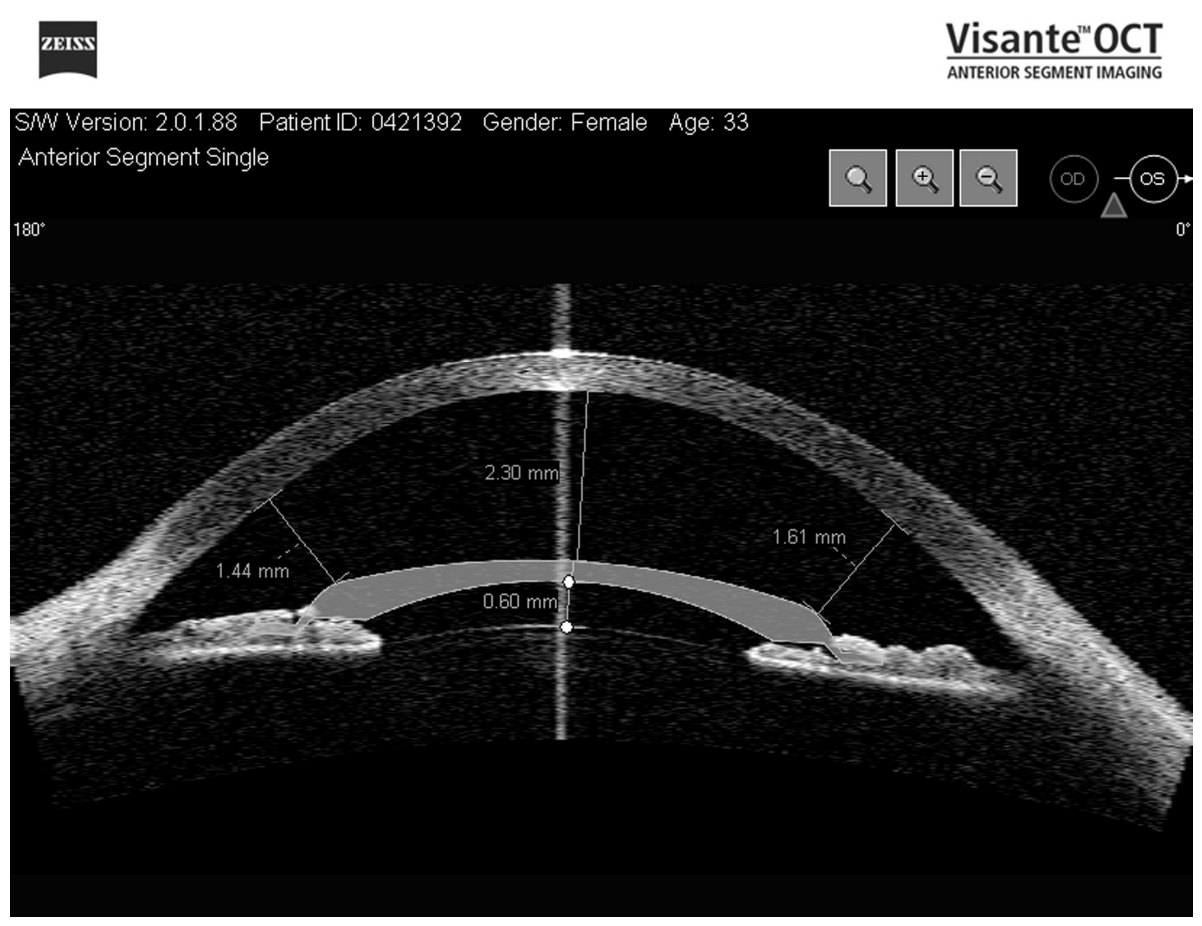

Figure 10. Visante iris-fixated phakic intraocular lens simulation with measured safety distances. 
The same measurements as previously mentioned for iris-fixated plOLs can be performed in patients with angle-supported pIOLs, another type of anterior chamber plOLs. 68

Besides anterior chamber pIOLs, posterior chamber pIOLs such as the implantable collamer lens (ICL) and phakic refractive lens (PRL) can also be visualized by ASOCT. These posterior chamber pIOLs are placed behind the iris with the haptics in the ciliary sulcus. They are designed with an anterior vault to avoid contact between the posterior side of the pIOL and the crystalline lens. The distance between the pIOL and the anterior surface of the crystalline lens, also known as lens vault, should be carefully evaluated to avoid cataract formation during long-term follow-up. ASOCT can objectively measure lens vault distance, using the caliper tools, with a random error between repeated measurements of $5 \% .{ }^{69-71}$

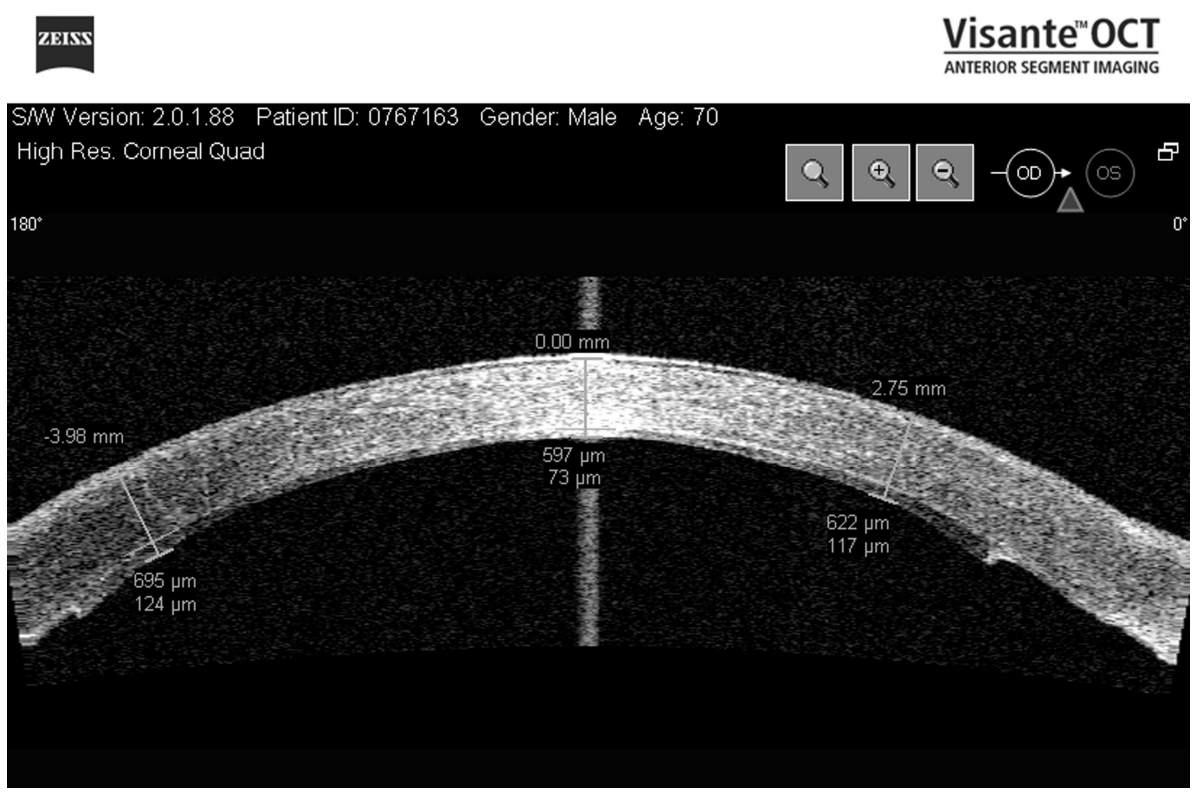

Figure 11. Visante high resolution corneal scan of patient after descemet stripping automated endothelial keratoplasty.

\section{Corneal Transplantation}

In the last decade, new techniques for corneal transplantation have been developed, including femtosecond laser shaped penetrating keratoplasties (PK), Descemet stripping (automated) endothelial keratoplasty (DS(A)EK), and deep anterior lamellar keratoplasty (DALK). Posterior lamellar keratoplasty, e.g. DS(A)EK, is a new development in the treatment of endothelial failure. ${ }^{72}$ AS-OCT can clearly visualize the donor lamellae on the posterior side of the cornea, and because of its non 
contact technique it can be used immediately after surgery (Figure 11). Evaluation of the donor graft by slit-lamp examination in the early postoperative period can be challenging due to the optical irregularities such as corneal edema. Lim et al. evaluated the use of AS-OCT after lamellar keratoplasty in detecting specific complications, such as donor malapposition, Descemet membrane detachment, posterior lamellar dislocation, and anterior chamber angle closure. ${ }^{73}$ AS-OCT seemed to offer advantages in the diagnosis and management of these complications (Figure 12). A recent article by Tarnawska showed that interface fluid detected by AS-OCT on the first postoperative day was missed in more than half of the patients during slit-lamp examination. ${ }^{74}$ This clearly demonstrates the benefits of AS-OCT in the early postoperative period.

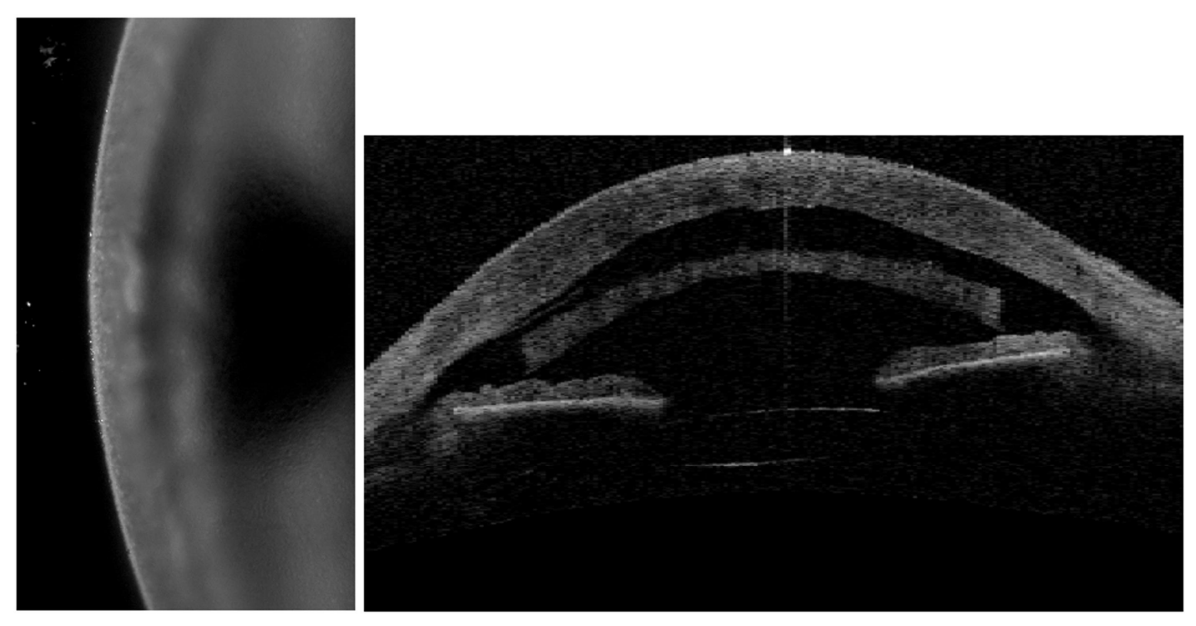

Figure 12. Dislocation of flap after femtosecond laser Descemet stripping endothelial keratoplasty.

Cheng et al. explained the hyperopic shift, which is present after DSEK, by imag-

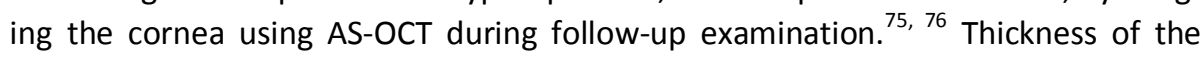
donor lamellae and recipient anterior cornea can be measured on different locations. ${ }^{77,78}$ The lamellae is reported to be significantly thicker at the edges compared to the center. Changes in the posterior curvature of the cornea probably account for the hyperopic shift of approximately +1 diopter (D) after DS(A)EK. Although a recent study did not find a correlation between graft thickness measured with AS-OCT and visual acuity, ${ }^{79}$ corneal thickness is an important predictor of DSAEK failure; i.e. a thicker postoperative donor graft has a higher probability of primary graft failure. ${ }^{80}$

In the DALK procedure, the anterior lamellae of the cornea is replaced by donor tissue, which requires the separation of Descemet's membrane form the stromal tissue. This separation can be established by the big bubble technique, previously described by Anwar et al. ${ }^{81}$ The injected air seems to find the path of least re- 
sistance, spreading posteriorly, since the anterior stroma is much denser. AS-OCT was able to visualize this big bubble technique performed in donor corneas. ${ }^{82}$

After conventional corneal transplantations intraocular pressure (IOP) elevation is quite common. It is important to evaluate the chamber angle to exclude peripheral anterior synechiae as a cause of this pressure rise. However, the periphery of the cornea is often cloudy due to the pre-existent corneal disease, which makes this evaluation difficult. AS-OCT can detect and measure anterior synechiae in patients after PK through a cloudy peripheral cornea. ${ }^{83}$

Overall, AS-OCT can visualize the graft-host interface of all lamellar procedures (Figure 13), can help in the management of surgical complications, and can document apposition of the graft.
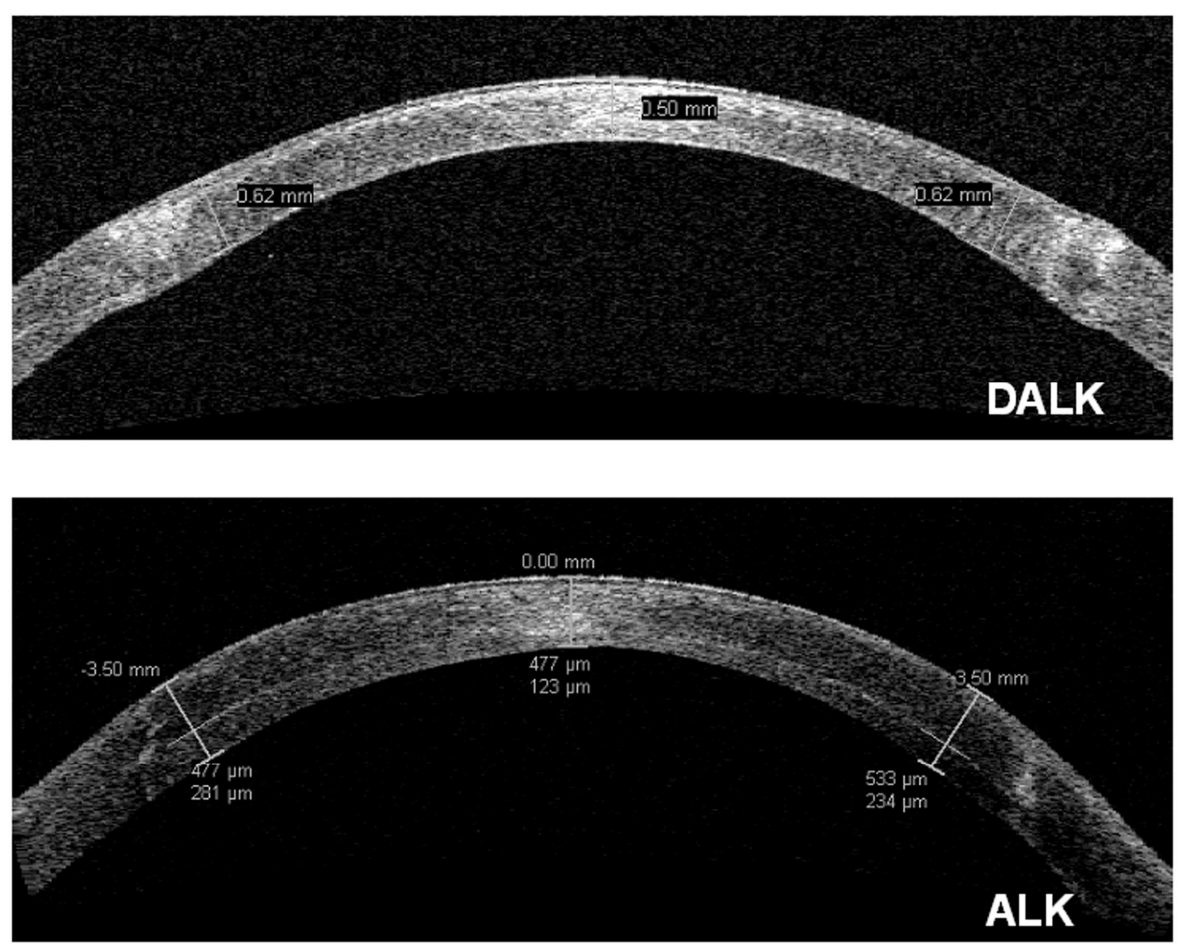

Figure 13. High resolution scan of deep anterior lamellar keratoplasty (DALK) with no interface visible versus anterior lamellar keratoplasty (ALK) with a clearly visible interface.

\section{Cataract Surgery}

A self-sealing clear corneal incision allows for rapid visual rehabilitation after phacoemulsification, less surgically induced corneal astigmatism, and a more stable anterior chamber and less bleeding during surgery. ${ }^{84}$ AS-OCT is capable of producing 
a high-resolution detailed image of the cornea and can therefore visualize the clear corneal incision. Measurements of corneal thickness at the incision site can be easily performed and the integrity of the incision can be visualized, e.g.epithelial or endothelial gaping, endothelial misalignment, loss of coaptation along the stroma tunnel and descemet's membrane detachment. ${ }^{85-89}$ Especially Descemet's membrane detachment was detected frequently with AS-OCT and missed by slit-lamp examination. Length of the corneal incision, corneal thickness at the incision site, and position of the incision could be measured with high repeatability. ${ }^{90}$ The use of AS-OCT for imaging clear corneal incisions has increased our understanding of their architecture, and by minimizing loss of coaptation and wound gaping, we might be able to reduce the risk of wound leakage and thus the risk of endophthalmitis.

Furthermore, the position of an IOL after cataract surgery can be evaluated with AS-OCT. Lens tilt can be measured using the limbus as a reference. ${ }^{91}$ This may be useful in the evaluation of optical complaints of patients who received premium (toric or multifocal) IOLs.

\section{Evaluation of Glaucoma Surgery}

AS-OCT can assess bleb morphology, extent of the bleb, and patency of filtration after trabeculectomy. Changes in bleb morphology can be demonstrated after digital ocular pressure and laser suture lysis. ${ }^{92,93}$ It has a great advantage over UBM, since it is a non-contact technique and can be used directly postoperatively, with no risk of damaging the bleb wall. Guthoff et al. showed that encapsulated blebs can be easily identified using AS-OCT. It provided information about the height of the bleb and its internal morphology, which can be used to identify blebs that are suitable for bleb needling. ${ }^{94}$ Furthermore, AS-OCT can be used to assess the patency and position of tubes after glaucoma drainage implant surgery (Figure 14), ${ }^{95}$ and is especially useful in patients with an opaque cornea or vulnerable cornea for example shortly after penetrating keratoplasty. ${ }^{96}$ AS-OCT can also evaluate the effectiveness of iridotomies. ${ }^{97}$ All mentioned measurements are now mainly descriptive, but may provide useful information to help to plan post-surgical management.

\section{AS-OCT in the Operating Theatre}

Geerling et al. described the use of AS-OCT during surgery by coupling an AS-OCT device to the operating microscope for intraoperative 2-dimensional visualisation of the anterior segment and corneal pachymetry readings. ${ }^{98}$ Possible applications include measuring thickness of the scleral flap and visualize the filtering bleb at the end of a trabeculectomy, and measuring corneal thickness during limbal relaxing incisions and LASIK-flap procedures. Furthermore, when performing DALK, the lamellar interface can be visualized and abnormalities in the cornea detected 
intraoperatively. AS-OCT was able to show the exact depth of the intrastromal dissection, and might help to reduce the risk of intraoperative perforation of Descemet's membrane.

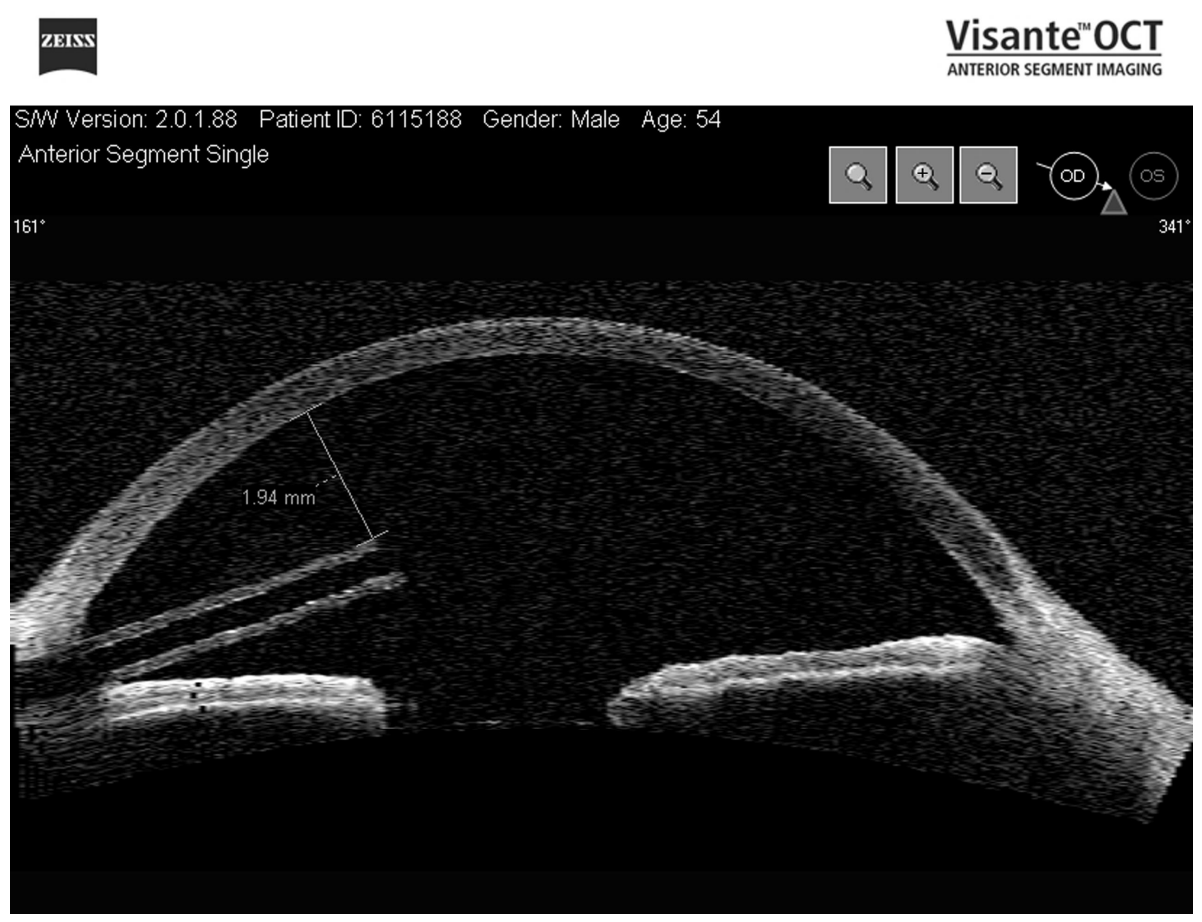

Figure 14. Visante anterior segment scan of patient after glaucoma drainage implant surgery (Baerveldt tube).

\section{New Developments}

The Visante OCT and SL-OCT are time-domain based OCT devices. Fourier-domain OCTs were primarily developed to investigate the posterior segment. However, in 2002 an adjustment was made to image the anterior segment with a Fourierdomain OCT. Instead of the movable mirror used in time-domain OCT, the Fourierdomain detects the signals with a spectrometer (also known as spectral-domain OCT). They have an axial resolution of $5 \mu \mathrm{m}$ and a transverse resolution of $15 \mu \mathrm{m}$ and image acquisition is much faster than with the Visante OCT. ${ }^{99}$ The higher resolution of the Fourier-domain OCT allows visualisation of more details, for example all layers of the cornea can be identified, which can be useful in the evaluation of corneal dystrophies and degenerations, ${ }^{100}$ and epithelial thickness can be measured. ${ }^{101}$ However, the time-domain OCT shows all anterior segment structures in a single 
image, whereas the Fourier-domain OCT provides high details, but only of small components of the anterior segment. ${ }^{55}$

Schlemm's canal and the trabecular meshwork can be detected due to the higher resolution images of Fourier-domain OCT. ${ }^{102}$ One major advantage of this OCT type is its capability of imaging the anterior as well as the posterior segment.

Due to the limitations of measurement speed of the time-domain AS-OCT, 3dimensional (3D) imaging of the ocular tissue is not possible. With the higher measurement speed of the Fourier-domain OCT, 3D imaging is possible and has recently been described by Fukuda et al. ${ }^{103}$ Their imaging device produced high resolution 3D images of the anterior segment of the eye, with excellent repeatability and interoperator and intersession reproducibility for CCT and ACD measurements. For example, 3D AS-OCT was recently used to study the accommodative movement of IOLs after cataract surgery. ${ }^{104}$

\section{CONCLUSION}

AS-OCT is a rapidly advancing new non-contact imaging device, which will have a major influence on clinical practise and research in ophthalmology. Some of the biometry measurements which can be performed include a quantitative and qualitative assessment of the anterior chamber angle, corneal thickness, anterior chamber depth, angle-to-angle distance, crystalline lens rise, and lens thickness. Furthermore, AS-OCT is able to assess a wide spectrum of corneal and anterior segment conditions, such as corneal opacities, uveitis, traumatic eyes, LASIK-flaps, intracorneal ring segments, safety distances of pIOLs, and lamellar and penetrating keratoplasties. In the future, this new imaging technique can help ophthalmologist to objectively assess the chamber angle which will be helpful as a glaucoma screening tool, to give more insight information in the architecture of incisions, to early identify complications after keratoplasties, and to improve the safety of refractive surgery procedures.

\section{AIM AND OUTLINE OF THE THESIS}

This thesis aims to evaluate and explore the possibilities of a new time-domain anterior segment imaging device: the Visante OCT (Carl Zeiss Meditec Inc., Dublin, CA). As described in the previous review of the literature, AS-OCT can be used in several clinical settings. However, to set measurements of a new imaging device into perspective, it first has to be compared to imaging devices which are already used in clinical practise. 
Chapter $\mathbf{2}$ evaluates the intraobserver repeatability of biometry measurements with AS-OCT, and investigates the comparability of these measurements with currently used alternative imaging devices (Pentacam and Orbscan II).

Subsequently, several AS-OCT measurements were performed on a large population of refractive surgery patients. Analysis of the preoperative and postoperative position of iris-fixated pIOLs became our main focus of research. The use of AS-OCT in preoperative patient selection and postoperative evaluation of iris-fixated plOLs will be outlined in the next chapters.

Chapters 3, 4, and 5 investigate the possibilities of AS-OCT in patients with irisfixated pIOLs. Anterior segment morphometrics, with special attention to the distance between the edge of the pIOL to the corneal endothelium, are described. A preoperative pIOL simulation tool is described and compared to the actual postoperative position of the plOL. Finally, a model is presented which predicts endothelial cell loss after iris-fixated pIOL implantation, taking edge distance, patient age, and preoperative endothelial cell density (ECD) into account. The pIOL simulation tool and model can assist ophthalmologists in patient selection and long-term follow-up of patients with pIOLs.

Chapters 6 and 7 describe a case series and a large multicenter study, using AS-OCT as a tool for preoperative patient selection and postoperative evaluation of irisfixated pIOL position.

Besides refractive surgery patients, AS-OCT can also be used in patients with specific corneal pathology, such as keratoconus and Fuchs' endothelial dystrophy. The next chapters will evaluate the benefits of AS-OCT in these two conditions.

Chapter 8 discusses the application of AS-OCT in the detection of a corneal demarcation line after corneal cross-linking in patients with progressive keratoconus and evaluates the interobserver reliability of measuring demarcation line depth.

In chapter 9 AS-OCT is used to measure corneal thickness before and after phacoemulsification in patients with Fuchs endothelial dystrophy. Furthermore, a model is presented, calculating the risk of corneal decompensation after cataract surgery using preoperative corneal thickness as a key parameter.

The ultimate goal of this thesis is to make the ophthalmologist familiar with a new measurement technique and its added value in making refractive and cataract surgery safer in the future. 


\section{REFERENCES}

1. Huang D, Swanson EA, Lin CP, et al. Optical coherence tomography. Science 1991;254(5035):117881.

2. Radhakrishnan S, Rollins AM, Roth JE, et al. Real-time optical coherence tomography of the anterior segment at $1310 \mathrm{~nm}$. Arch Ophthalmol 2001;119(8):1179-85.

3. Testoni PA. Optical coherence tomography. ScientificWorldJournal 2007;7:87-108.

4. van den Berg TJ, Spekreijse H. Near infrared light absorption in the human eye media. Vision Res 1997;37(2):249-53.

5. Sakata LM, Wong TT, Wong HT, et al. Comparison of Visante and slit-lamp anterior segment optical coherence tomography in imaging the anterior chamber angle. Eye 2010;24(4):578-87.

6. Li H, Leung CK, Wong L, et al. Comparative study of central corneal thickness measurement with slitlamp optical coherence tomography and visante optical coherence tomography. Ophthalmology 2008;115(5):796-801 e2.

7. Baikoff G, Lutun E, Ferraz C, Wei J. Static and dynamic analysis of the anterior segment with optical coherence tomography. J Cataract Refract Surg 2004;30(9):1843-50.

8. Choi CY, Youm DJ, Kim MJ, Tchah H. Changes in central corneal thickness of preserved corneas over time measured using anterior segment optical coherence tomography. Cornea 2009;28(5):536-40.

9. Neubauer AS, Priglinger SG, Thiel MJ, et al. Sterile structural imaging of donor cornea by optical coherence tomography. Cornea 2002;21(5):490-4.

10. Dada T, Sihota R, Gadia R, et al. Comparison of anterior segment optical coherence tomography and ultrasound biomicroscopy for assessment of the anterior segment. J Cataract Refract Surg 2007;33(5):837-40.

11. Kim HY, Budenz DL, Lee PS, et al. Comparison of central corneal thickness using anterior segment optical coherence tomography vs ultrasound pachymetry. Am J Ophthalmol 2008;145(2):228-32.

12. Li EY, Mohamed S, Leung CK, et al. Agreement among 3 methods to measure corneal thickness: ultrasound pachymetry, Orbscan II, and Visante anterior segment optical coherence tomography. Ophthalmology 2007;114(10):1842-7.

13. Leung DY, Lam DK, Yeung BY, Lam DS. Comparison between central corneal thickness measurements by ultrasound pachymetry and optical coherence tomography. Clin Experiment Ophthalmol 2006;34(8):751-4.

14. Doors M, Cruysberg LP, Berendschot TT, et al. Comparison of central corneal thickness and anterior chamber depth measurements using three imaging technologies in normal eyes and after phakic intraocular lens implantation. Graefes Arch Clin Exp Ophthalmol 2009;247(8):1139-46.

15. Muscat S, McKay N, Parks S, et al. Repeatability and reproducibility of corneal thickness measurements by optical coherence tomography. Invest Ophthalmol Vis Sci 2002;43(6):1791-5.

16. Li Y, Shekhar R, Huang D. Corneal pachymetry mapping with high-speed optical coherence tomography. Ophthalmology 2006;113(5):792-9 e2.

17. Mohamed S, Lee GK, Rao SK, et al. Repeatability and reproducibility of pachymetric mapping with Visante anterior segment-optical coherence tomography. Invest Ophthalmol Vis Sci 2007;48(12):5499-504.

18. Li $\mathrm{Y}$, Meisler DM, Tang $M$, et al. Keratoconus diagnosis with optical coherence tomography pachymetry mapping. Ophthalmology 2008;115(12):2159-66.

19. Goldsmith JA, Li Y, Chalita MR, et al. Anterior chamber width measurement by high-speed optical coherence tomography. Ophthalmology 2005;112(2):238-44.

20. Pinero DP, Plaza AB, Alio JL. Anterior segment biometry with 2 imaging technologies: very-highfrequency ultrasound scanning versus optical coherence tomography. J Cataract Refract Surg 2008;34(1):95-102.

21. Kucumen RB, Yenerel NM, Gorgun E, et al. Anterior segment optical coherence tomography measurement of anterior chamber depth and angle changes after phacoemulsification and intraocular lens implantation. J Cataract Refract Surg 2008;34(10):1694-8. 
22. Javaloy J, Alio JL, Iradier MT, et al. Outcomes of ZB5M angle-supported anterior chamber phakic intraocular lenses at 12 years. J Refract Surg 2007;23(2):147-58.

23. Alio JL, Abdelrahman AM, Javaloy J, et al. Angle-supported anterior chamber phakic intraocular lens explantation causes and outcome. Ophthalmology 2006;113(12):2213-20.

24. Kohnen T, Thomala MC, Cichocki M, Strenger A. Internal anterior chamber diameter using optical coherence tomography compared with white-to-white distances using automated measurements. J Cataract Refract Surg 2006;32(11):1809-13.

25. Baikoff G. Anterior segment OCT and phakic intraocular lenses: a perspective. J Cataract Refract Surg 2006;32(11):1827-35.

26. Baikoff G, Bourgeon G, Jodai HJ, et al. Pigment dispersion and Artisan phakic intraocular lenses: crystalline lens rise as a safety criterion. J Cataract Refract Surg 2005;31(4):674-80.

27. Nolan W. Anterior segment imaging: identifying the landmarks. Br J Ophthalmol 2008;92(12):1575-6.

28. Leung $\mathrm{CK}$, Cheung $\mathrm{CY}$, $\mathrm{Li} \mathrm{H}$, et al. Dynamic analysis of dark-light changes of the anterior chamber angle with anterior segment OCT. Invest Ophthalmol Vis Sci 2007;48(9):4116-22.

29. Wang B, Congdon NG, Wang N, et al. Dark Room Provocative Test and Extent of Angle Closure: An Anterior Segment OCT Study. J Glaucoma 2010;19(3):183-7.

30. Nolan WP, See JL, Chew PT, et al. Detection of primary angle closure using anterior segment optical coherence tomography in Asian eyes. Ophthalmology 2007;114(1):33-9.

31. Narayanaswamy A, Sakata LM, He MG, et al. Diagnostic performance of anterior chamber angle measurements for detecting eyes with narrow angles: an anterior segment OCT study. Arch Ophthalmol 2010;128(10):1321-7.

32. Sakata LM, Lavanya R, Friedman DS, et al. Comparison of gonioscopy and anterior segment ocular coherence tomography in detecting angle closure in different quadrants of the anterior chamber angle. Ophthalmology 2008;115(5):769-74.

33. Sakata LM, Lavanya R, Friedman DS, et al. Assessment of the scleral spur in anterior segment optical coherence tomography images. Archives of Ophthalmology 2008;126(2):181-5.

34. Li HT, Leung CKS, Cheung CYL, et al. Repeatability and reproducibility of anterior chamber angle measurement with anterior segment optical coherence tomography. British Journal of Ophthalmology 2007;91(11):1490-2.

35. Nolan W. Anterior segment imaging: ultrasound biomicroscopy and anterior segment optical coherence tomography. Curr Opin Ophthalmol 2008;19(2):115-21.

36. Aptel F, Denis P. Optical coherence tomography quantitative analysis of iris volume changes after pharmacologic mydriasis. Ophthalmology 2010;117(1):3-10.

37. Aptel F, Beccat S, Fortoul V, Denis P. Biometric analysis of pigment dispersion syndrome using anterior segment optical coherence tomography. Ophthalmology 2011;118(8):1563-70.

38. Cheung $\mathrm{CY}$, Liu S, Weinreb RN, et al. Dynamic analysis of iris configuration with anterior segment optical coherence tomography. Invest Ophthalmol Vis Sci 2010;51(8):4040-6.

39. Wang B, Sakata LM, Friedman DS, et al. Quantitative iris parameters and association with narrow angles. Ophthalmology 2010;117(1):11-7.

40. Lehman BM, Berntsen DA, Bailey MD, Zadnik K. Validation of optical coherence tomography-based crystalline lens thickness measurements in children. Optom Vis Sci 2009;86(3):181-7.

41. Richdale K, Bullimore MA, Zadnik K. Lens thickness with age and accommodation by optical coherence tomography. Ophthalmic and Physiological Optics 2008;28(5):441-7.

42. Atchison D, Markwell E, Kasthurirangan S, et al. Age-related changes in optical and biometric characteristics of emmetropic eyes. J Vis 2008;8(4):29.1-0.

43. Wong AL, Leung CK, Weinreb RN, et al. Quantitative assessment of lens opacities with anterior segment optical coherence tomography. Br J Ophthalmol 2009;93(1):61-5.

44. Liu X, Wang F, Xiao Y, et al. Measurement of the limbus-insertion distance in adult strabismus patients with anterior segment optical coherence tomography. Invest Ophthalmol Vis Sci 2011;52(11):8370-3. 
45. Konstantopoulos A, Kuo J, Anderson D, Hossain P. Assessment of the use of anterior segment optical coherence tomography in microbial keratitis. Am J Ophthalmol 2008;146(4):534-42.

46. Khurana RN, Li Y, Tang M, et al. High-speed optical coherence tomography of corneal opacities. Ophthalmology 2007;114(7):1278-85.

47. Pavlin CJ, Vasquez LM, Lee R, et al. Anterior segment optical coherence tomography and ultrasound biomicroscopy in the imaging of anterior segment tumors. Am J Ophthalmol 2009;147(2):214-9 e2.

48. Pong JCF, Lai JSM. Imaging of primary cyst of the iris pigment epithelium using anterior segment OCT and ultrasonic biomicroscopy. Clinical and Experimental Optometry 2009;92(2):139-41.

49. Bianciotto C, Shields CL, Guzman JM, et al. Assessment of anterior segment tumors with ultrasound biomicroscopy versus anterior segment optical coherence tomography in 200 cases. Ophthalmology 2011;118(7):1297-302.

50. Shields CL, Belinsky I, Romanelli Gobbi M, et al. Anterior segment optical coherence tomography of conjunctival nevus. Ophthalmology 2011;118(5):915-9.

51. Agarwal A, Ashokkumar D, Jacob S, et al. High-speed optical coherence tomography for imaging anterior chamber inflammatory reaction in uveitis: clinical correlation and grading. Am J Ophthalmol 2009;147(3):413-6 e3.

52. Igbre AO, Rico MC, Garg SJ. High-speed optical coherence tomography as a reliable adjuvant tool to grade ocular anterior chamber inflammation. Retina 2013; epub.

53. Prakash G, Ashokumar D, Jacob S, et al. Anterior segment optical coherence tomography-aided diagnosis and primary posterior chamber intraocular lens implantation with fibrin glue in traumatic phacocele with scleral perforation. J Cataract Refract Surg 2009;35(4):782-4.

54. Mateo-Montoya A, Dreifuss S. Anterior segment optical coherence tomography as a diagnostic tool for cyclodialysis clefts. Arch Ophthalmol 2009;127(1):109-10.

55. Wylegala E, Teper S, Nowinska AK, et al. Anterior segment imaging: Fourier-domain optical coherence tomography versus time-domain optical coherence tomography. J Cataract Refract Surg 2009;35(8):1410-4.

56. Mireskandari K, Tehrani NN, Vandenhoven C, Ali A. Anterior segment imaging in pediatric ophthalmology. J Cataract Refract Surg 2011;37(12):2201-10.

57. Cheng ACK, Ho T, Lau S, et al. Measurement of LASIK Flap Thickness With Anterior Segment Optical Coherence Tomography. Journal of Refractive Surgery 2008;24(9):879-84.

58. Li Y, Netto MV, Shekhar R, et al. A longitudinal study of LASIK flap and stromal thickness with highspeed optical coherence tomography. Ophthalmology 2007;114(6):1124-32.

59. von Jagow B, Kohnen T. Corneal architecture of femtosecond laser and microkeratome flaps imaged by anterior segment optical coherence tomography. J Cataract Refract Surg 2009;35(1):35-41.

60. Rabinowitz YS. Keratoconus. Surv Ophthalmol 1998;42(4):297-319.

61. Rabinowitz YS. INTACS for keratoconus. Int Ophthalmol Clin 2006;46(3):91-103.

62. Lai MM, Tang M, Andrade EM, et al. Optical coherence tomography to assess intrastromal corneal ring segment depth in keratoconic eyes. J Cataract Refract Surg 2006;32(11):1860-5.

63. Seiler T, Hafezi F. Corneal cross-linking-induced stromal demarcation line. Cornea 2006;25(9):10579

64. Mazzotta C, Balestrazzi A, Traversi C, et al. Treatment of progressive keratoconus by riboflavin-UVAinduced cross-linking of corneal collagen: ultrastructural analysis by Heidelberg Retinal Tomograph II in vivo confocal microscopy in humans. Cornea 2007;26(4):390-7.

65. Doors M, Tahzib NG, Eggink FA, et al. Use of Anterior Segment Optical Coherence Tomography to Study Corneal Changes after Collagen Cross-linking. Am J Ophthalmol 2009;148(6):844-51.

66. Guell JL, Morral M, Gris O, et al. Evaluation of Verisyse and Artiflex phakic intraocular lenses during accommodation using Visante optical coherence tomography. J Cataract Refract Surg 2007;33(8):1398-404.

67. Doors $\mathrm{M}$, Berendschot $\mathrm{TT}$, Hendrikse $\mathrm{F}$, et al. Value of preoperative phakic intraocular lens simulation using optical coherence tomography. J Cataract Refract Surg 2009;35(3):438-43. 
68. Alio JL, Pinero DP, Sala E, Amparo F. Intraocular stability of an angle-supported phakic intraocular lens with changes in pupil diameter. J Cataract Refract Surg 2010;36(9):1517-22.

69. Alfonso JF, Lisa C, Palacios A, et al. Objective vs Subjective Vault Measurement After Myopic Implantable Collamer Lens Implantation. American Journal of Ophthalmology 2009;147(6):978-83.

70. Baikoff G, Lutun E, Wei J, Ferraz C. Contact between 3 phakic intraocular lens models and the crystalline lens: an anterior chamber optical coherence tomography study. J Cataract Refract Surg 2004;30(9):2007-12.

71. Koivula A, Kugelberg M. Optical coherence tomography of the anterior segment in eyes with phakic refractive lenses. Ophthalmology 2007;114(11):2031-7.

72. Melles GR, Eggink FA, Lander F, et al. A surgical technique for posterior lamellar keratoplasty. Cornea 1998;17(6):618-26.

73. Lim LS, Aung HT, Aung T, Tan DTH. Corneal imaging with anterior segment optical coherence tomography for lamellar keratoplasty procedures. American Journal of Ophthalmology 2008;145(1):81-90.

74. Tarnawska D, Wylegala E. Monitoring Cornea and Graft Morphometric Dynamics After Descemet Stripping and Endothelial Keratoplasty With Anterior Segment Optical Coherence Tomography. Cornea 2010;29(3):272-7.

75. Cheng YY, Kang SJ, Grossniklaus HE, et al. Histologic evaluation of human posterior lamellar discs for femtosecond laser Descemet's stripping endothelial keratoplasty. Cornea 2009;28(1):73-9.

76. Holz HA, Meyer JJ, Espandar L, et al. Corneal profile analysis after Descemet stripping endothelia keratoplasty and its relationship to postoperative hyperopic shift. Journal of Cataract and Refractive Surgery 2008;34(2):211-4.

77. Pascuale MA, Prasher P, Schlecte $C$, et al. Corneal Deturgescence after Descemet Stripping Automated Endothelial Keratoplasty Evaluated by Visante Anterior Segment Optical Coherence Tomography. Am J Ophthalmol 2009;148(1):32-7.

78. Nieuwendaal CP, van Velthoven ME, Biallosterski C, et al. Thickness measurements of donor posterior disks after descemet stripping endothelial keratoplasty with anterior segment optical coherence tomography. Cornea 2009;28(3):298-303.

79. Shinton AJ, Tsatsos M, Konstantopoulos A, et al. Impact of graft thickness on visual acuity after Descemet's stripping endothelial keratoplasty. Br J Ophthalmol 2012;96(2):246-9.

80. Shih $\mathrm{CY}$, Ritterband DC, Palmiero PM, et al. The Use of Postoperative Slit-Lamp Optical Coherence Tomography to Predict Primary Failure in Descemet Stripping Automated Endothelial Keratoplasty. American Journal of Ophthalmology 2009;147(5):796-800.

81. Anwar M, Teichmann KD. Big-bubble technique to bare Descemet's membrane in anterior lamellar keratoplasty. J Cataract Refract Surg 2002;28(3):398-403.

82. Kaiserman I, Bahar I, Rootman DS. Optical coherence tomography of Descemet membrane separation by the big bubble technique. Cornea 2007;26(9):1115-7.

83. Fukuda R, Usui T, Tomidokoro A, et al. Noninvasive Observations of Peripheral Angle in Eyes After Penetrating Keratoplasty Using Anterior Segment Fourier-Domain Optical Coherence Tomography. Cornea 2012;31(3):259-63.

84. Lyle WA, Jin GJ. Prospective evaluation of early visual and refractive effects with small clear corneal incision for cataract surgery. J Cataract Refract Surg 1996;22(10):1456-60.

85. Xia Y, Liu X, Luo L, et al. Early changes in clear cornea incision after phacoemulsification: an anterior segment optical coherence tomography study. Acta Ophthalmol 2009;87(7):764-8.

86. Calladine D, Packard R. Clear corneal incision architecture in the immediate postoperative period evaluated using optical coherence tomography. J Cataract Refract Surg 2007;33(8):1429-35.

87. Calladine D, Tanner V. Optical coherence tomography of the effects of stromal hydration on clear corneal incision architecture. J Cataract Refract Surg 2009;35(8):1367-71.

88. Fine IH, Hoffman RS, Packer M. Profile of clear corneal cataract incisions demonstrated by ocular coherence tomography. Journal of Cataract and Refractive Surgery 2007;33(1):94-7.

89. Dupont-Monod S, Labbe A, Fayol N, et al. In vivo architectural analysis of clear corneal incisions using anterior segment optical coherence tomography. J Cataract Refract Surg 2009;35(3):444-50. 
90. Schallhorn JM, Tang M, Li Y, et al. Optical coherence tomography of clear corneal incisions for cataract surgery. J Cataract Refract Surg 2008;34(9):1561-5.

91. Kumar DA, Agarwal A, Prakash G, et al. Evaluation of intraocular lens tilt with anterior segment optical coherence tomography. Am J Ophthalmol 2011;151(3):406-12.e2.

92. Park HY, Ahn MD. Imaging of trabeculectomy blebs with Visante anterior segment optical coherence tomography after digital ocular compression. Jpn J Ophthalmol 2012;56(1):38-45.

93. Sng CC, Singh M, Chew PT, et al. Quantitative Assessment of Changes in Trabeculectomy Blebs After Laser Suture Lysis Using Anterior Segment Coherence Tomography. J Glaucoma 2012;21(5):313-7.

94. Guthoff R, Guthoff T, Hensler D, et al. Bleb Needling in Encapsulated Filtering Blebs: Evaluation by Optical Coherence Tomography. Ophthalmologica 2009;224(4):204-8.

95. Mendrinos E, Dosso A, Sommerhalder J, Shaarawy T. Coupling of HRT II and AS-OCT to evaluate corneal endothelial cell loss and in vivo visualization of the Ahmed glaucoma valve implant. Eye 2009;23(9):1836-44.

96. Chua J, Mehta JS, Tan DT. Use of anterior segment optical coherence tomography to assess secondary glaucoma after penetrating keratoplasty. Cornea 2009;28(2):243-5.

97. Laemmer R, Mardin CY, Juenemann AG. Visualization of changes of the iris configuration after peripheral laser iridotomy in primary melanin dispersion syndrome using optical coherence tomography. J Glaucoma 2008;17(7):569-70.

98. Geerling G, Muller M, Winter C, et al. Intraoperative 2-dimensional optical coherence tomography as a new tool for anterior segment surgery. Arch Ophthalmol 2005;123(2):253-7.

99. Sarunic MV, Asrani S, Izatt JA. Imaging the ocular anterior segment with real-time, full-range FourierDomain optical coherence tomography. Archives of Ophthalmology 2008;126(4):537-42.

100.Vajzovic LM, Karp CL, Haft P, et al. Ultra high-resolution anterior segment optical coherence tomography in the evaluation of anterior corneal dystrophies and degenerations. Ophthalmology 2011;118(7):1291-6.

101.Francoz M, Karamoko I, Baudouin C, Labbe A. Ocular surface epithelial thickness evaluation with spectral-domain optical coherence tomography. Invest Ophthalmol Vis Sci 2011;52(12):9116-23.

102.Asrani S, Sarunic M, Santiago C, Izatt J. Detailed visualization of the anterior segment using Fourierdomain optical coherence tomography. Archives of Ophthalmology 2008;126(6):765-71.

103. Fukuda S, Kawana K, Yasuno Y, Oshika T. Anterior ocular biometry using 3-dimensional optical coherence tomography. Ophthalmology 2009;116(5):882-9.

104.Marcos S, Ortiz S, Perez-Merino $P$, et al. Three-dimensional evaluation of accommodating intraocular lens shift and alignment in vivo. Ophthalmology 2013;epub. 



\section{Chapter 2}

Comparison of central corneal thickness and anterior chamber depth measurements using three imaging technologies in normal eyes and after phakic intraocular lens implantation

Muriël Doors, Lars P.J. Cruysberg, Tos T.J.M. Berendschot, John de Brabander, Frenne Verbakel, Carroll A.B. Webers, Rudy M.M.A. Nuijts

Graefes Arch Clin Exp Ophthalmol. 2009 Aug;247(8):1139-46 


\section{ABSTRACT}

Background: The repeatability and interchangeability of imaging devices measuring central corneal thickness (CCT) and anterior chamber depth (ACD) are important in the assessment of patients considering refractive surgery. The purpose of this study was to investigate the agreement of CCT and ACD measurements using 3 imaging technologies in healthy eyes and eyes after phakic intraocular lens implantation (pIOL).

Methods: In this comparative study, CCT and ACD were measured using anterior segment optical coherence tomography (AS-OCT), Orbscan II, and Pentacam in 33 healthy volunteers (66 eyes) and 22 patients (42 eyes) after plOL implantation. Intraobserver repeatability was evaluated for all three devices in the healthy volunteer group.

Results: Pair wise comparison of CCT measurements showed significant differences between all devices $(P<0.001)$, except for the AS-OCT and Orbscan II in the healthy volunteer group $(P=0.422)$ and the Orbscan II and Pentacam in the plOL group $(P=0.214)$. ACD measurements demonstrated significant differences between all pair wise comparisons in both groups $(P \leq 0.001)$. Intraobserver reliability was high for CCT and ACD measurements in the healthy volunteer group, with coefficients of variation ranging from $0.6 \%$ to $1.2 \%$ and $0.4 \%$ to $0.5 \%$, respectively.

Conclusions: CCT and ACD measurements using AS-OCT, Orbscan II, and Pentacam demonstrated high intraobserver reliability. However, these devices should not be used interchangeably for measurements of CCT and ACD in healthy subject and patients after pIOL implantation. 


\section{INTRODUCTION}

Measurements of central corneal thickness (CCT) are important in the assessment of a variety of corneal diseases, the precision of intraocular pressure readings, and eligibility of patients considering refractive surgery. Doughty and Zaman described that a $10 \%$ difference in CCT may result in a $3.4 \mathrm{mmHg}$ change in intraocular pressure (IOP). ${ }^{1}$ Furthermore, changes in corneal thickness can be a warning sign of endothelial cell loss, ${ }^{2}$ which can be helpful in evaluating the safety of iris-fixated phakic intraocular lenses (pIOLs).

Currently, a variety of non-contact imaging technologies are available to measure CCT. Applications such as the Visante anterior segment optical coherence tomography (AS-OCT; Carl Zeiss Meditec, Dublin, CA), Orbscan II (Bausch \& Lomb, Munich, Germany), and Pentacam (Oculus, Wetzlar, Germany), can all assess CCT without being in contact with the eye. Non-contact devices are becoming more popular as they eliminate the disadvantages of ultrasound biometry, such as the risk of corneal abrasions and infections due to corneal contact, as well as discomfort experienced by the patient.

Besides CCT measurements, AS-OCT, Orbscan II and Pentacam also calculate anterior chamber depth (ACD). ACD is particularly important when evaluating patients' eligibility for iris-fixated pIOL implantation. Iris-fixated pIOL implantation is a safe method for correcting higher refractive errors when strict inclusion criteria for surgery are applied. ${ }^{3}$ Hence, an accurate measurement of the ACD is of immense value to assure the safety of the adjacent corneal endothelium.

Although previously several of these imaging devices were compared in normal eyes, eyes diagnosed with keratoconus and eyes after corneal refractive surgery, no studies are reported in which these methods were compared in patients after pIOL implantation. ${ }^{4-11}$ In this study, we evaluated CCT measurements in healthy volunteers and patients after pIOL implantation using AS-OCT, Orbscan II, and Pentacam. Additionally, we compared the ACD measurements using these three devices and evaluated their repeatability.

\section{MATERIALS AND METHODS}

\section{Patient Population and Study Design}

Thirty-three healthy volunteers (66 eyes) were prospectively recruited from our outpatient clinic at the Academic Hospital Maastricht. The mean age of this group was $22.3 \pm 1.6$ years (range 20-29) and included 14 men and 19 women.

Furthermore, a group of 22 patients ( 42 eyes), who had undergone iris-fixated plOL implantation, were evaluated. The mean age of this group was $51.1 \pm 9.3$ years 
(range 33-67) and included 9 men and 13 women. Before pIOL implantation the mean spherical equivalent was $-11.84 \pm 6.13$ diopters $(D)$ and mean implanted pIOL power was $-11.85 \pm 5.91 \mathrm{D}$.

The study was conducted in accordance with the Declaration of Helsinki and informed consent was obtained from all included subject. Patients and volunteers with corneal pathology, previous refractive surgery, or abnormalities in the anterior segment were excluded from this study. All subject were examined using AS-OCT, Orbscan II and Pentacam. In the healthy volunteer group, three consecutive measurements of each device were obtained by the same investigator to evaluate the intraobserver repeatability. The first measurement was used for the comparative analysis. In the pIOL group, all measurements were done once by the same investigator.

\section{Imaging Devices}

Visante AS-OCT is a non-contact high-resolution device, which can be used to measure CCT and ACD. Multiple A-scans form a two dimensional image of the anterior segment, using low coherence interferometry. In our study, all images were made in the anterior segment single-scan mode, on the horizontal meridian, in an unaccommodated state, and in the same light conditions (50 lux). All subjects were asked to look at the optical target in the system. When the corneal reflex, a vertical white line along the center of the cornea, was visible, the image was captured. ACD was measured using the chamber function as provided by the manufacturer (from corneal endothelium to crystalline lens). Using this chamber function, the CCT was automatically computed by the system, using built-in analysis software which marks the boundaries of the anterior and posterior surface of the cornea. These automated measurements were used for the comparative analysis. In the healthy volunteer group, CCT was also measured manually in the anterior segment single-scan and the high resolution scan using the caliper function as provided by the manufacturer. The high resolution-scan is an enhanced image of the central cornea, which was also made on the horizontal meridian.

The Orbscan topography system (Orbscan II; version 3.10.31) uses a computerized slit-scanning method, which creates 40 vertical slit projections sequentially onto the cornea at an angle of 45․ The anterior and posterior corneal surfaces are obtained, and a corneal pachymetric map is created in a non-contact manner. Because initial comparative studies showed an overestimation of CCT using Orbscan II, an acoustic correction factor has to be used. ${ }^{12-15}$ The manufacturer recommends an acoustic correction factor of 0.92 , which was applied in our study. During the measurements, all patients were instructed to fixate on a fixation target in the center of the device. The corneal thickness in the center of the pupil was used for analysis. 
Besides CCT measurements, Orbscan II calculated the ACD, measured from corneal endothelium to crystalline lens.

The Pentacam is a non-contact device using a rotating Scheimpflug camera. The software constructs a three-dimensional image of the anterior segment, which gives information about the anterior and posterior surface of the cornea, and ACD (from corneal endothelium to crystalline lens). In our study, the patient was asked to fixate on a blue light target in the center of the camera. The device automatically determined when the image was in focus and the corneal apex correctly aligned. The rotating camera obtained 25 slit images of the anterior segment. The pachymetric measurement at the pupil center was used for analysis.

\section{Statistical Analysis}

Previous studies have reported a standard deviation (SD) of within-subject CCT measurements ranging from 4.9 to $6.9 \mu \mathrm{m}$ for Orbscan, Pentacam and AS-OCT. ${ }^{16-17}$ Therefore, with a significance level of 0.05 , our study with 66 healthy eyes and 42 pIOL eyes has a power of $>90 \%$ for both groups to detect a $15 \mu \mathrm{m}$ difference between two measurement methods. For within-subject ACD measurements, a SD ranging from 0.001 to $0.052 \mathrm{~mm}$ for Orbscan, Pentacam and AS-OCT has been described. ${ }^{11,18}$ Thus, with a significance level of 0.05 , our study with 66 healthy eyes and $42 \mathrm{plOL}$ eyes has a power of $>90 \%$ for both groups to detect a $0.10 \mathrm{~mm}$ difference between two measurement methods. All data were collected in an Excel database and transferred to SPSS (SPSS for Windows, version 15.0, SPSS Inc, Chicago, IL) for data analysis. Continuous variables were described as mean \pm SD. Paired $t$ tests were applied to compare CCT and ACD measurements between two applications in the healthy volunteer group and the pIOL group. To determine a relationship between the measurements of two devices, the Pearson's correlation coefficient $(r)$ was used. The agreement between two devices was studied using the method described by Bland and Altman.[19] This method also computed 95\% limits of agreement (LoA $=$ mean difference $\pm 1.96 * \mathrm{SD}$ ). To determine intraobserver reliability between three consecutive measurements in the healthy volunteer group, the mean standard deviation between three consecutive measurements (SD ${ }^{\text {within }}$ ), the coefficient of variation (COV) (ratio of SD ${ }^{\text {within }}$ and mean in percentage), and precision $\left(1.96 * \mathrm{SD}^{\text {within }}\right)$ were calculated. A $P$-value of $<0.05$ was considered significant. 


\section{RESULTS}

\section{Agreement of Central Corneal Thickness Measurements}

The results of the pair wise comparisons of the healthy volunteer group and the pIOL group are shown in Table 1 and Figure 1 . In the healthy volunteer group CCT was measured using AS-OCT, Orbscan II, and Pentacam, with means of $532.1 \pm 25.3$, $536.1 \pm 28.1$ and $551.3 \pm 26.2 \mu \mathrm{m}$, respectively. In this group, all pair wise correlations were highly significant. However, all pair wise comparisons showed a significant difference, except for the comparison between automatic measurements in the anterior segment single-scan of the AS-OCT and the Orbscan II measurements $(P=0.422)$. Pentacam overestimated CCT measurements compared to the other 2 devices $(P<0.001)$.

In the pIOL group, the mean CCT using AS-OCT was $529.8 \pm 40.3 \mu \mathrm{m}$, and the mean Orbscan II and Pentacam CCT were 541.4 \pm 36.7 and $543.8 \pm 38.6 \mu \mathrm{m}$, respectively. All comparisons were highly correlated and there was no significant difference between the Orbscan II and Pentacam CCT measurements in the pIOL group $(P=0.214)$. AS-OCT measurements significantly underestimated CCT when compared to Orbscan II and Pentacam $(P<0.001)$.

The pair wise comparisons of the CCT measurements using three different ASOCT measurement modes in the healthy volunteer group are also listed in Table 1. Automatic CCT measurement using the anterior segment single-scan demonstrated the smallest values, whereas manual CCT measurements using the same scan showed the highest CCT values. All three AS-OCT modes comparisons were significantly different $(P<0.001)$.

\section{Agreement of Anterior Chamber Depth Measurements}

In the healthy volunteer group, the mean ACD using AS-OCT, Orbscan II, and Pentacam were $3.41 \pm 0.25,3.25 \pm 0.29$ and $3.34 \pm 0.27 \mathrm{~mm}$, respectively. All pair wise comparisons demonstrated a significant difference between ACD measurements (Table 2). ACD measurements using Orbscan II were always smaller than the measurements of the other two imaging devices $(P<0.001)$. The AS-OCT demonstrated higher ACD measurements than the Pentacam $(P<0.001)$.

In the pIOL group, mean ACD using AS-OCT, Orbscan II and Pentacam were 3.15 $\pm 0.22,2.94 \pm 0.31$ and $3.06 \pm 0.24 \mathrm{~mm}$, respectively. All pair wise comparisons showed a significant differences between ACD measurements (Table 2). Similar to the healthy volunteer group, Orbscan II underestimated ACD compared to AS-OCT and Pentacam measurements, and AS-OCT overestimated ACD when compared to Pentacam measurements. In Figure 2 Bland-Altman plots visualize the ACD differences between the three imaging systems for both groups. 

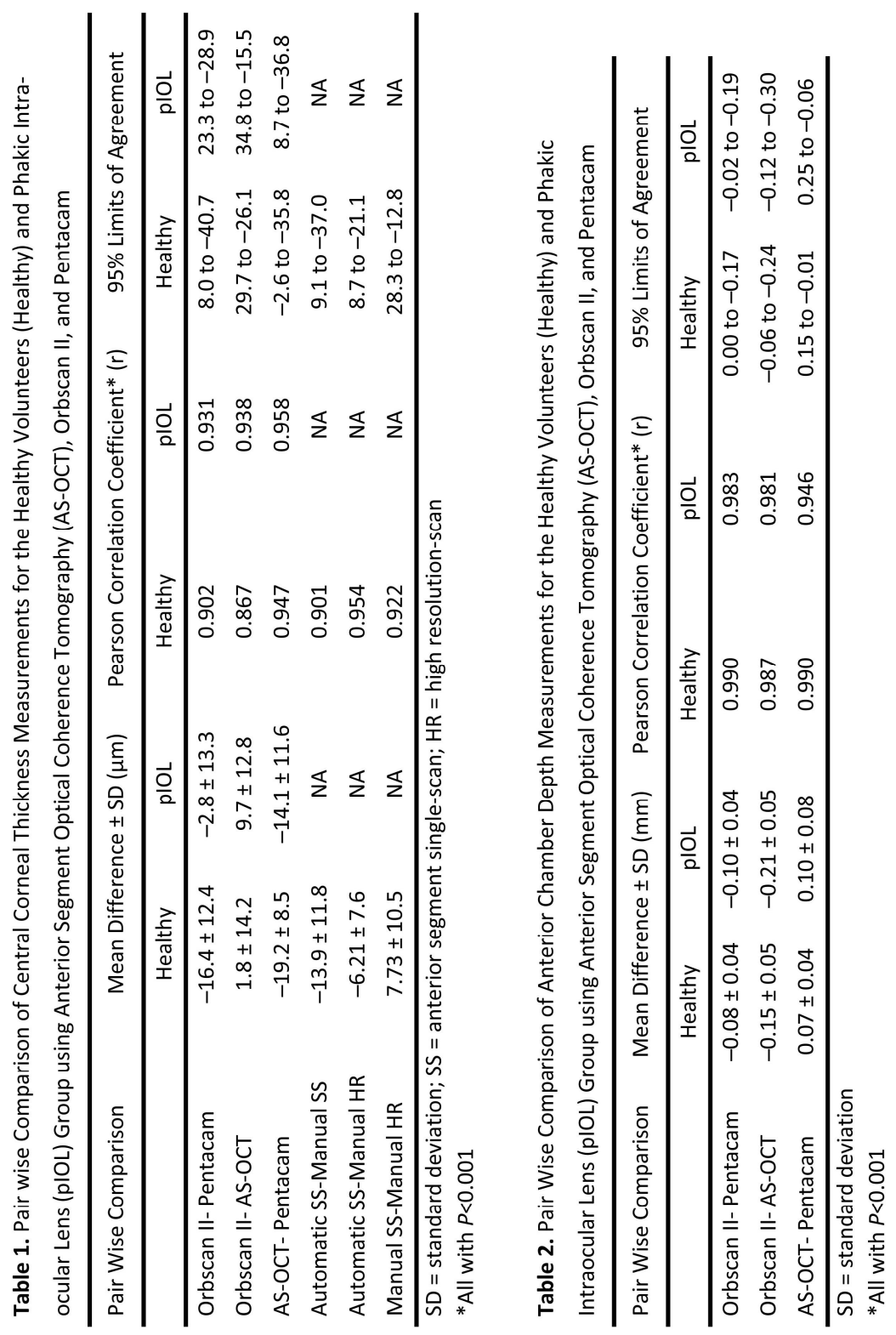


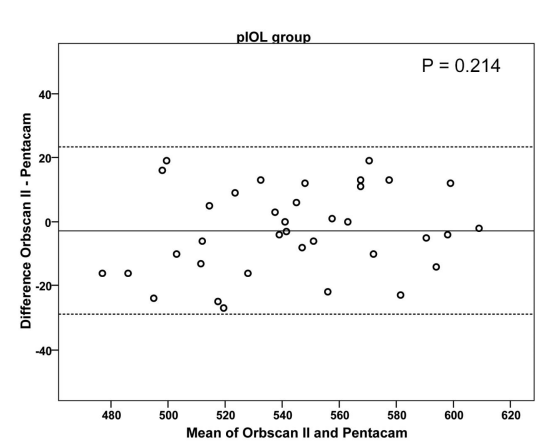

Figure 1
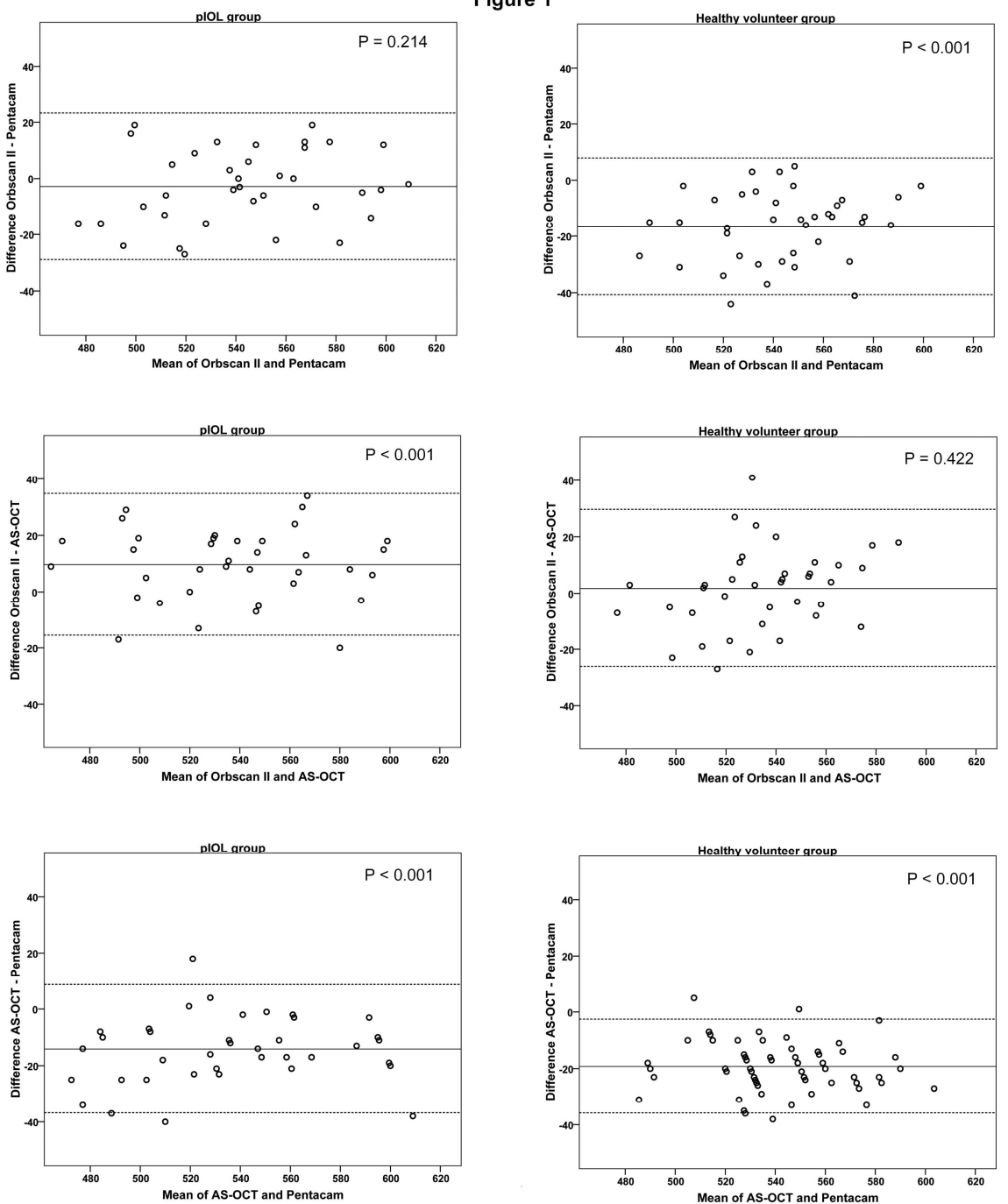

Figure 1. Bland-Altman plots of the differences between anterior segment optical coherence tomography (AS-OCT), Orbscan II and Pentacam central corneal thickness measurements in the healthy volunteer group and the phakic intraocular lens ( $\mathrm{plOL}$ ) group with P-value of the paired t-test. All scales in $\mu \mathrm{m}$.

\section{Intraobserver Reliability}

Table 3 presents the intraobserver reliability for measurements of CCT using three AS-OCT modes, Orbscan II, and Pentacam. In all imaging devices the repeatability was high. Manual measurements of CCT using the high resolution-scan showed the smallest SD ${ }^{\text {within }}$ and COV, and manual measurements in the anterior segment single-scan showed the highest SD ${ }^{\text {within }}$ and COV. 
The intraobserver reliability of the ACD measurements using AS-OCT, Orbscan II, and Pentacam was high, with a SD ${ }^{\text {within }}$ of $0.014 \pm 0.009,0.015 \pm 0.009$ and $0.017 \pm$ $0.009 \mathrm{~mm}$, respectively. The AS-OCT showed the smallest variation between ACD measurements, with a COV of $0.4 \pm 0.3 \%$ and a precision of $0.028 \pm 0.018$ and the Pentacam presented the largest variation, with a COV of $0.5 \pm 0.3 \%$ and a precision of $0.033 \pm 0.019$. The COV and precision of the Orbscan II were $0.5 \pm 0.3 \%$ and 0.029 \pm 0.017 , respectively.

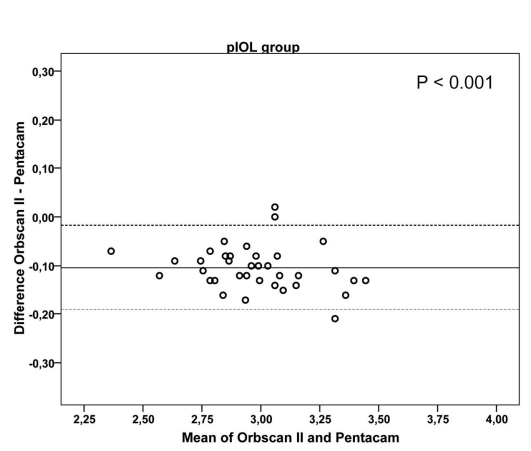

Figure 2
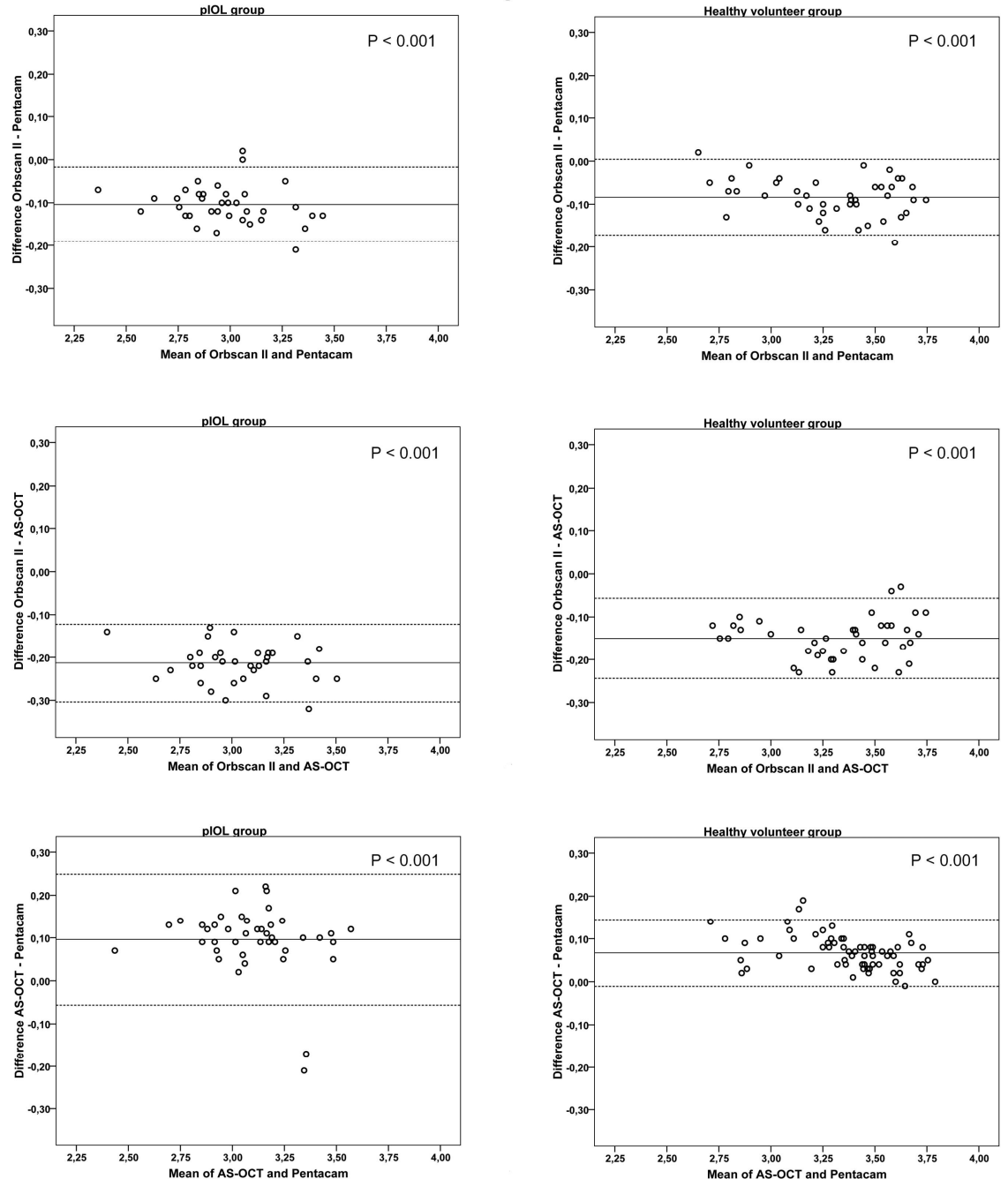

Figure 2. Bland-Altman plots of the differences between anterior segment optical coherence tomography (AS-OCT), Orbscan II and Pentacam anterior chamber depth measurements in the healthy volunteer group and the phakic intraocular lens $(\mathrm{plOL})$ group with $P$-value of the paired $t$-test. All scales in $\mathrm{mm}$. 


\section{DISCUSSION}

This study revealed significant differences in ACD measurements using AS-OCT, Orbscan II, and Pentacam, between all pair wise comparisons in the healthy volunteer group and the $\mathrm{pIOL}$ group. Furthermore, the pair wise comparisons of CCT measurements using AS-OCT, Orbscan II, and Pentacam, showed significant differences in both groups, except for the comparison between AS-OCT and Orbscan II in the healthy volunteer group and between Orbscan II and Pentacam in the pIOL group. However, these last two comparisons did show large $95 \%$ limits of agreement. Overall, this indicates the existence of systematic offsets in CCT and ACD values between the investigated imaging technologies in healthy volunteers and patients after plOL implantation.

Table 3. Intraobserver Reliability from 3 Consecutive Central Corneal Thickness Measurements of the Healthy Volunteer Group

\begin{tabular}{lcccc}
\hline Device & $\begin{array}{c}\text { Overall Mean } \pm \text { SD } \\
(\mu \mathrm{m})\end{array}$ & $\begin{array}{c}\text { SD }^{\text {within }} \pm \text { SD } \\
\text { AS-OCT }\end{array}$ & $\begin{array}{c}\text { COV } \pm \text { SD } \\
(\%)\end{array}$ & Precision \pm SD \\
Automatic Segment Single & $531.1 \pm 25.1$ & $3.8 \pm 2.7$ & $0.7 \pm 0.5$ & $7.5 \pm 5.4$ \\
Manual Segment Single & $545.3 \pm 25.1$ & $6.8 \pm 6.0$ & $1.2 \pm 1.1$ & $13.3 \pm 11.7$ \\
Manual High Resolution & $538.8 \pm 24.4$ & $3.3 \pm 4.1$ & $0.6 \pm 0.7$ & $6.5 \pm 8.0$ \\
Orbscan II & $530.3 \pm 40.8$ & $5.4 \pm 3.5$ & $1.0 \pm 0.7$ & $10.5 \pm 6.8$ \\
Pentacam & $551.6 \pm 25.6$ & $4.0 \pm 2.3$ & $0.7 \pm 0.4$ & $7.9 \pm 4.6$ \\
\hline
\end{tabular}

$\mathrm{SD}=$ standard deviation; $\mathrm{SD}^{\text {within }}=$ mean standard deviation between three consecutive measurements; $\mathrm{COV}=$ coefficient of variation; AS-OCT = anterior segment optical coherence tomography

The CCT values measured with automatic AS-OCT were significantly smaller than Pentacam measurements in both groups. Furthermore, we found significantly smaller CCT measurements using AS-OCT compared to Orbscan II in the pIOL group. In the healthy volunteer group, this difference did not reach significance. The reported differences are in accordance with recent literature. ${ }^{20}$ Significantly smaller CCT measurements using AS-OCT were described by Ho et al., comparing AS-OCT values to Pentacam, and Orbscan II measurements. ${ }^{4}$ A possible explanation for these smaller CCT values using AS-OCT was described by Li et al. They reported that the algorithm for the Visante OCT places the anterior corneal surface boundary slightly below the anterior corneal surface. ${ }^{16}$ This results in slightly smaller CCT values when using the automatic CCT measurements, which we used for our comparative analysis. During the manual CCT measurements of this study, the calipers were placed on the anterior corneal surface. This resulted in significantly higher manual AS-OCT measurements compared to the automatic CCT measurements. 
Orbscan II showed smaller CCT measurements than Pentacam, with a significant difference in the healthy volunteer group. Rosa et al. also reported smaller Orbscan II CCT measurements than Pentacam measurements in normal eyes. ${ }^{21}$ Lackner et al. investigated the intensity profiles of the Pentacam and Orbscan II. The Pentacam showed steeper corneal edge depictions than the Orbscan, which resulted in less blurred images using Pentacam. ${ }^{17}$ The reliability of the detection of the posterior corneal surface using the Orbscan II is still unknown and could be the explanation for the reported differences. ${ }^{22}$

To our knowledge, no studies evaluated all three imaging techniques in healthy eyes and compared them to ultrasound pachymetry, which is known to be the gold standard. There are several studies reported in the literature comparing AS-OCT, Pentacam and Orbscan II separately to ultrasound pachymetry. Studies comparing CCT measurements with ultrasound pachymetry to AS-OCT in healthy eyes, showed an underestimation of AS-OCT measurements, with mean differences of $26.6 \mu \mathrm{m}$ reported by Kim et al. ${ }^{23}$ and $31.9 \mu \mathrm{m}$ by Wong et al. ${ }^{24}$ Some comparison studies investigating the agreement between Obscan II and ultrasound pachymetry, found no statistical significant difference in CCT measurements when the mentioned acoustic correction factor of 0.92 was applied to the Orbscan II values. ${ }^{5,20,25}$ However, other studies reported underestimations of CCT measurements using Orbscan II, after the acoustic correction factor was applied. ${ }^{8,15,17,26}$ Amano et al. found no significant difference between Pentacam and ultrasound pachymetry CCT measurements. ${ }^{5}$ However, there are studies reporting a significant difference between these two devices. ${ }^{8,27}$ Since there are a large amount of studies reporting significant differences between the AS-OCT, Pentacam and Orbscan II when compared to ultrasound pachymetry, even with the application of a correction factor in the Orbscan II, these devices can not be used interchangeably.

Limits of agreement give an idea about how much the devices can differ in 95\% of the patients. In this study, the significant mean differences in CCT measurements were between 10 and $19 \mu \mathrm{m}$, with spans of the $95 \%$ limits of agreement between 38.4 and $50.3 \mu \mathrm{m}$. In the comparison between Orbscan II and Pentacam in the pIOL group and between Orbscan II and AS-OCT in the healthy volunteer group, the mean differences were not statistically significant. However, these two comparisons showed the largest 95\% limits of agreements, with spans of $52.2 \mu \mathrm{m}$ between Orbscan II and Pentacam and $55.8 \mu \mathrm{m}$ between Orbscan II and AS-OCT. In our opinion, the reported CCT differences with their 95\% limits of agreement are clinically significant, especially in patients considering refractive surgery. Furthermore, these large limits of agreement come close or even exceed the mentioned $10 \%$ difference in CCT measurements by Doughty et al., which may result in IOP differences of 3.4 $\mathrm{mmHg}$ or more depending on the used imaging device. ${ }^{1}$ Some investigators recommend categorizing corneal thickness as thin, average, or thick and not use a specific 
algorithm to correct for corneal thickness, since CCT measurements can differ between devices and there are different algorithms reported in the literature. ${ }^{28,29}$

ACD measurements using AS-OCT were significantly higher than the Pentacam values in both groups. Pentacam ACD measurements are automatically calculated by the device. However, when using AS-OCT the ACD had to be measured manually. The chamber-function provides a caliper which has to be placed on the anterior surface of the lens. This caliper has a thickness of approximately $40 \mu \mathrm{m}$ and was placed with the anterior surface of the caliper on the anterior surface of the lens. Placing the posterior surface of the caliper onto the lens surface might improve the agreement between AS-OCT and Pentacam ACD measurements.

Orbscan II ACD measurements were significantly smaller than AS-OCT, and Pentacam measurements. This could be due to the relatively low depth resolution of slit scanning compared to Pentacam and AS-OCT. ${ }^{22}$

The mean differences in ACD measurements between two devices ranged from 0.07 to $0.21 \mathrm{~mm}$, with a large range in the spans of $95 \%$ limits of agreement from 0.16 to $0.31 \mathrm{~mm}$. The mean differences between the three imaging devices seem quite small, however the $95 \%$ limits of agreement are large and clinically relevant, especially in pIOL power calculation and the assessment of plOL safety. Although the devices were highly correlated, they can not be used interchangeably.

The intraobserver reliability for ACD and CCT was excellent for the AS-OCT, Orbscan II, and Pentacam. The manual CCT measurement using the anterior segment single-scan demonstrated the largest variability. The caliper function in this scan shows large steps for each pixel, i.e. one pixel means $20 \mu \mathrm{m}$, with explains the larger variability. Measurements in the high resolution-scan were more precise. In this scan one pixel is $10 \mu \mathrm{m}$. Li et al. also evaluated the intraobserver reliability of CCT measurements using manual and automatic AS-OCT. They described a SD ${ }^{\text {within }}$ of 4.9 and 6.9 for automatic AS-OCT and manual AS-OCT, with a COV of 0.9 and $1.2 \%$, respectively, which are consistent with our results. ${ }^{16}$ Furthermore, the AS-OCT showed the best intraobserver reliability for ACD measurements in our study, with the smallest standard deviation and coefficient of variation. In accordance with our results, Pinero et al. reported a COV of $0.38 \%$ using AS-OCT for ACD measurements. ${ }^{30}$

In conclusion, the intraobserver reliability of AS-OCT, Pentacam, and Orbscan II were excellent for CCT and ACD measurements. However, all investigated devices should not be used interchangeably for measurement of ACD and CCT in healthy subjects and patients after plOL implantation. Pair wise comparison of the imaging technologies showed significant mean differences, with large $95 \%$ limits of agreement. 


\section{REFERENCES}

1. Doughty MJ, Zaman ML: Human corneal thickness and its impact on intraocular pressure measures: A review and meta-analysis approach. Surv Ophthalmol 2000;44:367-408.

2. Cheng H, Bates AK, Wood L, McPherson K: Positive correlation of corneal thickness and endothelial cell loss. Serial measurements after cataract surgery. Arch Ophthalmol 1988;106:920-922.

3. Tahzib NG, Nuijts RM, Wu WY, Budo CJ: Long-term study of artisan phakic intraocular lens implantation for the correction of moderate to high myopia: Ten-year follow-up results. Ophthalmology 2007;114:1133-1142.

4. Ho T, Cheng AC, Rao SK, Lau S, Leung CK, Lam DS: Central corneal thickness measurements using orbscan ii, visante, ultrasound, and pentacam pachymetry after laser in situ keratomileusis for myopia. J Cataract Refract Surg 2007;33:1177-1182.

5. Amano S, Honda N, Amano Y, Yamagami S, Miyai T, Samejima T, Ogata M, Miyata K: Comparison of central corneal thickness measurements by rotating scheimpflug camera, ultrasonic pachymetry, and scanning-slit corneal topography. Ophthalmology 2006;113:937-941.

6. Kim SW, Byun YJ, Kim EK, Kim TI: Central corneal thickness measurements in unoperated eyes and eyes after prk for myopia using pentacam, orbscan ii, and ultrasonic pachymetry. J Refract Surg 2007;23:888-894.

7. de Sanctis U, Missolungi A, Mutani B, Richiardi L, Grignolo FM: Reproducibility and repeatability of central corneal thickness measurement in keratoconus using the rotating scheimpflug camera and ultrasound pachymetry. Am J Ophthalmol 2007;144:712-718.

8. Hashemi H, Mehravaran S: Central corneal thickness measurement with pentacam, orbscan ii, and ultrasound devices before and after laser refractive surgery for myopia. J Cataract Refract Surg 2007;33:1701-1707.

9. Lavanya R, Teo L, Friedman DS, Aung HT, Baskaran M, Gao H, Alfred T, Seah SK, Kashiwagi K, Foster $\mathrm{PJ}$, Aung T: Comparison of anterior chamber depth measurements using the iolmaster, scanning peripheral anterior chamber depth analyser, and anterior segment optical coherence tomography. $\mathrm{Br} \mathrm{J}$ Ophthalmol 2007;91:1023-1026.

10. Haque S, Simpson T, Jones L: Corneal and epithelial thickness in keratoconus: A comparison of ultrasonic pachymetry, orbscan ii, and optical coherence tomography. J Refract Surg 2006;22:486-493.

11. Lackner B, Schmidinger G, Skorpik C: Validity and repeatability of anterior chamber depth measurements with pentacam and orbscan. Optom Vis Sci 2005;82:858-861.

12. Yaylali V, Kaufman SC, Thompson HW: Corneal thickness measurements with the orbscan topography system and ultrasonic pachymetry. J Cataract Refract Surg 1997;23:1345-1350.

13. Liu Z, Huang AJ, Pflugfelder SC: Evaluation of corneal thickness and topography in normal eyes using the orbscan corneal topography system. Br J Ophthalmol 1999;83:774-778.

14. Chakrabarti HS, Craig JP, Brahma A, Malik TY, McGhee CN: Comparison of corneal thickness measurements using ultrasound and orbscan slit-scanning topography in normal and post-lasik eyes. J Cataract Refract Surg 2001;27:1823-1828.

15. Hashemi H, Roshani M, Mehravaran S, Parsafar H, Yazdani K: Effect of corneal thickness on the agreement between ultrasound and orbscan ii pachymetry. J Cataract Refract Surg 2007;33:16941700 .

16. Li H, Leung CK, Wong L, Cheung CY, Pang CP, Weinreb RN, Lam DS: Comparative study of central corneal thickness measurement with slit-lamp optical coherence tomography and visante optical coherence tomography. Ophthalmology 2008;115:796-801.

17. Lackner B, Schmidinger G, Pieh S, Funovics MA, Skorpik C: Repeatability and reproducibility of central corneal thickness measurement with pentacam, orbscan, and ultrasound. Optom Vis Sci 2005;82:892-899.

18. Goldsmith JA, Li Y, Chalita MR, Westphal V, Patil CA, Rollins AM, Izatt JA, Huang D: Anterior chamber width measurement by high-speed optical coherence tomography. Ophthalmology 2005;112:238244. 
19. Bland JM, Altman DG: Statistical methods for assessing agreement between two methods of clinical measurement. Lancet 1986;1:307-310.

20. Li EY, Mohamed S, Leung CK, Rao SK, Cheng AC, Cheung CY, Lam DS: Agreement among 3 methods to measure corneal thickness: Ultrasound pachymetry, orbscan ii, and visante anterior segment optical coherence tomography. Ophthalmology 2007;114:1842-1847.

21. Rosa N, Lanza M, Borrelli M, Polito B, Filosa ML, De Bernardo M: Comparison of central corneal thickness measured with orbscan and pentacam. J Refract Surg 2007;23:895-899.

22. Cairns G, McGhee CN: Orbscan computerized topography: Attributes, applications, and limitations. J Cataract Refract Surg 2005;31:205-220.

23. Kim HY, Budenz DL, Lee PS, Feuer WJ, Barton K: Comparison of central corneal thickness using anterior segment optical coherence tomography vs ultrasound pachymetry. Am J Ophthalmol 2008;145:228-232.

24. Wong AC, Wong CC, Yuen NS, Hui SP: Correlational study of central corneal thickness measurements on hong kong chinese using optical coherence tomography, orbscan and ultrasound pachymetry. Eye 2002;16:715-721.

25. Suzuki S, Oshika T, Oki K, Sakabe I, Iwase A, Amano S, Araie M: Corneal thickness measurements: Scanning-slit corneal topography and noncontact specular microscopy versus ultrasonic pachymetry. J Cataract Refract Surg 2003;29:1313-1318.

26. McLaren JW, Nau CB, Erie JC, Bourne WM: Corneal thickness measurement by confocal microscopy, ultrasound, and scanning slit methods. Am J Ophthalmol 2004;137:1011-1020.

27. Fujioka $M$, Nakamura $M$, Tatsumi $Y$, Kusuhara A, Maeda $H$, Negi A: Comparison of pentacam scheimpflug camera with ultrasound pachymetry and noncontact specular microscopy in measuring central corneal thickness. Curr Eye Res 2007;32:89-94.

28. Brandt JD: Corneal thickness in glaucoma screening, diagnosis, and management. Curr Opin Ophthalmol 2004;15:85-89.

29. Behki R, Damji KF, Crichton A: Canadian perspectives in glaucoma management: The role of central corneal thickness. Can J Ophthalmol 2007;42:66-74.

30. Pinero DP, Plaza AB, Alio JL: Anterior segment biometry with 2 imaging technologies: Very-highfrequency ultrasound scanning versus optical coherence tomography. J Cataract Refract Surg 2008;34:95-102. 


\section{Chapter 3}

\section{Influence of anterior chamber morphometrics on endothelial cell changes after phakic intraocular lens implantation}

Muriël Doors, Diana W.J.K. Cals, Tos T.J.M. Berendschot, John de Brabander, Fred Hendrikse, Carroll A.B. Webers, Rudy M.M.A. Nuijts

J Cataract Refract Surg. 2008 Dec;34(12):2110-8 


\section{ABSTRACT}

Purpose: To analyze the position of iris-fixated phakic intraocular lenses (plOLs) using anterior segment optical coherence tomography (AS-OCT) and investigate the effect of anterior chamber morphometrics on endothelial cell changes.

Setting: Department of Ophthalmology, Academic Hospital Maastricht, The Netherlands.

Methods: In this cross-sectional study, AS-OCT was used to measure the distances from the center and the edges of the pIOL to the corneal endothelium in 242 eyes implanted with various models of myopic plOLs. Endothelial cell measurements were performed preoperatively and at each follow-up examination. Follow-up ranged from 3 months to 7 years, with a mean follow-up of $34.1 \pm 24.7$ months.

Results: The mean distance between the edge of the pIOL and the endothelium was $1.37 \pm 0.22 \mathrm{~mm}$. In $68.6 \%$ of the eyes this distance was smaller than the safety value of $1.5 \mathrm{~mm}$, but none of these eyes developed corneal decompensation. There was a significant endothelial cell density (ECD) loss of $1.28 \pm 8.46 \%, 3.25 \pm 8.24 \%$, and 5.02 $\pm 10.40 \%$ at 2,5 , and 7 years, respectively. A linear mixed model analysis, predicted a yearly endothelial cell loss of $0.98 \%$ for the mean edge distance of $1.37 \mathrm{~mm}$, $0.15 \%$ for an edge distance of $1.59 \mathrm{~mm}$ (mean plus $1 \mathrm{SD}$ ), and $1.8 \%$ for an edge distance of $1.15 \mathrm{~mm}$ (mean minus $1 \mathrm{SD}$ ).

Conclusions: A shorter distance between the edge of the pIOL and the endothelium was significantly associated with higher endothelial cell loss. For safety reasons, postoperative examination should include long-term investigation of the anterior chamber morphometrics in addition to ECD counts. 


\section{INTRODUCTION}

Iris-fixated phakic intraocular lenses (plOLs) are used worldwide to correct high myopia, hyperopia, and astigmatism. In 1986 the first iris-fixated lenses were implanted in phakic myopic eyes. ${ }^{1}$ The original biconcave Worst myopia claw lens was changed into a convex-concave shape in 1991 and in 1998 the name of the lens changed to the Artisan lens (Ophtec BV). More recently the Artisan toric pIOL was introduced in which both spherical and cylindrical correction are combined. A foldable model of the myopic Artisan lens (Artiflex; Ophtec BV) became available in 2003. This Artiflex lens may offer an advantage over the Artisan lens because it can be inserted through a smaller incision, with a decrease in surgically induced astigmatism and a faster visual recovery. ${ }^{2}$

Several published clinical studies have demonstrated that visual results of the Artisan and Artiflex lenses are stable and predictable. ${ }^{3-8}$ However, the long-term effect of pIOLs on the corneal endothelium is a point of discussion. To investigate the safety of iris-fixated lenses, clinical trials on endothelial cell changes after lens implantation have been conducted. Pop et al. ${ }^{9}$ reported no statistically significant change in mean endothelial cell loss rates up to 2 years after $\mathrm{plOL}$ implantation. The percentage of hexagonal cells (ie, an indicator of cell pleomorphism) remained stable and the coefficient of variation (ie, an index of cell size variation) showed a significant decrease at 1 year postoperatively. In contrast, Benedetti et al. ${ }^{10}$ found a significant change in mean endothelial cell loss of 3.5\% after 12 months and $9.0 \%$ after 5 years. Saxena et al. ${ }^{11}$ also reported a significant loss in endothelial cell density (12.6\% after 7 years). In addition they revealed a significant negative correlation between anterior chamber depth and endothelial cell loss after 3 years of follow-up.

In a recent study by Kohnen et al., ${ }^{2}$ data is presented on the position of the plOL in the anterior chamber. The distance between the $\mathrm{plOL}$ and the central corneal endothelium is measured using Scheimpflug photography. However, a myopic plOL has a convex-concave shape, which means that the edges of the plOL are in closer proximity to the peripheral corneal endothelium. Baikoff et al. ${ }^{12}$ mention that the minimum distance between the edge of the optic and the endothelium measured by AS-OCT, must be $1.5 \mathrm{~mm}$ to minimize the risk to corneal decompensation. Furthermore, Guell et al. ${ }^{13}$ reported an arbitrary safety distance between the center of the $\mathrm{pIOL}$ and the endothelium of $2.0 \mathrm{~mm}$. The distance from the pIOL to the crystalline lens has also been measured and a lens rise of $0.60 \mathrm{~mm}$ or more has been described as a risk factor for the development of pupillary pigment dispersion. ${ }^{14}$ Anterior chamber OCT allows a rapid, non-contact examination, and the software includes a measuring system capable of calculating distances between 2 points. Several studies have shown that AS-OCT is useful for determining pIOL position. ${ }^{12-16}$

In 2006 we started using the Visante OCT (Carl Zeiss Meditec Inc.) to visualize the $\mathrm{pIOL}$ in the anterior chamber. In this cross-sectional study, we analyzed the 
position of the iris-fixated Artisan and Artiflex pIOL in the anterior chamber using AS-OCT and investigated the endothelial cell changes in relation to the anterior chamber morphometrics.

\section{PATIENTS AND METHODS}

\section{Patient Population and Study Design}

From June 2006 to March 2008, 131 consecutive patients (242 eyes) were evaluated using Visante OCT to analyze anterior chamber morphometrics. All patients had undergone Artisan or Artiflex implantation from May 1998 to September 2007 for the correction of moderate to high myopia and astigmatism. The study was conducted in accordance with the Declaration of Helsinki and informed consent was obtained from all patients.

\section{Inclusion Criteria}

Criteria for plOL implantation were: a stable refractive error during the previous 2 years; an anterior chamber depth (ACD) of $2.8 \mathrm{~mm}$ or more (measured from the epithelium to the crystalline lens); pupil (in mesopic light conditions) less than 6 $\mathrm{mm}$; no corneal, pupil or iris abnormalities; and no history of glaucoma and chronic or recurrent uveitis. Another safety criteria for pIOL implantation is an endothelial cell density (ECD) count of 2000 cells $/ \mathrm{mm}^{2}$ or more. In our study 8 patients still wanted the pIOL implantation despite an ECD less than 2000 cells $/ \mathrm{mm}^{2}$ and our warnings about possible complications. These patients were included in the study and had the implantation due to complete contact lens intolerance and the inability to continue their occupation with spectacle correction. Patients who had more than one operation in one eye were excluded from analysis after their second procedure.

\section{Endothelial Cell Density}

Endothelial cell density measurements were performed preoperatively and repeated at 3 and 6 months and 1, 2, 3, 5, and 7 years after surgery. All ECD counts were performed by 2 independent employees using the Noncon Robo SP-9000 noncontact specular microscope (Konan Medical Inc.). During the investigation, 3 consecutive endothelial images of the central cornea were obtained. The images were analyzed using the dot method, in which the centers of approximately 50 contiguous cells are marked. The ECD data consisted of the average of 3 measurements. The percentage of hexagonal cells and coefficient of variation were also evaluated. Endothelial cell density loss was defined as the decrease in cell density between the 
preoperative and postoperative examination. Follow-up ranged from 3 months to 7 years, with a mean follow-up of $34.12 \pm 24.72$ months per eye.

\section{Anterior Segment Optical Coherence Tomography}

The position of the iris-fixated pIOL was analyzed once per eye using AS-OCT (Visante OCT). All OCT images were made on the horizontal meridian, in an unaccommodated state and in the same light conditions (50 lux). Cross-sectional images were taken using the anterior segment single-scan. Enhanced images of the pIOL were made using the high resolution scan. One examiner (M.D.) analyzed the images. In the 2-dimensional anterior segment single scan, the distance between the anterior surface of the center of the pIOL and the corneal endothelium, the lens rise $^{14}$ (the distance from the anterior surface of the crystalline lens to the horizontal line between the two angle recesses) and the distance between the posterior surface of the center of the pIOL and the anterior surface of the crystalline lens were measured using the calipers of the computer program provided by the manufacturer (Figure 1, A). The distances between the edges of the $\mathrm{plOL}$ and the corneal endothelium were measured in the high resolution scan, also using the calipers (Figure 1, $B$ ). Of the 2 edge distances (nasal and temporal side), the smallest distance was used for statistical analysis.

Due to the enhancement of the plOL in the high resolution scan, the central cornea is not captured in the image. When the central cornea is not pictured, the Visante OCT does not take the refractive index of the cornea into account. To get accurate measurements of the distances in this scan, a correction is necessary. In 22 eyes of 11 patients included in this study, the distances from the edges of the pIOL to the corneal endothelium and the peripheral corneal thickness were measured in the high resolution scan and the anterior segment single scan. Analysis of these results led to a mean correction factor of 1.31 . In this report all distances measured in the high resolution scan were corrected with this factor before analysis.

\section{Surgical Procedure}

The power of the implanted pIOL was calculated using the van der Heijde formula based on the mean corneal curve (K), adjusted anterior chamber depth (ACD - 0.8 $\mathrm{mm}$ ), and the spherical equivalent (SE) of the patient's spectacle correction at a 12.0 $\mathrm{mm}$ vertex. ${ }^{17}$ In case of Artiflex lens implantation, the adjusted anterior chamber depth calculation was changed slightly by the manufacturer. The power of the IOL was chosen to obtain emmetropia. When the emmetropic pIOL was not available, a slight residual myopia was preferred.

The Artisan pIOL has a convex-concave shape with either a $6 \mathrm{~mm}$ (for intraocu-

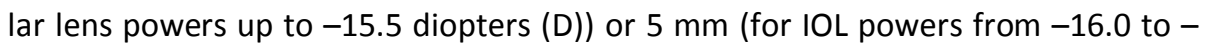


24.0 D) optic and is available in increments of 0.50 D. This single-piece IOL is composed of polymethyl methacrylate (PMMA) and manufactured by compression molding technology.

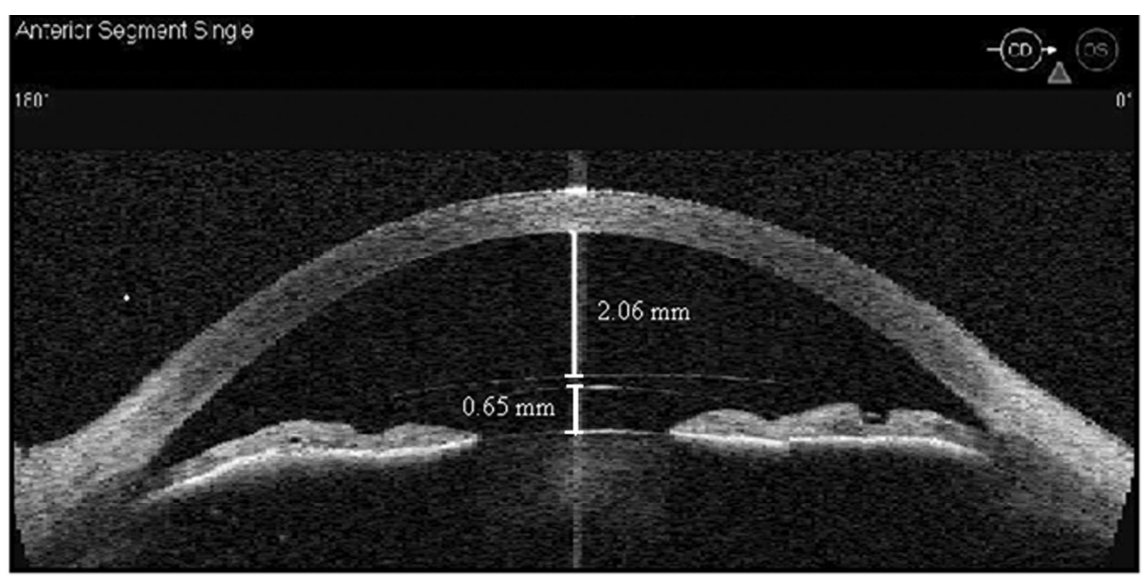

A

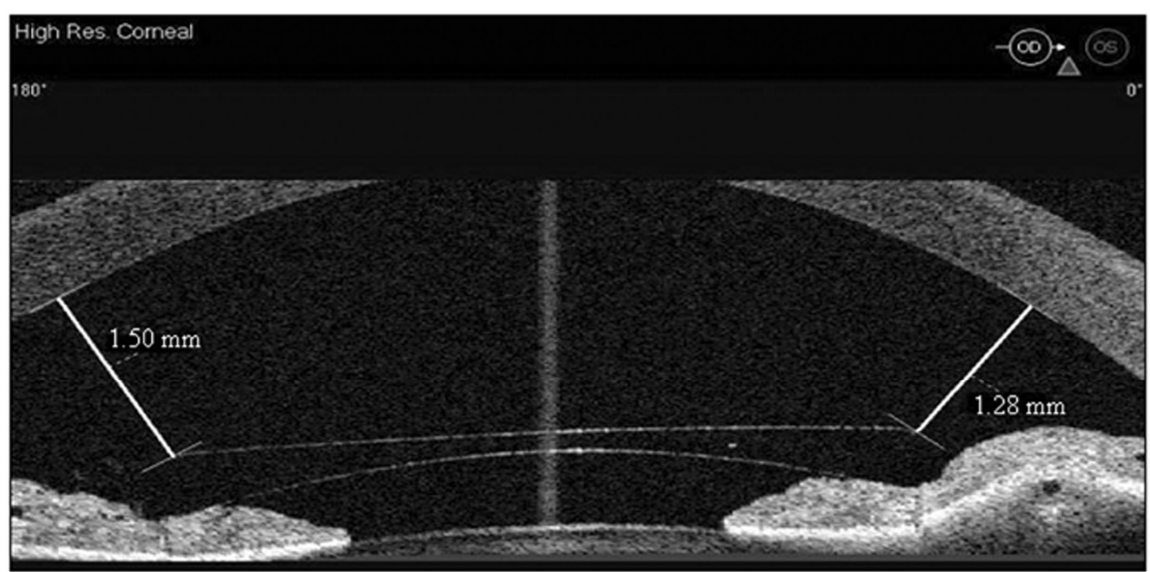

B

Figure 1. A: Anterior segment single scan with measured distance between the center of the plOL and endothelium $(2.06 \mathrm{~mm})$ and distance between $\mathrm{pIOL}$ and crystalline lens $(0.65 \mathrm{~mm})$. B: High resolution scan with measured distances between the edge of the pIOL and endothelium, $1.50 \mathrm{~mm}$ on the temporal side and $1.28 \mathrm{~mm}$ on the nasal side.

The PMMA Artisan toric pIOL has a convex-concave toric optic with a spherical anterior surface, a spherocylindrical posterior surface and a $5 \mathrm{~mm}$ optical zone. The toric pIOL is available in dioptric powers of -2.0 to -23.0 for myopia and +2.0 to +12.0 for hyperopia, with a cylindrical correction of 1.0 to $7.5 \mathrm{D}$. The hyperopic toric pIOL was not used in this study. 
The Artiflex IOL also has a convex-concave shape, with a $6 \mathrm{~mm}$ optical zone. It is a three-piece IOL that consists of a flexible optical part made of ultravioletabsorbing silicone and 2 rigid haptics made of PMMA. It is available in dioptric powers of -2.0 to -14.5 (in increments of $0.50 \mathrm{D}$ ). In this study we included 2 Artiflex types: the Artiflex I and the Artiflex II, which have different designs. In the Artiflex I the vault between the optic-haptic junction and the iris plane is $0.13 \mathrm{~mm}$ and in the Artiflex II the vault is $0.20 \mathrm{~mm}$ (Figure 2).

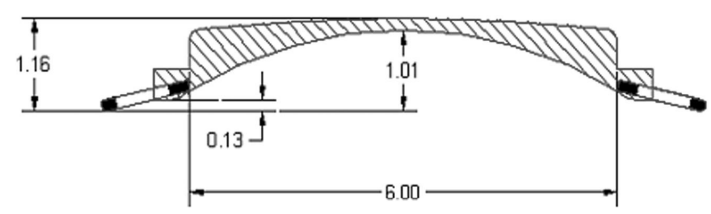

A

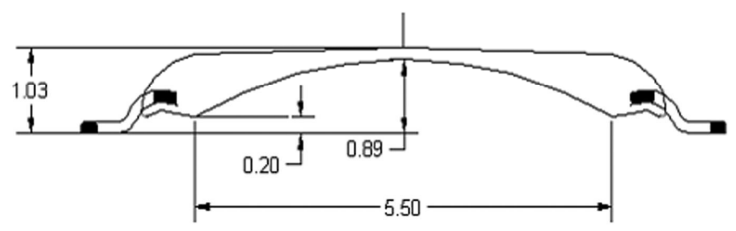

B

Figure 2. A: Cross-section of the Artiflex I-12.0 D, as provided by the manufacturer. $B$ : Cross-section of the Artiflex II -14.0 D, as provided by the manufacturer. Reported distances in $\mathrm{mm}$.

All surgical procedures were performed by the same surgeon (R.N.) between May 1998 and September 2007 at the Academic Center for Refractive Surgery, University Eye Clinic of Maastricht. The surgical technique for Artisan lens implantation is described elsewhere. ${ }^{18}$ The method of implantation of the Artisan toric pIOL was identical to the implantation of the Artisan myopia IOL, except that the haptics were aligned on the cylindrical axis (or perpendicular to the axis, depending on the IOL used) according to the alignment marks on the cornea.

The Artiflex IOL was inserted with a specially designed spatula that allows the surgeon to fold and insert the lens through a smaller $3.4 \mathrm{~mm}$ incision. The incision was centered at 12 o'clock, similar to the Artisan IOL implantation. The wound was sutured with two 10-0 nylon sutures.

After the operation, in all 3 techniques, topical tobramycin $0.3 \%$ combined with dexamethasone $0.1 \%$ (Tobradex) and ketorolac trometamol $0.5 \%$ (Acular) were 
used 4 times a day during 3 weeks in a tapered schedule and 3 times a day for 1 week, respectively.

\section{Statistical Analysis}

All collected data were transferred to SPSS (SPSS for Windows, version 15.0, SPSS Inc.) for data analysis. Continuous variables were described with mean, standard deviation and range. One-way analysis of variance was used to evaluate differences between the $5 \mathrm{plOL}$ groups (Artisan $5 \mathrm{~mm}$, Artisan $6 \mathrm{~mm}$, Artisan toric, Artiflex I, and Artiflex II). When significant differences were observed, the Tukey's least significant difference test was performed between all pairs of groups to identify pairs with and without significant differences. Comparisons between preoperative and postoperative data were performed by paired $t$ tests. To determine a relationship between endothelial cell loss and the distance from the edge and the center of the pIOL to the corneal endothelium, the Pearson's correlation coefficient $(r)$ was used. We applied a Linear mixed model analysis to investigate the association between endothelial cell loss and the distance from the edge of the plOL to the endothelium, correcting for the factor age and assuming a random intercept per eye. The benefit of this model is that it allowed the use of all available ECD data. In order to look for possible differences in endothelial cell loss for pIOLs with different distances between the edge of the pIOL and the corneal endothelium, we also included an interaction term "time" $\mathrm{x}$ "edge plOL-corneal endothelium distance." Furthermore, this analysis was used to determine significant changes in the coefficient of variation and the percentage of hexagonal cells during the course of the study. A linear regression model was applied to evaluate the relationship between the distance from the anterior surface of the crystalline lens to the posterior surface of the $\mathrm{plOL}$ and patient age. A P-value of less than 0.05 was considered significant.

\section{RESULTS}

\section{Patient Population}

All patient demographics are listed in Table 1. One hundred thirty-one patients (242 eyes) were included in the study. The mean age was $41.6 \pm 10.8$ years. Five eyes were excluded after they had lens exchange $(n=3)$ or reattachment of the haptics $(n=2)$. Lens exchange was necessary because of preoperative power calculation errors $(n=1)$ and pigment dispersion on the pIOL $(n=2)$. One eye required reenclavation of the nasal haptic due to trauma. The other needed reattachment of the haptic due to poor enclavation. 
Table 1. Patient Demographics

\begin{tabular}{lcc}
\hline Variable & Mean \pm Standard Deviation & Range \\
\hline Age (yrs) & $41.6 \pm 10.8$ & $18-62$ \\
Number of females ( $\mathrm{n}$ ) & 171 & \\
Number of eyes ( $\mathrm{n}$ ) & 242 & \\
Right eyes ( $\mathrm{n}$ ) & 119 & \\
Left eyes (n) & 123 & 0 to -28.00 \\
Sphere (D) & $-10.72 \pm 4.57$ & 0 to -5.00 \\
Cylinder (D) & $-1.20 \pm 0.99$ & $2.83-4.73$ \\
ACD (mm) & $3.65 \pm 0.34$ & $1588-3753$ \\
Preoperative ECD (cells/mm ${ }^{2}$ ) & $2664 \pm 337$ & -24.0 to -2.00 \\
Implanted lens power (D) & $-11.78 \pm 3.87$ & \\
Type of lens (n) & & \\
Artisan 5 mm & 32 & \\
Artisan 6 mm & 129 & \\
Artisan toric & 11 & \\
Artiflex I & 20 & \\
Artiflex II & 50 & \\
\hline ACD $=$ anteior chamber & & \\
\hline
\end{tabular}

$\mathrm{ACD}=$ anterior chamber depth; $\mathrm{D}=$ diopters; $\mathrm{ECD}=$ endothelial cell density

\section{Distances Measured With Anterior Segment Optical Coherence Tomography}

Measurements performed using AS-OCT are listed in Table 2. The Artisan $6 \mathrm{~mm}$ group showed a significantly higher mean distance between the center of the pIOL and the endothelium when compared to the other 4 groups $(P<.001)$.

The mean edge distances for the Artisan 5 and $6 \mathrm{~mm}$ groups were significantly higher than the distances for the Artiflex I and II groups $(P=.001, P=.002, P=.004$, $P=.007$, respectively). The mean edge distance in the Artisan toric group differed only significantly from the Artiflex I group $(P=.05)$.

There was no significant difference in lens rise between the 5 groups $(P=.058)$.

Furthermore, no pIOLs were in contact with the crystalline lens (range 0.26 to $0.96 \mathrm{~mm}$ ). Distances from the posterior surface of the pIOL to the crystalline lens were significantly shorter in the Artiflex II, Artisan $5 \mathrm{~mm}$ and $6 \mathrm{~mm}$ group, than in the Artiflex I group $(P=.002, P=.001, P=.030$, respectively). In Figure 3 , the distance between the posterior surface of the center of the pIOL and the anterior surface of the crystalline lens is plotted versus patient age. This distance was significantly smaller in older eyes $(r=-0.247 ; P<.001)$. The linear decrease of the distance between the pIOL and the crystalline lens was $3.1 \pm 0.8 \mu$ m (mean $\pm \mathrm{SE}$ ) per year. Furthermore, the distance from the edge of the pIOL to the endothelium was significantly smaller in eyes of older patients $(r=-0.204 ; P=.001)$. 
Table 2. Anterior Chamber Optical Coherence Tomography Measurements (in $\mathrm{mm}$ )

\begin{tabular}{lcccc}
\hline Lens Type (no.) & $\begin{array}{c}\text { Mean Distance } \\
\text { Endothelium-Center } \\
\text { plOL } \pm \text { SD (Range) }\end{array}$ & $\begin{array}{c}\text { Mean Distance } \\
\text { Endothelium-Edge } \\
\text { plOL } \pm \text { SD (Range) }\end{array}$ & $\begin{array}{c}\text { Mean Distance } \\
\text { Crystalline lens- } \\
\text { plOL } \pm \text { SD (Range) }\end{array}$ & $\begin{array}{c}\text { Lens rise } \pm \text { SD } \\
\text { (Range) }\end{array}$ \\
\hline Artisan 5 mm (32) & $2.07 \pm 0.26$ & $1.45 \pm 0.25$ & $0.65 \pm 0.14$ & $0.34 \pm 0.24$ \\
& $(1.40-2.50)$ & $(0.70-1.91)$ & $(0.33-0.96)$ & $(0.00-0.75)$ \\
Artisan 6 mm (129) & $2.28 \pm 0.23$ & $1.41 \pm 0.21$ & $0.62 \pm 0.14$ & $0.21 \pm 0.25$ \\
& $(1.70-2.70)$ & $(0.78-1.98)$ & $(0.26-0.92)$ & $(-0.35-0.81)$ \\
Artisan toric (11) & $1.94 \pm 0.18$ & $1.40 \pm 0.19$ & $0.65 \pm 0.08$ & $0.29 \pm 0.10$ \\
& $(1.70-2.20)$ & $(0.99-1.69)$ & $(0.51-0.76)$ & $(0.06-0.39)$ \\
Artiflex I (20) & $1.99 \pm 0.14$ & $1.25 \pm 0.15$ & $0.73 \pm 0.14$ & $0.27 \pm 0.17$ \\
& $(1.60-2.20)$ & $(0.99-1.52)$ & $(0.37-0.92)$ & $(0.00-0.65)$ \\
Artiflex II (50) & $2.10 \pm 0.27$ & $1.31 \pm 0.22$ & $0.62 \pm 0.11$ & $0.28 \pm 0.23$ \\
& $(1.70-2.80)$ & $(0.89-1.89)$ & $(0.39-0.84)$ & $(-0.10-0.67)$ \\
Total (242) & $2.18 \pm 0.26$ & $1.37 \pm 0.22$ & $0.64 \pm 0.14$ & $0.25 \pm 0.24$ \\
& $(1.40-2.80)$ & $(0.70-1.98)$ & $(0.26-0.96)$ & $(-0.35-0.81)$ \\
P-value* & $<0.001$ & 0.001 & 0.017 & 0.058 \\
\hline
\end{tabular}

pIOL = phakic intraocular lens; SD = standard deviation;

*ANOVA between the $5 \mathrm{plOL}$ groups

The central distance was smaller than the recommended $2.0 \mathrm{~mm}$ in $27.3 \%$ (63 of 231 eyes) of the eyes in our study. Furthermore, the distance between the edge of the pIOL and the endothelium was less than the advised $1.5 \mathrm{~mm}$ in 166 eyes (68.6\%). Despite the high number of eyes not meeting the safety criteria, all corneas stayed clear during follow-up. A lens rise of $0.60 \mathrm{~mm}$ or more has been reported as a risk factor for the development of pupillary pigment dispersion. In our study population $8.1 \%$ (19 eyes) had a lens rise of more than $0.60 \mathrm{~mm}$. Eleven of these 19 eyes (57.9\%) developed pigment dispersion on the pIOL.

Table 3. Endothelial Cell Density Counts before and after Phakic Intraocular Lens Implantation

\begin{tabular}{|c|c|c|c|c|c|}
\hline Period & $\begin{array}{l}\text { Number } \\
\text { of eyes }\end{array}$ & $\begin{array}{c}\text { Mean ECD } \pm \text { SD } \\
\text { (cells } / \mathrm{mm}^{2} \text { ) }\end{array}$ & $\begin{array}{c}\text { Mean ECD Change } \\
\pm \text { SD (\%) }\end{array}$ & $P$-value* & Yearly Rate (\%) \\
\hline Preoperative & 242 & $2664 \pm 337$ & NA & NA & NA \\
\hline $6 \mathrm{mos}$ & 157 & $2663 \pm 351$ & $-0.06 \pm 9.81$ & 0.934 & -0.12 \\
\hline $1 \mathrm{yr}$ & 136 & $2636 \pm 350$ & $-0.18 \pm 9.58$ & 0.468 & -0.18 \\
\hline $2 \mathrm{yrs}$ & 134 & $2637 \pm 346$ & $-1.28 \pm 8.46$ & 0.020 & -0.64 \\
\hline 3 yrs & 66 & $2548 \pm 343$ & $-4.35 \pm 10.86$ & $<0.001$ & -1.45 \\
\hline 5 yrs & 46 & $2594 \pm 325$ & $-3.25 \pm 8.24$ & 0.005 & -0.65 \\
\hline 7 yrs & 18 & $2426 \pm 286$ & $-5.02 \pm 10.40$ & 0.045 & -0.72 \\
\hline
\end{tabular}

$\mathrm{ECD}=$ endothelial cell density; $\mathrm{SD}=$ standard deviation; mos = months; $\mathrm{yr}=$ year;

$\mathrm{NA}=$ not applicable

*Paired $t$ test between postoperative and preoperative endothelial cell density counts 


\section{Endothelial Cell Changes}

Table 3 shows the endothelial cell loss from 6 months to 7 years postoperatively. Preoperatively, the mean ECD count was $2664 \pm 337$ cells $/ \mathrm{mm}^{2}$. A significant mean endothelial cell loss as compared to preoperatively was seen 2 years after pIOL implantation, which continued up to 7 years postoperatively.

The coefficient of variation and the percentage of hexagonal cells are outlined in Table 4. Preoperatively, the mean coefficient of variation in cell size was $32.7 \pm$ 7.0. A significant decrease in coefficient of variation was seen after 6 months, when compared to preoperative values. This significant decrease continued up to 5 years postoperatively. Linear mixed model analysis showed a yearly decrease in coefficient of variation of $0.027(P=.001)$.

The mean percentage of hexagonal cells increased over the course of this study, although the difference between preoperative and postoperative hexagonal cells was only significant after 6 months and 1 year. Linear mixed model analysis showed no significant differences in the percentage of hexagonal cells over the course of the study.

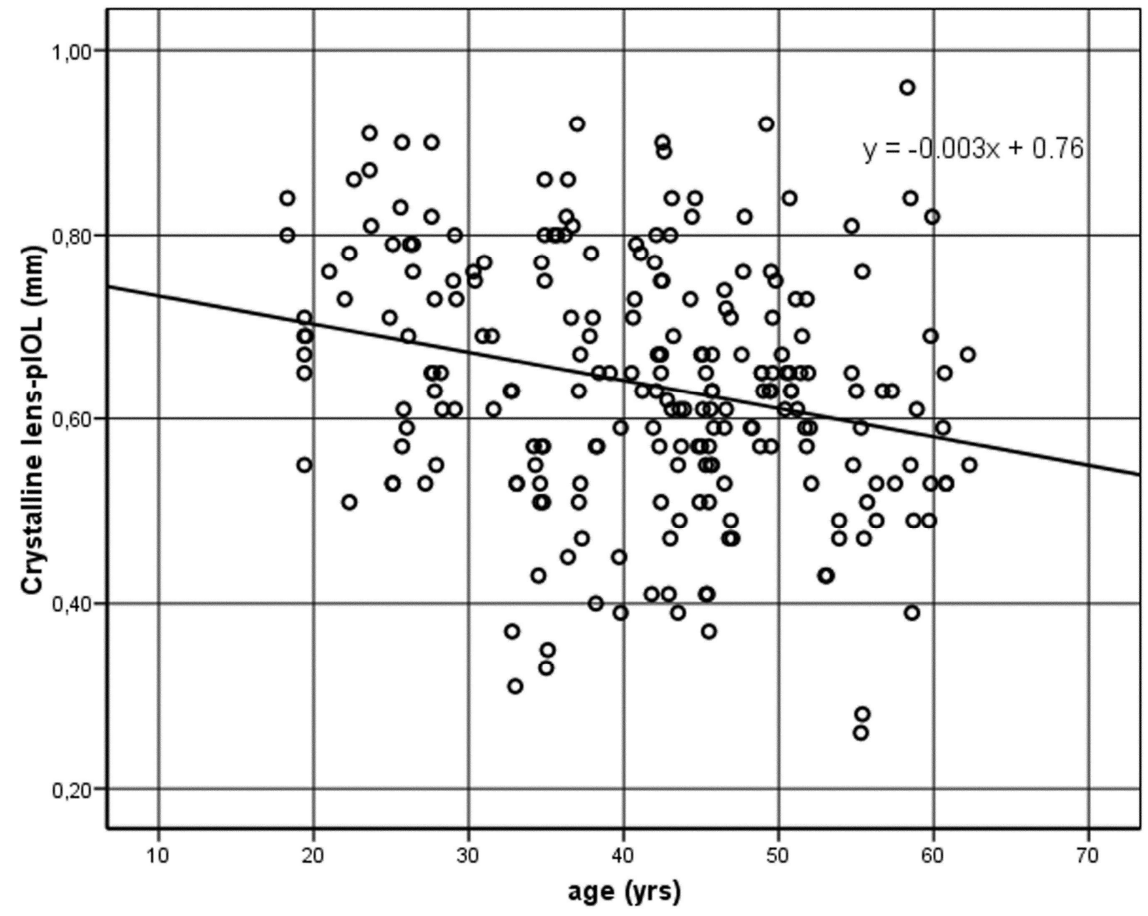

Figure 3. Relationship between age of the patient and the distance between the pIOL and the crystalline lens per eye $(n=242, P<.001, r=-0.247)$. 


\section{Correlation of Endothelial Cell Loss and Anterior Chamber Optical Coherence Tomograpy Measurements}

The relationship between endothelial cell loss and the distance from the edge of the pIOL to the endothelium at 1 and 5 years postoperatively is shown in Figures 4 and 5 , respectively. After 1 year, a statistically significant negative correlation between endothelial cell loss and the distance from the edge of the pIOL to the corneal endothelium was revealed $(r=-0.216 ; P=.012)$. This relationship continued to be present up to 5 years postoperatively $(r=-0.322 ; P=.029)$.

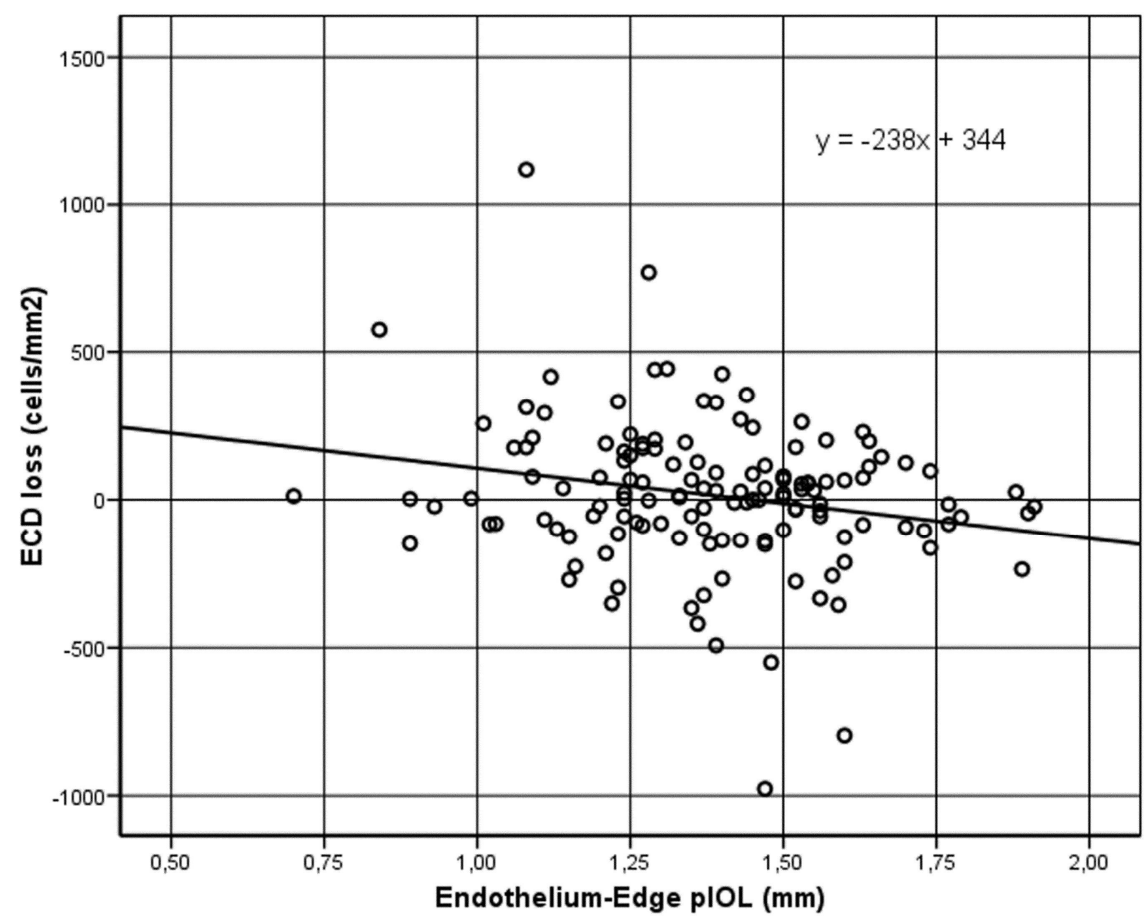

Figure 4. Relationship between endothelial cell loss (preoperative ECD - postoperative ECD) and the distance between the edge of the pIOL and the endothelium per eye at 1 year postoperatively $(n=136, P$ $=.012, r=-0.216)$.

Linear mixed model analysis showed a statistically significant effect of the interaction term time and the distance from the edge of the pIOL to the endothelium on endothelial cell loss. A shorter distance from the edge of the pIOL to the endothelium was associated with higher endothelial cell loss. In our study, the mean distance from the edge of the pIOL to the endothelium was $1.37 \mathrm{~mm}$. For example, when using this mean distance in the linear model, the model predicted a yearly endothelial cell loss of $0.98 \%$. However, when a distance between the edge of the plOL and 
the endothelium of $1.15 \mathrm{~mm}$ was used, which is our mean edge distance minus one standard deviation, the model predicted an endothelial cell loss of $1.8 \%$ per year, whereas an edge distance of $1.59 \mathrm{~mm}$ (ie, mean distance plus one standard deviation) resulted in an endothelial cell loss of $0.15 \%$ per year. The distance from the edge of the pIOL to the endothelium and the distance from the center of the pIOL to the endothelium were highly correlated $(r=0.790 ; P<.001)$. Linear mixed model analysis of the distance between the center of the pIOL and the endothelium showed the same association with endothelial cell loss. When using the Pearson correlation coefficient, we did not find a significant relationship between the center distance and endothelial cell loss.

The coefficient of variation and the percentage of hexagonal cells were not correlated to the distance between the edge of the $\mathrm{pIOL}$ and the endothelium.

Table 4. Coefficient of Variation and Percentage of Hexagonal Cells before and after Phakic intraocular Lens Implantation

\begin{tabular}{lccccccc}
\hline Period & $\begin{array}{c}\text { Number } \\
\text { of } \\
\text { eyes }\end{array}$ & $\begin{array}{c}\text { Mean COV } \pm \\
\text { SD }\end{array}$ & $\begin{array}{c}\text { Mean COV } \\
\text { Change } \pm \text { SD }\end{array}$ & $\begin{array}{c}P- \\
\text { value* }\end{array}$ & $\begin{array}{c}\text { Mean Hex } \pm \\
\text { SD (\%) }\end{array}$ & $\begin{array}{c}\text { Mean Hex } \\
\text { Change } \pm \text { SD (\%) }\end{array}$ & $\begin{array}{c}P- \\
\text { value* }\end{array}$ \\
\hline Pre & 221 & $32.73 \pm 6.99$ & NA & NA & $56.01 \pm 8.03$ & NA & NA \\
6 mos & 156 & $31.35 \pm 4.53$ & $-1.95 \pm 7.49$ & 0.002 & $57.43 \pm 7.88$ & $1.88 \pm 8.67$ & 0.009 \\
1 yr & 136 & $31.27 \pm 4.78$ & $-2.26 \pm 6.49$ & $<0.001$ & $57.81 \pm 9.01$ & $1.61 \pm 8.49$ & 0.039 \\
2 yrs & 134 & $30.95 \pm 4.99$ & $-1.85 \pm 7.29$ & 0.005 & $57.06 \pm 7.81$ & $1.04 \pm 9.31$ & 0.213 \\
3 yrs & 66 & $31.57 \pm 5.50$ & $-3.96 \pm 8.05$ & 0.001 & $56.00 \pm 7.54$ & $1.33 \pm 9.46$ & 0.306 \\
5 yrs & 46 & $30.50 \pm 3.99$ & $-5.15 \pm 5.47$ & $<0.001$ & $58.62 \pm 8.97$ & $3.45 \pm 11.00$ & 0.081 \\
7 yrs & 18 & $29.11 \pm 3.88$ & $-4.94 \pm 7.35$ & 0.160 & $56.70 \pm 9.72$ & $7.33 \pm 13.25$ & 0.233 \\
\hline
\end{tabular}

COV = coefficient of variation; SD = standard deviation; Hex = hexagonal cells; pre = preoperative; mos = months; $y r=$ year; NA = not applicable

*Paired $t$ test between postoperative and preoperative measurements

\section{DISCUSSION}

The purpose of this cross-sectional study was to evaluate the position of various irisfixated pIOL models in the anterior chamber and the effect of this position on the corneal endothelium. Our most important finding was the relationship between endothelial cell loss and the distance from the edge of the pIOL to the endothelium. A shorter distance between the edge of the $\mathrm{pIOL}$ and the endothelium was associated with higher endothelial cell loss. We applied a linear mixed model analysis, which is an extremely useful test as it uses all available ECD data to fit the best linear model. The model predicted a yearly endothelial cell loss of $0.98 \%$ for an edge distance of $1.37 \mathrm{~mm}$, which was the mean distance from the edge of the plOL to the endothelium in our study population. We feel that an endothelial cell loss rate of 
$0.98 \%$ per year is an acceptable rate when compared to the natural yearly endothelial cell loss of $0.6 \% \pm 0.5 \%$. $^{19}$

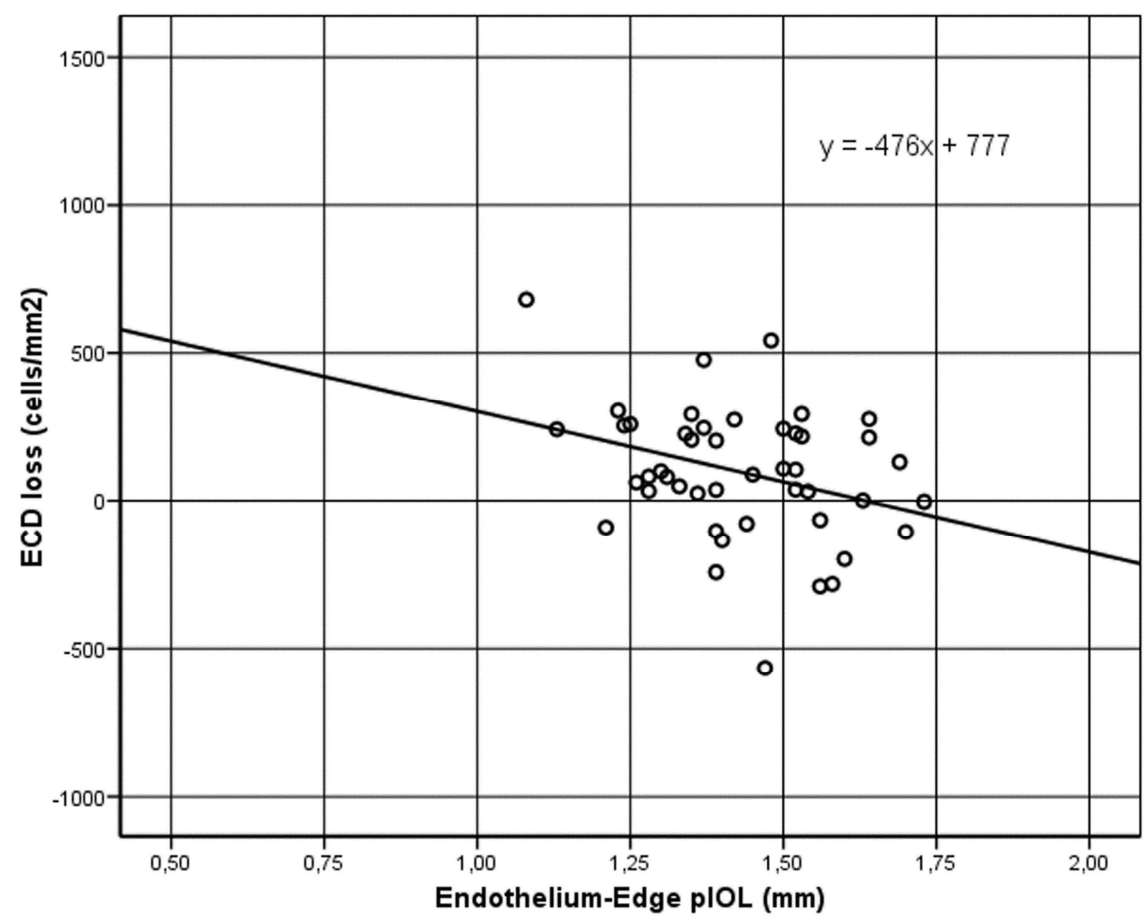

Figure 5. Relationship between endothelial cell loss (preoperative ECD - postoperative ECD) and the distance between the edge of the $\mathrm{pIOL}$ and the endothelium per eye at 5 years postoperatively $(n=46, P$ $=.029, r=-0.322$ ).

Several studies evaluated endothelial changes after plOL implantation. Short term reports have demonstrated that corneal endothelial cell changes after pIOL implantation vary from gains of $0.5 \%$ to losses of $6.6 \%$ at 1 year and losses of $0.7 \%$ to $11.7 \%$ at 3 years, postoperatively., ${ }^{3,5,9-11,20}$ Long-term endothelial cell loss studies have described losses of $2.9 \%$ to $9.1 \% 6$ years after plOL implantation. ${ }^{7,11}$ To our knowledge, endothelial cell loss 10 years after Artisan pIOL implantation, was only investigated by Tahzib and colleagues. In that study a mean endothelial cell loss of $0.6 \%$ at 10 years was reported. ${ }^{7}$ In our study, a significant endothelial cell loss of $1.28 \%$ at 2 years, $4.35 \%$ at 3 years, $3.25 \%$ at 5 years and $5.02 \%$ at 7 years postoperatively was seen. Furthermore, we evaluated the changes in coefficient of variation and percentage of hexagonal cells. An increase of the coefficient of variation may be an early sign of continuing endothelial cell loss. ${ }^{21}$ In our study, a significant decrease of the coefficient of variation was observed, meaning that the stability of the corneal endothelium increased. A decrease of the percentage of hexagonal cells indicates 
some form of endothelial injury. ${ }^{21}$ Over the course of this study, the percentage of hexagonal cells showed a slight but insignificant increase, indicating the stability of the endothelial monolayer. These changes in percentage of hexagonal cells and coefficient of variation are in accordance with other studies. $3,9,10,22$

Recently, new imaging devices became available, which enabled us to visualize the pIOL in the anterior chamber. Several studies analyzed anterior chamber morphometrics in patients with implanted iris-fixated plOLs. Baumeister et al. ${ }^{23}$ investigated the position of Artisan pIOLs in 20 eyes using Scheimpflug photography. They report distances of $2.51 \pm 0.18 \mathrm{~mm}$ and $0.41 \pm 0.12 \mathrm{~mm}$ from the center of the pIOL to the endothelium and the pIOL to the crystalline lens, respectively, 1 year after implantation. Güell et al. ${ }^{13}$ studied 11 eyes implanted with an Artiflex pIOL using AS-OCT. They reported a mean distance from the center of the plOL to the endothelium of $2.41 \pm 0.16 \mathrm{~mm}$ and a mean distance between the plOL and the crystalline lens was $0.74 \pm 0.05 \mathrm{~mm}$. Tehrani et al. ${ }^{24}$ evaluated 17 myopic eyes implanted with a foldable iris-fixated pIOL using Scheimpflug photography. They reported mean distances from the center and the edge of the $\mathrm{PIOL}$ to the endothelium of $2.01 \pm 0.26 \mathrm{~mm}$ and $1.34 \pm 0.21 \mathrm{~mm}$, respectively. The mean distance between the pIOL and the crystalline lens was $0.73 \pm 0.09 \mathrm{~mm}$. In our study, the mean distance between the edge of the $\mathrm{plOL}$ and the endothelium was $1.37 \pm 0.22 \mathrm{~mm}$. The mean central distance to the endothelium was $2.18 \pm 0.26 \mathrm{~mm}$. These measurements are comparable to the distances reported by Tehrani et al. ${ }^{24}$

When evaluating the differences between the various plOL types, we found a significantly higher mean distance between the center of the $\mathrm{pIOL}$ and the endothelium in the Artisan $6 \mathrm{~mm}$ group, compared to the other 4 groups (Artisan $5 \mathrm{~mm}$, Artisan toric, Artiflex I, and Artiflex II). This difference is also detected by Kohnen et al., ${ }^{2}$ who showed that the mean distance between the center of the pIOL and the endothelium was significantly higher in the Artisan $6 \mathrm{~mm}$ group, as compared to the Artiflex I and Artiflex II group. Central lens thickness, as provided by the manufacturer, is variable for the Artiflex pIOLs, ranging from 0.14 to $0.52 \mathrm{~mm}$ depending on the dioptric power of the lens. The Artisan pIOLs show a constant central thickness of $0.14 \mathrm{~mm}$. This might explain the significant difference between the Artisan and Artiflex pIOLs in the distance from the center of the pIOL to the endothelium.

The mean edge distances for the Artisan 5 and $6 \mathrm{~mm}$ pIOLs were significantly higher than the distances for the Artiflex I and II plOLs. The flexible optical part of the Artiflex pIOL is made of ultraviolet-absorbing silicone, which has a refractive index of 1.43. In contrast, the PMMA optic of the Artisan pIOL has a refractive index of 1.49. This higher refractive index leads to a safer distance from the edge to the endothelium for the Artisan pIOL as compared to the Artiflex pIOL. New materials with higher refractive indices would decrease the height of the optic edge.

In our study, the distance between the pIOL and the crystalline lens decreased with increasing patient age. A linear decrease of $3.1 \mu \mathrm{m}$ per year was found. This 
relationship was also reported by Koivula et al., ${ }^{25}$ analyzing the position of posterior chamber pIOLs using AS-OCT. In recent studies, a yearly $20 \mu \mathrm{m}$ forward progression of the anterior pole of the crystalline lens due to aging is described, which is much higher than the decrease in distance from the pIOL to the crystalline lens we found. ${ }^{14,26}$ However, a stable distance between the pIOL and the crystalline lens during accommodation is reported by Güell et al., ${ }^{13}$ which might suggest that the iris and crystalline lens act as a unit and move forward. This movement as a unit, could be an explanation for the minimal decrease in the distance from the plOL to the crystalline lens. However, if the iris and the crystalline lens move forward with an iris-fixated pIOL, the distance from the edges of the pIOL to the endothelium might decrease with increasing patient age. In the future, this effect should be monitored during long-term follow-up.

In conclusion, ECD measurements are mandatory before and after pIOL implantation to monitor the long-term effect of the $\mathrm{pIOL}$ on the endothelium. In addition to ECD counts, anterior chamber morphometrics should be analyzed during longterm follow-up to evaluate the safety of pIOLs. A potential decrease in the distance from the edge of the pIOL to the endothelium, due to age-related changes of the crystalline lens, should be carefully monitored. 


\section{REFERENCES}

1. Fechner PU, van der Heijde GL, Worst JGF. The correction of myopia by lens implantation into phakic eyes. Am J Ophthalmol 1989; 107:659-663.

2. Kohnen T, Cichocki M, Koss MJ. Position of rigid and foldable iris-fixated myopic phakic intraocular lenses evaluated by Scheimpflug photography. J Cataract Refract Surg 2008; 34:114-120.

3. Stulting RD, John ME, Maloney RK, Assil KK, Arrowsmith PN, Thompson VM. Three-year results of Artisan/Verisyse phakic intraocular lens implantation; results of the United States Food and Drug Administration Clinical Trial; the U.S. Verisyse Study Group. Ophthalmology 2008; 115:464-472.

4. Tehrani M, Dick HB. Iris-fixated toric phakic intraocular lens: three-year follow-up. J Cataract Refract Surg 2006; 32:1301-1306.

5. Budo C, Hessloehl JC, Izak M, Luyten GPM, Menezo JL, Sener BA, Tassignon MJ, Termote H, Worst JGF, Multicenter study of the Artisan phakic intraocular lens. J Cataract Refract Surg 2000; 26:11631171.

6. Tehrani M, Dick HB. Short-term follow-up after implantation of a foldable iris-fixated intraocular lens in phakic eyes. Ophthalmology 2005; 112:2189-2195.

7. Tahzib NG, Nuijts RM, Wu WY, Budo CJ. Long-term study of Artisan phakic intraocular lens implantation for the correction of moderate to high myopia; ten-year follow-up results. Ophthalmology 2007; 114:1133-1142.

8. Landesz M, van Rij G, Luyten G. Iris-claw phakic intraocular lens for high myopia. J Refract Surg 2001; 17:634-640.

9. Pop M, Payette Y. Initial results of endothelial cell counts after Artisan lens for phakic eyes: an evaluation of the United States Food and Drug Administration Ophtec Study. Ophthalmology 2004; 111:309-317.

10. Benedetti S, Casamenti V, Benedetti M. Long-term endothelial changes in phakic eyes after Artisan intraocular lens implantation to correct myopia; five-year study. J Cataract Refract Surg 2007; 33:784-790.

11. Saxena R, Boekhoorn SS, Mulder PGH, Noordzij B, van Rij G, Luyten GPM. Long-term follow-up of endothelial cell change after Artisan phakic intraocular lens implantation.Ophthalmology 2008; 115:608-613.

12. Baikoff G. Anterior segment OCT and phakic intraocular lenses: a perspective. J Cataract Refract Surg 2006; 32:1827-1835.

13. Güell JL, Morral M, Gris O, Gaytan J, Sisquella M, Manero F. Evaluation of Verisyse and Artiflex phakic intraocular lenses during accommodation using Visante optical coherence tomography. J Cataract Refract Surg 2007; 33:1398-1404.

14. Baikoff G, Bourgeon G, Jodai HJ, Fontaine A, Viera Lellis F, Trinquet L. Pigment dispersion and Artisan phakic intraocular lenses; crystalline lens rise as a safety criterion. J Cataract Refract Surg 2005; 31:674-680.

15. Baikoff G, Lutun E, Ferraz C, Wei J. Static and dynamic analysis of the anterior segment with optical coherence tomography. J Cataract Refract Surg 2004; 30:1843-1850.

16. Baikoff G, Lutun E, Wei J, Ferraz C. Contact between 3 phakic intraocular lens models and the crystalline lens: an anterior chamber optical coherence tomography study. J Cataract Refract Surg 2004; 30:2007-2012.

17. van der Heijde GL, Fechner PU, Worst JGF. Optische Konsequenzen der Implantation einer negativen Intraokularlinse bei myopen Patienten. [Optical consequences of implantation of a concave intraocular lens in a patient with myopia.] Klin Monatsbl Augenheilkd 1988; 193:99-102.

18. Tahzib NG, Bootsma SJ, Eggink FAGJ, Nuijts RMMA. Functional outcome and patient satisfaction after Artisan phakic intraocular lens implantation for the correction of myopia. Am J Ophthalmol 2006 142:31-39. 
19. Bourne WM, Nelson LR, Hodge DO. Central corneal endothelial cell changes over a ten-year period. Invest Ophthalmol Vis Sci 1997; 38:779-782. Available at: http://www.iovs.org/cgi/reprint/38/3/ 779. Accessed August 30, 2008.

20. Menezo JL, Cisneros AL, Rodriguez Salvador V. Endothelial study of iris-claw phakic lens: four year follow-up. J Cataract Refract Surg 1998; 24:1039-1049.

21. Shaw EL, Rao GN, Arthur EJ, Aquavella JV. The functional reserve of corneal endothelium. Ophthalmology 1978; 85:640-649.

22. Edelhauser HF, Sanders DR, Azar R, Lamielle H. Corneal endothelial assessment after ICL implantation; the ICL in Treatment of Myopia Study Group. J Cataract Refract Surg 2004; 30:576-583.

23. Baumeister M, Bühren J, Kohnen T. Position of angle-supported, iris-fixated, and ciliary sulcusimplanted myopic phakic intraocular lenses evaluated by Scheimpflug photography. Am J Ophthalmol 2004; 138:723-731.

24. Tehrani M, Dick HB. Scheimpflug biometry of the anterior segment after implantation of foldable irisfixated lenses. J Refract Surg 2006; 22:243-246.

25. Koivula A, Kugelberg M. Optical coherence tomography of the anterior segment in eyes with phakic refractive lenses. Ophthalmology 2007; 114:2031-2037.

26. Atchison D, Markwell E, Kasthurirangan S, Pope JM, Smith G, Swann PG. Age-related changes in optical and biometric characteristics of emmetropic eyes. J Vis 2008; 8(4):29.1-20. Available at: http://journalofvision.org/8/4/29/Atchison-2008-jov-8-4-29.pdf. Accessed August 30, 2008. 


\section{Chapter 4}

The Value of Preoperative Phakic Intraocular Lens Simulation using Optical Coherence Tomography

Muriël Doors, Tos T.J.M. Berendschot, Fred Hendrikse, Carroll A.B. Webers, Rudy M.M.A. Nuijts

J Cataract Refract Surg. 2009 Mar;35(3):438-43 


\section{ABSTRACT}

Purpose: To compare the position of the iris-fixated phakic intraocular lens (pIOL) in preoperative simulation and after implantation using anterior segment optical coherence tomography (AS-OCT).

Setting: Department of Ophthalmology, Academic Hospital Maastricht, The Netherlands.

Methods: In this prospective study, the morphometrics of the anterior chamber were analyzed using preoperative $\mathrm{pIOL}$ simulation and postoperative images assessed with AS-OCT. Thirty-four eyes (18 patients) were examined before and 6 months after pIOL implantation. Measured distances included: center plOL - endothelium, edge plOL - endothelium (nasal and temporal side), and back plOL - crystalline lens.

Results: All morphometric parameters showed highly significant correlations and small mean differences between preoperative and postoperative measurements. However, the distance from the nasal edge of the pIOL to the endothelium and the distance from the pIOL to the crystalline lens showed a statistically significant difference between preoperative simulation and the actual postoperative measurements $(P=0.045 ; P=0.001)$. Furthermore, the ranges of agreement between all preoperative simulations and postoperative measurements ranged between $0.24 \mathrm{~mm}$ and $0.29 \mathrm{~mm}$.

Conclusions: Preoperative simulation is a useful additional tool in the selection of patients considering plOL implantation and an important development towards ensuring the long-term safety of plOLs. However, clinicians should be aware of the presented range between the preoperative simulation and the postoperative measurements. 


\section{INTRODUCTION}

For the correction of moderate to high myopia, iris-fixated phakic intraocular lenses (plOLs) have proven to be predictable and stable, when strict inclusion criteria are applied. ${ }^{1-5}$ The rigid Artisan lens (Ophtec B.V., Groningen, The Netherlands) was first introduced in 1991. More recently, the iris-fixated Artiflex plOL (Ophtec B.V., Groningen, The Netherlands) became available, which is a foldable model, requiring a smaller incision. The position of the $\mathrm{plOL}$ in the anterior chamber is important, as it provides information about the distance of the plOL to its surrounding structures. To facilitate an adequate patient selection for these pIOLs and to ensure their longterm safety, the distance from the pIOL to the corneal endothelium and to the crystalline lens should be carefully monitored. Recently, anterior segment optical coherence tomography (AS-OCT) became available, which is a useful imaging technique to evaluate the position of the $\mathrm{plOL}$ in the anterior chamber. Baikoff et al. demonstrated that AS-OCT is easy to use and capable of producing good-quality images. ${ }^{6}$

Scheimpflug photography has also been used to analyse the morphometrics of the anterior chamber. ${ }^{7-9}$ Tehrani et al. presented a new software tool for the Scheimpflug camera; a preoperative simulation program of the position of the pIOL in the anterior chamber. They described one case in which pIOL simulation seemed a useful tool for preoperative evaluation of the postoperative plOL position. ${ }^{10}$ Currently, the Visante OCT (Carl Zeiss Meditec, Dublin, CA) was updated with a similar tool. In this study, we analysed the agreement between the anterior chamber morphometrics measured during preoperative pIOL simulation and after $\mathrm{pIOL} \mathrm{im-}$ plantation using AS-OCT.

\section{PATIENTS AND METHODS}

\section{Patient Selection and Study Design}

From November 2006 to September 2007, eighteen consecutive patients (34 eyes) underwent Artiflex plOL implantation at the Department of Ophthalmology, Academic Hospital Maastricht. All patients met the inclusion criteria for plOL implantation used in our institution, which are: a stable refractive error during the previous 2 years; an anterior chamber depth (ACD) of $2.8 \mathrm{~mm}$ or more (measured from the endothelium to the crystalline lens); pupil (in mesopic light conditions) $<6 \mathrm{~mm}$; endothelial cell density $\geq 2000$ cells $/ \mathrm{mm}^{2}$; no corneal, pupil or iris abnormalities; and no history of glaucoma and chronic or recurrent uveitis. The mean age of the study group was $43.2 \pm 11.5$ years (range 26-63) and included 3 men and 15 women. The mean implanted Artiflex plOL power was $-9.70 \pm 2.30 \mathrm{D}$, ranging from -5.00 
to $-14.50 \mathrm{D}$. Patients were evaluated preoperatively and 6 months postoperatively using Visante AS-OCT. The study was conducted in accordance with the Declaration of Helsinki and informed consent was obtained from all patients.

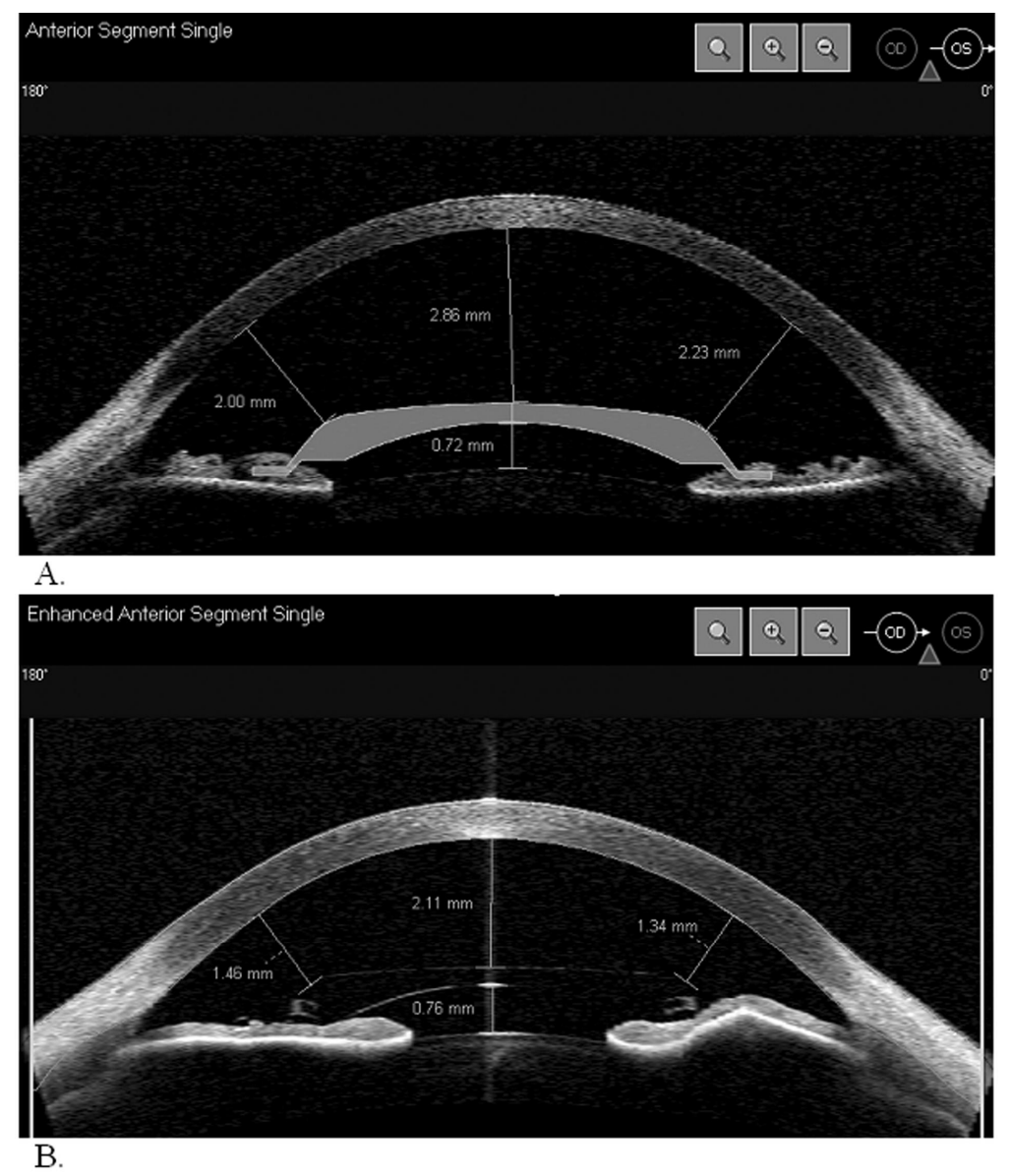

Figure 1. A. Preoperative phakic intraocular lens [ $\mathrm{plOL}$ ] simulation of Artiflex -10.5 diopters with measured distances from center of pIOL to endothelium $(2.86 \mathrm{~mm}), \mathrm{plOL}$ to crystalline lens $(0.72 \mathrm{~mm})$, edge of pIOL to endothelium ( $2.00 \mathrm{~mm}$ nasal side; $2.23 \mathrm{~mm}$ temporal side). B. Anterior segment single-scan after pIOL implantation with measured distances from center of pIOL to endothelium $(2.11 \mathrm{~mm}), \mathrm{plOL}$ to crystalline lens $(0.76 \mathrm{~mm})$, and edges of $\mathrm{plOL}$ to endothelium (1.34 mm nasal side; $1.46 \mathrm{~mm}$ temporal side).

\section{Anterior Segment Optical Coherence Tomography}

AS-OCT is a non-contact device, which images the anterior chamber using $1310 \mathrm{~nm}$ wavelength infrared light. In this study, all AS-OCT images were made on the horizontal meridian, in an unaccommodated state and in the same light conditions (50 
lux). Preoperatively and postoperatively, the anterior chamber was imaged using the anterior segment single-scan. All scans were analysed by one examiner. The ACD (measured from endothelium to the crystalline lens), central corneal thickness (CCT), lensrise ${ }^{11}$, and angle-to-angle distance were measured using the chamber function as provided by the manufacturer. Pupil diameter and iris thickness (nasal and temporal side) were measured using the caliper function. A pIOL simulation was applied in the preoperative image using the pIOL template. After selecting the right lens model and power, the pIOL was placed manually in the center of the pupil with the haptics in the middle of the iris tissue (Figure $1 \mathrm{~A}$ ). The position of the pIOL was analysed in the preoperative simulation and compared to the position after pIOL implantation. The following measurements were evaluated using the refractive tools as provided by the manufacturer: the distance between the anterior surface of the center of the pIOL and the corneal endothelium, the distance between the posterior surface of the center of the $\mathrm{pIOL}$ and the anterior surface of the crystalline lens, and the distances between the edges (nasal and temporal side) of the pIOL and the corneal endothelium (Figure 1B).

Table 1. Mean \pm Standard Deviation (SD) of Preoperative Simulation and Actual Postoperative Measurements

\begin{tabular}{lcc}
\hline Variable & Preoperative Mean \pm SD & Postoperative Mean \pm SD \\
\hline Anterior chamber depth $(\mathrm{mm})$ & $3.08 \pm 0.28$ & $3.07 \pm 0.25$ \\
Central corneal thickness $(\mu \mathrm{m})$ & $523 \pm 33$ & $523 \pm 34$ \\
Lensrise $(\mathrm{mm})$ & $0.25 \pm 0.21$ & $0.28 \pm 0.22$ \\
Angle-to-angle distance $(\mathrm{mm})$ & $11.88 \pm 0.45$ & $11.95 \pm 0.41$ \\
Center plOL-endothelium $(\mathrm{mm})$ & $2.09 \pm 0.29$ & $2.07 \pm 0.24$ \\
Nasal edge plOL-endothelium $(\mathrm{mm})$ & $1.37 \pm 0.25$ & $1.41 \pm 0.19$ \\
Temporal edge plOL-endothelium $(\mathrm{mm})$ & $1.48 \pm 0.27$ & $1.51 \pm 0.22$ \\
Center plOL-crystalline lens $(\mathrm{mm})$ & $0.68 \pm 0.15$ & $0.61 \pm 0.13$ \\
\hline
\end{tabular}

pIOL = phakic intraocular lens

\section{Statistical Analysis}

All collected data were exported from an Excel-spreadsheet to SPSS (SPSS for Windows, version 15.0, SPSS Inc, Chicago, IL) for data analysis. Continuous variables were described as mean \pm standard deviation (SD). To compare the preoperative and postoperative measurements, paired $t$ tests were applied and the Pearson's correlation coefficient $(r)$ was used to determine a relationship between both measurements. The agreement of preoperative and postoperative distances was studied using the method described by Bland and Altman. ${ }^{12}$ Using this method, the $95 \%$ limits of agreement ( $L O A=$ mean difference $\pm 1.96 *$ SD) were calculated. Linear 
regression analysis and Pearson's correlation coefficient were used to analyse the relationship between preoperative variables (pupil diameter, angle-to-angle distance, anterior chamber depth, iris thickness, and lensrise) and the differences between preoperative simulation and the actual postoperative situation.

\section{RESULTS}

The mean values of the preoperative simulation and actual postoperative measurements are listed in Table 1 . Furthermore, the results of the preoperative and postoperative comparisons are shown in Table 2. Measurements from the pIOL to the crystalline lens were significantly larger in the preoperative simulation when compared to postoperative measurements, with a mean difference of $0.072 \mathrm{~mm}$ $(P=0.001)$. In the preoperative simulation, both edge distances were measured smaller than postoperatively with mean differences of 0.045 and $0.028 \mathrm{~mm}$ for the nasal and temporal side, respectively. However, only the nasal edge difference was statistically significant $(P=0.045)$. All other comparisons between preoperative and postoperative measurements were not statistically significant. The correlations between all pair wise comparisons were highly significant, with Pearson correlation coefficients of 0.636 and higher.

Table 2. Comparison of Preoperative Simulation and Actual Postoperative Measurements using Anterior Segment Optical Coherence Tomography

\begin{tabular}{lcccc}
\hline Pair Wise Comparison & $\begin{array}{c}\text { Mean Differ- } \\
\text { ence } \pm \text { SD }\end{array}$ & P-value & $\begin{array}{c}\text { Pearson } \\
\text { Correlation } \\
\text { Postoperficient* }\end{array}$ & $\begin{array}{c}\text { 95\% Limits of } \\
\text { Agreement }\end{array}$ \\
\hline Center pIOL-endothelium $(\mathrm{mm})$ & $-0.020 \pm 0.13$ & 0.390 & 0.888 & 0.24 to -0.28 \\
Nasal edge plOL-endothelium $(\mathrm{mm})$ & $0.045 \pm 0.13$ & 0.045 & 0.876 & 0.29 to -0.20 \\
Temporal edge plOL-endothelium $(\mathrm{mm})$ & $0.028 \pm 0.15$ & 0.282 & 0.835 & 0.32 to -0.26 \\
Center pIOL-crystalline lens $(\mathrm{mm})$ & $-0.072 \pm 0.12$ & 0.001 & 0.636 & 0.16 to -0.30 \\
\hline
\end{tabular}

$\mathrm{SD}=$ standard deviation; $\mathrm{plOL}=$ phakic intraocular lens; $\mathrm{P}$-value = paired $t$ test

*All with $P<0.001$

In Figure 2, Bland-Altman plots visualize the agreement between the preoperative pIOL simulation and postoperative measurements. Although, the mean differences between the four preoperatively simulated distances and the postoperative distances were small, the ranges of agreement $(1.96 * \mathrm{SD})$ were $0.25 \mathrm{~mm}, 0.25 \mathrm{~mm}$, $0.29 \mathrm{~mm}, 0.24 \mathrm{~mm}$, for the distances from the center, nasal edge and temporal edge of the pIOL to the endothelium, and the pIOL to the crystalline lens, respectively. Larger preoperative distances from the center and the edges of the pIOL to 
the endothelium correlated with smaller preoperative distances between the $\mathrm{pIOL}$ and crystalline lens (Figure 3).

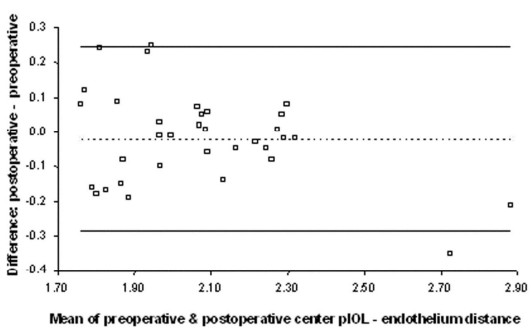

A.

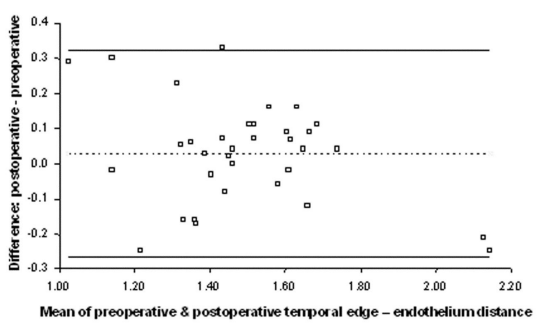

C.

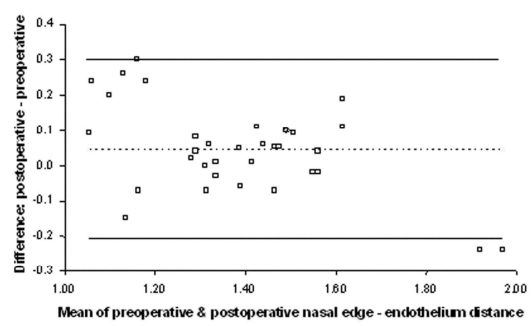

B.

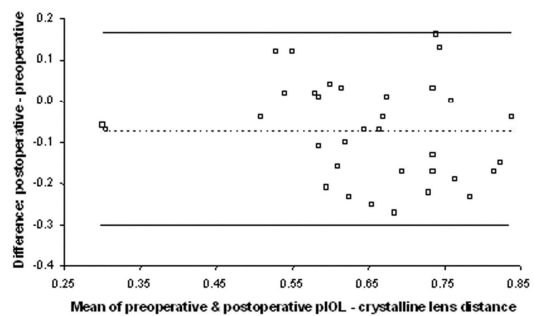

D.

Figure 2. Bland-Altman plot showing the difference between preoperative simulation and actual postoperative situation in: $A$. the distance from the center of the phakic intraocular lens (plOL) to the endothelium; $B$. the distance from the nasal edge of the pIOL to the endothelium; $C$. the distance from the temporal edge of the pIOL to the endothelium; $D$. the distance from the pIOL to the crystalline lens.

Significant correlations were found between preoperative pupil diameter and the difference between preoperative simulation and actual postoperative measurements in the distances from the center of the plOL to the endothelium $(r=$ $0.469 ; P=0.005)$, the nasal edge to the endothelium ( $r=0.572 ; P<0.001)$, the temporal edge to the endothelium ( $r=0.458 ; P=0.007)$, and the pIOL to the crystalline lens $(r=-0.431 ; P=0.011)$. Their relationships are shown in Figure 4. Preoperative pupil diameter (mean $4.65 \pm 0.91 \mathrm{~mm}$ ) was significantly correlated to iris thickness on the nasal side (mean $0.48 \pm 0.10 \mathrm{~mm}$ ) and temporal side (mean $0.42 \pm 0.08 \mathrm{~mm}$ ) with correlation coefficients of $0.680(P<0.001)$ and $0.440(P=0.009)$, respectively.

\section{DISCUSSION}

Proper preoperative patient selection is mandatory to safely implant iris-fixated pIOLs in healthy eyes. This study demonstrates the value of preoperative pIOL simu- 
lation using AS-OCT for patients considering plOL implantation and investigates the agreement between preoperatively simulated measurements and actual measurements after implantation. Several clinical studies have shown that Artisan and Artiflex implantation leads to stable long-term visual results. ${ }^{1,2,5}$ However, some studies demonstrate an ongoing endothelial cell loss after implantation. ${ }^{13}$ Saxena et al. found a significant endothelial cell loss of $12.6 \%$ at 7 years postoperatively, with a significant negative correlation between anterior chamber depth and endothelial cell loss after 3 years of follow-up. ${ }^{14}$ The development of new non-contact imaging techniques, which analyse the dimensions of the anterior segment, have shown to be extremely valuable in guaranteeing a safe distance from the pIOL to critical ocular tissues.

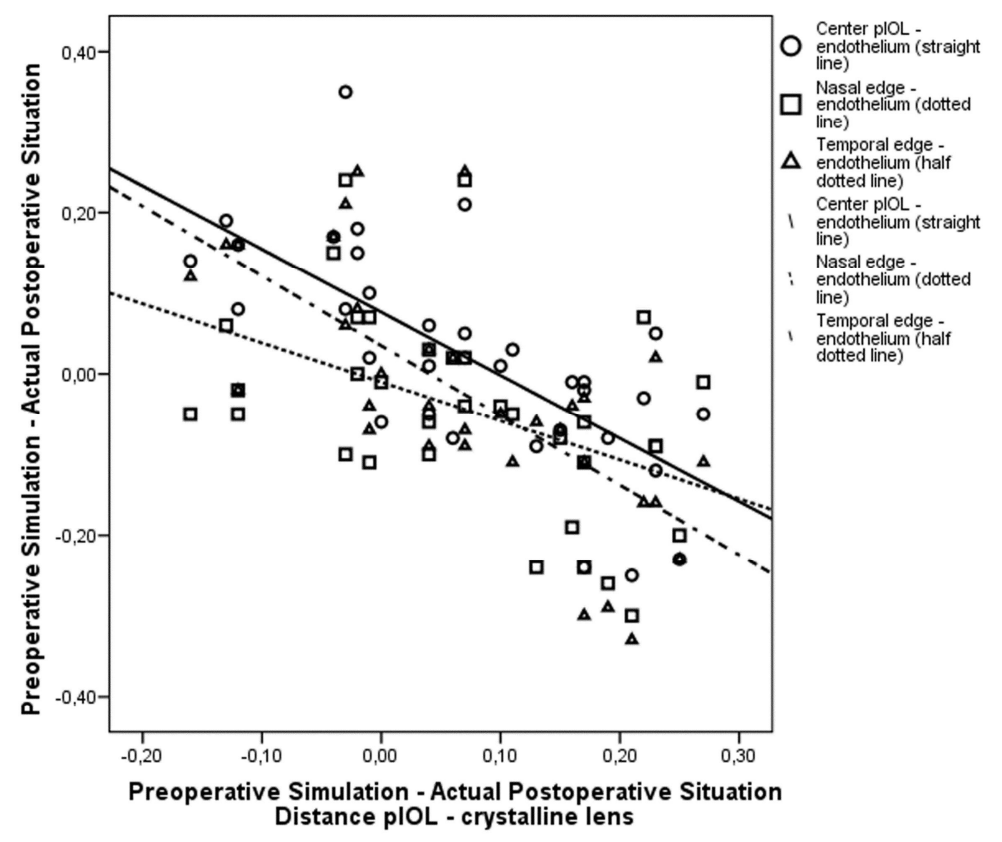

Figure 3. Relationship between difference of distance from phakic intraocular lens (pIOL) to crystalline lens and differences in distances from the center, nasal edge and temporal edge of pIOL to the endothelium between preoperative simulation and actual postoperative situation.

One of the safety criteria for plOL implantation is a minimal ACD of $2.80 \mathrm{~mm}$, measured from the endothelium to the crystalline lens. ${ }^{9}$ Furthermore, a minimum distance from the edge of the pIOL to the endothelium of $1.50 \mathrm{~mm}$ is mentioned, 
which is the shortest distance from the pIOL to the endothelium due to the convexconcave shape of the plOL. ${ }^{15}$ Furthermore, an arbitrary safety distance from the center of the pIOL to the endothelium of $2.0 \mathrm{~mm}$ is described by Guell et al. ${ }^{16}$ Due to the development of preoperative pIOL simulation, all critical distances can be measured in a preoperative setting, which is an important step in ensuring the safety of pIOLs.

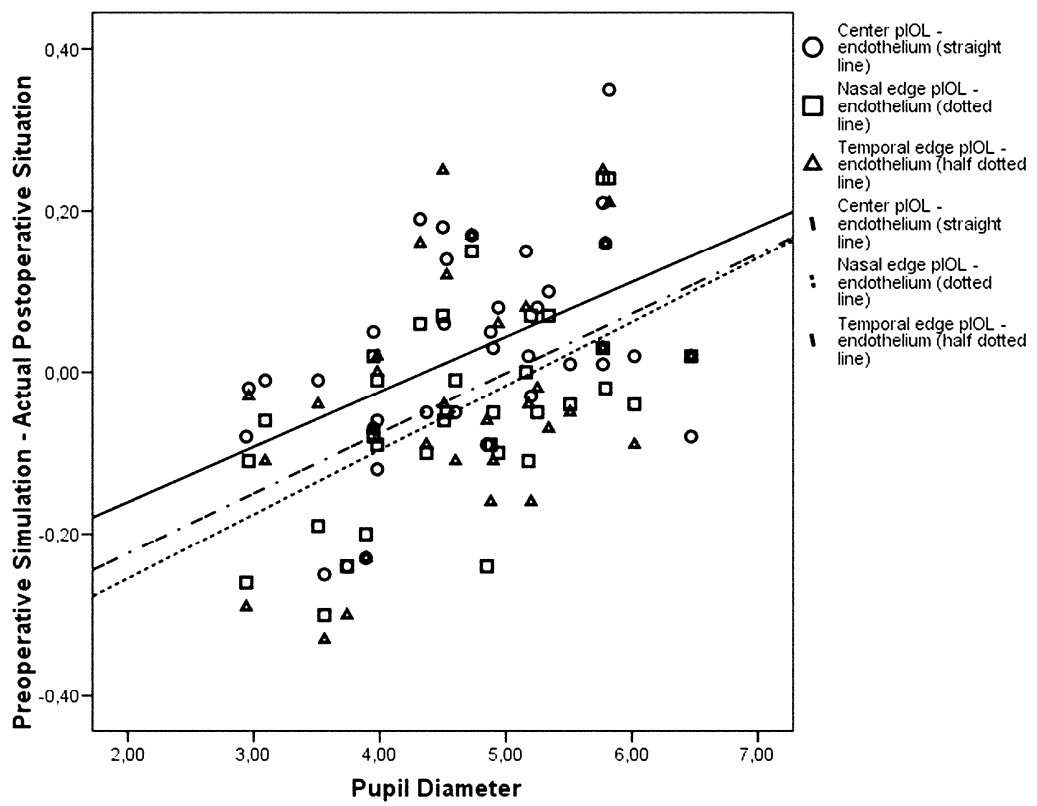

Figure 4. Relationship between preoperative pupil diameter and the differences in distances from the center, nasal edge and temporal edge of the phakic intraocular lens ( $p I O L$ ) to the endothelium between preoperative simulation and actual postoperative situation.

In our study, all anatomical parameters, including ACD, CCT, lensrise and angleto-angle distance, did not show a significant difference between preoperative and postoperative measurements, which could be expected since these distances should not change in a mean time span of 6 months. The mean differences between the preoperative $\mathrm{pIOL}$ simulation and the actual postoperative measurements were small, with differences of $-0.020,0.045,0.028$ and -0.072 for the distance from the center of the pIOL to the endothelium, the nasal edge to the endothelium, the temporal edge to the endothelium, and the pIOL to the crystalline lens, respectively. However, the ranges of agreement ranged between 0.24 and $0.29 \mathrm{~mm}$ and could be clinically relevant, especially in patients considering plOL implantation. 
Tehrani et al. presented preoperative pIOL simulation using Scheimpflug photography and reported the outcomes of one patient. When comparing the preoperative simulation with the actual postoperative position of the $\mathrm{plOL}$, all distances from the pIOL to the endothelium were $0.05 \mathrm{~mm}$ smaller in the simulation mode, due to the alignment of the simulated $\mathrm{pIOL}$ on the upper surface of the iris tissue. In the postoperative situation, the pIOL is enclavated in the iris tissue, which explains the reported difference. ${ }^{10}$ In our study, the pIOL was manually placed in the middle of the iris tissue, to minimize the difference between the simulation and the postoperative situation. Overall, the measured edge distances were smaller in the preoperative simulation than in the postoperative images, with distances from the nasal and temporal edge to the endothelium of 1.37 and $1.48 \mathrm{~mm}$ preoperatively versus 1.41 and $1.51 \mathrm{~mm}$ postoperatively, respectively. However, only the difference in nasal edge distance was statistically significant. As shown in Figure 3, a larger postoperative distance between the edges of the $\mathrm{pIOL}$ and the endothelium led to a smaller postoperative distance between the pIOL and the crystalline lens. We found a significant decrease from $0.68 \mathrm{~mm}$ preoperatively to $0.61 \mathrm{~mm}$ postoperatively in the distance from the pIOL to the crystalline lens.

In order to improve our simulation we looked for preoperative parameters that could explain the difference between the simulation and the postoperative situation. Preoperative pupil diameter was the only variable that influenced the accuracy of the simulation. Small preoperative pupil diameters caused an underestimation of the distance from the pIOL to the endothelium, whereas large pupil diameters caused an overestimation of the actual postoperative situation (Figure 4). Our hypothesis is that these differences are caused by the fact that the pupil diameter correlates with iris thickness, i.e. a larger pupil leads to thicker iris tissue. In a thick iris the actual placement of the pIOL should probably not be in the middle of the iris tissue, as was done in this study, but more to the posterior side. However, we did not find a significant correlation between iris thickness and the differences between preoperative simulation and actual postoperative measurements. This might be due to the irregular configuration of the iris, which makes iris thickness a difficult measurement. Iris volume could be a better variable to investigate iris thickness.

In conclusion, preoperative simulation is a useful additional tool in the selection of patients considering pIOL implantation. However, clinicians should be aware of the presented range between the preoperative simulation and the actual postoperative measurements. 


\section{REFERENCES}

1. Tahzib NG, Nuijts RM, Wu WY, Budo CJ. Long-term study of Artisan phakic intraocular lens implantation for the correction of moderate to high myopia: ten-year follow-up results. Ophthalmology 2007; 114:1133-1142.

2. Budo C, Hessloehl JC, Izak M, et al. Multicenter study of the Artisan phakic intraocular lens. J Cataract Refract Surg 2000; 26:1163-1171.

3. Coullet J, Guell JL, Fournie P, et al. Iris-supported phakic lenses (rigid vs foldable version) for treating moderately high myopia: randomized paired eye comparison. Am J Ophthalmol 2006; 142:909-916.

4. Pop M, Payette Y. Initial results of endothelial cell counts after Artisan lens for phakic eyes: an evaluation of the United States Food and Drug Administration Ophtec Study. Ophthalmology 2004; 111:309-317.

5. Landesz M, van Rij G, Luyten G. Iris-claw phakic intraocular lens for high myopia. J Refract Surg 2001; 17:634-640.

6. Baikoff G, Lutun E, Ferraz C, Wei J. Static and dynamic analysis of the anterior segment with optical coherence tomography. J Cataract Refract Surg 2004; 30:1843-1850.

7. Tehrani M, Dick HB. Scheimpflug biometry of the anterior segment after implantation of foldable irisfixated lenses. J Refract Surg 2006; 22:243-246.

8. Kohnen T, Cichocki M, Koss MJ. Position of rigid and foldable iris-fixated myopic phakic intraocular lenses evaluated by Scheimpflug photography. J Cataract Refract Surg 2008; 34:114-120.

9. Baumeister M, Buhren J, Kohnen T. Position of angle-supported, iris-fixated, and ciliary sulcusimplanted myopic phakic intraocular lenses evaluated by Scheimpflug photography. Am J Ophthalmol 2004; 138:723-731.

10. Tehrani M, Schaefer M, Koeppe J, Dick HB. Preoperative simulation of postoperative iris-fixated phakic intraocular lens position and simulation of aging using high-resolution Scheimpflug imaging. J Cataract Refract Surg 2007; 33:11-14.

11. Baikoff G, Bourgeon G, Jodai HJ, et al. Pigment dispersion and Artisan phakic intraocular lenses: crystalline lens rise as a safety criterion. J Cataract Refract Surg 2005; 31:674-680.

12. Bland JM, Altman DG. Statistical methods for assessing agreement between two methods of clinical measurement. Lancet 1986; 1:307-310.

13. Benedetti S, Casamenti V, Benedetti M. Long-term endothelial changes in phakic eyes after Artisan intraocular lens implantation to correct myopia: five-year study. J Cataract Refract Surg 2007; 33:784-790.

14. Saxena R, Boekhoorn SS, Mulder PG, et al. Long-term follow-up of endothelial cell change after Artisan phakic intraocular lens implantation. Ophthalmology 2008; 115:608-613.

15. Baikoff G. Anterior segment OCT and phakic intraocular lenses: a perspective. J Cataract Refract Surg 2006; 32:1827-1835.

16. Guell JL, Morral M, Gris O, et al. Evaluation of Verisyse and Artiflex phakic intraocular lenses during accommodation using Visante optical coherence tomography. J Cataract Refract Surg 2007; 33:1398-1404. 



\section{Chapter 5}

\section{Model to predict endothelial cell loss after iris-fixated phakic intraocular lens implantation}




\section{ABSTRACT}

Purpose: To describe a model predicting endothelial cell (EC) loss after iris-fixated phakic intraocular lens (plOL) implantation, taking distance from the edge of the plOL to endothelium into account.

Methods: This prospective observational study, monitored long term EC changes in 306 eyes after pIOL implantation. EC density (ECD) was determined preoperatively, 6 months postoperatively and then yearly, up to 8 years postoperatively. Mean follow-up was $31.7 \pm 25.7$ months. All eyes underwent anterior segment optical coherence tomography to determine minimum distance from the edge of the pIOL to endothelium. Linear mixed model analysis was performed to present a model which describes endothelial cell loss as a linear decrease and an additional decrease depending on the postoperative edge distance of the patient.

Results: Mean minimum edge distance was $1.43 \pm 0.23 \mathrm{~mm}$ (range $0.70-2.21 \mathrm{~mm}$ ). For this mean edge distance, the model predicted a yearly endothelial cell loss of $1.0 \%$, whereas an edge distance of $1.20 \mathrm{~mm}$ resulted in a yearly endothelial cell loss of $1.7 \%$, and $1.66 \mathrm{~mm}$ led to a yearly endothelial cell loss of only $0.2 \%$. Furthermore, the model predicted that for patients with preoperative ECDs of 3000, 2500 or 2000 cells $/ \mathrm{mm}^{2}$ and edge distances of $1.43 \mathrm{~mm}$, a critical ECD of 1500 cells $/ \mathrm{mm}^{2}$ (at which point pIOL explantation and cataract extraction can still safely be performed) will be reached at 56, 37, and 18 years after implantation.

Conclusions: The presented model predicts endothelial cell loss after iris-fixated pIOL implantation in relation to the measured edge distance, patient age, and preoperative ECD, which can assist ophthalmologists in patient selection and follow-up process of plOLs. 


\section{INTRODUCTION}

Since 1991 iris-fixated phakic intraocular lenses (pIOLs) have been successfully implanted in healthy eyes to correct myopia, hyperopia and astigmatism. Previous studies have demonstrated that these plOLs show stable and predictable visual results, when strict inclusion criteria for implantation are applied. ${ }^{1-3}$ However, the long-term endothelial cell loss remains a point of discussion. To investigate the effect of iris-fixated pIOLs on the corneal endothelium, several clinical trials studied endothelial cell loss after pIOL implantation, with variable results. Some investigators reported no statistically significant endothelial cell loss, whereas others found highly significant endothelial cell losses continuing up to 5 years after pIOL implantation $\left(9.0 \%\right.$ at 5 years postoperatively) ${ }^{4,5}$ Furthermore, Saxena et al. reported a significant endothelial cell loss of $12.6 \% 7$ years after plOL implantation and in addition a significant negative correlation between anterior chamber depth (ACD) and endothelial cell loss after 3 years. ${ }^{6}$

New non-contact imaging techniques have been shown to be extremely valuable in guaranteeing a safe distance from the pIOL to critical ocular tissues. ${ }^{7}$ Anterior segment optical coherence tomography (AS-OCT) has proven to be a good imaging tool to visualize the $\mathrm{pIOL}$ in the anterior chamber and analyze its distance from the corneal endothelium and the crystalline lens. ${ }^{8}$ This has led to the development of new criteria to warrant the long-term safety of plOLs. One of the mentioned criteria is a minimum distance from the edge of the $\mathrm{plOL}$ to the corneal endothelium, which is the smallest distance from the plOL to the endothelium due to its convex-concave shape, of $1.50 \mathrm{~mm} .{ }^{9}$ A new software update of the Visante AS-OCT (Carl Zeiss Meditec Inc., Dublin, CA) has the ability to perform a pIOL simulation and consequently can measure the edge distance in the preoperative situation.

Recently, the importance of this edge distance has been demonstrated by Doors et al. ${ }^{10}$ They found that endothelial cell loss after plOL implantation was associated with the distance from the edge of the plOL to the corneal endothelium. An edge distance of $1.37 \mathrm{~mm}$ resulted in a yearly endothelial cell loss of $0.98 \%$, whereas an edge distance of $1.15 \mathrm{~mm}$ predicted a yearly loss of $1.8 \%$. Furthermore, the edge distance might not be constant with advancing age. Age-related changes to the crystalline lens cause a decrease in ACD of approximately $20 \mu \mathrm{m}$ per year. ${ }^{11,12}$ Guell et al. reported a stable distance between the plOL and the crystalline lens during accommodation, which might suggest that the iris and crystalline lens act as a unit and move forward. ${ }^{13}$ Consequently, if the iris and the crystalline lens move forward with an iris-fixated pIOL, the distance from the edges of the pIOL to the endothelium might decrease with increasing patient age.

In this study, we have extended our previous observations to an increased number of patients and assessed whether the endothelial cell density (ECD) changes conform to a mathematical model, taking the relationship between endothelial cell 
loss and edge distance into account. The main purpose was to design a model which can help physicians during the patient selection and follow-up process. It might be used to predict when a patient will reach a critical endothelial cell density level, e.g. an ECD of 1500 cells $/ \mathrm{mm}^{2}, 14,15$ at which point in our opinion plOL explantation and cataract extraction can still safely be performed. To help ophthalmologists in patient selection, the model might be used to predict how long the pIOL can remain safely in the eye using the preoperative edge distance, measured using the Visante AS-OCT pIOL simulation program, and preoperative ECD count.

\section{METHODS}

This prospective observational study included 306 consecutive eyes of 162 patients, who had Artisan or Artiflex pIOL (Ophtec B.V., Groningen, The Netherlands) implantation between 1998 and 2008 at the Academic Center for Refractive Surgery, University Eye Clinic Maastricht, for the correction of moderate to high myopia and astigmatism. Forty-eight men and 114 women were included in this study, with a mean age of $41.8 \pm 10.6$ years (range 18 to 63 years) at the time of plOL implantation. The study was conducted in accordance with the Declaration of Helsinki and informed consent was obtained from all patients. Investigational review board approval was obtained from the Academic Hospital Maastricht.

The Artisan pIOL is a rigid single-piece lens composed of polymethyl methacrylate (PMMA). It has a convex-concave shape with either a $6 \mathrm{~mm}$ (for intraocular lens powers up to -15.5 diopters (D)) or $5 \mathrm{~mm}$ (for intraocular lens powers from -16.0 to $-24.0 \mathrm{D}$ ) optic. In contrast, the foldable Artiflex pIOL is a three-piece lens that consists of a flexible optical part made of ultraviolet-absorbing silicone and two rigid haptics made of PMMA. Due to its foldable $6 \mathrm{~mm}$ silicone optic, this lens can be inserted through a smaller incision. The Artiflex $\mathrm{pIOL}$ is available in dioptic powers of -2.0 to -14.5 . The surgical procedures were performed by the same surgeon (RN). The surgical technique of plOL implantation and postoperative eye drops regimen has been described elsewhere. ${ }^{10,16}$ The incision size for implantation of the rigid Artisan pIOL was 6.2 or $5.2 \mathrm{~mm}$, depending on the size of the optic. For the foldable Artiflex plOL, a $3.2 \mathrm{~mm}$ incision was used. The criteria for performing plOL implantation in our institution are: a stable refractive error during the previous 2 years; a central anterior chamber depth (ACD) of $2.8 \mathrm{~mm}$ or more (measured from the endothelium to the crystalline lens); pupil (in mesopic light conditions) $<6 \mathrm{~mm}$; endothelial cell density $\geq 2000$ cells $/ \mathrm{mm}^{2}$; no corneal, pupil or iris abnormalities; and no history of glaucoma or chronic or recurrent uveitis.

Preoperatively central ECD measurements were performed using the Noncon Robo SP-8000 non-contact specular microscope (Konan Medical Inc., Hyogo, Japan), which were repeated at 3 and 6 months and 1, 2, 3, 4, 5, 6, 7 and 8 years postopera- 
tively. Follow-up ranged from 3 months to 8 years, with a mean follow-up of $31.7 \pm$ 25.7 months per eye. Three consecutive endothelial images of the central cornea were obtained and analyzed using the dot method, in which the centers of $\geq 50$ contiguous cells are marked. The average of these three measurements was used for the analysis. Endothelial cell loss was defined as the decrease in cell density between the preoperative and postoperative examination expressed as a percentage of the preoperative cell density. Paired $t$ tests were used to compare preoperative EC counts to postoperative EC counts for each follow-up visit. To correct for the multiple tests, we used a Bonferroni correction, meaning that a P-value of $<0.009$ was considered significant for the conducted paired $t$ tests (Table 1). During all follow-up examinations patients were examined to detect complications, such as glaucoma or corneal edema.

Table 1. Longitudinal Endothelial Cell Density (ECD) Changes after Phakic Intraocular Lens Implantation

\begin{tabular}{|c|c|c|c|c|c|}
\hline Period & $\begin{array}{l}\text { Number } \\
\text { of Eyes }\end{array}$ & $\begin{array}{c}\text { Mean ECD } \\
\left.\text { (cells } / \mathrm{mm}^{2}\right) \pm S D\end{array}$ & $\begin{array}{l}\text { Preoperative Mean } \\
\mathrm{ECD}\left(\text { cells } / \mathrm{mm}^{2}\right) \pm \mathrm{SD}\end{array}$ & $\begin{array}{c}\text { Mean ECD loss } \\
(\%)\end{array}$ & P-value* \\
\hline Preoperatively & 306 & $2693 \pm 347$ & & & \\
\hline 6 months & 181 & $2669 \pm 354$ & $2680 \pm 343$ & $0.40 \pm 9.85$ & 0.829 \\
\hline 1 year & 155 & $2660 \pm 353$ & $2692 \pm 344$ & $1.23 \pm 9.52$ & 0.742 \\
\hline 2 years & 147 & $2627 \pm 349$ & $2679 \pm 363$ & $2.03 \pm 8.83$ & 0.004 \\
\hline 3 years & 79 & $2562 \pm 330$ & $2673 \pm 294$ & $4.91 \pm 12.64$ & $<0.001$ \\
\hline 5 years & 53 & $2576 \pm 319$ & $2659 \pm 339$ & $4.34 \pm 8.92$ & 0.011 \\
\hline 7 years & 20 & $2446 \pm 278$ & $2576 \pm 248$ & $5.41 \pm 9.11$ & 0.036 \\
\hline
\end{tabular}

From 2006 to 2008, AS-OCT was performed once in all included patients to analyze the position of the iris-fixated pIOL using the Visante ${ }^{\mathrm{TM}}$ OCT system (Carl Zeiss Meditec Inc., Dublin, CA). All AS-OCT images were made on the horizontal meridian, in an unaccommodated state and in the same light conditions (50 lux). Crosssectional images were taken using the enhanced anterior segment single-scan. One examiner analyzed the images and measured the distances from the edges of the pIOL to the corneal endothelium using the refractive tools as provided by the manufacturer (Fig 1). Of the two edge distances (nasal and temporal side), the smallest distance was used for statistical analysis.

A Linear Mixed Model analysis was applied to our data, with ECD as independent variable, time as covariate and assuming a random intercept per eye. This linear model is an useful test as it uses all available ECD data for each patient to fit the best linear model. In order to look for possible differences in endothelial cell loss for pIOLs with different distances between the edge of the pIOL and the corneal endo- 
thelium, we also included an interaction term "time" $x$ "edge plOL-corneal endothelium distance". Our approach was to fit a mixed linear model using the following equation:

$$
y_{i}(t, d)=\alpha+\alpha_{i}+\beta * t+\gamma *(t * d)+\varepsilon_{i}
$$

where $y_{i}(t, d)$ is ECD count of an eye $i$ after a follow-up of $t$ months with edge distance $d$; $\alpha$ represents the intercept; $\alpha_{i}$ represents the random intercept per eye; $\beta$ is the effect of time after a follow-up of $t$ months; $\gamma$ is the interaction effect of time and edge distance with edge distance $d$ and a follow-up of $t$ months; and $\varepsilon_{i}$ is the residual error.

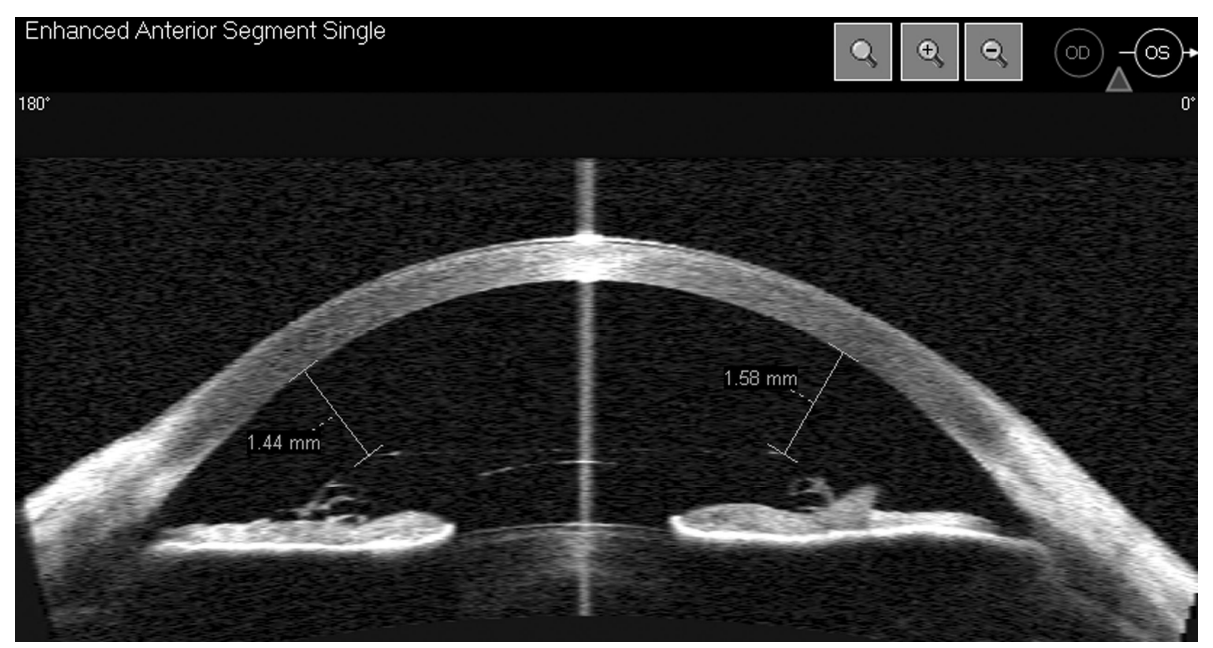

Figure 1. Anterior segment optical coherence tomography scan showing measured edge distances on the nasal $(1.44 \mathrm{~mm})$ and temporal $(1.58 \mathrm{~mm})$ side.

\section{RESULTS}

Of the 306 included eyes, 186 eyes received an Artisan Myopia plOL with a mean lens power of $-12.91 \pm 3.79$ diopters (D) (range -5.00 to $-23.50 \mathrm{D}$ ), 15 eyes were implanted with an Artisan Toric plOL with a mean lens power of $-7.77 \pm 4.04 \mathrm{D}$ (range -2.00 to $-15.00 \mathrm{D}$ ), 99 eyes received an Artiflex Myopia pIOL with a mean lens power of $-10.06 \pm 2.25 \mathrm{D}$ (range -4.00 to $-14.50 \mathrm{D}$ ), and 6 eyes an Artiflex Toric pIOL with a mean lens power of $-8.33 \pm 2.32 \mathrm{D}$ (range -5.00 to $-10.50 \mathrm{D}$ ). The mean preoperative ECD count was $2693 \pm 347$ cells $/ \mathrm{mm}^{2}$ (range $1588-3753$ cells $/ \mathrm{mm}^{2}$ ) and the mean minimum edge distance was $1.43 \pm 0.23 \mathrm{~mm}$ (range 0.70 to $2.21 \mathrm{~mm}$ ). The Artisan plOLs showed a mean edge distance of $1.48 \pm 0.23 \mathrm{~mm}$ and a mean 
preoperative ECD count of $2624 \pm 355$ cells $/ \mathrm{mm}^{2}$. The mean edge distance of the Artiflex pIOLs was $1.32 \pm 0.20 \mathrm{~mm}$ and the mean preoperative ECD count was 2775 \pm 310 cells $/ \mathrm{mm}^{2}$. There were 11 patients included in this study who wanted the $\mathrm{plOL}$ implantation despite an ECD less than 2000 cells $/ \mathrm{mm}^{2}$ and our warnings about possible complications, with most of the patients $(n=8)$ between 1950 and 2000 celss $/ \mathrm{mm}^{2}$. They underwent the implantation due to complete contact lens intolerance and the inability to continue their occupation with spectacle correction. The mean endothelial cell losses at 6 months and 1 year after plOL implantation were $0.40 \pm 9.85 \%$ and $1.23 \pm 9.52 \%$, respectively. To illustrate the ECD data used to compute the model, the changes in ECD at each follow-up visit compared to preoperatively are shown in Table 1. All corneas of the included eyes stayed clear during follow-up.

Table 2. Parameter Estimates of Linear Mixed Model Analysis

\begin{tabular}{lcc}
\hline Parameter & Estimate $\left(\right.$ cells $/ \mathrm{mm}^{2}$ ) $\pm \mathrm{SE}$ & $95 \% \mathrm{Cl}$ \\
\hline Intercept $\alpha$ & $2693 \pm 18.5$ & $2656-2729$ \\
Effect of time $\beta$ & $-12.95 \pm 1.58$ & -16.05 to -9.85 \\
Interaction effect $\gamma$ & $7.51 \pm 1.06$ & $5.44-9.58$ \\
\hline
\end{tabular}

$\mathrm{SE}=$ standard error $; \mathrm{Cl}=$ confidence interval

The estimated parameters of the linear mixed model are listed in Table 2. When using these estimates in the described model, the following equation can be computed:

$$
y_{i}(t, d)=2693+\alpha_{i}-12.95 * t+7.51 *(t * d)+\varepsilon_{i}
$$

When applying this model to a patient with a preoperative ECD count of 2693 cells $/ \mathrm{mm}^{2}$ (i.e. mean ECD count of the investigated population) and a minimum edge distance of $1.43 \mathrm{~mm}$ (i.e. mean edge distance of the investigated population), the predicted ECD at 5 years postoperatively would be: $y(60,1.43)=2693-12.95$ * $60+7.51 *(60 * 1.43)=2560$ cells $/ \mathrm{mm}^{2}$. We can also calculate that after 44 years the patient will have enough endothelial cells $\left(1525 \mathrm{cells} / \mathrm{mm}^{2}\right)^{14,15}$ left to undergo plOL explantation and cataract extraction (Fig 2 and 3). The predictions of minimum edge distances of $1.66 \mathrm{~mm}$ and $1.20 \mathrm{~mm}$ (i.e. mean edge distance +/- $1 \mathrm{SD}$ ) in the same patient are also shown in Figure 2 with the corresponding years of reaching ECD counts of 1500 cells $/ \mathrm{mm}^{2}$ in Table 3 . For the mean edge distance of $1.43 \mathrm{~mm}$, the model predicted a yearly endothelial cell loss of $1.0 \%$, whereas an edge distance of $1.20 \mathrm{~mm}$ resulted in a yearly endothelial cell loss of $1.7 \%$, and $1.66 \mathrm{~mm}$ led to a yearly endothelial cell loss of only $0.2 \%$. 
Table 3. Linear Mixed Model applied to Patient with Preoperative Endothelial Cell Density (ECD) Count of 2693 cells $/ \mathrm{mm}^{2}$ and Different Edge distances with Corresponding Years of Reaching ECD Levels of 1500 cells $/ \mathrm{mm}^{2}$

\begin{tabular}{ccc}
\hline Edge distance $(\mathrm{mm})$ & Estimate ECD $\left(\right.$ cells $\left./ \mathrm{mm}^{2}\right)$ & Years after plOL Implantation \\
\hline 1.20 & 1511 & 25 \\
1.43 & 1525 & 44 \\
1.66 & 1500 & 205 \\
\hline
\end{tabular}

$\mathrm{ECD}=$ endothelial cell density; $\mathrm{pIOL}=$ phakic intraocular lens

For patients with preoperative ECDs of 3000,2500 or 2000 cells $/ \mathrm{mm}^{2}$ and edge distances of $1.43 \mathrm{~mm}$, the model predicted that a critical ECD of 1500 cells $/ \mathrm{mm}^{2}$ will be reached at 56,37 , and 18 years after implantation, respectively.

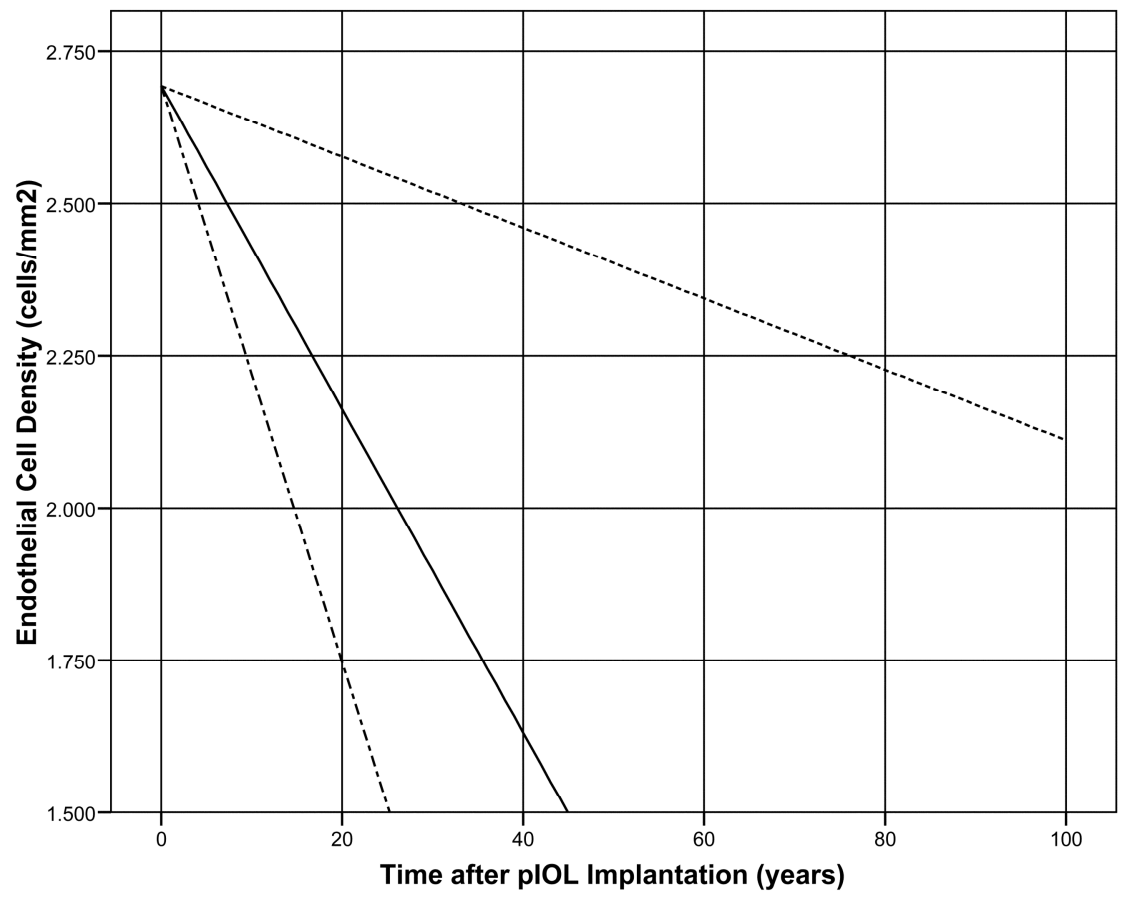

Figure 2. Linear mixed model applied to patient eligible for phakic intraocular lens (plOL) implantation with preoperative endothelial cell count of 2693 cells $/ \mathrm{mm}^{2}$ and edge distance of $1.20 \mathrm{~mm}$ (half dotted line), $1.43 \mathrm{~mm}$ (straight line) and $1.66 \mathrm{~mm}$ (dotted line). 


\section{DISCUSSION}

In this study, we analyzed the data of 306 eyes after iris-fixated pIOL implantation and computed a linear mixed model to predict long-term endothelial cell loss in relation to the distance from the edge of the pIOL to the corneal endothelium. To our knowledge, this is the first attempt to describe such a model for patients after pIOL implantation. In the past, models predicting endothelial cell loss after cataract surgery and penetrating keratoplasty (PK) have been presented using exponential decay models. ${ }^{17-19}$ Patel et al. ${ }^{19}$ and Armitage et al. ${ }^{17}$ both described a biexponential model of endothelial cell loss after PK. Single exponential decay models have shown to underestimate the early endothelial cell loss and overestimate late endothelial cell loss after PK.

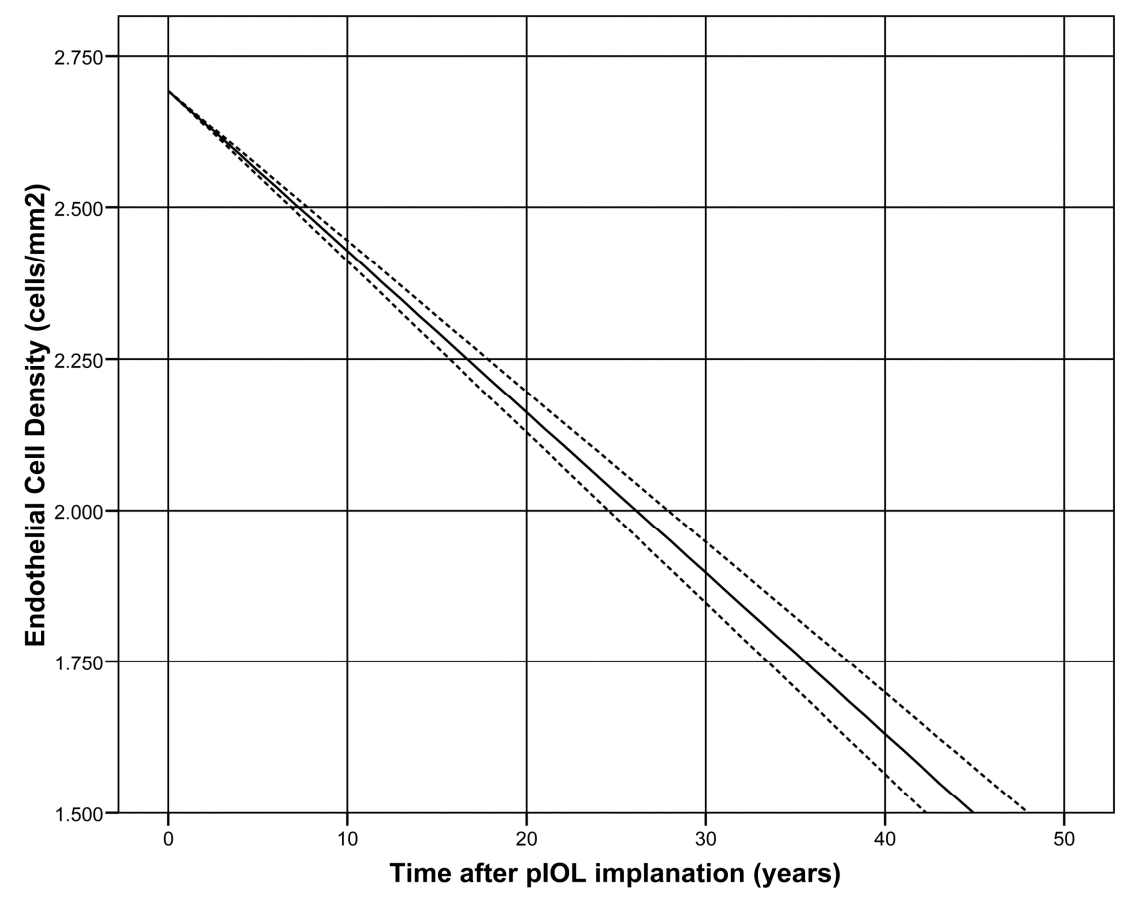

Figure 3. Linear mixed model applied to patient eligible for phakic intraocular lens (pIOL) implantation with preoperative endothelial cell count of 2693 cells $/ \mathrm{mm}^{2}$ and edge distance of $1.43 \mathrm{~mm}$ (straight line) with the confidence intervals of the model (dotted lines).

Other possibilities include: an exponential followed by a linear decrease, or a twophased linear decrease with a rapid linear decrease in the early postoperative period. ${ }^{20}$ We used a single linear model as it was the best fit to our data. Our endothelial cell loss results show that we did not find a large endothelial cell loss shortly after 
pIOL implantation, which is the case after cataract surgery and penetrating keratoplasty and thus follow an exponential decay model. An explanation for this stable ECD in the first months after pIOL implantation might be the redistribution of endothelial cells from the periphery to the center after the discontinuation of contact lens wear. Peripheral corneal ECD seems to be significantly higher than centrally, and function as a physiologic reserve for endothelial cells. ${ }^{21}$ Similar to our results, most studies investigating endothelial cell loss after pIOL implantation did not report a rapid loss in the first 6 months postoperatively. $1,3,4,22,23$ In these studies, short term endothelial cell losses varied from $0.09 \%$ at 6 months to $3.3 \%$ at 1 year postoperatively. Our reported mean endothelial cell losses of $4.3 \%$ at 5 years and $5.4 \%$ at 7 years after pIOL implantation is in accordance with recent literature. Three years after pIOL implantation Stulting et al. ${ }^{3}$ reported an endothelial cell loss of $4.8 \%$ and Benedetti et al. ${ }^{5}$ found an endothelial cell loss of $9.0 \%$ at 5 years postoperatively.

The aim of our study was to describe a model to assist ophthalmologists in their decision to implant iris-fixated pIOLs into healthy eyes. The presented model uses preoperative ECD and the minimum edge distance to estimate ECD counts during follow-up. To built the described model, the edge distance was measured postoperatively because AS-OCT has only been available in our institution since 2006. A new software update of the Visante OCT System now has the possibility to assess the edge distance in the preoperative setting using a pIOL simulation program. Recently, we tested this pIOL simulation tool and found small mean differences between the preoperative simulation and actual postoperative measurements. ${ }^{24}$ Therefore, this preoperative simulation is a useful tool in determining edge distance in the preoperative patient, which can be used in the presented model.

However, as we mentioned before, it is known that ACD decreases with age, which might result in a decrease in the minimum edge distance over time. In our opinion, all patients should be monitored using AS-OCT during long-term follow-up to investigate the effect of age on the minimum edge distance. For example, when presuming a yearly ACD decrease of $20 \mu \mathrm{m}$, which, in a worst case scenario, will result in a decreasing edge distance of $0.02 \mathrm{~mm}$ per year, the presented patient with a preoperative ECD count of 2693 cells $/ \mathrm{mm}^{2}$ and a minimum edge distance of $1.43 \mathrm{~mm}$, will reach an ECD count of 1500 cells $/ \mathrm{mm}^{2} 42$ years after pIOL implantation (Fig 4). This is 2 years sooner than predicted without taking this decrease of $A C D$ into account. As more data become available during long-term follow-up of pIOLs using AS-OCT, we hope this leads to the development of a good mathematical description of the postoperative endothelial cell loss with an accurate estimation of the decrease in edge distance over time.

We tried to evaluate our model, using studies reporting endothelial cell loss after iris-fixated pIOL implantation. ${ }^{1,2,4-6,23,25-29}$ However, the main problem of previously reported studies was the unavailability of measured edge distances, which can 
be expected since the Visante OCT has only been on the market since 2006. Computing an estimated mean edge distance for all available data was very difficult, since the edge distance is related to ACD but also to the power and design of the pIOL. Furthermore, some studies did not report mean ACD or did not describe the measurement device, which makes it difficult to assess whether ACD was measured from crystalline lens to endothelium or epithelium. Our suggestion would be to perform AS-OCT preoperatively and use the pIOL simulation program to estimate edge distance, but also to continue the evaluation of this edge distance during long-term follow-up.

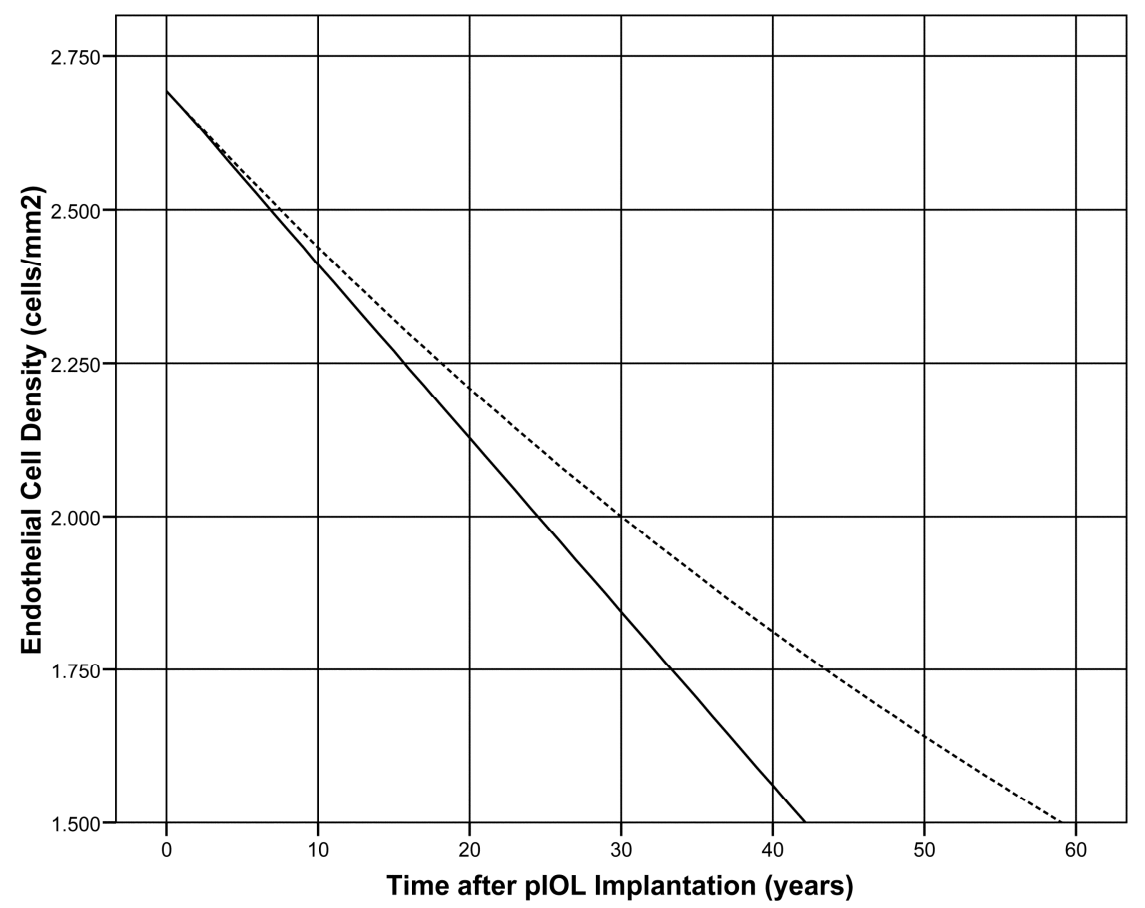

Figure 4. Linear mixed model with decreasing edge distance due to aging (straight line) and relative endothelial cell loss (dotted line) applied to patient eligible for phakic intraocular lens ( $\mathrm{plOL}$ ) implantation with preoperative endothelial cell count of 2693 cells $/ \mathrm{mm}^{2}$ and edge distance of $1.43 \mathrm{~mm}$.

One of the limitations of a prediction model in general is the uncertainty of extrapolation of the data outside the ranges of the estimated values. The minimum edge distances of the eyes included in our study ranged between 0.70 and $2.21 \mathrm{~mm}$. Therefore, in patients with minimum edge distances lower than $0.70 \mathrm{~mm}$, the model should not be used, since this could lead to inaccurate ECD estimates. Second, our maximum follow-up period was 8 years with a limited number of eyes. Therefore, extrapolation after our 8 years of follow-up could become more unreliable. We will 
continue to monitor our ECD data in the upcoming years and hope to provide more accurate values beyond 8 years of follow-up with a larger number of eyes in the future. Furthermore, to increase the validity of the presented model, it should be applied to a second independent population for validation. In our model we included both eyes of a large number of patient, which can cause bias in the statistical analysis. However, when repeating the analysis using only right or left eyes, the results were not very different from the presented model and therefore we believe that the inclusion of both eyes did not lead to severe bias.

Our decrease in ECD is described as an absolute decrease in endothelial cells, which is actually a worst case scenario. When using a relative decrease, which is usually reported in articles about endothelial cell loss, the decrease in ECD would be not as fast as the absolute decrease. An example of a relative decrease is visualized for the presented patient in Figure 4. During the first 15 years of follow-up the relative and absolute endothelial cell losses are almost identical. After this period, the difference between the models becomes evident. The patient will reach our critical ECD count of 1500 cells $/ \mathrm{mm}^{2} 70$ years after implantation, which is 14 years later when compared to the absolute decrease in ECD. When follow-up periods of 15 years and longer will become available in the future, the choice between a relative and absolute decrease will be more reliable.

In conclusion, a linear mixed model analysis was used to describe a linear model which predicts ECD counts after iris-fixated pIOL implantation in relation to the measured minimum edge distance using AS-OCT. A longer follow-up with AS-OCT will be needed to evaluate the effect of age-related changes of the natural lens on the distance from the edge of the pIOL to the endothelium. 


\section{REFERENCES}

1. Tahzib NG, Nuijts RM, Wu WY, Budo CJ. Long-term study of Artisan phakic intraocular lens implantation for the correction of moderate to high myopia: ten-year follow-up results. Ophthalmology 2007;114:1133-1142.

2. Budo C, Hessloehl JC, Izak M, et al. Multicenter study of the Artisan phakic intraocular lens. J Cataract Refract Surg 2000;26:1163-1171.

3. Stulting RD, John ME, Maloney RK, Assil KK, Arrowsmith PN, Thompson VM. Three-year results of Artisan/Verisyse phakic intraocular lens implantation. Results of the United States Food And Drug Administration clinical trial. Ophthalmology 2008;115:464-472.e461.

4. Pop M, Payette Y. Initial results of endothelial cell counts after Artisan lens for phakic eyes: an evaluation of the United States Food and Drug Administration Ophtec Study. Ophthalmology 2004;111:309-317.

5. Benedetti S, Casamenti V, Benedetti M. Long-term endothelial changes in phakic eyes after Artisan intraocular lens implantation to correct myopia: five-year study. J Cataract Refract Surg 2007;33:784-790.

6. Saxena R, Boekhoorn SS, Mulder PG, Noordzij B, van Rij G, Luyten GP. Long-term follow-up of endothelial cell change after Artisan phakic intraocular lens implantation. Ophthalmology 2008;115:608613 e601.

7. Kohnen T, Cichocki M, Koss MJ. Position of rigid and foldable iris-fixated myopic phakic intraocular lenses evaluated by Scheimpflug photography. J Cataract Refract Surg 2008;34:114-120.

8. Baikoff G, Lutun E, Ferraz C, Wei J. Static and dynamic analysis of the anterior segment with optical coherence tomography. J Cataract Refract Surg 2004;30:1843-1850.

9. Baikoff G. Anterior segment OCT and phakic intraocular lenses: a perspective. J Cataract Refract Surg 2006;32:1827-1835.

10. Doors M, Cals DW, Berendschot TT, et al. Influence of anterior chamber morphometrics on endothelial cell changes after phakic intraocular lens implantation. J Cataract Refract Surg 2008;34:21102118 .

11. Baikoff G, Bourgeon G, Jodai HJ, Fontaine A, Lellis FV, Trinquet L. Pigment dispersion and Artisan phakic intraocular lenses: crystalline lens rise as a safety criterion. J Cataract Refract Surg 2005;31:674-680

12. Atchison D, Markwell E, Kasthurirangan S, Pope J, Smith G, Swann P. Age-related changes in optical and biometric characteristics of emmetropic eyes. J Vis 2008;8:29.21-20.

13. Guell JL, Morral M, Gris O, Gaytan J, Sisquella M, Manero F. Evaluation of Verisyse and Artiflex phakic intraocular lenses during accommodation using Visante optical coherence tomography. J Cataract Refract Surg 2007;33:1398-1404.

14. Baradaran-Rafii A, Rahmati-Kamel M, Eslani M, Kiavash V, Karimian F. Effect of hydrodynamic parameters on corneal endothelial cell loss after phacoemulsification. J Cataract Refract Surg 2009;35:732-737.

15. Storr-Paulsen A, Norregaard JC, Ahmed S, Storr-Paulsen T, Pedersen TH. Endothelial cell damage after cataract surgery: divide-and-conquer versus phaco-chop technique. J Cataract Refract Surg 2008;34:996-1000.

16. Tahzib NG, Bootsma SJ, Eggink FA, Nuijts RM. Functional outcome and patient satisfaction after Artisan phakic intraocular lens implantation for the correction of myopia. Am J Ophthalmol 2006;142:31-39.

17. Armitage WJ, Dick AD, Bourne WM. Predicting endothelial cell loss and long-term corneal graft survival. Invest Ophthalmol Vis Sci 2003;44:3326-3331.

18. Bates AK, Hiorns RW, Cheng $\mathrm{H}$. Modelling of changes in the corneal endothelium after cataract surgery and penetrating keratoplasty. Br J Ophthalmol 1992;76:32-35.

19. Patel SV, Hodge DO, Bourne WM. Corneal endothelium and postoperative outcomes 15 years after penetrating keratoplasty. Am J Ophthalmol 2005;139:311-319. 
20. Moller-Pedersen T. A comparative study of human corneal keratocyte and endothelial cell density during aging. Cornea 1997;16:333-338.

21. Odenthal MT, Gan IM, Oosting J, Kijlstra A, Beekhuis WH. Long-term changes in corneal endothelial morphology after discontinuation of low gas-permeable contact lens wear. Cornea 2005;24:32-38.

22. Maloney RK, Nguyen LH, John ME. Artisan phakic intraocular lens for myopia:short-term results of a prospective, multicenter study. Ophthalmology 2002;109:1631-1641.

23. Moshirfar M, Holz HA, Davis DK. Two-year follow-up of the Artisan/Verisyse iris-supported phakic intraocular lens for the correction of high myopia. J Cataract Refract Surg 2007;33:1392-1397.

24. Doors M, Berendschot TT, Hendrikse F, Webers CA, Nuijts RM. Value of preoperative phakic intraocular lens simulation using optical coherence tomography. J Cataract Refract Surg 2009;35:438-443.

25. Menezo JL, Cisneros AL, Rodriguez Salvador V. Endothelial study of iris-claw phakic lens: four year follow-up. J Cataract Refract Surg 1998;24:1039-1049.

26. Landesz M, van Rij G, Luyten G. Iris-claw phakic intraocular lens for high myopia. J Refract Surg 2001;17:634-640.

27. Silva RA, Jain A, Manche EE. Prospective long-term evaluation of the efficacy, safety, and stability of the phakic intraocular lens for high myopia. Arch Ophthalmol 2008;126:775-781.

28. Guell JL, Morral M, Gris O, Gaytan J, Sisquella M, Manero F. Five-year follow-up of 399 phakic Artisan-Verisyse implantation for myopia, hyperopia, and/or astigmatism. Ophthalmology 2008;115:1002-1012.

29. Stulting RD, John ME, Maloney RK, Assil KK, Arrowsmith PN, Thompson VM. Three-year results of Artisan/Verisyse phakic intraocular lens implantation. Results of the United States Food And Drug Administration clinical trial. Ophthalmology 2008;115:464-472 e461. 


\section{Chapter 6}

\section{Late-onset decentration of iris-fixated phakic intraocular lenses: a case series}

Muriël Doors, Fred A. Eggink, Carroll A.B. Webers, Rudy M.M.A. Nuijts

Am J Ophthalmol. 2009 Jun;147(6):997-1003 


\section{ABSTRACT}

Purpose: To investigate late-onset downward decentration of iris-fixated phakic intraocular lenses (plOLs) due to progressive shifting of the haptics through the iris, and its influence on the position of the plOL and the amount of enclavated iris tissue.

Design: Institutional prospective observational case series.

Methods: Six patients (9 eyes) of 368 eyes presented with one shifted haptic during long term follow-up. Anterior segment optical coherence tomography (AS-OCT) was used to measure the distance between the edges of the $\mathrm{pIOL}$ and the corneal endothelium. Slit-lamp photography pictured the plOL after implantation and after decentration. The images were analyzed to determine decentration and amount of iris tissue at the enclavation sites.

Results: Shifting of the haptics occurred in $2.4 \%$ and was discovered at a mean follow-up of 4.8 years (range 3-7 years). Mean downward decentration was $0.28 \pm 0.15$ $\mathrm{mm}$. Mean edge distances on the nasal, temporal, superior and inferior side were $1.71 \pm 0.30 \mathrm{~mm}, 1.86 \pm 0.31 \mathrm{~mm}, 1.86 \pm 0.31 \mathrm{~mm}$, and $1.58 \pm 0.34 \mathrm{~mm}$, respectively. Mean enclavated iris tissue on the nasal and temporal side was smaller after decentration when compared to directly postoperatively $(P=0.033$ and $P=0.017$, respectively). Shifting of the haptics did not result in a decreased uncorrected and best corrected visual acuity.

Conclusions: Late-onset downward decentration due to progressive shifting of the haptics occurred in $2.4 \%$ and was associated with a decrease in enclavated iris tissue. AS-OCT showed a mean distance between the edge of the plOL and the endothelium greater than the advised safety distance of $1.5 \mathrm{~mm}$. 


\section{INTRODUCTION}

In the last decade, iris-fixated phakic intraocular lenses (pIOLs) have proven to be a safe and reliable method for correcting high myopia, hyperopia and astigmatism, when strict inclusion criteria for implantation are applied. ${ }^{1-6}$ To retain a good quality of vision and prevent damage to intraocular structures, it is important that the plOL stays in position after implantation. In the past, it was difficult to investigate the stability of the $\mathrm{plOL}$ in the anterior chamber. Anterior segment optical coherence tomography (AS-OCT) is a new imaging device, which can visualize the plOL and its surrounding intraocular tissues. AS-OCT is a non-contact high-resolution device, which applies an infrared light of $1310 \mathrm{~nm}$ wavelength to obtain a two dimensional image of the anterior segment, using low coherence interferometry. ${ }^{7}$ Several studies have demonstrated that AS-OCT is a useful device for determining pIOL position. ${ }^{8-10}$

In reports about the short-term positional stability of iris-fixated pIOLs, no significant rotation around the optical axis has been described, which can be expected because of its firm fixation to the iris stroma. ${ }^{11-13}$ Postoperative dislocations due to trauma or poor enclavation of iris tissue have been reported. ${ }^{14,15}$ We are unaware of previous reports on the long-term positional stability of the $\mathrm{PIOL}$ in the anterior chamber and could find no reference to it in a computerized search utilizing (www.pubmed.gov; search terms: phakic intraocular lens and complications; performed November 17, 2008).

During long-term follow-up of our patients with an iris-fixated plOL, we discovered a downward decentration of the $\mathrm{plOL}$ due to progressive shifting of the haptics through the iris. In this study, we investigated this late-onset downward decentration, and its influence on the position of the $\mathrm{plOL}$ in the anterior chamber using AS-OCT.

\section{METHODS}

\section{Patient Population and Study Design}

In this prospective observational case series, we included 9 eyes of 6 patients, who presented with downward decentration of the pIOL due to progressive shifting of the haptics during long-term follow-up in our clinic. The included patients had undergone Artisan or Artiflex pIOL (Ophtec B.V., Groningen, The Netherlands) implantation from May 1999 to March 2005, with a mean implanted pIOL power of -11.44 \pm 2.62 D. Follow-up ranged from 40 to 109 months, with a mean follow-up of $74.0 \pm$ 23.7 months. 
The inclusion criteria for pIOL implantation at our institution are: a stable refractive error during the previous 2 years; an anterior chamber depth (ACD) of 2.8 $\mathrm{mm}$ or more (measured from the endothelium to the crystalline lens); pupil (in mesopic light conditions) $<6 \mathrm{~mm}$; endothelial cell density $\geq 2000$ cells $/ \mathrm{mm}^{2}$; no corneal, pupil or iris abnormalities; and no history of glaucoma and chronic or recurrent uveitis.

The Artisan Myopia pIOL is a single-pieced polymethyl methacrylate (PMMA) lens, which has a convex-concave shape with either a $6 \mathrm{~mm}$ (for intraocular lens powers up to -15.5 diopters (D)) or $5 \mathrm{~mm}$ (for intraocular lens powers from -16.0 to $-24.0 \mathrm{D})$ optic. The Artiflex lens has a convex-concave shape, with a $6 \mathrm{~mm}$ optical zone (lens powers from -2.0 to -14.5 ) and consists of three pieces: a flexible optical part (ultraviolet-absorbing silicone) and 2 rigid haptics (PMMA). There are two types of Artiflex lenses: the Artiflex I and the Artiflex II. The Artiflex I has a vault of 0.13 $\mathrm{mm}$ between the optic-haptic junction and the iris plane and the Artiflex II of 0.20 $\mathrm{mm}$. The Artiflex I was the first model of this foldable lens and was replaced by the Artiflex II in 2006. In this study, 7 eyes had undergone Artisan Myopia pIOL implantation and 2 eyes Artiflex I.

From May 1998 to April 2008 a total of 368 consecutive eyes underwent Artisan Myopia and Artiflex I implantation at the University Hospital Maastricht. The mean follow-up of this group of patients was $38.0 \pm 27.5$ months, range 3 to 108 months. All patients underwent standard clinical evaluation at each follow-up visit $(3,6$ and 12 months after pIOL implantation and every year thereafter), which included: uncorrected visual acuity (UCVA), best-corrected visual acuity (BCVA), slit-lamp and fundus examination, Goldmann applanation tonometry, and endothelial cell density (ECD) counts (Noncon Robo SP-8000; Konan Medical Inc., Hyogo, Japan). Three consecutive images of the central corneal endothelium were obtained. The images were analysed using the dot method, in which the centers of a minimum of 50 contiguous cells are marked. Averages of the three measurements were used for analysis.

During follow-up of all 368 eyes, 9 eyes presented with a shifted haptic through the iris tissue. The shifted haptics were identified at the slit-lamp.

\section{Surgical Procedure}

All surgical procedures were performed by the same surgeon (RN) at the Academic Center for Refractive Surgery, University Hospital Maastricht. The complete surgical technique for Artisan lens implantation is described elsewhere. ${ }^{16}$ The procedure of the Artiflex lens was similar to the Artisan technique. However, the Artiflex lens was inserted with a specially designed spatula that allows the surgeon to fold and insert the lens through a smaller $3.4 \mathrm{~mm}$ incision. The wound was sutured with two 10-0 
nylon sutures. In both techniques, the pIOL was always implanted horizontally and a disposable enclavation needle (Ophtec BV.) was used for iris enclavation.
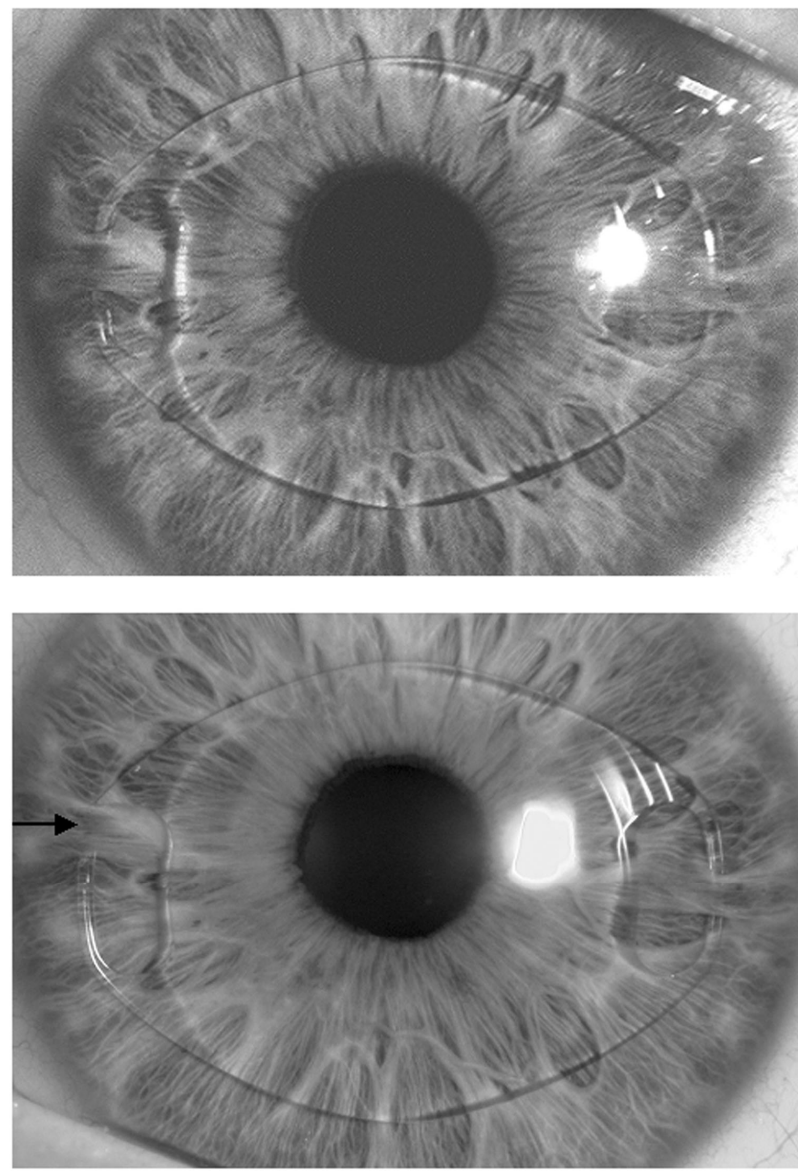

Figure 1. Slit-lamp photographs of case no. 1 with downward decentration of iris-fixated phakic intraocular lens (pIOL). (Top) Slit-lamp photograph after plOL implantation and (Bottom) after decentration. The black arrow points to the decentrated enclavation site.

\section{Analysis of Slit-Lamp Photographs}

A slit-lamp photograph was made using a Nikon BM-6 camera 1 month after pIOL implantation, and after downward decentration had occurred (Figure 1). The chinrest and headrest of the devise ensured that the patient was in the same position in both photographs. The images were analyzed using Adobe Photoshop (version 7.0; Adobe Systems Inc., San Jose, CA) to determine the amount of iris tissue at the enclavation sites and decentration. The diameter of the pIOL optic (either 5 or 6 $\mathrm{mm}$ depending on the power of the lens) was used as a reference for all measure- 
ments. The amount of iris tissue was measured using the scale provided by the software manufacturer. Decentration was defined as the deviation between the center of the pIOL and the center of the pupil. The amount of decentration of the pIOL, after shifting of the haptics through the iris tissue, was calculated by subtracting the decentration after shifting had occurred from the decentration measured directly after implantation.
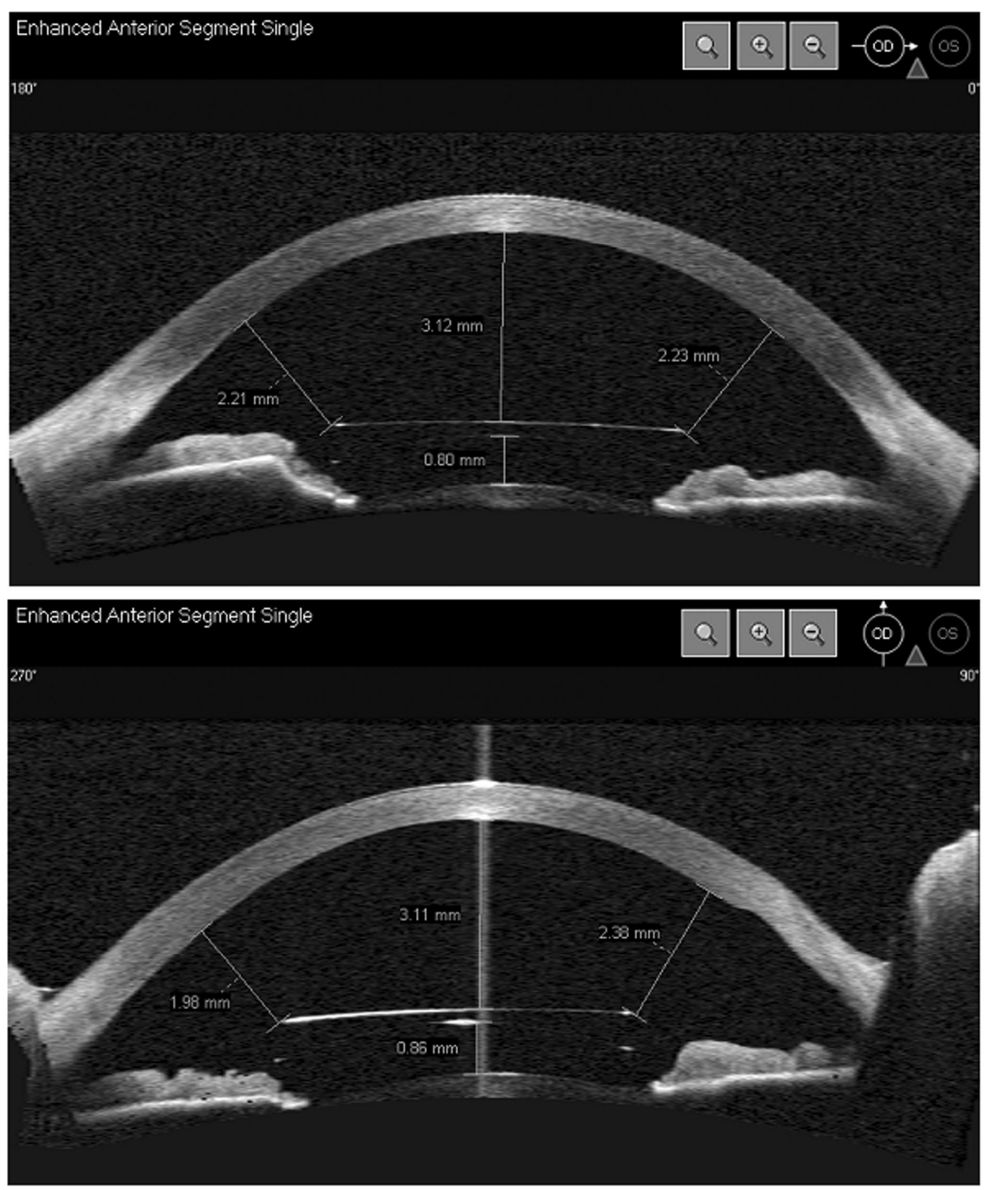

Figure 2. Optical Coherence Tomography (OCT) scans of case no. 3 with downward decentration of irisfixated phakic intraocular lens. (Top) Horizontal OCT scan with measured nasal $(2.23 \mathrm{~mm})$ and temporal $(2.21 \mathrm{~mm})$ edge distance. (Bottom) Vertical OCT scan with measured superior $(2.38 \mathrm{~mm})$ and inferior $(1.98 \mathrm{~mm})$ edge distance.

\section{Anterior Chamber Optical Coherence Tomography}

Visante $^{\mathrm{TM}}$ OCT (Carl Zeiss Meditec Inc., Dublin, CA) was used to analyze the position of the decentrated iris-fixated pIOL in the anterior chamber. All AS-OCT images were 
made in an unaccommodated state and in the same light conditions (50 Ix). Two cross-sectional images were made using the anterior segment single-scan; one on the horizontal meridian (0-180 degrees), and one on the vertical meridian (90-270 degrees). One examiner analyzed the images (MD). In both anterior segment singlescans, the distance between the anterior surface of the center of the pIOL and the corneal endothelium, the distances from the edges of the pIOL (temporal, nasal, superior and inferior side) to the corneal endothelium, and the distance between the posterior surface of the center of the pIOL and the anterior surface of the crystalline lens were measured (Figure 2). All measurements were performed using the refractive tools of the software provided by the manufacturer.

\section{Statistical analysis}

Data were collected and analyzed in SPSS (SPSS for Windows, version 15.0, SPSS Inc, Chicago, IL). All continuous variables were reported with mean \pm standard deviation and range. Paired $t$ tests were performed to compare measurements before and after shifting of the haptics had occurred. Mann-Whitney tests were done to compare the 368 consecutive patients to the 9 cases with shifted haptics. Yearly endothelial cell density loss was calculated comparing ECD counts one year before and after decentration to ECD counts at the time of decentration. In three eyes the downward decentration occurred within the last 4 months, therefore we could not calculate a yearly endothelial cell loss after decentration for these eyes. A $P$-value of 0.05 was considered significant.

Table 1. Characteristics and Analysis of Slit-Lamp Photographs of Patients Presenting with Shifted Haptics after Iris-fixated Phakic Intraocular Lens Implantation

\begin{tabular}{|c|c|c|c|c|c|c|c|c|c|}
\hline \multirow[b]{2}{*}{$\begin{array}{l}\text { Case } \\
\text { No. }\end{array}$} & \multirow[b]{2}{*}{ Age } & \multirow[b]{2}{*}{ Eye } & \multirow[b]{2}{*}{$\begin{array}{l}\text { Location } \\
\text { DCT }\end{array}$} & \multirow[b]{2}{*}{$\begin{array}{c}\text { Time of } \\
\text { DCT } \\
\text { (yrs) }\end{array}$} & \multirow[b]{2}{*}{$\begin{array}{c}\text { DCT } \\
(\mathrm{mm})\end{array}$} & \multicolumn{2}{|c|}{$\begin{array}{l}\text { Iris Thickness Nasal } \\
\qquad(\mathrm{mm})\end{array}$} & \multicolumn{2}{|c|}{$\begin{array}{l}\text { Iris Thickness Tempo- } \\
\text { ral }(\mathrm{mm})\end{array}$} \\
\hline & & & & & & before DCT & after DCT & before DCT & after DCT \\
\hline 1 & 38 & OS & Nasal & 4 & 0.39 & 0.65 & 0.56 & 0.69 & 0.61 \\
\hline 2 & 38 & OD & Temporal & 4 & 0.43 & 0.57 & 0.57 & 0.43 & 0.29 \\
\hline 3 & 51 & OS & Temporal & 6 & 0.37 & 0.85 & 0.78 & 0.90 & 0.83 \\
\hline 4 & 51 & OD & Temporal & 6 & 0.21 & 1.12 & 1.12 & 1.04 & 0.80 \\
\hline 5 & 37 & OS & Temporal & 7 & 0.22 & 1.29 & 1.19 & 1.01 & 1.01 \\
\hline 6 & 39 & OS & Temporal & 4 & 0.48 & 0.73 & 0.70 & 0.73 & 0.73 \\
\hline 7 & 35 & OS & Nasal & 3 & 0.02 & 0.88 & 0.52 & 0.85 & 0.57 \\
\hline 8 & 35 & OD & Nasal & 3 & 0.27 & 0.51 & 0.35 & 0.89 & 0.82 \\
\hline 9 & 44 & OS & Temporal & 6 & 0.13 & 1.18 & 1.13 & 1.06 & 1.03 \\
\hline
\end{tabular}




\section{RESULTS}

Late-onset decentration occurred in 9 of 368 eyes (2.4\%). Patient characteristics and slit-lamp photograph analyses are listed in Table 1 . The mean age was $40.7 \pm 6.2$ years, ranging from 34 to 51 years. Downward decentration did not result in complaints about halos or starburst. Decentration occurred between 3 and 7 years after plOL implantation, with a mean decentration of $0.28 \pm 0.15 \mathrm{~mm}$ (range 0.02-0.48 $\mathrm{mm}$ ). The mean enclavated iris tissue was smaller after decentration when compared to directly postoperatively, with means of $0.86 \pm 0.28$ and $0.84 \pm 0.20 \mathrm{~mm}$ postoperatively compared to $0.77 \pm 0.31$ and $0.74 \pm 0.23 \mathrm{~mm}$ after decentration on the nasal and temporal side, respectively. This decrease was significant for both the nasal and temporal side ( $P=0.033$ and $P=0.017$, respectively).

Table 2. Anterior Segment Optical Coherence Tomography Measurements after Shifting of Haptics in Irisfixated Phakic Intraocular Lenses

\begin{tabular}{cccccccc}
\hline $\begin{array}{l}\text { Case } \\
\text { No. }\end{array}$ & Eye & $\begin{array}{l}\text { Nasal Edge } \\
\text { plOL- } \\
\text { Endothelium } \\
0-180^{\circ}(\mathrm{mm})\end{array}$ & $\begin{array}{l}\text { Temporal } \\
\text { Edge plOL- } \\
\text { Endothelium } \\
0-180^{\circ}(\mathrm{mm})\end{array}$ & $\begin{array}{l}\text { Superior Edge } \\
\text { plOL- } \\
\text { Endothelium } \\
90-270^{\circ}(\mathrm{mm})\end{array}$ & $\begin{array}{l}\text { Inferior Edge } \\
\text { plOL- } \\
\text { Endothelium } \\
90-270^{\circ}(\mathrm{mm})\end{array}$ & $\begin{array}{l}\text { Center plOL- } \\
\text { Endothelium } \\
(\mathrm{mm})\end{array}$ & $\begin{array}{l}\text { Crystalline } \\
\text { lens-plOL } \\
(\mathrm{mm})\end{array}$ \\
\hline 1 & OS & 1.69 & 1.70 & 1.71 & 1.67 & 2.41 & 0.66 \\
2 & OD & 1.90 & 1.91 & 1.94 & 1.66 & 2.45 & 0.66 \\
3 & OS & 2.23 & 2.21 & 2.38 & 1.98 & 3.12 & 0.80 \\
4 & OD & 1.87 & 2.41 & 2.24 & 2.03 & 3.01 & 0.78 \\
5 & OS & 1.52 & 1.63 & 1.64 & 1.31 & 2.20 & 0.60 \\
6 & OS & 1.75 & 1.80 & 1.70 & 1.55 & 2.44 & 0.70 \\
7 & OS & 1.38 & 1.55 & 1.53 & 1.40 & 2.11 & 0.74 \\
8 & OD & 1.32 & 1.63 & 1.75 & 1.02 & 2.13 & 0.66 \\
9 & OD & NA & NA & NA & NA & NA & NA \\
\hline
\end{tabular}

pIOL = phakic intraocular lens; NA = not available

The distances from the plOL to the endothelium and crystalline lens are presented in Table 2. The mean distances between the edge of the PIOL and the endothelium on the nasal and temporal side were $1.71 \pm 0.30$ and $1.86 \pm 0.31 \mathrm{~mm}$, respectively. The mean edge distances measured using the 90-270 degrees anterior segment single scan were $1.86 \pm 0.31 \mathrm{~mm}$ at the superior side and $1.58 \pm 0.34 \mathrm{~mm}$ at the inferior side. The inferior edge distance showed the smallest distance between the edge of the phakic $\mathrm{IOL}$ and the endothelium. The distance from the center of the pIOL to the endothelium and the distance from the posterior surface of the pIOL to the anterior surface of the crystalline lens were the same in both meridians, with means of $2.48 \pm 0.38$ and $0.70 \pm 0.07 \mathrm{~mm}$, respectively. 


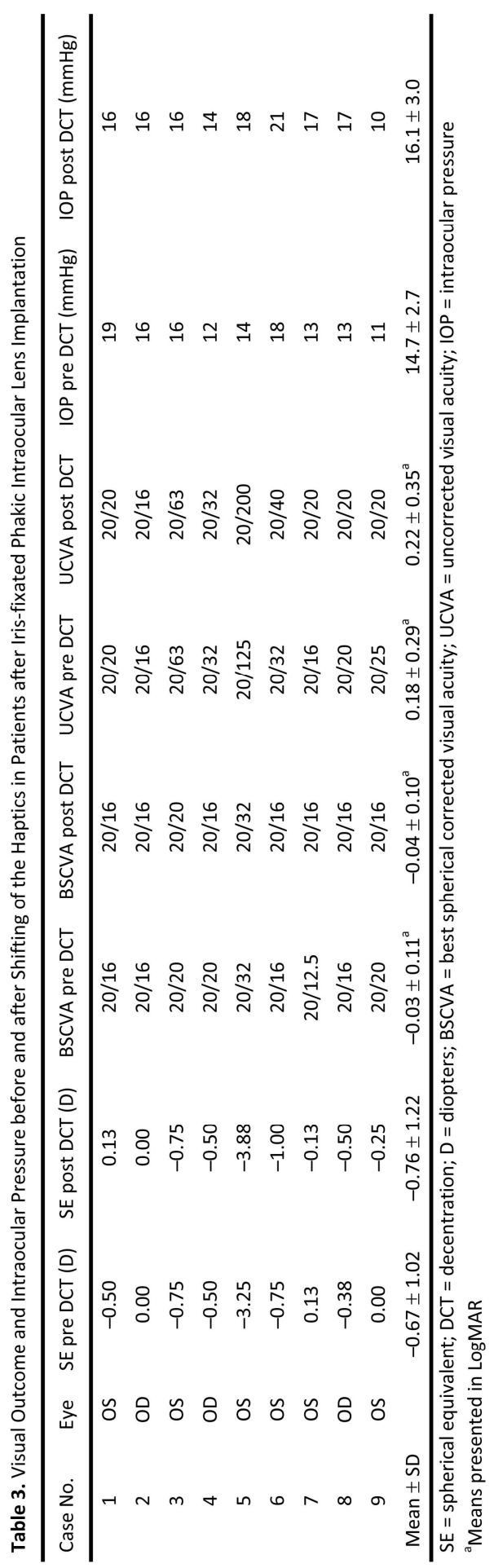


In Table 3 visual outcomes and intraocular pressure (IOP) are outlined for all 9 cases. There were no significant differences between BSCVA, UCVA and IOP before and after shifting of the haptics had occurred $(P=0.573 ; P=0.259 ; P=0.128$; respectively). Visual outcomes, IOP and ECD preoperatively and at last follow-up examination for the 368 consecutive eyes are listed in Table 4. When comparing these postoperative results to the results of the 9 cases after shifting of the haptics had occurred, there were no significant differences in postoperative spherical equivalent, UCVA and IOP between the consecutive group en the 9 cases $(P=0.954 ; P=0.560$; $P=0.321$; respectively). BSCVA was significantly higher in the shifted haptic group compared to the 368 consecutive eyes $(P=0.032)$.

Table 4. Visual Outcome, Endothelial Cell Density and Intraocular Pressure of 368 Consecutive Patients after Iris-fixated Phakic Intraocular Lens Implantation

\begin{tabular}{lcc}
\hline & Preoperative & Last Follow-Up \\
\hline Spherical Equivalent (Diopters) & $-12.11 \pm 4.55$ & $-0.62 \pm 0.87$ \\
BSCVA (LogMAR) & $0.11 \pm 0.16$ & $0.04 \pm 0.18$ \\
UCVA (LogMAR) & NA & $0.22 \pm 0.29$ \\
ECD (cells/mm ${ }^{2}$ ) & $2653 \pm 357$ & $2557 \pm 408$ \\
IOP $(\mathrm{mmHg})$ & $14.4 \pm 3.0$ & $15.4 \pm 3.0$
\end{tabular}

BSCVA = best spherical corrected visual acuity; UCVA = uncorrected visual acuity; $\mathrm{ECD}=$ endothelial cell density; IOP = intraocular pressure; NA = not available

The mean yearly endothelial cell loss was $1.1 \pm 3.0 \%$ before decentration and $2.1 \pm 5.4 \%$ after decentration $(n=6)$. The yearly endothelial cell loss of the total group $(n=368)$ was $1.1 \pm 6.9 \%$.

\section{DISCUSSION}

Long-term positional stability of iris-fixated pIOLs is important as movement of the pIOL might cause contact with the crystalline lens or the corneal endothelium, which can cause cataract or lead to endothelial cell loss and corneal decompensation. Iris-fixated pIOLs showed no significant rotation and a general stable position regarding the distance to the corneal endothelium and the crystalline lens during a 12 months follow-up period. ${ }^{11}$ Coppens et al. found no significant positional changes over a period of 24 months. ${ }^{12}$ This indicates that the position of iris-fixated pIOLs appears to be stable over a short follow-up period.

Our study included 368 patients up to eight years after pIOL implantation and detected 9 eyes with late-onset downward decentration due to progressive shifting of the haptics through the iris. A decrease of the enclavated iris tissue was seen after decentration. The mechanism of this decrease is currently unknown, but we 
hypothesize that this decrease might be caused by atrophy of iris tissue at the enclavation site and/or downward pressure of the superior half of the haptic on the iris tissue.

The development of new non-contact imaging techniques, which analyze the dimensions of the anterior segment, have shown to be extremely valuable in guaranteeing a safe distance from the pIOL to critical ocular tissues. ${ }^{13}$ This has led to the development of new safety criteria for pIOLs. A minimum distance from the edge of the pIOL to the endothelium of $1.5 \mathrm{~mm}$ is mentioned, which is the shortest distance from the pIOL to the endothelium due to the convex-concave shape of the plOL. ${ }^{8}$ Furthermore, an arbitrary safety distance from the center of the pIOL to the endothelium of $2.0 \mathrm{~mm}$ is described by Guell et al. ${ }^{17}$ Doors et al. has shown that a smaller distance from the edge of the pIOL to the endothelium is associated with a larger endothelial cell loss. ${ }^{18}$ An edge distance of $1.37 \mathrm{~mm}$ resulted in a yearly endothelial cell loss of $0.98 \%$, whereas an edge distance of $1.15 \mathrm{~mm}$ predicted a yearly loss of $1.8 \%$. In the current study, the inferior edge distance was the smallest distance between the edge of the phakic IOL and the endothelium, which can be expected as the lens moved slightly downward. Despite this inferior decentration, the edge distances at all 4 locations were larger than the mentioned safety distance of 1.5 $\mathrm{mm}$. Furthermore, the mean distance from the center of the plOL to the endothelium was larger than the safety criteria of $2.0 \mathrm{~mm}$.

Shifting of the haptics did not result in a decrease of UCVA and BSCVA. The shifted haptic group even presented with a significantly larger BSCVA than the consecutive group. Furthermore, the shifted haptic patients did not complain about halos or starburst, which seems to be in accordance with a recent report by Tahzib et al. ${ }^{16}$ They found that higher levels of decentration, with a mean decentration of $0.36 \pm 0.14 \mathrm{~mm}$, did not lead to increased glare complaints.

The comparison of ECD counts before and after decentration could only be calculated for 6 eyes. This resulted in yearly endothelial cell losses of $1.1 \%$ before and $2.1 \%$ after decentration. In recently published series of Artisan and Artiflex plOL implantation, yearly endothelial cell losses varied from 0.4 to $3.3 \%$ and our 368 consecutive patients presented with a mean yearly endothelial cell loss of $1.1 \%{ }^{1,5}$, ${ }^{14,19-23}$ Our $2.1 \%$ endothelial cell loss after decentration is well within the range of previous studies. Although the endothelial cell loss after decentration is twice the cell loss before decentration and twice the cell loss of the total consecutive group, we feel that the series is too small to support that decentration results in significant yearly endothelial cell loss. A larger number of patients and longer follow-up will be necessary to analyze the long-term effect of downward decentration on the corneal endothelium.

In conclusion, late-onset downward decentration due to progressive shifting of the haptics through the iris tissue occurred in 9 of 368 eyes (2.4\%). This downward decentration was associated with a decrease in iris tissue, but did not result in a 
distance from the edge of the plOL to the endothelium smaller than the recommended safety distance of $1.5 \mathrm{~mm}$. A careful follow-up of these patients is necessary to decide whether timely refixation is indicated. 


\section{REFERENCES}

1. Tahzib NG, Nuijts RM, Wu WY, Budo CJ. Long-term study of Artisan phakic intraocular lens implantation for the correction of moderate to high myopia: ten-year follow-up results. Ophthalmology 2007;114:1133-1142.

2. Budo C, Hessloehl JC, Izak M, et al. Multicenter study of the Artisan phakic intraocular lens. J Cataract Refract Surg 2000;26:1163-1171.

3. Dick HB, Alio J, Bianchetti M, et al. Toric phakic intraocular lens: European multicenter study. Ophthalmology 2003;110:150-162.

4. Landesz M, van Rij G, Luyten G. Iris-claw phakic intraocular lens for high myopia. J Refract Surg 2001;17:634-640.

5. Pop M, Payette Y. Initial results of endothelial cell counts after Artisan lens for phakic eyes: an evaluation of the United States Food and Drug Administration Ophtec Study. Ophthalmology 2004;111:309-317.

6. Stulting RD, John ME, Maloney RK, Assil KK, Arrowsmith PN, Thompson VM. Three-year results of Artisan/Verisyse phakic intraocular lens implantation. Results of the United States Food And Drug Administration clinical trial. Ophthalmology 2008;115:464-472.

7. Radhakrishnan S, Rollins AM, Roth JE, et al. Real-time optical coherence tomography of the anterior segment at $1310 \mathrm{~nm}$. Arch Ophthalmol 2001;119:1179-1185.

8. Baikoff G. Anterior segment OCT and phakic intraocular lenses: a perspective. J Cataract Refract Surg 2006;32:1827-1835.

9. Baikoff G, Lutun E, Ferraz C, Wei J. Static and dynamic analysis of the anterior segment with optical coherence tomography. J Cataract Refract Surg 2004;30:1843-1850.

10. Koivula A, Kugelberg M. Optical coherence tomography of the anterior segment in eyes with phakic refractive lenses. Ophthalmology 2007;114:2031-2037.

11. Baumeister M, Buhren J, Kohnen T. Position of angle-supported, iris-fixated, and ciliary sulcusimplanted myopic phakic intraocular lenses evaluated by Scheimpflug photography. Am J Ophthalmol 2004;138:723-731.

12. Coppens JE, van den Berg TJ, Budo CJ. Biometry of phakic intraocular lens using Scheimpflug photography. J Cataract Refract Surg 2005;31:1904-1914.

13. Kohnen T, Cichocki M, Koss MJ. Position of rigid and foldable iris-fixated myopic phakic intraocular lenses evaluated by Scheimpflug photography. J Cataract Refract Surg 2008;34:114-120.

14. Menezo JL, Cisneros AL, Rodriguez Salvador V. Endothelial study of iris-claw phakic lens: four year follow-up. J Cataract Refract Surg 1998;24:1039-1049.

15. Yoon H, Macaluso DC, Moshirfar M, Lundergan M. Traumatic dislocation of an Ophtec Artisan phakic intraocular lens. J Refract Surg 2002;18:481-483.

16. Tahzib NG, Bootsma SJ, Eggink FA, Nuijts RM. Functional outcome and patient satisfaction after Artisan phakic intraocular lens implantation for the correction of myopia. Am J Ophthalmol 2006;142:31-39.

17. Guell JL, Morral M, Gris O, Gaytan J, Sisquella M, Manero F. Evaluation of Verisyse and Artiflex phakic intraocular lenses during accommodation using Visante optical coherence tomography. J Cataract Refract Surg 2007;33:1398-1404.

18. Doors M, Cals DW, Berendschot TT, et al. Influence of anterior chamber morphometrics on endothelial cell changes after phakic intraocular lens implantation. J Cataract Refract Surg 2008;34:21102118.

19. Stulting RD, John ME, Maloney RK, Assil KK, Arrowsmith PN, Thompson VM. Three-year results of Artisan/Verisyse phakic intraocular lens implantation. Results of the United States Food And Drug Administration clinical trial. Ophthalmology 2008;115:464-472.

20. Moshirfar M, Holz HA, Davis DK. Two-year follow-up of the Artisan/Verisyse iris-supported phakic intraocular lens for the correction of high myopia. J Cataract Refract Surg 2007;33:1392-1397. 
21. Guell JL, Morral M, Gris O, Gaytan J, Sisquella M, Manero F. Five-year follow-up of 399 phakic Artisan-Verisyse implantation for myopia, hyperopia, and/or astigmatism. Ophthalmology 2008;115:1002-1012.

22. Saxena R, Boekhoorn SS, Mulder PG, Noordzij B, van Rij G, Luyten GP. Long-term follow-up of endothelial cell change after Artisan phakic intraocular lens implantation. Ophthalmology 2008;115:608613.

23. Benedetti S, Casamenti V, Benedetti M. Long-term endothelial changes in phakic eyes after Artisan intraocular lens implantation to correct myopia: five-year study. J Cataract Refract Surg 2007;33:784-790. 


\title{
Chapter 7
}

\section{Artiflex Toric foldable phakic intraocular lens:}

\author{
short-term results of a prospective European \\ multicenter study
}

Muriël Doors, Camille J. Budo, Ben J. Christiaans, Michiel Luger, Antonio A.P. Marinho, H. Burkhard Dick, Jose L. Güell, Rudy M.M.A. Nuijts

Am J Ophthalmol. 2012 Oct;154(4):730-9 


\section{ABSTRACT}

Purpose: To evaluate the short term efficacy, predictability, stability and safety of the foldable Artiflex Toric phakic intraocular lens (plOL; Ophtec, Groningen, Netherlands) for the correction of myopia with astigmatism.

Design: Prospective, non-randomized multicenter study.

Methods: 115 eyes of 73 patients were implanted with an Artiflex Toric pIOL. Mean implanted spherical and cylindrical powers were $-7.10 \pm 2.70$ diopters (D) and $2.14 \pm 0.80 \mathrm{D}$, respectively. Total follow-up was 6 months. Outcome parameters included: uncorrected visual acuity (UCVA), best spectacle-corrected visual acuity (BSCVA), subjective manifest refraction (used for vector analysis), intraocular pressure and endothelial cell density (ECD).

Results: At 6 months, $99.0 \%$ of eyes had an UCVA of $\geq 20 / 40$, and $81.8 \%$ of eyes were between $\pm 0.5 \mathrm{D}$ of the intended refraction. In $74.5 \%$ postoperative UCVA was equal to or better than preoperative BSCVA; 2 eyes lost 2 or more lines of BSCVA postoperatively due to the development of synechiae. In $75.5 \%$ of eyes the remaining cylinder was between $\pm 0.5 \mathrm{D}$. There was a significant decrease in ECD after 3

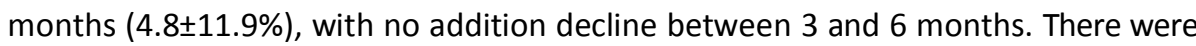
few complications, except for the incidence of pigment and non-pigment precipitates (14.8\% and $12.2 \%$, respectively at 6 months). Mean misalignment was $0.6 \pm 1.5$ degrees (range 0-8).

Conclusions: The Artiflex Toric pIOL effectively and safely corrects myopia and astigmatism on the short term, with stable and predictable visual results after 6 months, when strict inclusion criteria are applied. Deposition of pigment and non-pigment precipitates on the pIOL warrants further investigation. 


\section{INTRODUCTION}

Several treatment options are available to correct myopia with astigmatism. Laser refractive surgery, such as photorefractive keratectomy (PRK) and laser in situ keratomileusis (LASIK), can only be used in mild to moderate myopia. ${ }^{1,2}$ Especially in thin corneas, these refractive procedures can not adequately and safely correct high ametropia, due to the risk of post-LASIK ectasia. ${ }^{3}$ Although these procedures are adjustable, they can never be reversed. Another available treatment option is refractive lens exchange with implantation of a Toric IOL. ${ }^{4}$ However, young refractive patients lose their ability to accommodate, which makes them dependent on reading glasses. Phakic intraocular lenses (plOLs) can correct high myopia and astigmatism, and patients keep there ability to accommodate. Also the quality of vision in patients with high myopia has been reported to be better after pIOL implantation as compared to LASIK. ${ }^{5,6}$

The first iris-fixated plOL was introduced in 1986 (mentioned iris-fixated plOLs throughout this manuscript are made by Ophtec BV, Groningen, The Netherlands). The first Artisan pIOL had a biconcave design, which was changed into a convexoconcave model in 1991 to reduce potential complications. In the last decade, this lens has proven to be stable, predictable and safe, when strict inclusion criteria are applied to maintain a safe distance from the pIOL to the endothelium and natural lens. ${ }^{7-10}$ In 2001 the Toric Artisan pIOL was marketed in Europe, after a multicenter study showed that it effectively reduced or eliminated high ametropia and astigmatism in only one procedure. ${ }^{11}$

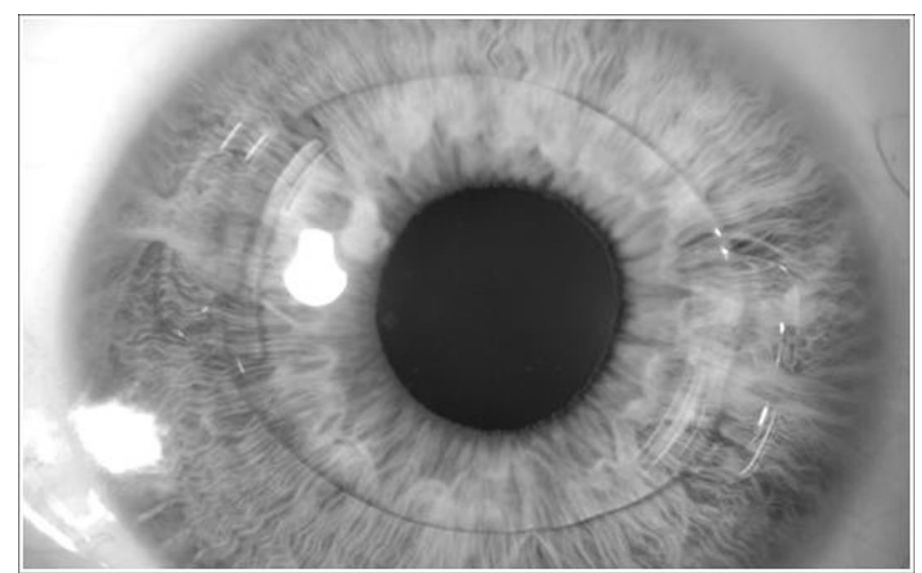

Figure 1. Artiflex Toric phakic intraocular lens (Ophtec BV, Groningen, The Netherlands) with a flexible optical part made of ultraviolet-absorbing silicone and two rigid haptics made of polymethyl methacrylate. 
The developments in cataract surgery with IOL placements through smaller incisions, led to the development of a foldable iris-fixated pIOL type in 2005: the Artiflex Myopia plOL, which can be inserted through a $3.2 \mathrm{~mm}$ incision. This Artiflex pIOL may offer an advantage over the Artisan pIOL due to its smaller incision size, with a decrease in surgically induced astigmatism and a faster visual recovery. ${ }^{12,13}$ Combining the toric technology with the foldable Artiflex pIOL, resulted in the development of the Artiflex Toric. This new Toric plOL corrects myopia and astigmatism and has a flexible, cylindrical $6 \mathrm{~mm}$ optic, which is different from the $5 \mathrm{~mm}$ rigid, spherical optic of the Toric Artisan pIOL. It is a three-piece lens that consists of a flexible optical part made of ultraviolet-absorbing silicone and two rigid haptics made of polymethyl methacrylate (PMMA) (Figure 1). It is available in spherical powers of -1.0 to $-13.5 \mathrm{D}$ (in increments of $0.50 \mathrm{D}$ ) and cylindrical powers of -1.0 to $-5.0 \mathrm{D}$ (in increments of $0.50 \mathrm{D}$ ). The sum of spherical and cylindrical power should not exceed $-14.5 \mathrm{D}$.

Most surgeons prefer to place the non-toric Artiflex plOL in the horizontal position. To facilitate the surgeons to implant the Artiflex Toric pIOL in the position they are accustomed to, the cylindrical correction can be manufactured with the cylinder axis at $0^{\circ}$ or $90^{\circ}$ (Figure 2). When the cylinder axis of the patient is between $0^{\circ}$ and $45^{\circ}$ or between $135^{\circ}$ and $180^{\circ}$, the manufacturer recommends a plOL with the cylinder axis at $0^{\circ}$. The Toric pIOL should be implanted in the axis of the refractive cylinder of the patient. However, when the patient presents with a cylinder between $45^{\circ}$ and $135^{\circ}$, the manufacturer recommends a plOL with the cylinder axis at $90^{\circ}$. In this case, the implantation axis in which the pIOL should be positioned will be the axis of the refractive cylinder of the patient plus $90^{\circ}$. To ensure a proper placement of the Artiflex Toric plOL and avoid implantation errors, all surgeons receive an illustration of the correct toric plOL position.
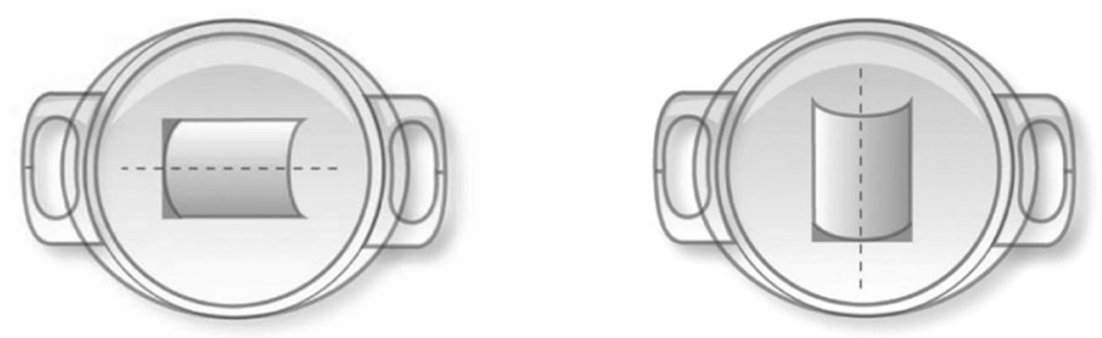

Figure 2. Artiflex Toric phakic intraocular lens (Ophtec BV, Groningen, The Netherlands) with the cylinder axis at $0^{\circ}$ (left) or $90^{\circ}$ (right).

The purpose of this study was to evaluate the short term safety and effectiveness of this new Artiflex Toric pIOL for the correction of myopia and astigmatism. 


\section{PATIENTS AND METHODS}

\section{Study Design and Study Population}

In this prospective, non-randomized, open label multicenter study 115 eyes of 73 patients were analyzed. Toric Artiflex plOLs were implanted in the period between September 2007 and March 2009 by 7 investigators. The inclusion criteria for the conducted study were: age between 18 and 60 years; stable refraction for a minimum of 12 months prior to the surgery and regular astigmatism between 0.75 and 4.50 diopters (D); a minimum best-corrected spherical equivalent of 0.5 ; a difference between cycloplegic and manifest refraction of $<0.75 \mathrm{D}$; anterior chamber depth $(A C D) \geq 3.2$ $\mathrm{mm}$ (measured from center of corneal epithelium to crystalline lens); no corneal, pupil or iris abnormalities; pupil $\leq 7.0 \mathrm{~mm}$ in scotopic light conditions; endothelial cell density (ECD) count according to age, with a minimum of $>2000$ cells $/ \mathrm{mm}^{2}$ for the highest age group; no prior intraocular or corneal surgery; and no history of glaucoma, monocular vision, amblyopia or diabetes mellitus. Immune-compromised patients and pregnant women were excluded from the study.

\section{Preoperative and Postoperative Examinations}

All included subjects were evaluated preoperatively and 1 day, 1 week, 1 month, and 3 and 6 months postoperatively. At the 6 months follow-up visit 6 eyes were lost to follow-up (5.2\%). Examinations during the preoperative visit included: uncorrected visual acuity (UCVA), best spectacle-corrected visual acuity (BSCVA), subjective and objective manifest refraction, cycloplegic subjective refraction, axial length, $A C D$, intraocular pressure (IOP) by applanation tonometry, slit-lamp and fundus examination, pupillometry, keratometry (Pentacam HR (software version 2.73; Oculus, Wetzlar, Germany), Orbscan II (software version 3.10.31; Bausch \& Lomb, Munich, Germany), and Humphrey Atlas topographer (software version A12.2; Carl Zeiss, Jena, Germany)), and ECD measurements by specular microscopy (different types of Topcon (Tokyo, Japan) and Konan Medical Inc.(Hyogo, Japan) devices). Before the examinations, contact lenses were not worn for at least 2 weeks if using rigid contact lenses or at least 3 days if using soft contact lenses.

All postoperative visits included: UCVA, BSCVA, subjective and objective manifest refraction, IOP, slit-lamp biomicroscopy to evaluate lens position and axis of enclavation, and keratometry. Furthermore, ECD measurements were performed at 3 and 6 months postoperatively, using a non contact specular microscope. Three consecutive images of the central corneal endothelium were obtained and the mean of these three measurements was used for statistical analysis. All examinations were performed by the clinical investigator or by a qualified optometrist supervised by the investigator. 
Examinations during the preoperative visit included: anterior segment imaging (Pentacam HR (software version 2.73; Oculus, Wetzlar, Germany) or Visante Optical Coherence Tomography (OCT; Model 1000 with software version 2.0; Carl Zeiss Meditec, Dublin, CA.

Preoperatively, a lens simulation was performed with the Visante OCT or Pentacam using the implemented programmes available in both devices. Three months postoperatively, the actual lens position was measured with the same devices. Preoperative and postoperative distances from the $\mathrm{plOL}$ to the endothelium and crystalline lens were measured and compared for both devices.

\section{Lens Power Calculation}

The power calculation of the Artiflex Toric plOL was performed by Ophtec BV Groningen, The Netherlands, using the Van der Heijde formula. ${ }^{14}$ This formula uses the corneal curvature, adjusted ACD (ACD - 0.9), and the patient's subjective refraction to calculate the spherical and cylindrical power of the pIOL. Calculations were performed for 2 cylinder axes perpendicular to each other.

\section{Surgical Procedure}

All surgeons had at least 1 year of experience with implantation of Artiflex Myopia pIOLs and Artisan Toric plOLs. There were some minor differences in surgical approach between the 7 surgeons involved in the study. Preoperatively, one surgeon marked the enclavation spots on the iris with an argon laser in $20.9 \%$ of cases $(n=24)$. Furthermore, in $49.6 \%(n=57)$ limbal reference marks were placed using a special surgical marker with the patient sitting in an upright position to correct for cyclotorsion. Intraoperatively, the actual implantation axis was marked using a toric axis marker. Alternatively, two surgeons used digital photography in $27.8 \%$ of cases $(n=32)$, using the iris structures (e.g. crypts, pigment, vessels) as a natural marker for lens enclavation. Miotic eye drops (pilocarpine $1 \%$ or $2 \%$ ) were administered to prepare the iris for lens fixation and reduce the risk of lens touch during surgery.

For implantation of the Artiflex Toric pIOL a $3.2 \mathrm{~mm}$ (range 3.0 to $3.4 \mathrm{~mm}$ ) primary incision was made at the 12 o'clock position in $85.8 \%$ of eyes. Furthermore, two $1.2 \mathrm{~mm}$ paracenteses were made at 2 and 10 o'clock for access of instruments to fixate the lens in the mid-peripheral iris stroma. For some surgeons $(9.2 \%)$ the site of the approach depended on the predetermined location of implantation and cylindrical axis. The surgeons used several incision types: clear corneal incision in $13.0 \%$ of eyes, limbal incision in $84.3 \%$ of eyes, and corneoscleral incision in $0.9 \%$ of eyes.

After intracameral injection of a miotic agent and the insertion of a cohesive viscoelastic substance, the Artiflex Toric lens was inserted with a specially designed 
spatula (Ophtec BV, Groningen, The Netherlands). The lens was fixated using a disposable enclavation needle (Ophtec BV, Groningen, The Netherlands), aligning the haptics on the cylindrical axis (or perpendicular to the axis, depending on the lens used) according to the alignment marks on the cornea. In $73.9 \%$ of the cases an iridectomy was performed at 12 o'clock during surgery to avoid pupillary block glaucoma. Two surgeons (11.3\% of eyes) always made an iridotomy during the procedure and another surgeon (13.0\% of cases) performed the iridotomy preoperatively using a YAG-laser. At the end of the procedure, the viscoelastic substance was exchanged for balanced salt solution (Alcon, Fort Worth, Texas). Safety sutures were placed depending on the preference of the surgeon. One surgeon injected Cefuroxime (Zinacef, GlaxoSmithKline, Brentford, UK) into the anterior chamber at the end of the procedure. Postoperatively, a steroid/antibiotic combination was used for at least 3 weeks.

\section{Vector analysis of refractive astigmatism}

Preoperative and postoperative astigmatism were evaluated using the vector analysis according to Alpins. ${ }^{15}$ We calculated refractive astigmatism to the corneal plane by adjusting for a back vertex distance of $12 \mathrm{~mm}$. Individual magnitude (D) and axis values were transformed into rectangular $x$ and $y$ coordinates and used to calculate the following vectors: target induced astigmatism (TIA) which represents the change (in magnitude and axis) that the toric pIOL was intended to induce; surgically induced astigmatism (SIA) which is the astigmatic change the surgery actually induced; difference vector (DV) which represents the vector that enables the achieved astigmatic outcome to achieve the intended astigmatic outcome (this is an absolute measure of success and is preferably zero); magnitude of error (ME) which is defined as the arithmetic difference between the magnitudes of the SIA and TIA (positive for overcorrection and negative for under correction); angle of error (AE) which is the angle between the SIA vector and TIA vector (positive if the achieved correction is counter-clockwise to the intended axis and negative if the achieved correction is clock-wise to the intended axis); flattening effect (FE) which is the amount of astigmatism reduction achieved at the intended meridian of treatment (TIA meridian); flattening index which is calculated by dividing the FE by the TIA and is preferably 1.0; correction index which is calculated by the ratio of the magnitude of SIA to the magnitude of TIA (preferably 1.0; > 1.0 with overcorrection; < 1.0 with undercorrection); index of success which is calculated by dividing DV by TIA (relative measure of success and is preferably zero). Furthermore, overall mean magnitude of residual astigmatism and the residual astigmatism at the meridian of treatment were calculated. ${ }^{16}$ 


\section{Statistical Analysis}

All data were collected on standardized case-record forms and then entered in a Microsoft Access 2003 database, which were exported to Microsoft Excel (Microsoft Office Excel 2003) and SPSS (SPSS for Windows, version 15.0, SPSS Inc, Chicago, IL) for statistical analysis. Continuous variables were described as mean \pm standard deviation (SD). Snellen visual acuities were converted to logarithm of the minimum angle of resolution ( $\log M A R)$ values for statistical analysis. Pair wise comparisons were used to evaluate the results over time. To compare differences between groups, independent sample t-tests or one-way ANOVA analyses were applied. Preoperative and postoperative astigmatism were evaluated using vector analysis according to Alpins. ${ }^{15}$ Postoperative changes in astigmatism vectors were analyzed using a repeated measures analysis of variance (ANOVA). Preoperative simulated lens position was compared to actual postoperative lens position with anterior segment imaging (Visante OCT and Pentacam device) using paired t-tests. A $P$-value $<0.05$ was considered statistically significant.

Sphere (D)

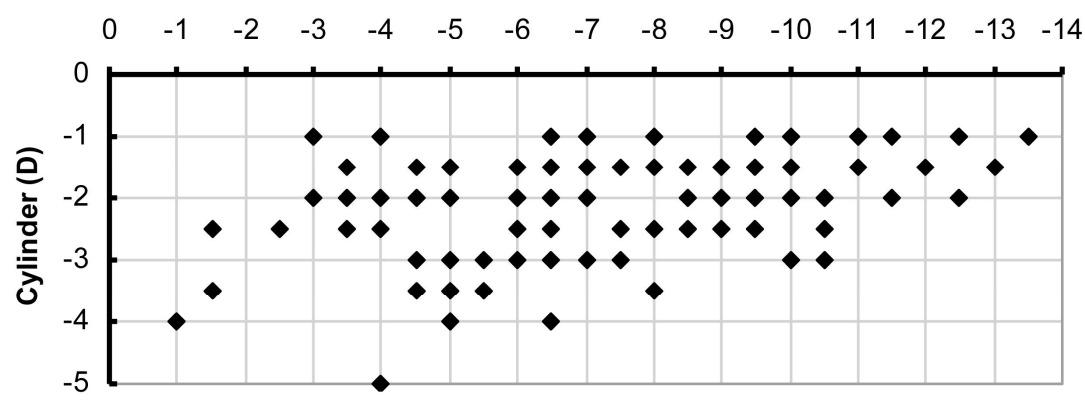

Figure 3. Distribution of Artiflex Toric phakic intraocular lenses (Ophtec BV, Groningen, The Netherlands) implanted in this study, with sphere in diopters (D) on x-axis and cylinder in D on y-axis.

\section{RESULTS}

Mean age of the included patients was $37.7 \pm 8.0$ years (range 20 to 60 years). Sixtyseven $(37.1 \%)$ of lenses were implanted in female eyes. Left $(47.8 \%)$ and right eyes were equally implanted. Mean preoperative spherical equivalent (SE) was $-7.53 \pm$ 2.70 D, with a mean absolute cylinder of $-2.18 \pm 0.79 \mathrm{D}$ (range -0.75 to $-4.50 \mathrm{D}$ ). Mean ACD was $3.65 \pm 0.25 \mathrm{~mm}$ (range 3.20 to $4.28 \mathrm{~mm}$ ), and the mean axial length was $26.20 \pm 1.24 \mathrm{~mm}$ (range 23.53 to $29.32 \mathrm{~mm}$ ). Mean scotopic pupil size was 5.70 
$\pm 0.97 \mathrm{~mm}$. Figure 3 shows the lens power distribution of the implanted Artiflex Toric pIOLs.

\section{Short-term Safety}

The mean preoperative BSCVA was $0.03 \pm 0.09 \log$ MAR. After 1,3 and 6 months, the mean postoperative BSCVA was $-0.01 \pm 010,-0.01 \pm 0.08$, and $-0.02 \pm 0.09 \log M A R$, respectively. Ninety-nine percent (99.1\%), $100.0 \%$ and $100.0 \%$ of eyes had a BSCVA of 20/40 or better at 1,3 , and 6 months postoperatively, respectively. Furthermore, the safety indices (ratio of mean postoperative BSCVA to mean preoperative BSCVA) at these three follow-up visits were $1.12,1.13$, and 1.13, respectively. $95.1 \%, 83.3 \%$, and $40.2 \%$ of eyes had a BSCVA of 20/25, 20/20, and 20/16 or better, respectively, 6 months after plOL implantation. In $90.5 \%, 94.0 \%$, and $92.2 \%$ of eyes, there was no change or an improvement in Snellen lines at 1, 3, and 6 months postoperatively compared to preoperative BSCVA, respectively (Figure 4). At 6 months postoperatively, $2.0 \%(n=2)$ lost 2 lines of Snellen BSCVA.

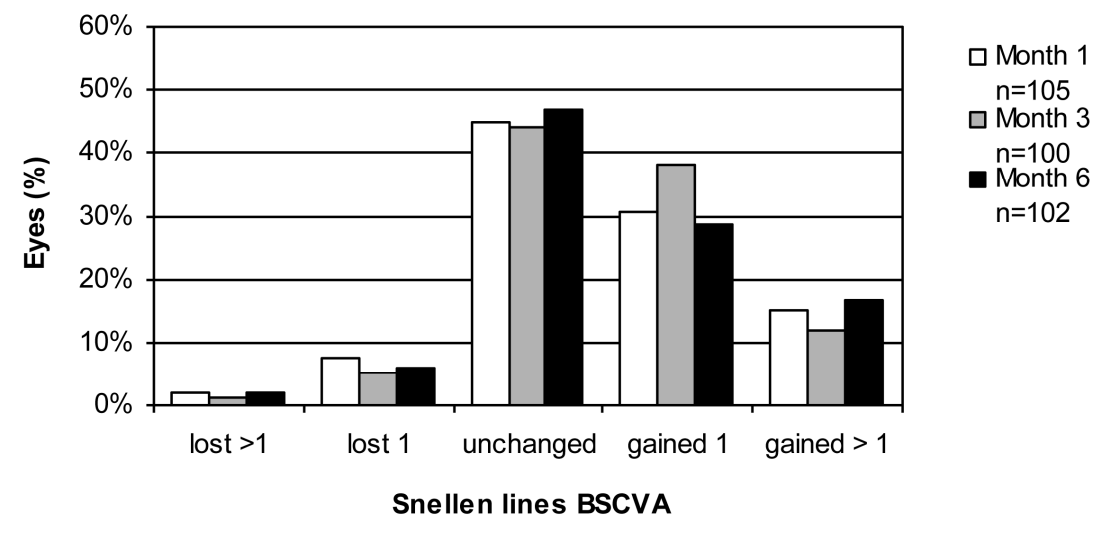

Figure 4. Bar graph demonstrating the number of lost and gained Snellen lines of best spectaclecorrected visual acuity (BSCVA) 1, 3 and 6 months after Artiflex Toric phakic intraocular lens implantation (Ophtec BV, Groningen, The Netherlands).

\section{Short-term Efficacy}

At 1,3 , and 6 months postoperatively the UCVA was $0.05 \pm 0.14,0.03 \pm 0.12$, and $0.02 \pm 0.10 \operatorname{logMAR}$, respectively. The efficacy index (mean postoperative UCVA / mean preoperative BSCVA) was $0.99,1.02$, and 1.04 at 1,3 , and 6 months after Artiflex Toric plOL implantation, respectively. UCVA was $20 / 40$ or better in $97.1 \%$ $(n=102), 99.0 \%(n=98)$, and $99.0 \%(n=101)$ of the cases at 1,3 , and 6 months postoperatively, respectively. $90.2 \%, 65.7 \%$ and $29.4 \%$ of eyes had a UCVA of $20 / 25$, 
20/20, and 20/16 or better respectively, 6 months after pIOL implantation. The postoperative UCVA was equal to or better than preoperative BSCVA in $66.7 \%$, $76.7 \%$, and $74.5 \%$ of eyes at 1,3 , and 6 months after plOL implantation, respectively. Postoperative UCVA for all follow-up visits are visualized in Figure 5.

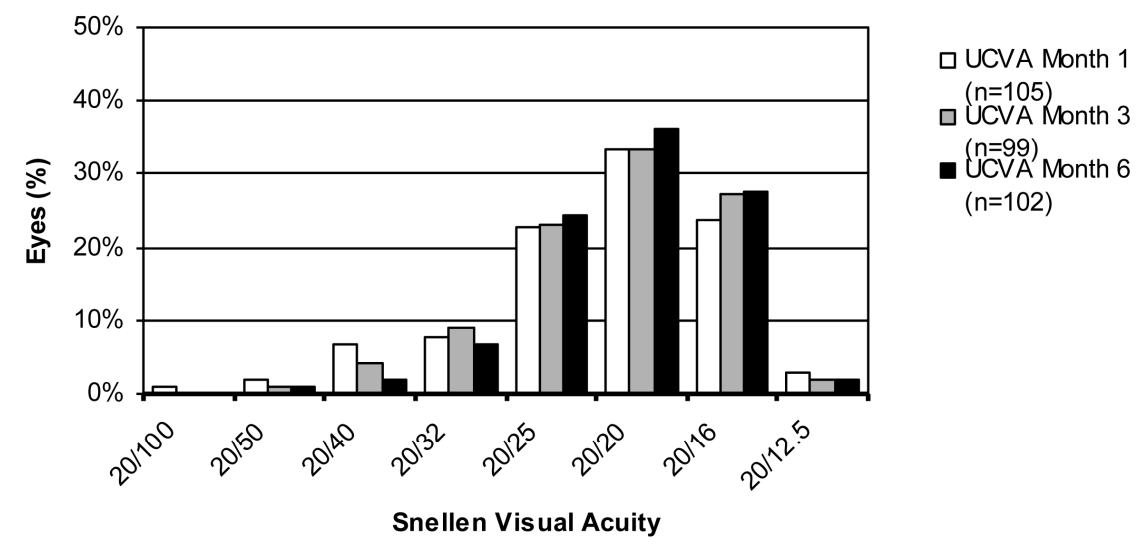

Figure 5. Bar graph showing the uncorrected visual acuity (UCVA) at 1, 3, and 6 months after Artiflex Toric phakic intraocular lens implantation (Ophtec BV, Groningen, The Netherlands).

\section{Predictability}

The intended versus achieved correction at 6 months of follow-up is presented in Figure 6 . After 6 months, $81.8 \%$ of eyes were within $\pm 0.5 \mathrm{D}$ and $99.0 \%$ of eyes within $\pm 1.0 \mathrm{D}$ from the intended refraction. All eyes were within $\pm 1.1 \mathrm{D}$ of the intended correction 6 months after plOL implantation.

The absolute refractive cylinder was reduced from $2.20 \pm 0.84 \mathrm{D}$ (range 0.75 to $4.50 \mathrm{D}$ ) preoperatively to $0.38 \pm 0.41 \mathrm{D}$ (range 0.00 to $2.00 \mathrm{D}$ ) at 6 months postoperatively. In $75.5 \%$ of eyes, the remaining cylinder was $0.50 \mathrm{D}$ or less and in $96.0 \%$ it was $1.00 \mathrm{D}$ or less.

\section{Stability}

The change in SE from 1 day to 6 months postoperatively was not statistically significant, with a mean SE of $-0.05 \pm 0.45 \mathrm{D}$ after 1 day and $-0.06 \pm 0.31 \mathrm{D}$ after 6 months $(P>0.05)$. Stability of the absolute cylinder values are demonstrated in Figure 7 , with no significant changes between 1 day and 6 months after implantation ( $P>0.05)$. At 1,3 , and 6 months postoperatively, $86.7 \%, 88.8 \%$, and $93.0 \%$ of eyes had a SE within $\pm 0.5 \mathrm{D}$ from emmetropia and $98.1 \%, 94.9 \%$, and $100.0 \%$ were within $\pm 1.0 \mathrm{D}$ from emmetropia, respectively. There were no significant changes in BSCVA be- 
tween the postoperative follow-up visits, indicating a stable visual acuity after Artiflex Toric implantation ( $P>0.05$ ). UCVA improved from 1 day postoperatively to 3 and 6 months after pIOL implantation $(P<0.05)$.

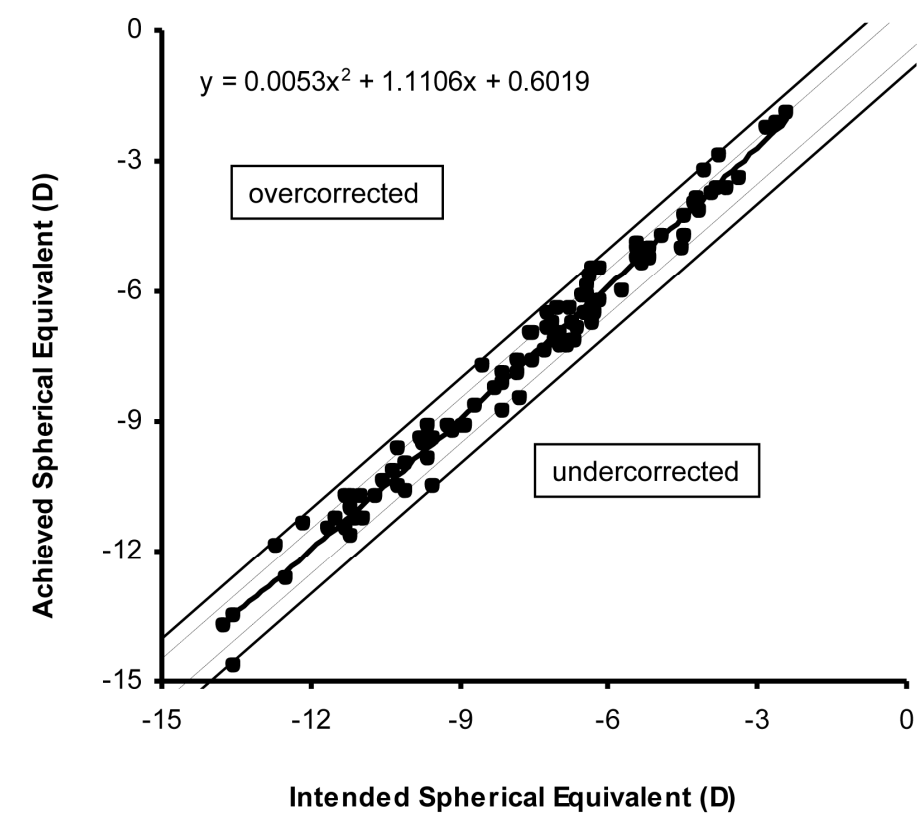

Figure 6. Scatterplot showing the spread of achieved versus intended correction in spherical equivalent 6 months after Artiflex Toric phakic intraocular lens implantation ( $n=99$ ) (Ophtec BV, Groningen, The Netherlands). The dotted diagonal lines show overcorrection and undercorrection by 0.5 diopter (D) and the straight lines by 1 diopter; $99 \%$ were within $1 \mathrm{D}$ of the desired refraction.

Mean preoperative corneal astigmatism of $2.15 \pm 0.70 \mathrm{D}$ was significantly reduced to $1.78 \pm 0.61 \mathrm{D}$ at 6 months postoperatively $(P<0.05)$. There was no significant difference in surgically induced astigmatism between the clear corneal and the limbal incisions $(P>0.05)$. The effect of the corneoscleral incision could not be compared to the other incision types, since it was only used in 1 eye.

Table 1 shows the results of the Alpins vector analysis based on preoperative and postoperative refractive astigmatism. Figure 8 demonstrates preoperative refractive astigmatism and achieved refractive astigmatism at 6 months postoperatively. The difference vector at 6 months was significantly lower when compared to 1 week postoperatively $(P=0.048)$. All other calculated vectors were not significantly different in the repeated measures ANOVA between all follow-up visits (all with $\mathrm{P}>0.05$ ). 


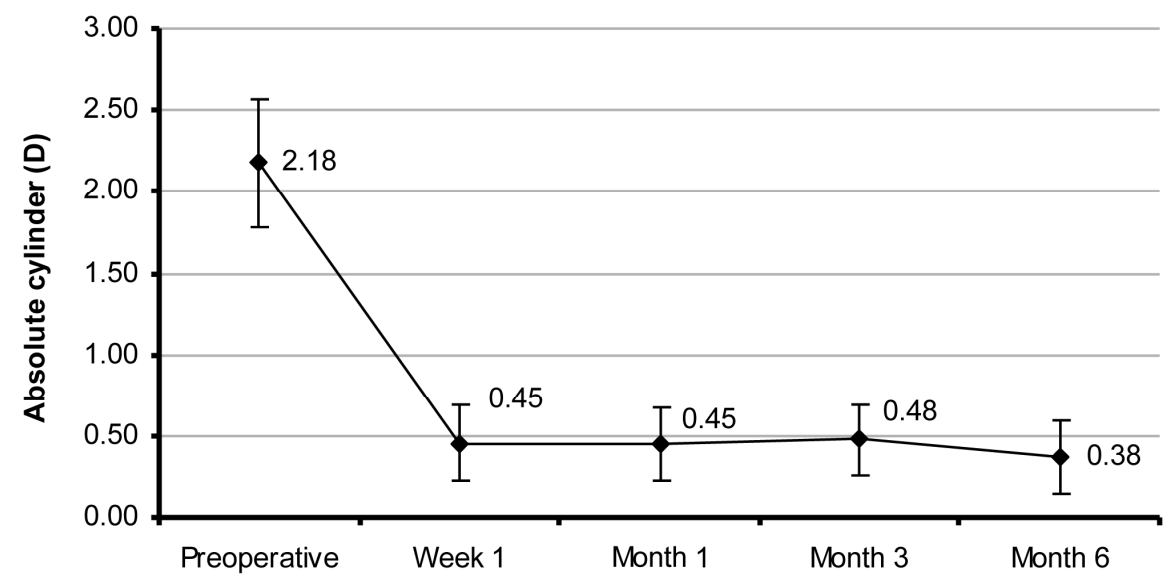

Figure 7. Graph demonstrating stability of absolute cylinder values before and after Artiflex Toric phakic intraocular lens implantation (Ophtec BV, Groningen, The Netherlands). Mean standard deviations of absolute cylinder values in diopters (D) are demonstrated.

Table 1. Refractive astigmatism outcomes at 1 week and 6 months postoperatively in patients who received an Artiflex Toric pIOL $(n=106)$

\begin{tabular}{|c|c|c|c|}
\hline Follow-up visit & 1 week & 6 months & P-value* \\
\hline TIA Vector mean (D @ ) & $1.43 @ 90$ & $1.43 @ 90$ & NA \\
\hline SIA (D @ ) & $1.55 @ 91$ & $1.55 @ 90$ & 0.440 \\
\hline Difference vector (D @ ) & $0.14 @ 14$ & $0.12 @ 5$ & 0.048 \\
\hline Magnitude of error (D) & $0.20 \pm 0.40$ & $0.16 \pm 0.36$ & 0.440 \\
\hline Angle of error $\left({ }^{\circ} \pm S D\right)$ & $1 \pm 13$ & $1 \pm 13$ & 1.000 \\
\hline Flattening effect (D) & $1.86 \pm 0.78$ & $1.82 \pm 0.80$ & 0.621 \\
\hline Flattening index & 1.01 & 0.97 & 0.347 \\
\hline Correction index & 1.12 & 1.08 & 0.267 \\
\hline Index of success & 0.27 & 0.19 & 0.066 \\
\hline \multicolumn{4}{|l|}{ Residual astigmatism } \\
\hline Overall mean (D) & $0.34 \pm 0.30$ & $0.30 \pm 0.30$ & 1.000 \\
\hline
\end{tabular}

\section{Endothelial Cell Counts}

Mean preoperative ECD count was $2805 \pm 363$ cells $/ \mathrm{mm}^{2}$. At 3 and 6 months postoperatively mean ECD count was $2670 \pm 43$ cells $/ \mathrm{mm}^{2}$ and $2676 \pm 362$ cells $/ \mathrm{mm}^{2}$, respectively. There was a significant decrease in ECD after 3 and 6 months of followup, with mean decreases of $4.8 \pm 11.9 \%$ and $4.3 \pm 11.5 \%$, respectively (both with $P<0.001)$. There was no significant difference in ECD between 3 and 6 months postoperatively $(P>0.05)$. 


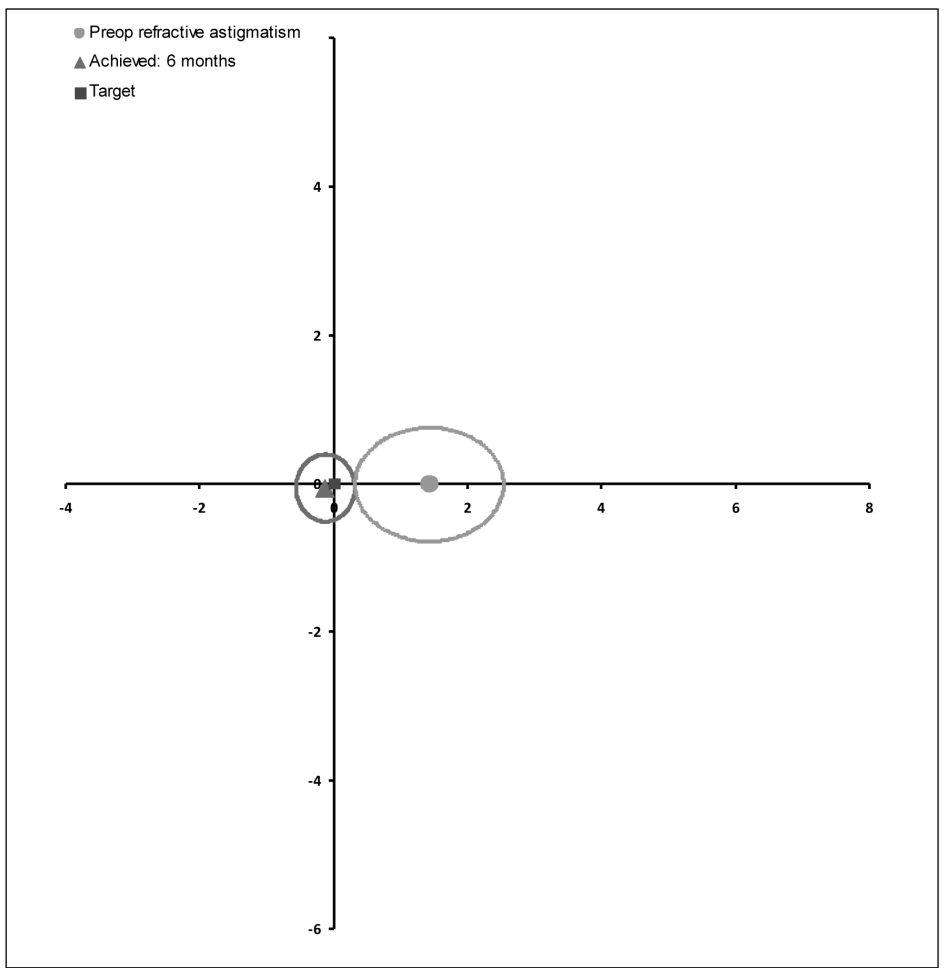

Figure 8. Mean preoperative refractive astigmatism before Artiflex Toric phakic intraocular lens implantation and mean achieved refractive astigmatism at 6 months postoperatively $(n=106)$.

\section{Anterior Segment Imaging}

In a subgroup of patients, anterior segment imaging was performed using rotational Scheimpflug imaging or anterior segment OCT. The position of the Artiflex Toric pIOL was simulated using the pIOL simulation programmes available in both devices for preoperative measurements. The distances from the center and edges of the pIOL to the corneal endothelium and the distance from the back of the pIOL to the crystalline lens were measured preoperatively (in the simulation model) and 3 months postoperatively (Table 2 and 3). A total of 53 eyes were measured using Visante OCT before and after Artiflex Toric pIOL implantation. There were no significant differences between the preoperative simulated distances from the pIOL to the endothelium when compared to the actual postoperative measurements (all with $\mathrm{P}>0.385)$. Furthermore, 26 eyes were measured using the Pentacam device before and after Artiflex Toric pIOL implantation, which also showed no significant differences between the preoperative simulated distances from the pIOL to the endothelium when compared to the actual postoperative measurements (all with $P>0.142$ ). Postoperative distances measured from the $\mathrm{pIOL}$ to the crystalline lens were signifi- 
cantly smaller in the postoperative situation when compared to the simulated distances for measurements using Visante OCT and Pentacam (both with $\mathrm{P}<0.001$ ).

Table 2. Optical coherence tomography measurements before (simulation) and after Artiflex Toric phakic intraocular lens implantation $(n=53)$

\begin{tabular}{lccc}
\hline Variable & $\begin{array}{c}\text { Preoperative Simu- } \\
\text { lation Mean }( \pm \mathrm{SD})\end{array}$ & $\begin{array}{c}\text { Postoperative } \\
\text { Mean } \pm \text { SD) }\end{array}$ & $\begin{array}{c}\text { Paired t-test } \\
\text { P-value }\end{array}$ \\
\hline Distance plOL to endothelium: & $2.09 \pm 0.40$ & $2.05 \pm 0.23$ & 0.386 \\
Center (mm) & $1.43 \pm 0.23$ & $1.41 \pm 0.21$ & 0.504 \\
Periphery (mm) & $0.72 \pm 0.17$ & $0.62 \pm 0.10$ & $<0.001$ \\
Distance plOL to crystalline lens (mm) & &
\end{tabular}

$\mathrm{SD}=$ standard deviation; $\mathrm{plOL}=$ phakic intraocular lens

Table 3. Pentacam measurements before (simulation) and after Artiflex Toric phakic intraocular lens implantation $(n=26)$

\begin{tabular}{lccc}
\hline Variable & $\begin{array}{c}\text { Preoperative Simu- } \\
\text { lation Mean }( \pm \text { SD) }\end{array}$ & $\begin{array}{c}\text { Postoperative } \\
\text { Mean } \pm \text { SD) }\end{array}$ & $\begin{array}{c}\text { Paired t-test } \\
\text { P-value }\end{array}$ \\
\hline Distance plOL to endothelium: & $2.04 \pm 0.35$ & $2.08 \pm 0.25$ & 0.425 \\
Center (mm) & $1.40 \pm 0.29$ & $1.49 \pm 0.21$ & 0.143 \\
Periphery (mm) & $0.87 \pm 0.16$ & $0.69 \pm 0.12$ & $<0.001$ \\
\hline Distance plOL to crystalline lens $(\mathrm{mm})$ & &
\end{tabular}

$\mathrm{SD}=$ standard deviation; $\mathrm{plOL}=$ phakic intraocular lens

\section{Misalignment of Cylinder Axis}

In a total of 82 eyes misalignment of the Artiflex Toric pIOL was measured using the slit-lamp (with the protractor installed on the slit lamp) at 3 months postoperatively. This method ensures a good head position in the chin and head rest. Mean misalignment was $0.6 \pm 1.5$ degrees (range 0-8 degrees), with a maximum counter clockwise misalignment of 8 degrees and a clockwise misalignment of 5 degrees. Eighty percent $(n=66)$ of eyes presented with a misalignment below 1 degree, $18.3 \%$ $(n=15)$ were between 1 and 5 degrees, and 1.2\% $(n=1)$ presented with a misalignment above 5 degrees.

\section{Complications and Secondary Interventions}

Mean preoperative IOP was $15.0 \pm 2.5 \mathrm{mmHg}$. There was a significant rise in IOP at 1 week and 1 month postoperatively $(P<0.001$ and $P=0.023$, respectively), which dropped back to preoperative levels at 3 months postoperatively and remained stable up to 6 months postoperatively (both with $P>0.05$; Figure 9).

There were no serious intraoperative complications. During the course of the study there were no reports of iris prolapse, iris atrophy, touch of the anterior lens 
capsule, persistent corneal edema, pupillary block, cataract formation, retinal detachment, or endophthalmitis. Mild to moderate glare complaints were reported in 8 eyes $(7.0 \%)$ at 6 months of follow-up, with the highest incidence of glare at 1 month postoperatively (13.9\%). Mild halo complaints were reported by $11.3 \%$ (13 eyes) of the patients 1 month after plOL implantation, which reduced to $4.3 \%$ (5 eyes) at 6 months postoperatively.

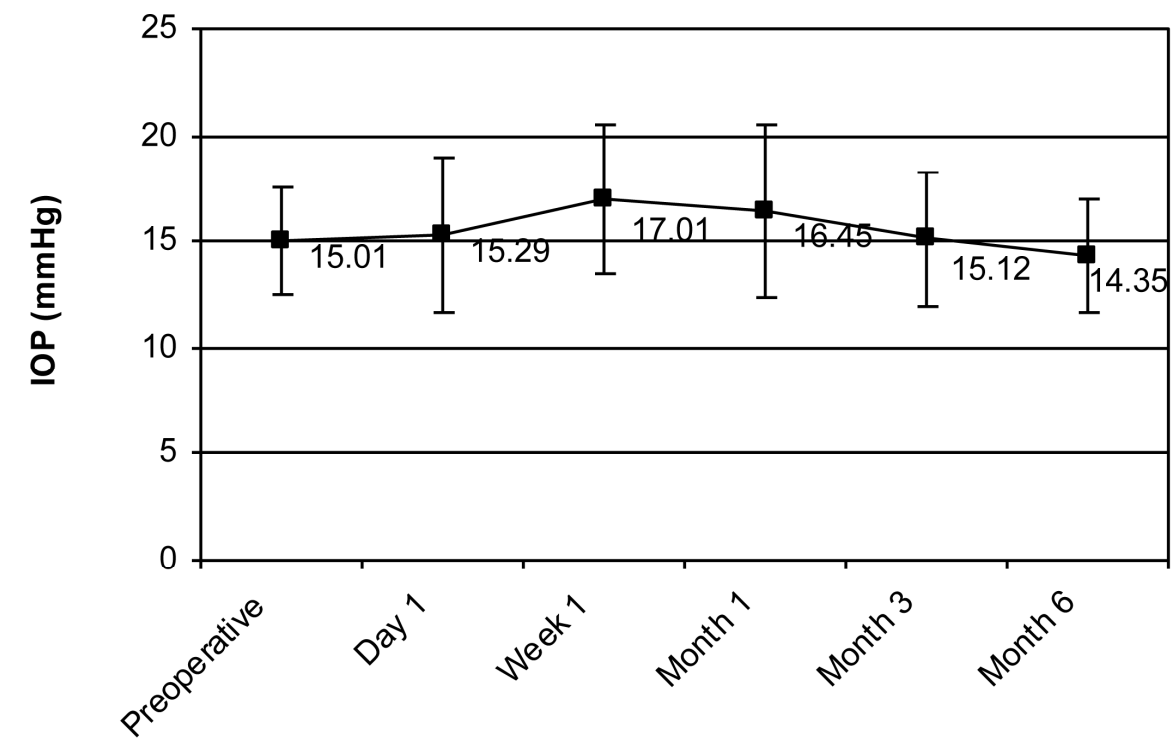

Figure 9. Graph demonstrating intraocular pressure (IOP) before and after implantation of the Artiflex Toric phakic intraocular lens (Ophtec BV, Groningen, The Netherlands). Mean standard deviations of intraocular pressure $(\mathrm{mmHg})$ are demonstrated.

Pigment precipitates were documented in 17 eyes (14.8\%) of 13 patients. These precipitates were found on the haptics and/or on the optic of the pIOL. The pigment precipitates were mild in 14 eyes, moderate in 2 eyes, and severe in 1 eye. Six out of these 17 eyes (35\%) had received a YAG-laser iridotomy. Non-pigment precipitates were reported in 14 eyes (12.2\%) of 8 patients and were described as giant cells. These giant cell precipitates were documented as mild in 11 eyes, moderate in 3 eyes, and severe in none of the investigated eyes. Patients with precipitates had a significantly lower UCVA 6 months after implantation when compared to patients without precipitates $(P=0.015)$. However, there was no significant difference in BSCVA between patient with or without precipitates $(P>0.05)$. A dark iris color was not associated with the occurrence of pigment or non-pigment precipitates ( $P=0.355$ and $P=0.421$, respectively). Overall, none of the patients requested pIOL explantation or exchange. 
Two patients, who were implanted with a Artiflex Toric pIOL in both eyes, developed posterior synechiae at 1 and 6 months postoperatively in both eyes and 1 patient developed posterior synechiae in one eye at 3 months postoperatively. One patient wanted both lenses exchanged for a Toric Artisan pIOL, since the synechiae did not resolve during the course of the study. BSCVA was 20/40 and 20/25 in right and left eyes 6 months after Artiflex Toric plOL implantation, which was a loss of 2 and 0 Snellen lines when compared to preoperative BSCVA, respectively. In the other patient the synechiae disappeared in 1 eye after 6 months of follow-up and remained stable in the other eye, with an UCVA of 20/20 in both eyes. No secondary surgical procedure was planned for this patient. The third patient was lost to followup.

\section{DISCUSSION}

In this multicenter prospective study with a follow-up of 6 months, 115 eyes were implanted with a new foldable iris-fixated toric pIOL (Artiflex Toric) to correct myopia and astigmatism in patients seeking refractive surgery. Due to the foldable silicone optic, the incision size was reduced to a $3.2 \mathrm{~mm}$ incision compared to the 5.3 $\mathrm{mm}$ necessary to implant the rigid Toric Artisan pIOL. The overall design of the Artiflex Toric is based on the Artiflex Myopia, with identical dimensions (optic of 6.0 $\mathrm{mm}$ and overall length of $8.5 \mathrm{~mm}$ ). Even the surgical technique and postoperative medications are comparable, except for the positioning of the plOL. Patient selection is a little different, since the optical power of the Artiflex Toric can not exceed 14.5 D, which is the sum of the spherical and cylindrical power. In the Artiflex Myopia multicenter study, 300 eyes with a follow-up of 2 years were investigated. ${ }^{17}$ This study demonstrated the safety of the Artiflex pIOL, and therefore the long-term safety of the Artiflex Toric was not the main objective of the current investigation.

This 6-months experience with the Artiflex Toric showed excellent uncorrected and best-corrected visual results for distance, which demonstrates the short term safety, efficacy, predictability and stability of this lens to correct myopia and astigmatism. At 6 months postoperatively, $99.0 \%$ of eyes were within $\pm 1.00 \mathrm{D}$ of the intended correction, and $81.8 \%$ of eyes were within $\pm 0.50 \mathrm{D}$, which is in accordance with other reported investigations. ${ }^{11,17,18}$

The vector analysis calculated a small residual astigmatism of $0.34 \mathrm{D}$ at 1 week postoperatively, which remained stable up to 6 months after surgery, showing the advantage of the small incision size. Only the DV declined significantly during the course of the study. However, these differences were very small (from 0.14 to 0.12 D) which is, in our opinion, not clinically relevant.

Concerning the short term efficacy of the Artiflex Toric, the postoperative UCVA was comparable to the preoperative BSCVA and the efficacy indices were close to or 
above 1.0 for all follow-up visits, indicating that the myopia and astigmatism were efficiently reduced. UCVA was equal to preoperative BCVA or improved in $74.5 \%$ of eyes at 6 months of follow-up, which may be caused by the increased size of the retinal image. ${ }^{19}$ Besides an adequate short term efficacy, the Artiflex Toric plOL demonstrated to be stable and predictable, with a stable postoperative SE and $93.0 \%$ of eyes within $0.5 \mathrm{D}$ from emmetropia at 6 months postoperatively. These results are similar to the result from the earlier multicenter study investigating the Artiflex Myopia plOL. ${ }^{17}$ Furthermore, the safety indices were above 1.0 at all followup visits, demonstrating the good short term safety profile of this pIOL.

One of the mentioned concerns of iris-fixated pIOLs is an ongoing ECD loss after implantation, and this topic has led to many discussions. Bourne et al. demonstrated that there is a natural yearly endothelial cell loss of $0.6 \pm 0.5 \%{ }^{20}$ Iris-fixated pIOLs potentially cause an additional ECD loss since an intermittent contact between the plOL and the corneal endothelium has been suggested. A recent study found that a shorter distance from the edge of the iris-fixated plOL was associated with higher ECD loss. ${ }^{21}$ During the preoperative selection process, it is of major importance to take preoperative ECD, patient age, configuration of the iris, and ACD into account in order to maintain a safe distance from the pIOL to the corneal endothelium and crystalline lens with increasing patient age. Furthermore, it is important to inform all patients that rubbing the eye is potentially harmful to the cornea. Considering this criterion, it might be better not to treat patients with severe atopic complaints.

In the current study a significant ECD loss of $4.8 \%$ was found 3 months after plOL implantation. However, at 6 months postoperatively there was no significant additional loss of ECD, which indicates that the ECD loss at 3 months is related to the surgery. We presume that this plOL will not behave differently than the Artisan and Artiflex pIOLs, which are already on the market and have acceptable long-term ECD loss data. ${ }^{7,9}$ However, there are studies which do demonstrate an additional ECD loss over time, with yearly losses ranging from $1.0 \%$ to $3.3 \%{ }^{10,22-26}$ Longer follow-up will be necessary to fully support the assumption that no additional endothelial cells will be lost due to this pIOL over time. Furthermore, we included both eyes of a large number of patients (62.5\%), which can cause bias in the statistical analysis. Since this is a multicenter trial, several different specular microscopes were used to count ECD, which is also a limitation of this study. To increase the validity of the presented results, this study should be repeated in a second study population.

To ensure an excellent visual outcome, the plOL should be implanted in the correct cylinder axis. In this study, $80 \%$ of eyes presented with a misalignment below 1 degree. Only 1 eye presented with a misalignment above 5 degrees, which can be visually significant. The unique enclavation technique using the iris-claw principle, makes it almost impossible for the Artiflex Toric to rotate off axis. Preoperative marking in the upright position eliminates cyclotorsion as a potential cause of wrong-axis im- 
plantation. In the future, new intraoperative marking techniques, for example iris tracking devices which show the correct axis through the operating microscope, might be able to reduce misalignment even further.

One week postoperatively, we found a significant increase in IOP, which was reduced to preoperative levels after 1 month of follow-up. This peak was also reported in the multicenter study of the Artiflex Myopia pIOL, and was said to be related to the corticosteroid use, which were subscribed postoperatively. ${ }^{17}$ One other possible cause could be the incomplete removal of viscoelastics at the end of the surgical procedure. Since the IOP returned to normal preoperative levels after 1 month, we do not consider this temporary rise as a potential negative effect, and it does not compromise the short term safety of the pIOL.

Similar to the Artiflex Myopia study, ${ }^{17}$ we also detected a peak in non-pigment precipitates (12.2\% of eyes) 3 months after plOL implantation, which remained $12.2 \%$ at 6 months postoperatively. Besides non-pigment precipitates, there were also reports of pigment precipitates from 1 week to 6 months postoperatively. Although pigment and non-pigment precipitates have been reported on Artisan pIOLs, it seems that the incidence is higher in the Artiflex pIOLs. In a case report by Tahzib et al. cell and pigment deposits were clearly visualized by scanning electron microscopy on the back of the pIOL and the optic-haptic junction. ${ }^{27}$ The precipitates did not significantly influence BSCVA and none of the patients requested pIOL explantation. To limit these precipitates in the future, the investigators of the current study suggest to pay attention to patient selection. Some of the most important patient selection criteria are $A C D \geq 3.2 \mathrm{~mm}$ (measured from epithelium), a flat iris and/or crystalline lens rise $<600$ microns as mentioned by Baikoff et al. ${ }^{28}$, and an open chamber-angle. The latter two criteria should preferably be evaluated using an anterior segment imaging devices, e.g. a high-resolution Scheimpflug camera or optical coherence tomography. Furthermore, subconjunctival steroids at the end of surgery and topical corticosteroids for at least 4 weeks are recommended. Finally, future research could evaluate whether a different iridectomy technique, for example the previously described pigment vacuum iridectomy, can decrease the incidence of pigment precipitates in the future..$^{29}$ Data in our study suggest that preoperative laser iridotomy might increase the risk of pigment precipitates, since only 15 eyes received this laser treatment and 6 eyes developed precipitates.

During the course of the study, 5 eyes of 3 patients presented with posterior synechiae after Artiflex Toric pIOL implantation. This problem has previously been described by Koss et al., presenting an 45 year old female with unilateral Artiflex (type I) implantation who developed pigment dispersion and posterior synechiae at 1 month postoperatively. ${ }^{30}$ However, this Artiflex I is an older lens type with a vault between the optic-haptic junction and the iris plane of $0.13 \mathrm{~mm}$. The marketed Artiflex Myopia and Artiflex Toric plOL have a vault of $0.20 \mathrm{~mm}$, leaving more space 
between the back of the pIOL and the iris tissue. The cause of these synechiae formations remains unknown.

Glare and halo complaints are somewhat higher in this study than previously reported in studies investigating the Artisan plOL., 11, 19, 22 Although the comparative study by Coullet et al. found no significant difference in glare and halo complaints between the Artisan and Artiflex plOL. ${ }^{13}$ In the current study, the overall patient satisfaction was high and visual acuity was good. This might imply that the effect of glare and halos was relatively mild. It is not likely that the cylindrical optic causes the glare and halo complaints, since only 1 patient reported persistent glare in the Toric Artisan multicenter study. ${ }^{11}$ However, a longer follow-up will be needed to evaluate the course of these complaints over time.

The comparison of the Visante OCT and Pentacam measurement before and after Artiflex Toric plOL implantation are similar to previously published studies involving the Artiflex plOL. ${ }^{28-30}$ The study by Doors et al. also found smaller postoperative distances from the pIOL to the crystalline lens measured by Visante OCT. The calculated difference in this study was only $0.1 \mathrm{~mm}$, which is not clinically relevant in our opinion. The most important distance is the shortest distance from the edge of the $\mathrm{pIOL}$ to the endothelium, which can be simulated quite accurately, with no significant differences between the preoperative and postoperative values for both the Pentacam and Visante OCT measurements.

In conclusion, this study demonstrates that the Artiflex Toric effectively and safely corrects myopia and astigmatism on the short term, with stable and predictable visual results. Strict inclusion criteria, correct surgical technique according to the manufacturer's specifications, and accurate postoperative examinations are required to achieve these results. This lens can perfectly compete against the Toric Artisan pIOL, with the great benefit of the Artiflex Toric needing a smaller incision resulting in a faster visual recovery for the patient. 


\section{REFERENCES}

1. Alpins N, Stamatelatos G. Clinical outcomes of laser in situ keratomileusis using combined topography and refractive wavefront treatments for myopic astigmatism. J Cataract Refract Surg 2008;34(8):1250-1259.

2. O'Connor J, O'Keeffe M, Condon PI. Twelve-year follow-up of photorefractive keratectomy for low to moderate myopia. J Refract Surg 2006;22(9):871-877.

3. Binder PS. Analysis of ectasia after laser in situ keratomileusis: risk factors. J Cataract Refract Surg 2007;33(9):1530-8.

4. Ruiz-Mesa R, Carrasco-Sanchez D, Diaz-Alvarez SB, Ruiz-Mateos MA, Ferrer-Blasco T, Montes-Mico R. Refractive lens exchange with foldable toric intraocular lens. Am J Ophthalmol 2009;147(6):990-996.

5. Barsam A, Allan BD. Excimer laser refractive surgery versus phakic intraocular lenses for the correction of moderate to high myopia. Cochrane Database Syst Rev;5:CD007679.

6. El Danasoury MA, El Maghraby A, Gamali TO. Comparison of iris-fixed Artisan lens implantation with excimer laser in situ keratomileusis in correcting myopia between -9.00 and -19.50 diopters: a randomized study. Ophthalmology 2002;109(5):955-964.

7. Tahzib NG, Nuijts RM, Wu WY, Budo CJ. Long-term study of Artisan phakic intraocular lens implantation for the correction of moderate to high myopia: ten-year follow-up results. Ophthalmology 2007;114(6):1133-1142

8. Maloney RK, Nguyen LH, John ME. Artisan phakic intraocular lens for myopia:short-term results of a prospective, multicenter study. Ophthalmology 2002;109(9):1631-1641.

9. Pop M, Payette Y. Initial results of endothelial cell counts after Artisan lens for phakic eyes: an evaluation of the United States Food and Drug Administration Ophtec Study. Ophthalmology 2004;111(2):309-317.

10. Stulting RD, John ME, Maloney RK, Assil KK, Arrowsmith PN, Thompson VM. Three-year results of Artisan/Verisyse phakic intraocular lens implantation. Results of the United States Food And Drug Administration clinical trial. Ophthalmology 2008;115(3):464-472.

11. Dick HB, Alio J, Bianchetti M, et al. Toric phakic intraocular lens: European multicenter study. Ophthalmology 2003;110(1):150-162.

12. Kohnen T, Cichocki M, Koss MJ. Position of rigid and foldable iris-fixated myopic phakic intraocular lenses evaluated by Scheimpflug photography. J Cataract Refract Surg 2008;34(1):114-120.

13. Coullet J, Guell JL, Fournie P, et al. Iris-supported phakic lenses (rigid vs foldable version) for treating moderately high myopia: randomized paired eye comparison. Am J Ophthalmol 2006;142(6):909916.

14. van der Heijde GL, Fechner PU, Worst JG. [Optical consequences of implantation of a negative intraocular lens in myopic patients]. Klin Monatsbl Augenheilkd 1988;193(1):99-102.

15. Alpins N. Astigmatism analysis by the Alpins method. J Cataract Refract Surg 2001;27(1):31-49.

16. Visser N, Berendschot TT, Bauer NJ, Jurich J, Kersting O, Nuijts RM. Accuracy of toric intraocular lens implantation in cataract and refractive surgery. J Cataract Refract Surg 2011;37(8):1394-1402.

17. Dick HB, Budo C, Malecaze F, et al. Foldable Artiflex phakic intraocular lens for the correction of myopia: two-year follow-up results of a prospective European multicenter study. Ophthalmology 2009;116(4):671-677.

18. Tehrani M, Dick HB. Short-term follow-up after implantation of a foldable iris-fixated intraocular lens in phakic eyes. Ophthalmology 2005;112(12):2189-2195.

19. Budo C, Hessloehl JC, Izak M, et al. Multicenter study of the Artisan phakic intraocular lens. J Cataract Refract Surg 2000;26(8):1163-1171.

20. Bourne WM, Nelson LR, Hodge DO. Central corneal endothelial cell changes over a ten-year period. Invest Ophthalmol Vis Sci 1997;38(3):779-782.

21. Doors M, Cals DW, Berendschot TT, et al. Influence of anterior chamber morphometrics on endothelial cell changes after phakic intraocular lens implantation. J Cataract Refract Surg 2008;34(12):21102118. 
22. Moshirfar M, Holz HA, Davis DK. Two-year follow-up of the Artisan/Verisyse iris-supported phakic intraocular lens for the correction of high myopia. J Cataract Refract Surg 2007;33(8):1392-1397.

23. Saxena R, Boekhoorn SS, Mulder PG, Noordzij B, van Rij G, Luyten GP. Long-term follow-up of endothelial cell change after Artisan phakic intraocular lens implantation. Ophthalmology 2008;115(4):608-613.

24. Benedetti S, Casamenti V, Benedetti M. Long-term endothelial changes in phakic eyes after Artisan intraocular lens implantation to correct myopia: five-year study. J Cataract Refract Surg 2007;33(5):784-790.

25. Tehrani M, Dick HB. Endothelial cell loss after toric iris-fixated phakic intraocular lens implantation: three-year follow-up. J Refract Surg 2007;23(2):172-177.

26. Guell JL, Morral M, Gris O, Gaytan J, Sisquella M, Manero F. Five-year follow-up of 399 phakic Artisan-Verisyse implantation for myopia, hyperopia, and/or astigmatism. Ophthalmology 2008;115(6):1002-1012.

27. Tahzib NG, Eggink FA, Frederik PM, Nuijts RM. Recurrent intraocular inflammation after implantation of the Artiflex phakic intraocular lens for the correction of high myopia. J Cataract Refract Surg 2006;32(8):1388-1391.

28. Baikoff G, Bourgeon G, Jodai HJ, Fontaine A, Lellis FV, Trinquet L. Pigment dispersion and Artisan phakic intraocular lenses: crystalline lens rise as a safety criterion. J Cataract Refract Surg 2005;31(4):674-680.

29. Hoffer KJ. Pigment vacuum iridectomy for phakic refractive lens implantation. J Cataract Refract Surg 2001;27(8):1166-1168.

30. Koss MJ, Cichocki M, Kohnen T. Posterior synechias following implantation of a foldable silicone irisfixated phakic intraocular lens for the correction of myopia. J Cataract Refract Surg 2007;33(5):905909. 



\section{Chapter 8}

\section{Use of anterior segment optical coherence tomography to study corneal changes after collagen cross-linking}

Muriël Doors, Nayyirih G. Tahzib, Fred A. Eggink, Tos T.J.M. Berendschot, Carroll A.B. Webers, Rudy M.M.A. Nuijts

Am J Ophthalmol. 2009 Dec;148(6):844-51 


\section{ABSTRACT}

Purpose: To investigate the stromal demarcation line after corneal cross-linking using anterior segment optical coherence tomography (AS-OCT) and its influence on the short-term results of cross-linking in patients with progressive keratoconus.

Design: Prospective non-randomized study.

Methods: Twenty-nine eyes of 29 patients with progressive keratoconus $(n=28)$ or post-laser in situ keratomileus ectasia $(n=1)$ were included and treated with corneal cross-linking at our institution. Measurements at 1, 3, 6 and 12 months after corneal cross-linking were: refraction, best-corrected visual acuity (BCVA), tonometry, corneal topography, AS-OCT, specular microscopy and aberrometry. Demarcation line depth was measured centrally, $2 \mathrm{~mm}$ temporally, and $2 \mathrm{~mm}$ nasally by two independent observers using AS-OCT and was correlated with clinical parameters.

Results: The stromal demarcation line was visible with AS-OCT at 1 month postoperatively in 28 of 29 eyes. Pair-wise comparisons between the 2 observers of the ASOCT measurements did not show a statistically significant difference. After an initial steepening of maximal keratometry (K)-values and decrease in BCVA at 1 month postoperatively (both with $P<0.012$ ), no significant changes were found at 3,6 and 12 months postoperatively compared to preoperatively. Refractive cylinder, topographic astigmatism, aberration values, endothelial cell density and intraocular pressure remained stable during all postoperative visits. A deeper demarcation line depth was associated with a larger decrease in corneal thickness $(r=-0.506$; $P=0.012$ ).

Conclusions: AS-OCT is a useful device to detect the stromal demarcation line after corneal cross-linking. At 3 to 12 months follow-up, all clinical parameters remained stable, indicating stabilisation of the keratoconic disease. 


\section{INTRODUCTION}

Keratoconus is a bilateral, progressive corneal disease with a multifactorial etiology and a classical onset at puberty. ${ }^{1}$ It is characterized by corneal collagen structure changes, decreased corneal rigidity, and corneal thinning, leading to a progressive corneal deformation (conical protrusion), and decreased vision. ${ }^{2}$ Early treatment options are correction of the refractive error by spectacles or contact lenses (such as soft, rigid or scleral lenses). ${ }^{3}$ In contact lens intolerant patients with mild to moderate keratoconus, the implantation of intracorneal ring segments can be considered, since they lead to a flattening-effect of the cornea and can increase contact lens tolerance. ${ }^{4}$ However, these treatment options do not interfere with the progression of the disease and are therefore insufficient in cases of progressive keratoconus. In advanced cases of keratoconus (e.g. with corneal scars and/or thin, bulging corneas), penetrating or lamellar keratoplasty procedures are the only solution. Until now, keratoconus remains one of the leading indications for keratoplasty. ${ }^{5}$ For progressive, non-advanced cases, corneal collagen cross-linking has become available, leading to a mechanical strengthening of the cornea and thereby achieving a stabilization of the disease. This could delay the need for keratoplasty in this young, non-advanced patient group.

Corneal cross-linking, which combines riboflavin eyedrops and ultraviolet-A (UVA) radiation, was first described by Spoerl and Seiler et al. in $1998 .{ }^{6}$ UVA radiation in combination with riboflavin generates reactive oxygen species, leading to the formation of crosslinks between the corneal collagen fibers. The primary goal of corneal cross-linking is to increase corneal rigidity by increasing the mechanical stability of the corneal stroma. Wollensak et al. reported a 4.5 times increase in biomechanical rigidity in human corneas after corneal cross-linking, with a primary treatment effect in the anterior $300 \mu \mathrm{m}$ of the corneal stroma. In current practise, patients with progressive keratoconus or post-laser in situ keratomileusis (LASIK) ectasia might be eligible for corneal cross-linking, provided that their corneas are clear and not too thin. ${ }^{8-10}$

In 2003, Wollensak et al. reported the first clinical short-term results of corneal cross-linking in patients with progressive keratoconus. ${ }^{9}$ They found that the progressive nature of keratoconus was at least stopped in all eyes after corneal crosslinking, with a decreased maximal keratometry $(\mathrm{K})$ value in $70 \%$ of eyes and an increased visual acuity in $65 \%$. In a recent study, with a maximum follow-up of 6 years, it was shown that the corneal cross-linking effect was also able to inhibit the progression of keratoconus over a longer period of time. ${ }^{11}$

The first reports on the appearance of a stromal demarcation line 2 weeks after corneal cross-linking were published in 2006 using slit lamp analysis and confocal microscopy. ${ }^{12,}{ }^{13}$ It has been postulated that this demarcation line indicates the transition zone between the crosslinked anterior corneal stroma and the untreated 
posterior corneal stroma and may result from the difference in refractive indices or reflection properties of crosslinked versus untreated corneal stroma. ${ }^{12}$ In a recent study, confocal microscopy showed a transition area, where an edematous zone with low cell density merged with a deeper zone with less edema and more keratocytes, at an average depth of $320 \mu \mathrm{m} .{ }^{13}$ Next to slit lamp analysis and confocal microscopy, the demarcation line can be visualised using anterior segment optical coherence tomography (AS-OCT). This is a new device, which can visualize the anterior segment, including the cornea, in great detail. ${ }^{14}$

The aim of this study was to report the short-term results of corneal crosslinking in patients with progressive keratoconus and to investigate the stromal demarcation line after corneal cross-linking using AS-OCT and its relationship to the short-term results.

\section{METHODS}

\section{Patient Population and Study Design}

Twenty-nine eyes of 29 consecutive patients with progressive keratoconus $(n=28)$ and post-LASIK ectasia $(n=1)$ were included in this prospective clinical study. All patients were treated at the University Hospital Maastricht from September 2007 to December 2008. The preoperative inclusion criteria for this study were: Snellen best- spectacle corrected visual acuity (BSCVA) $\geq 0.4$, pachymetry $\geq 400 \mu \mathrm{m}$ at the thinnest location, no other ocular pathology, no corneal scarring and patient age $\geq$ 18 years. All contact lenses needed to be removed $\geq 2$ weeks before all preoperative eye examinations. Progression of keratoconus was documented by corneal topography, refractive changes and/or pachymetry. Progression was defined as an increase in the maximum K-value by more than 1.0-1.5 diopters (D) and a corresponding change (>1.0-1.5 D) in the refractive cylinder in the previous 6 to 12 months, or a $\geq 5 \%$ decrease in central corneal thickness (CCT) in the previous 6 to 12 months.

The mean age of the included patients was $35.1 \pm 11.7$ years (range 19 to 76 years). Follow-up ranged between 1 and 12 months, with a mean follow-up of $6.3 \pm$ 3.7 months. Seven of the treated eyes were left eyes and 22 were right eyes.

\section{Preoperative and Postoperative Examinations}

Patients were examined preoperatively and 1, 3, 6, and 12 months after the corneal cross-linking treatment. Examinations included measurement of Snellen BSCVA, slit lamp examination, Goldmann applanation tonometry, corneal topography (EyeMap EH-290; Alcon, Fort Worth, TX), Pentacam HR tomography (Oculus, Wetzlar, Ger- 
many), Visante ${ }^{\mathrm{TM}}$ AS-OCT (Carl Zeiss Meditec Inc., Dublin, CA), endothelial cell density (ECD) counts (Noncon Robo SP-9000; Konan Medical Inc., Hyogo, Japan), and aberrometry (IRX-3 Wavefront Aberrometer; Imagine Eyes, Orsay, France). ECD measurements were performed using the dot method, in which the centers of a minimum of 50 contiguous cells of the center of the cornea are marked. ECD data consisted of the average of three consecutive measurements.

\section{Anterior Segment Optical Coherence Tomography Measurements}

Visante AS-OCT is a non-contact high-resolution device, which forms a twodimensional image of the anterior segment using low coherence interferometry. In this study, all scans were made in an unaccommodated state, and in the same light conditions (50 lux). All subjects were asked to look at the optical target in the system. When the corneal reflex, a vertical white line along the center of the cornea, was visible, the image was captured.

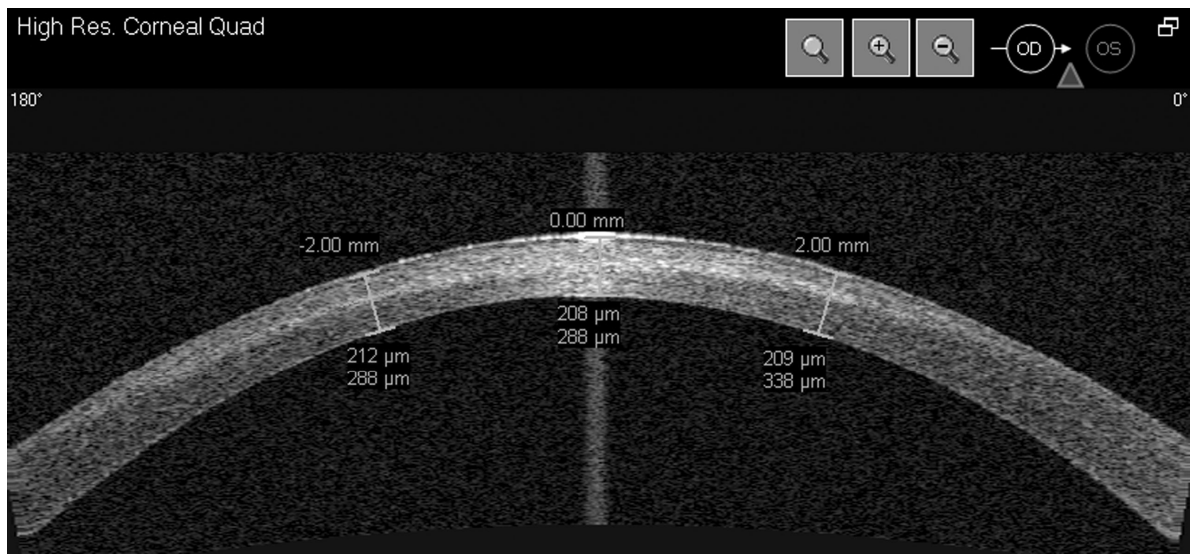

Figure 1. High resolution corneal optical coherence tomography scan visualizing the stromal demarcation line one month after corneal cross-linking in a patient with progressive keratoconus with central, nasal and temporal depths of 208,209 , and $212 \mu \mathrm{m}$.

The high resolution corneal scan was used to produce an enhanced image of the cornea on the horizontal meridian. The stromal demarcation line was identified in this enhanced scan and the demarcation line depth was measured using the flaptool as provided by the manufacturer (Figure 1). Two independent examiners (N.T. and M.D.) measured the depth of the demarcation line centrally and $2 \mathrm{~mm}$ nasally and temporally from the center. They also recorded the accuracy of their measurements by scoring the visibility of the demarcation line at the 3 above-mentioned locations ( 0 = line could not be detected; 1 = line visible, but measurement not very accurate; 2 = line easily identified and reliable measurement). The central demarca- 
tion line depth was used to analyze the relationship between demarcation line depth and short-term outcome parameters.

Furthermore, pachymetry maps were used to fully evaluate corneal thickness. These maps are made up of 8 scan lines and calculate corneal thickness at 25 locations on the cornea. The corneal thickness at the center of the scan was used for central corneal thickness evaluation.

\section{Cross-linking Procedure}

All corneal cross-linking treatments were performed (N.T.) at the Academic Center for Refractive Surgery, University Eye Clinic of Maastricht. UVA light of $370 \mathrm{~nm}$ wavelength and $3 \mathrm{~mW} / \mathrm{cm}^{2}$ was used for the corneal cross-linking procedure. Before every treatment, the irradiance of the VEGA CBM X-linker (SOOFT Italia SpA, Montegiorgio, Italy) was checked with a LaserMate-Q UVA meter (Laser 2000, Wessling, Germany).

Tetracaine $1 \%$ drops were applied three times before the treatment. After a 9 $\mathrm{mm}$ diameter corneal marker was applied, the corneal epithelium was removed using a blunt knife under sterile conditions in the operating room. After the abrasion, photosensitizing riboflavine $0.1 \%$ solution was applied on the cornea every 3 minutes during 30 minutes. The patient was then examined with the slit lamp to determine whether riboflavine was present in the anterior chamber ("yellow tyndall"). When present, the central cornea was irradiated using UVA light with a diameter of $8.0 \mathrm{~mm}$ during 30 minutes. Riboflavin drops were applied every 5 minutes during the UVA irradiation. The patient was instructed to look at the center of the light. During the corneal cross-linking procedure, centration was continuously monitored by the surgeon and adjusted when needed. If necessary, balanced salt solution and tetracaine drops were re-administered during irradiation.

Directly following the corneal cross-linking treatment, a soft bandage lens was applied. All patients received oral pain medication, preservative-free artificial tears (Duratears Free ${ }^{\circledR}$ ), non-steroidal anti-inflammatory drug (NSAID) drops (Acular $\AA$ ) and antibiotic eye drops (Ofloxacine, Trafloxal ${ }^{\circledR}$ ). The artificial tears were applied 8 times a day for 6 weeks, the NSAID 3 times a day during 1 week, and the antibiotics 4 times a day during 4 weeks.

Patients were seen 1 week after the corneal cross-linking treatment, to check whether re-epithelialization had occurred, at which point the bandage lens was removed.

\section{Statistical Analysis}

All data were collected in an Excel spreadsheet and transferred to SPSS (SPSS for Windows, version 15.0, SPSS Inc, Chicago, IL) for statistical analysis. Continuous 
variables were described as mean \pm standard deviation (SD). Comparisons between preoperative and postoperative data were performed by paired $t$ tests. Snellen visual acuities were converted to LogMar values for statistical comparison. Negative aberration values were not converted to absolute numbers for statistical analysis. The Pearson correlation coefficient $(r)$ was used to detect relationships between observers, and between stromal demarcation line depth and short-term outcome parameters correcting for the preoperative outcome parameters. A linear regression model was applied to evaluate the significant relationships. The agreement between the 2 observers measuring demarcation line depth was studied using the method described by Bland and Altman. ${ }^{15}$ This method also computed $95 \%$ limits of agreement ( $L O A=$ mean difference $\pm 1.96 * \mathrm{SD}$ ). Paired $t$ tests were performed between the measurements of both observers. To determine interobserver variability of the demarcation line measurements, the mean, SD and coefficient of variation (ratio of the standard deviation and the mean of both observers in percentage) were calculated. A $P$-value of $<0.05$ was considered significant.

\section{RESULTS}

\section{Demarcation Line Depth}

In $75 \%$ of the investigated eyes, the demarcation line was easily identified by both observers and a reliable measurement could be performed. In one eye, the demarcation line was not visible at the 1 month follow-up visit. In 7 out of the remaining 28 eyes (25\%), the demarcation line was scored as visible. However, measurements were not very accurate for at least 2 out of the 3 corneal locations or only one observer could identify the demarcation line. The mean stromal demarcation line depth measured by observer 1 was $313 \pm 61 \mu \mathrm{m}, 325 \pm 62 \mu \mathrm{m}$, and $305 \pm 61 \mu \mathrm{m}$; for observer 2 the values were $314 \pm 73 \mu \mathrm{m}, 324 \pm 73 \mu \mathrm{m}$, and $314 \pm 68 \mu \mathrm{m}$ on the central, nasal and temporal location, respectively. The pair-wise comparisons between the 2 observers did not show a statistically significant difference for the central, temporal and nasal measurements (all with $P>0.05$ ). Furthermore, the measurements at the three mentioned locations were highly correlated between the two observers (all with $r>0.924 ; P<0.001$ ). The coefficients of variation were between $4.8 \pm 4.7 \%$ and $5.5 \pm 5.1 \%$. The $95 \%$ limits of agreement were between -60 to $42 \mu \mathrm{m}$ and -58 to $56 \mu \mathrm{m}$.

Three months after corneal cross-linking, the demarcation line had disappeared in 15 out of 20 measured eyes (75\%). In the remaining 5 eyes, the demarcation line was scored by both observers as visible but not visible enough to enable an accurate measurement. At 6 months postoperatively, the line was scored as invisible for all included eyes by both observers. 


\section{Short-term Results}

The mean preoperative patient characteristics are shown in Table 1. The changes in short-term outcome parameters, comparing postoperative measurements to preoperative values, are listed in Table 2.

Table 1. Preoperative Characteristics of Progressive Keratoconus Patients

\begin{tabular}{lcc}
\hline Variable & Mean \pm Standard Deviation & Range \\
\hline Number of eyes $(\mathrm{n})$ & 29 & \\
Number of females $(\mathrm{n})$ & 9 & 4.50 to -14.00 \\
Sphere (D) & $-1.05 \pm 3.55$ & 0 to -7.00 \\
Cylinder (D) & $-2.84 \pm 2.12$ & 2.13 to -16.88 \\
Spherical equivalent (D) & $-2.47 \pm 3.72$ & 0.40 to -0.10 \\
BSCVA (LogMar) & $0.17 \pm 0.18$ & $7-20$ \\
Intraocular pressure (mmHg) & $11.9 \pm 3.5$ & $41.69-68.29$ \\
Maximum K-value (D) & $48.66 \pm 5.50$ & $40.89-67.29$ \\
Central K-value (D) & $47.49 \pm 6.39$ & $0.56-18.76$ \\
Topographic astigmatism (D) & $4.84 \pm 3.74$ & $427-618$ \\
Central corneal thickness $(\mu \mathrm{m})$ & $495 \pm 48$ & $404-594$ \\
Thinnest corneal thickness $(\mu \mathrm{m})$ & $470 \pm 48$ & $2071-3803$ \\
Preoperative ECD (cells/mm $\left.{ }^{2}\right)$ & $2701 \pm 352$ & \\
\hline
\end{tabular}

$\mathrm{D}=$ diopters; $\mathrm{BSCVA}=$ best spectacle corrected visual acuity; $\mathrm{ECD}=$ endothelial cell density

\section{Refractive and Visual Outcome}

The mean spherical equivalent $(S E)$ increased significantly from $-2.47 \pm 3.72 \mathrm{D}$ to $3.51 \pm 4.23 \mathrm{D}$ at 1 month postoperatively $(P=0.006)$. Mean SE remained stable at 3 , 6 and 12 months postoperatively compared to preoperative values $(P>0.05)$.

A significant increase in maximum and central K-values was seen 1 month after corneal cross-linking $(P<0.020)$. At 3 months postoperatively, the maximum and central K-values were back to preoperative values and remained stable at 6 and 12 months postoperatively $(P>0.05)$. Mean topographic astigmatism did not show a significant change compared to preoperatively at 1, 3, 6 and 12 months postoperatively $(P>0.05)$. In $62.5 \%$ of eyes, topographic astigmatism remained stable (within \pm $0.50 \mathrm{D}$ ) during the 6 months after treatment, and in $25 \%$ of eyes, topographic astigmatism decreased.

There was a significant decrease in BSCVA at 1 month postoperatively $(P=0.011)$. At 3, 6 and 12 months after treatment, BSCVA remained stable compared to preoperative values, with no significant changes at these three follow-up visits $(P>0.05$ ). At 3 months follow-up, 30.7\% (8 out of 26 eyes) gained at least 1 Snellen line and $42.3 \%$ (11 of 26 eyes) showed a stable BSCVA. Six months after corneal 
cross-linking, 10 out of 20 eyes (50\%) gained at least 1 Snellen line and 5 eyes (25\%) showed a stable BSCVA.

Table 2. Mean Change in Short Term Outcome Parameters and Changes in Central Corneal Thickness using Pentacam in Progressive Keratoconus Patients after Corneal Cross-linking

\begin{tabular}{llllll}
\hline $\begin{array}{l}\text { Follow-up } \\
\text { (months) }\end{array}$ & Central K (D) & Kmax (D) & Astigmatism (D) & BSCVA (LogMar) & $\begin{array}{l}\text { Central Corneal } \\
\text { Thickness }(\mu \mathrm{m})\end{array}$ \\
\hline $1(\mathrm{n}=29)$ & $0.89 \pm 1.74$ & $1.16 \pm 1.23$ & $0.53 \pm 1.53$ & $0.12 \pm 0.22$ & $-31 \pm 20$ \\
$3(\mathrm{n}=26)$ & $0.19 \pm 2.14$ & $0.14 \pm 2.13$ & $-0.20 \pm 1.26$ & $0.01 \pm 0.13$ & $-28 \pm 23$ \\
$6(\mathrm{n}=20)$ & $0.64 \pm 1.73$ & $-0.29 \pm 2.05$ & $-0.59 \pm 1.96$ & $-0.03 \pm 0.12$ & $-20 \pm 19$ \\
$12(n=8)$ & $0.19 \pm 2.21$ & $-0.08 \pm 1.56$ & $-0.51 \pm 0.78$ & $-0.02 \pm 0.08$ & $-24 \pm 19$ \\
& & & & & \\
\hline
\end{tabular}

$\mathrm{K}=$ keratometry; $\mathrm{Kmax}=$ maximum keratometric value; $\mathrm{BSCVA}=$ best spectacle corrected visual acuity

\section{Corneal Thickness}

Central corneal thickness and corneal thickness at the thinnest location were measured using Pentacam imaging. Central corneal thickness decreased significantly at 1 , 3,6 and 12 months postoperatively when compared to preoperative values $(P<0.001, P<0.001, P<0.001$, and $P=0.017$, respectively). However, there was a significant increase in corneal thickness between 1 and 6 months postoperatively from $473 \mu \mathrm{m}$ to $483 \mu \mathrm{m}(P=0.010)$. The same pattern was seen for corneal thickness at the thinnest location, with significant decreases of $31 \pm 22 \mu \mathrm{m}, 27 \pm 23 \mu \mathrm{m}, 19 \pm 24$ $\mu \mathrm{m}$, and $22 \pm 20 \mu \mathrm{m}$ between preoperatively and $1,3,6$, and 12 months postoperatively, respectively (all with $P<0.030$ ). Pachymetry measurements at the thinnest location also showed a significant increase in corneal thickness from $448 \mu \mathrm{m}$ to 459 $\mu \mathrm{m}$ between 1 and 6 months postoperatively ( $P=0.032$ ).

AS-OCT pachymetry maps were also used to measure central corneal thickness. Using this device, central corneal thickness decreased at 1, 3, 6 and 12 months postoperatively when compared to preoperatively, with mean decreases of $7.8 \pm 20$ $\mu \mathrm{m}, 11 \pm 16 \mu \mathrm{m}, 5.1 \pm 17 \mu \mathrm{m}$, and $5.0 \pm 21 \mu \mathrm{m}$, respectively. The decrease was only significant at 3 months postoperatively $(P=0.005)$. There was no significant increase in central corneal thickness measured using AS-OCT between 1 and 6 months postoperatively.

\section{Intraocular Pressure}

There were no significant changes in intraocular pressure during the entire followup $(P>0.05)$. 


\section{Aberrometry Results}

The higher order aberration values coma-x, coma-y and spherical aberrations were measured for a $5 \mathrm{~mm}$ pupil and remained stable throughout the entire follow-up, with no significant changes between preoperative and postoperative measurements $(P>0.05)$. Preoperatively and at 3 and 6 months postoperatively, coma-x was $-0.05 \pm$ $0.38 \mu \mathrm{m},-0.11 \pm 0.31 \mu \mathrm{m}$, and $-0.19 \pm 0.39 \mu \mathrm{m}$; coma-y was $-1.19 \pm 0.92 \mu \mathrm{m},-0.99$ $\pm 0.87 \mu \mathrm{m}$, and $-1.10 \pm 0.91 \mu \mathrm{m}$; and spherical aberration was $0.12 \pm 0.27 \mu \mathrm{m}, 0.06$ $\pm 0.25 \mu \mathrm{m}$, and $0.07 \pm 0.30 \mu \mathrm{m}$, respectively.

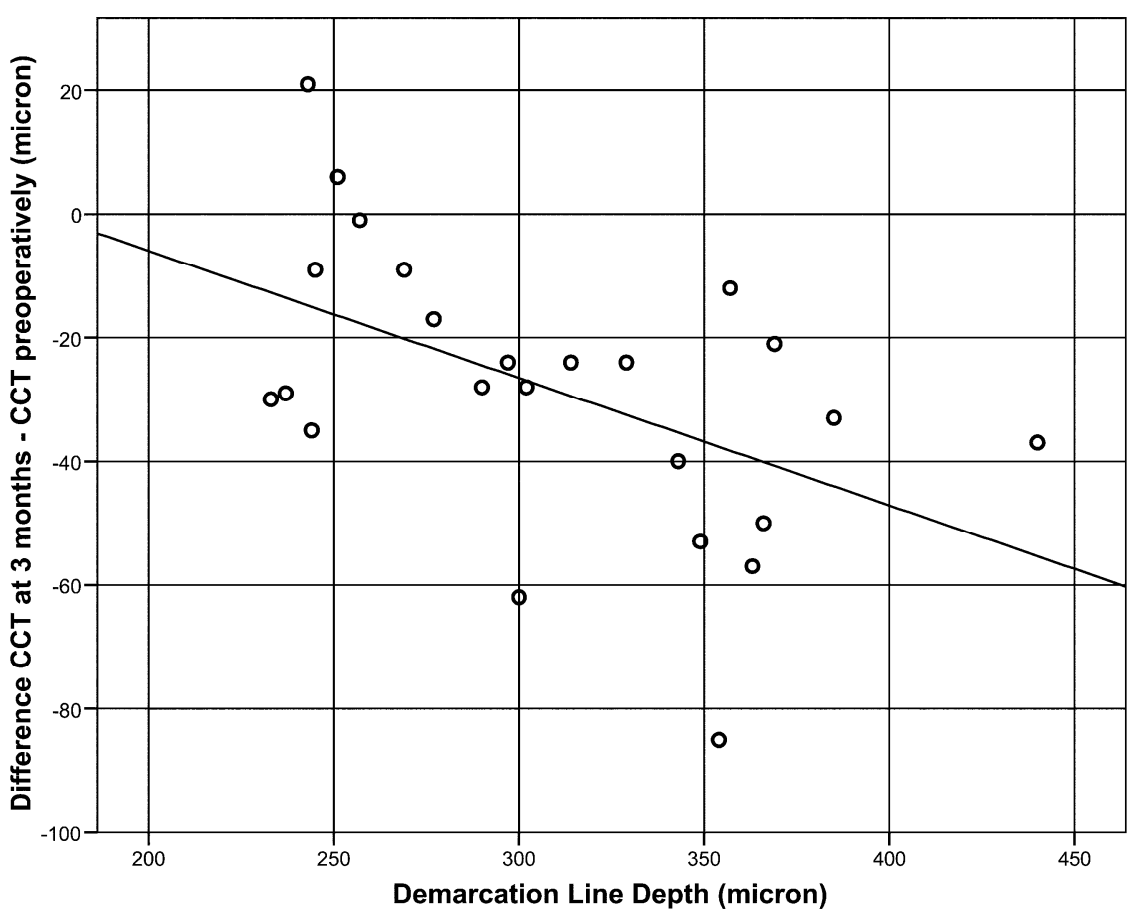

Figure 2. Scatterplot of stromal demarcation line depth and the change in central corneal thickness (CCT) between 3 months after corneal cross-linking and preoperatively in patients with progressive keratoconus.

\section{Endothelial Cell Density Results}

Mean ECD counts at 3, 6 and 12 months postoperatively were $2648 \pm 321,2678 \pm$ 312 , and $2703 \pm 273$ cells $/ \mathrm{mm}^{2}$, respectively. Changes in ECD counts compared to preoperatively were not statistically significant $(P>0.05)$. 


\section{Complications}

All patients reported some degree of pain during the first 2 to 3 days after treatment. All epithelial defects were closed at the 1-week follow-up visit. None of the patients showed epithelial wound healing problems. At 1 month postoperatively, 2 eyes presented with mild Descemet folds, which remained present in 1 eye up to 3 months postoperatively. In one eye endothelial irregularities were noted at 1 month after treatment and disappeared at 3 months postoperatively without visual limitations. None of the patients developed corneal haze or keratitis after treatment.

\section{Relationship between Demarcation Line and Short-Term Outcome Parameters}

The mean central depth of the stromal demarcation line was $313 \pm 66 \mu \mathrm{m} 1$ month aftercorneal cross-linking, ranging between 225 and $448 \mu \mathrm{m}$. There was a significant correlation between demarcation line depth and the change in central corneal thickness measured with Pentacam 3 months after corneal cross-linking $(r=-0.506$; $P=0.012$ ). A deeper demarcation line was associated with a larger decrease in central corneal thickness (Figure 2). Linear regression analysis showed that for an increase of $10 \mu \mathrm{m}$ in demarcation line depth, central corneal thickness decreased with $2 \pm 0.75 \mu \mathrm{m}$ (mean $\pm \mathrm{SE}$ ). There were no significant correlations between the other short-term outcome parameters and stromal demarcation line depth.

When performing the same correlation analyses using the clearly visible and reliable demarcation line depth measurements ( $75 \%$ of the depth measurements), the correlation between demarcation line depth and the change in central corneal thickness measured with Pentacam 3 months after corneal cross-linking remained significant $(r=-0.497 ; P=0.043)$. Furthermore, there was a significant correlation between the change in Pentacam pachymetry measurements at the thinnest location at 1 month postoperatively and demarcation line depth $(r=-0.561 ; P=0.008)$, indicating that a deeper demarcation line depth was associated with a larger decrease in corneal thickness at the thinnest location (Figure 3).

\section{DISCUSSION}

This study demonstrated that the stromal demarcation line, which appears after corneal cross-linking, can easily be visualized using AS-OCT, with the best visibility at 1 month after the treatment. To our knowledge, this is the first study to report on the stromal demarcation line after corneal cross-linking using AS-OCT. It is hypothesized that this line represents the activation of keratocytes, which is followed by the repopulation of keratocytes and new collagen synthesis. ${ }^{17}$ This indicates that the demarcation line represents the transition zone between corneal cross-linked tissue and corneal non-cross-linked tissue. 


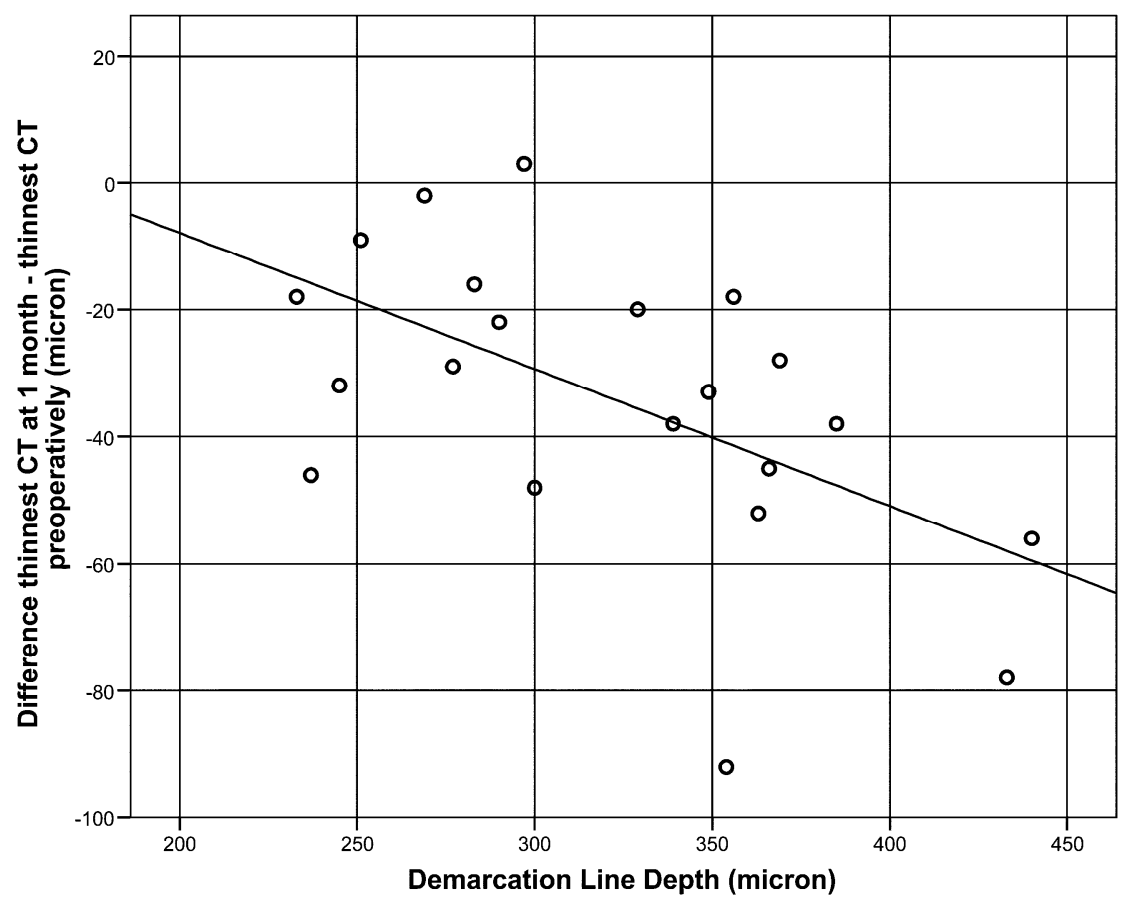

Figure 3. Scatterplot of stromal demarcation line depth and the change in corneal thickness (CT) at the thinnest location between 1 month after corneal cross-linking and preoperatively in patients with progressive keratoconus.

Seiler et al. explained that the stromal depth of effective corneal cross-linking depends on the concentration of riboflavin solution and the intensity of UVA light. ${ }^{12}$ The average demarcation line depth in our study was $313 \mu \mathrm{m}$, which is similar to the previously reported $300-320 \mu \mathrm{m}$ by Mazzotta et al. and Seiler et al. ${ }^{12,13}$ In both studies, the stromal demarcation line was investigated by biomicroscopy or confocal microscopy at 2-4 weeks after corneal cross-linking. Both measurement methods result in an estimation of the demarcation line depth. AS-OCT produces a high resolution image of the cornea in which tools can be selected to measure the distance between two points. Despite the subjective character of the measurement, this technique provides an accurate measurement of demarcation line depth. No significant differences were found for demarcation line depth measurements at the three corneal locations between the 2 observers. The interobserver reliability was good, with coefficients of variation between 4.8 and $5.5 \%$. In this study, the mean differences in demarcation line depth measurements were between 1 and $9 \mu \mathrm{m}$, with spans of the $95 \%$ limits of agreement between 102 and $114 \mu \mathrm{m}$. The mean differences are very small, however the limits of agreement are quite large. When analys- 
ing the outliers, we found that these were mostly cases in which both observers had scored the demarcation line as visible, but with no accurate measurement possible. This indicates that a reliable depth measurement can be done only if the line is clearly visible, which was the case in $75 \%$ of the investigated eyes. Three months after the corneal cross-linking treatment, the demarcation line had disappeared in almost all eyes. Our suggestion would be to perform AS-OCT no later than 1 month after corneal cross-linking in order to obtain the most accurate measurement of demarcation line depth.

Our results show that after an initial decrease in BSCVA and an increase in Kvalues and topographic astigmatism, corneal cross-linking resulted in stable Kvalues, topographic astigmatism and BSCVA during the first year after corneal crosslinking in eyes with progressive keratoconus and post-LASIK ectasia. Recently, Vinciguerra et al. also showed an initial worsening of BSCVA and K-values in 28 keratoconic eyes. ${ }^{16}$ We believe that these effects are directly related to the corneal remodelling process that occurs in the first month after corneal cross-linking. In vivo rabbit studies by Wollensak et al. showed that it takes up to 6 weeks for the cytoarchitecture of the cornea to recover from the cross-linking procedure. ${ }^{17}$

Vinciguerra et al. found that corneal cross-linking improved BSCVA by reducing average pupillary power, apical keratometry, and corneal and total wavefront aberrations after a follow-up of 12 months. ${ }^{16}$ In a long-term study, including 241 eyes with a minimum follow-up of 6 months and a maximum follow-up of 6 years, a significant decrease in maximum K-values was found. ${ }^{11}$ Furthermore, they reported an improved BCVA in $57 \%$ of eyes in the second year after corneal cross-linking and a stable BCVA in $24 \%$ of eyes. This reduction of $\mathrm{K}$-values and increase of BSCVA was confirmed by two other studies by Caporossi et al., with a follow-up of 6 months, and Wollensak et al, with a follow-up between 3 months and 4 years. ${ }^{9,} 18$ Hafezi et al. investigated the effectiveness of corneal cross-linking in 10 patients diagnosed with post-LASIK ectasia during a maximum follow-up of 25 months; they also found a reduction in maximum $\mathrm{K}$-values after corneal cross-linking. ${ }^{10}$

Next to the stabilization of the clinical keratoconus parameters in our study, we found a significant decrease in corneal thickness, in both the central as well as the thinnest location using Pentacam imaging. The largest decrease of $31 \mu \mathrm{m}$ was observed 1 month postoperatively, with a significant decrease of $24 \mu \mathrm{m}$ remaining at 12 months postoperatively. Vinciguerra et al. also found a significant decrease in central corneal thickness from $491 \mu \mathrm{m}$ preoperatively to $470 \mu \mathrm{m}$ at 12 months postoperatively using Pentacam measurements. ${ }^{16}$ In the current study, the AS-OCT pachymetry maps also showed a decrease in central corneal thickness postoperatively. This decrease was only significant at 3 months following corneal cross-linking, with decreases ranging between 5.0-11.0 $\mu \mathrm{m}$. AS-OCT and Pentacam imaging use different optical principles to construct the image of the anterior segment. A study by Seiler et al. implied that the refractive index of the cornea changes, especially at 
the site of the demarcation line, due to structure modifications after corneal crosslinking. ${ }^{12}$ These corneal refractive index changes might be an explanation for the differences found between the Pentacam and AS-OCT pachymetry measurements.

Another important finding was the association between demarcation line depth and the decrease in corneal thickness, i.e. a deeper demarcation line depth was associated with a larger decrease in corneal thickness. We believe that this decrease in corneal thickness does not imply a negative effect of corneal cross-linking, but rather a compacting process of corneal lamellae and a strengthening of collagen fibers. ${ }^{7}$ Other studies describe an edematous process in the corneal stroma in the early phase (first week) post corneal cross-linking. ${ }^{17}$ After this, the connections between the lamellae strengthen and the edema disappears, probably leading to a dehydration effect. The latter could explain the decreased thickness measurements 1 months after corneal cross-linking. Despite the overall decrease in corneal thickness, we found a significant increase between 1 month and 6 months postoperatively, indicating that this decrease is not due to the progression of the keratoconus. We hypothesize that this slight increase in corneal thickness, which probably starts 1 month after the treatment, might be due to the production of new proteoglycans by the new keratocytes that have repopulated the anterior stroma (personal communication Dr. H.F. Edelhauser). In a recent study by Koller et al. the same pattern of corneal thickness changes was observed using Pentacam. ${ }^{19}$ They also examined the untreated fellow eyes and found an ongoing thinning in those eyes, which is consistent with the progression of the disease and in contrast with the continuing increase of corneal thickness as of 1 month postoperatively in the treated eyes. We do not believe this clinical finding to be a detrimental one in the long run. However, in the experimental treatment of corneal cross-linking and subsequent topographicguided photorefractive keratectomy (PRK) to stabilize the keratoconus and afterwards minimize the refractive error, ${ }^{20}$ this decrease in corneal thickness should be kept in mind. Longer-term studies should address this finding in the future.

In conclusion, AS-OCT is a useful device to detect the corneal cross-linking stromal demarcation line. This line is a direct clinical sign of corneal cross-linking and can be found within the first month after the treatment, being most clearly visible 1 month after corneal cross-linking. The depth of the line can be accurately measured and perhaps in the future can be correlated to the effectiveness of the treatment. Future studies should be geared towards the explanation for and consequence of the decreased corneal thickness after corneal cross-linking. In terms of clinical outcome, our study showed that all clinical keratoconus parameters remained stable from 3 to 12 months of follow-up after corneal cross-linking, thereby indicating a stabilization of keratoconus on the short term without the occurrence of clinically significant side effects. A longer follow-up will be needed to evaluate the long-term stabilizing effect of corneal cross-linking on the progression of keratoconus. One long-term study by Raiskup-Wolf et al. did indicate a long-term stabilizing effect of 
corneal cross-linking. ${ }^{11}$ An overall used definition of the progression of keratoconus would significantly increase the ease to compare corneal cross-linking studies and evaluate the results on the long term. 


\section{REFERENCES}

1. Rabinowitz YS. Keratoconus. Surv Ophthalmol 1998;42:297-319.

2. Tuori AJ, Virtanen I, Aine E, et al. The immunohistochemical composition of corneal basement membrane in keratoconus. Curr Eye Res 1997;16:792-801.

3. Garcia-Lledo M, Feinbaum C, Alio JL. Contact lens fitting in keratoconus. Compr Ophthalmol Update 2006;7:47-52.

4. Rabinowitz YS. INTACS for keratoconus. Int Ophthalmol Clin 2006;46:91-103.

5. Ghosheh FR, Cremona FA, Rapuano CJ, et al. Trends in penetrating keratoplasty in the United States 1980-2005. Int Ophthalmol 2008;28:147-153.

6. Spoerl E, Huhle M, Seiler T. Induction of cross-links in corneal tissue. Exp Eye Res 1998;66:97-103.

7. Wollensak G, Spoerl E, Seiler T. Stress-strain measurements of human and porcine corneas after riboflavin-ultraviolet-A-induced cross-linking. J Cataract Refract Surg 2003;29:1780-1785.

8. Mackool RJ. Cross-linking for iatrogenic keratectasia after LASIK and for keratoconus. J Cataract Refract Surg 2008;34:879; author reply.

9. Wollensak G, Spoerl E, Seiler T. Riboflavin/ultraviolet-a-induced collagen cross-linking for the treatment of keratoconus. Am J Ophthalmol 2003;135:620-627.

10. Hafezi F, Kanellopoulos J, Wiltfang R, Seiler T. Corneal collagen cross-linking with riboflavin and ultraviolet $A$ to treat induced keratectasia after laser in situ keratomileusis. J Cataract Refract Surg 2007;33:2035-2040.

11. Raiskup-Wolf F, Hoyer A, Spoerl E, Pillunat LE. Collagen cross-linking with riboflavin and ultraviolet-A light in keratoconus: long-term results. J Cataract Refract Surg 2008;34:796-801.

12. Seiler T, Hafezi F. Corneal cross-linking-induced stromal demarcation line. Cornea 2006;25:10571059.

13. Mazzotta C, Balestrazzi A, Traversi C, et al. Treatment of progressive keratoconus by riboflavin-UVAinduced cross-linking of corneal collagen: ultrastructural analysis by Heidelberg Retinal Tomograph II in vivo confocal microscopy in humans. Cornea 2007;26:390-397.

14. Haque S, Simpson T, Jones L. Corneal and epithelial thickness in keratoconus: a comparison of ultrasonic pachymetry, Orbscan II, and optical coherence tomography. J Refract Surg 2006;22:486-493.

15. Bland JM, Altman DG. Statistical methods for assessing agreement between two methods of clinical measurement. Lancet 1986;1:307-310.

16. Vinciguerra P, Albe E, Trazza S, et al. Refractive, Topographic, Tomographic, and Aberrometric Analysis of Keratoconic Eyes Undergoing Corneal Cross-Linking. Ophthalmology 2009;116:369-378.

17. Wollensak G, lomdina E, Dittert DD, Herbst H. Wound healing in the rabbit cornea after corneal collagen cross-linking with riboflavin and UVA. Cornea 2007;26:600-605.

18. Caporossi A, Baiocchi S, Mazzotta C, et al. Parasurgical therapy for keratoconus by riboflavinultraviolet type $A$ rays induced cross-linking of corneal collagen: preliminary refractive results in an Italian study. J Cataract Refract Surg 2006;32:837-845.

19. Koller T, Iseli HP, Hafezi F, Vinciguerra P, Seiler T. Scheimpflug imaging of corneas after collagen cross-linking. Cornea 2009;28:510-515.

20. Kanellopoulos AJ, Binder PS. Collagen cross-linking (CCL) with sequential topography-guided PRK: a temporizing alternative for keratoconus to penetrating keratoplasty. Cornea 2007;26:891-895. 


\section{Chapter 9}

Phacopower modulation and the risk for postoperative corneal decompensation:

a randomized trial of cataract surgery in Fuchs' endothelial dystrophy

Muriël Doors, Tos T.J.M. Berendschot, Wouter Touwslager, Carroll A.B. Webers, Rudy M.M.A. Nuijts

JAMA Ophthalmol. 2013 Nov;131(11):1443-50 


\section{ABSTRACT}

Objective: To compare corneal thickness and corneal volume changes using torsional and longitudinal phacoemulsification in patients with Fuchs' endothelial dystrophy (FED) and determine risk factors of postoperative corneal decompensation.

Methods: In this prospective, randomized controlled trial, 52 eyes with FED and visually significant cataract underwent phacoemulsification using torsional $(n=26)$ or longitudinal $(n=26)$ phacoemulsification. Patients were evaluated preoperatively and 1 day, 1 week, 1 month, 3, and 6 months postoperatively. Visits included: best spectacle-corrected visual acuity (BSCVA), anterior segment optical coherence tomography (AS-OCT) evaluating central and peripheral corneal thickness (CCT; PCT), Scheimpflug imaging calculating corneal volume (CV). Randomization took place according to stage of FED, nucleus density grade and age. Intraoperatively, ultrasound (US) time and cumulative dissipated energy (CDE) were recorded.

Main Outcome Measures: CCT, PCT and CV

Results: US time and CDE were significantly lower in the torsional group for harder nucleus density grades compared to the longitudinal group $(P=0.009$ and $P=0.002$, respectively). PCT at 6 o'clock, $C C T$ and $C V$ were significantly smaller in the torsional group 1 day postoperatively $(P=0.002, P=0.025$ and $P=0.004$, respectively). Changes in PCT at 12 o'clock and BSCVA were not significantly different between the two groups $(P>0.05)$. Preoperative CCT was the only significant predictor of corneal decompensation postoperatively $(P<0.001)$. Preoperative CCT of $620 \mu \mathrm{m}$ corresponded to an odds ratio of 1 , meaning no increased risk of developing corneal decompensation. For each $10 \mu \mathrm{m}$ increase in preoperative $\mathrm{CCT}$, the odds of developing corneal decompensation increased 1.7 times.

Conclusions: Torsional phacoemulsification effectively reduces US time and CDE compared to longitudinal phaco in FED patients. However, there were only significant differences in corneal thickness and CV changes at 1 day postoperatively in favour of the torsional group. CCT above 620 microns, measured by non-contact pachymetry, leads to an increased risk for corneal decompensation after phacoemulsification in patients with FED.

Application to Clinical Practise: Preoperative non-contact pachymetry measurements can assist in optimalisation of patient selection and counselling when considering cataract surgery in FED patients. To increase the validity of the presented model, it should be applied to a second independent population for validation. 


\section{INTRODUCTION}

Fuchs' endothelial dystrophy (FED) is a progressive, bilateral disease of the corneal endothelium, which develops after the age of 40 and eventually leads to corneal decompensation. ${ }^{1}$ Central endothelial guttae form the main clinical sign, together with decreased vision and pain. ${ }^{2}$

After several years of conservative treatment visual acuity will decrease and corneal transplantation, usually Descemet stripping automated endothelial keratoplasty (DSAEK), becomes the only option to improve vision. DSAEK can be performed simultaneously with cataract extraction and intraocular lens (IOL) insertion, when visually significant cataract is present. In patients with an early stage of FED and cataract, cataract extraction alone may be preferable. The selection of patients that may undergo a successful phacoemulsification procedure is crucial, as unexpected corneal decompensation leads to dissatisfied patients. Seitzman et al. calculated a preoperative central corneal thickness (CCT) cut-off point of $640 \mu \mathrm{m}$, measured using ultrasound pachymetry, in patients with FED. ${ }^{3}$ They suggested that below this value many patients with FED can undergo cataract surgery without postoperative corneal decompensation. Others stated that the decision to perform cataract surgery, should not be based on corneal thickness measurements exclusively and preoperative evaluation should also include endothelial cell density (ECD), symptoms of early morning decompensation, presence of epithelial edema, and cataract density. $^{4-6}$

Routine cataract surgery has shown to induce an endothelial cell density loss of $6.3 \%$ to $12.8 \%$ due to ultrasound (US) power necessary for phacoemulsification. ${ }^{7-10}$ In compromised corneas, e.g. patients with FED, it is of utmost importance to use a technique that is the least traumatic to the corneal endothelium. To reduce the amount of energy during phacoemulsification, new phaco techniques have been described, e.g. phaco-chop ${ }^{11}$ and new phaco-power modulation technologies have been developed. In conventional longitudinal phacoemulsification, where US power is generated by the longitudinal excursions of the phaco needle, the risk for endothelial cell loss and damage has been described in previous studies. ${ }^{12-14}$ In 2006, a torsional emulsification mode was introduced where the handpiece produces rotary oscillations of the phaco tip with a frequency of $32 \mathrm{kHz}$, contrary to the forwardbackward movement of the tip in longitudinal phaco, which might reduce US power, because it limits repulsion and breaks up the cataract by shearing forces and not by the conventional jackhammer effect. ${ }^{15}$ Three recent studies compared torsional and longitudinal US in normal eyes with different stages of cataract. They reported a significantly lower use of US power and cumulative dissipated energy (CDE), smaller increases of central corneal thickness 1 and 7 days postoperatively, faster visual recovery and less endothelial cell loss in the torsional group. ${ }^{15-17}$ To our knowledge, there are no studies comparing these two phacoemulsification modes in patients 
with Fuchs' endothelial dystrophy, who might benefit the most from a reduction in endothelial cell damage.

The purpose of this study was to compare corneal thickness and corneal volume changes using torsional and longitudinal phacoemulsification in patients with Fuchs' endothelial dystrophy (FED) and determine preoperative and intraoperative risk factors for corneal decompensation after phacoemulsification. The effect of torsional and longitudinal phacoemulsification on intraoperative and postoperative outcome parameters was analysed to compute a prediction model, calculating the risk of corneal decompensation after phacoemulsification.

\section{PATIENTS AND METHODS}

\section{Patient Population and Study Design}

This prospective randomised controlled trial included a total of 52 eyes of 48 patients, and was conducted from November 2008 to May 2010 at the Maastricht University Medical Center. All patients diagnosed with FED and planning to undergo cataract surgery due to visually significant cataract were included in the study, regardless of endothelial cell counts and corneal thickness. Patients were excluded if they had a history of previous corneal or intraocular surgery, if they already needed a combined surgical procedure (e.g. triple procedure) or if they had other visually significant ocular diseases.

After patients were informed about the study and provided their informed consent, they were randomised to receive either torsional $(n=26)$ or longitudinal $(n=26)$ phacoemulsification using a computer based randomisation system. This system used permuted blocks for the stage of FED ${ }^{1}$, nucleus density grade (according to the LOCS II classification system ${ }^{18}$ ) and age of the patient. An independent investigator conducted the randomisation prior to surgery. Therefore, the patient, evaluating investigator and surgeon were all blinded for treatment allocation. Both phaco modes are integrated in the Infiniti Vision System (Alcon, Fort Worth, TX). Institutional Review Board approval was obtained from the Academic Hospital Maastricht.

\section{Main Outcome Measures}

Preoperatively, nucleus density grade using the Lens Opacities Classification System II (LOCS II) ${ }^{18}$ and stage of FED (stage 1-4 as described by Adamis et al.) ${ }^{1}$ was evaluated during slitlamp examination.

Postoperatively, patients were evaluated at 1 day, 7 days, 1 month, and 3 and 6 months after the surgery. All visits included measurement of best spectacle corrected visual acuity (BSCVA) using EDTRS chart, slit lamp evaluation, anterior segment 
optical coherence tomography (AS-OCT; Visante OCT, Carl Zeiss Meditec, Dublin, CA) to evaluate central corneal thickness (CCT) and peripheral corneal thickness (PCT), and Scheimpflug imaging (Pentacam HR; Oculus, Wetzlar, Germany) to calculate corneal volume (CV). Corneal decompensation was defined as decreased visual acuity attributable predominantly to increased corneal thickness and corneal edema visible during slit-lamp examination and resulting in DSAEK surgery.

We tried to measure endothelial cell density (ECD) counts using the NonCon Robo SP-9000 non-contact specular microscope (Konan Medical Inc., Hyogo, Japan) preoperatively, and at 3 and 6 months postoperatively. However, due to corneal guttae reliable ECD measurements, i.e. three consecutive endothelial images of the central cornea where the centers of approximately 50 contiguous cells should be marked, could only be obtained in 2 eyes in the longitudinal group and 3 eyes in the torsional group. Therefore, we decided not to mention these results in the manuscript. All patients had confluent guttae on specular microscopy, which made ECD counts impossible. Except for the 5 mentioned eyes, they showed some spread-out guttae in the photographed area (ECD range $1597-2359$ cells $/ \mathrm{mm}^{2}$ ).

\section{Anterior Segment Optical Coherence Tomography}

AS-OCT images were made using the Visante OCT Model 1000 with software version 2.0. At each visit one Enhanced Anterior Segment-scan was obtained on the horizontal meridian in an unaccommodated state under the same light conditions (50 lux). The 'chamber-function' was used to evaluate anterior chamber depth (ACD). To evaluate corneal thickness at different locations, three consecutive Global Pachymetric Maps were made (composed of 16 scans, on 16 meridians). Mean (of 3 consecutive scans) CCT and mean PCT at the 6 (opposite to incision site), and 12 (at incision site) o'clock position were used for analysis.

\section{Scheimpflug Imaging}

The Pentacam HR type 70900 is a non-contact device which can calculate CV using a rotating Scheimpflug camera. The patient was asked to fixate on a blue light target in the center of the camera, which obtained 25 slit images of the anterior segment. At each visit, three consecutive images were obtained to evaluate CV (mean was used for statistical analysis).

\section{Surgical Procedure}

All surgeries were performed by the same experienced cataract surgeon (RN). In both groups the same phacoemulsification procedure was followed using the divide and conquer nucleofractis technique ${ }^{19}$, the same phaco tip (45-degree mini flared 
Kelman tip with $0.9 \mathrm{~mm}$ Ultra Sleeve; Alcon, Fort Worth, Texas), and Intrepid FMS tubing (Alcon, Fort Worth, Texas). The only difference was the application of phacoemulsification energy through the phaco needle either by a torsional energy mode delivery or a longitudinal energy mode.

Patients received subtenon anaesthesia in $75 \%$ of eyes $(n=39)$ and retrobulbar anaesthesia in $25 \%$ of eyes $(n=13)$. A $2.2 \mathrm{~mm}$, self-sealing clear corneal incision was made on the 12 o'clock position. The soft shell technique, which combines the dispersive viscoelastic Viscoat (sodium hyaluronate 3.0\%-chondroitin 4.0\%, Alcon Laboratories, Fort Worth, Texas) with the cohesive viscoelastic Provisc (sodium hyaluronate $1.0 \%$, Alcon Laboratories, Fort Worth, Texas), was used to stabilise the anterior chamber and protect the corneal endothelium. A $5.5 \mathrm{~mm}$ capsulorrhexis was created, and hydrodelineation and hydrodissection were accomplished with a stream of balanced salt solution (BSS) from a 27-gauge cannula. Bottle height was the same in both groups ( 80 and $100 \mathrm{~cm} \mathrm{H}_{2} \mathrm{O}$ in sculpt and quadrant removal mode, respectively). Settings for quadrant removal in the longitudinal mode were: surgeon-controlled ultrasound power with a ceiling of $60 \%$ (linear), with a pulse frequency of 30 pulses per second, and a duty cycle of $40 \%$. In the torsional mode settings were $100 \%$ torsional continuous linear. In both groups, the aspiration flow rate was set at $28 \mathrm{cc}$ per minute and the vacuum limit at $350 \mathrm{~mm} \mathrm{Hg}$. After phacoemulsification, a monofocal IOL (AcrySof SN60WF, Alcon, Fort Worth, Texas) was inserted in the bag using the Monarch III IOL Delivery System with a D cartridge (Alcon, Fort Worth, Texas).

Intraoperatively, we measured total US time in minutes which represents the foot pedal time in position 3, cumulative dissipated energy (CDE), aspiration time in minutes, balanced salt solution (BSS) use during the different surgical steps (sculpt, quadrant removal, and irrigation/aspiration) and total operating time in minutes. Total US time, CDE, aspiration time were all automatically calculated by the phacomachine. Intraoperatively, the BSS bottle was attached to a scale which measured the BSS consumption during the different operating steps. The occurrence of surgical complications during cataract surgery were documented.

\section{Statistical Analysis}

All data were collected in an Excel-database and exported to SPSS (SPSS for Windows, version 15.0, SPSS Inc, Chicago, IL) for data analysis. All categorical data are presented as percentages and continuous variables as mean \pm standard deviation with ranges. The primary outcome parameter was the change in corneal thickness and volume 1 day and 1 week after cataract surgery, meaning the change from baseline to postoperatively. Our sample size calculation was based on changes in CCT from baseline to 1 day and 1 week after cataract surgery. Therefore, the a priori agreed time points were 1 and 7 days postoperatively. The mean change of corneal 
thickness and volume in the torsional group was compared to the mean change of corneal thickness and volume in the longitudinal group. Significance and $95 \%$ confidence intervals were tested using a linear mixed model analysis to correct for repeated measures, as were all other mentioned outcome measurements. Paired ttests were used to evaluate the within-group changes. Correlations were assessed using the Pearson or Kendall's tau correlation coefficient, depending on the outcome variable. Logistic regression analyses was performed to assess the data's predictive ability in determining the occurrence of corneal decompensation needing DSAEK surgery. Using this analysis, we present a mathematical model to quantify the risk of corneal decompensation after phacoemulsification. A $P$-value of $<0.05$ was considered significant.

\section{Sample size calculation}

In this study, we compared the increase in corneal thickness after cataract surgery of two groups: group I is treated with the torsional US mode and group II is treated with the longitudinal US mode. Zeng et al. ${ }^{16}$ compared torsional US to longitudinal US in eyes with hard nucleus cataract. They reported a standard deviation of $12 \mu \mathrm{m}$ in the difference between preoperative and postoperative corneal thickness measurements in both groups. The increase in corneal thickness is expected to be $12 \mu \mathrm{m}$ larger in group II than in group I, which is the mean difference between the torsional and longitudinal group on day 1 and 7 in the above mentioned study. Sample size calculation (independent study design) for a 0.05 level of significance with $90 \%$ power and the above mentioned values, indicated 22 eyes in each group. ${ }^{20}$ The loss to follow-up is expected to be around $15 \%$, which results in 26 eyes in each group.

Table 1. Preoperative Patient Demographics

\begin{tabular}{|c|c|c|c|}
\hline \multirow[t]{2}{*}{ Preoperative Variable } & \multicolumn{2}{|c|}{ Mean \pm Standard Deviation } & \multirow{2}{*}{$\frac{\text { Mean } \pm \text { Standard Deviation }}{\text { Total Population }(n=52)}$} \\
\hline & Torsional $(n=26)$ & Longitudinal(n=26) & \\
\hline Age (yrs) & $71.8 \pm 8.1$ & $73.0 \pm 7.6$ & $72.4 \pm 7.8$ \\
\hline Number of females ( $n$ ) & 17 & 15 & 32 \\
\hline Stage Fuchs disease & $1.7 \pm 0.8$ & $1.8 \pm 0.8$ & $1.8 \pm 0.8$ \\
\hline LOCS II nucleus density grade & $2.6 \pm 0.9$ & $2.8 \pm 0.9$ & $2.7 \pm 0.9$ \\
\hline $\mathrm{ACD}(\mathrm{mm})$ & $2.60 \pm 0.43$ & $2.45 \pm 0.34$ & $2.53 \pm 0.39$ \\
\hline $\mathrm{CCT}(\mu \mathrm{m})$ & $591 \pm 52$ & $593 \pm 50$ & $592 \pm 50$ \\
\hline РCT 6 o'clock $(\mu \mathrm{m})$ & $639 \pm 53$ & $642 \pm 43$ & $640 \pm 48$ \\
\hline РСТ 12 o'clock $(\mu \mathrm{m})$ & $685 \pm 65$ & $695 \pm 49$ & $690 \pm 57$ \\
\hline Corneal volume $\left(\mathrm{mm}^{3}\right)$ & $60.8 \pm 5.2$ & $60.6 \pm 4.3$ & $60.7 \pm 4.7$ \\
\hline BSCVA (LogMAR) & $0.40 \pm 0.20$ & $0.38 \pm 0.34$ & $0.39 \pm 0.27$ \\
\hline
\end{tabular}




\section{RESULTS}

\section{Patient Population}

Preoperative patient demographics are summarized in Table 1. Figure 1 represents a flow-chart of the participants. Mean CCT of the total study group was $592 \pm 50 \mu \mathrm{m}$ (range 460-720), with $593 \pm 50 \mu \mathrm{m}$ (range 480-660) for the longitudinal group and $591 \pm 52 \mu \mathrm{m}$ (range 460-720) for the torsional group. There were no statistically significant differences between the torsional and longitudinal group for all preoperative variables (all with $P>0.19$ ). No intraoperative complications such as posterior capsule rupture, bleeding, zonulolysis, or dropped nucleus were reported for both groups. Two eyes in the longitudinal group needed one suture (Nylon 10-0) to close the main incision due to thermal injury of the cornea. One of those eyes had a very hard nucleus (LOCS 4), which resulted in a long US time and high CDE. The other eye was a LOCS 3 nucleus with a CDE and US time comparable to others in the LOCS 3 group.

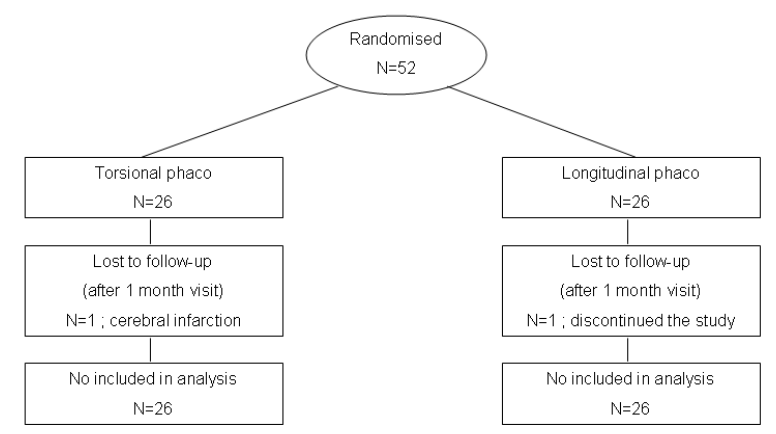

Figure 1. Flow chart of study participants.

\section{Intraoperative Parameters}

Table 2 shows the comparison of all intraoperative parameters between the torsional and longitudinal group. Overall, mean CDE and total US time were significantly lower in the torsional group when compared to the longitudinal group 
$(P=0.001$ and $P=0.003$, respectively). Mean CDE values and total US time for each nucleus density grade are visualized in Figure 2 for both groups.

Table 2. Comparison Intraoperative Parameters

\begin{tabular}{lccc}
\hline Intraoperative Variable & Mean \pm Standard Deviation & $\begin{array}{c}\text { P-Value (independant t- } \\
\text { test) }\end{array}$ \\
\hline & Torsional $(\mathrm{n}=26)$ & Longitudinal $(\mathrm{n}=26)$ & \\
\hline BSS use sculpt mode (ml) & $17.7 \pm 7.4$ & $21.3 \pm 9.0$ & 0.127 \\
BSS use quad removal (ml) & $44.8 \pm 18.0$ & $64.5 \pm 32.8$ & 0.011 \\
BSS use cortex removal (ml) & $38.5 \pm 22.0$ & $37.1 \pm 26.4$ & 0.833 \\
Total BSS use (ml) & $117.4 \pm 36.9$ & $138.0 \pm 56.5$ & 0.127 \\
Total ultrasound time (mm:ss) & $00: 57 \pm 00: 25$ & $01: 29 \pm 00: 44$ & 0.003 \\
CDE & $11.5 \pm 6.1$ & $24.4 \pm 16.7$ & 0.001 \\
Aspiration time (mm:ss) & $05: 19 \pm 01: 38$ & $06: 07 \pm 02: 19$ & 0.151 \\
Estimated fluid use (ml) & $62.8 \pm 16.2$ & $79.7 \pm 31.0$ & 0.018 \\
Operating time (mm:ss) & $10: 26 \pm 03: 08$ & $11: 58 \pm 04: 09$ & 0.140
\end{tabular}

BSS = Balanced Salt Solution Plus (Alcon Laboratories, Fort Worth, Texas); CDE = Cumulative Dissipated Energy

\section{Corneal Thickness and Corneal Volume Changes}

\section{Within group results}

Table 3 and 4 visualize the postoperative changes in CV, CCT and PCT for the torsional and longitudinal group. In the longitudinal group CV and PCT at 6 and 12 o'clock stabilized between 3 and 6 months postoperatively (paired t-test of 3 versus 6 months postoperatively; $P=0.542, P=0.130$, and $P=0.643$, respectively). CCT remained stable from 1 month to 6 months postoperatively in the longitudinal group $(P=0.057)$. In the torsional group stabilisation of CCT and PCT at 6 o'clock was already seen at 1 week postoperatively (all with $P>0.054$ ). Figure 3 (top) visualizes CCT over the course of the study for both groups.

Table 3. Postoperative Changes in Central Corneal Thickness and Corneal Volume

\begin{tabular}{lcccc}
\hline Visit & Change CV \pm Standard Deviation $\left(\mathrm{mm}^{3}\right)$ & \multicolumn{2}{c}{ Change CCT \pm Standard Deviation $(\mu \mathrm{m})$} \\
\hline & Torsional & Longitudinal & Torsional & Longitudinal \\
\hline 1 Day & $10.1 \pm 4.2^{*}$ & $12.8 \pm 5.7^{*}$ & $86 \pm 38^{*}$ & $111 \pm 58^{*}$ \\
1 Week & $6.2 \pm 3.7^{*}$ & $6.0 \pm 3.2^{*}$ & $22 \pm 27^{*}$ & $32 \pm 32^{*}$ \\
1 Months & $2.7 \pm 2.4^{*}$ & $3.0 \pm 2.2^{*}$ & $14 \pm 24^{*}$ & $19 \pm 23^{*}$ \\
3 Months & $1.9 \pm 2.1^{*}$ & $1.7 \pm 2.7^{*}$ & $11 \pm 24^{*}$ & $5 \pm 25^{\mathrm{ns}}$ \\
6 Months & $1.3 \pm 1.6^{*}$ & $1.9 \pm 2.2^{*}$ & $10 \pm 19^{*}$ & $9 \pm 25^{\mathrm{ns}}$ \\
\hline
\end{tabular}

$\mathrm{CV}=$ corneal volume; $\mathrm{CCT}=$ central corneal thickness

* Paired $t$-test comparing preoperative to postoperative values: all with $\mathrm{P}<0.034$

${ }^{n s}$ Paired $t$-test comparing preoperative to postoperative values not significant 


\section{Between group results}

The increases in PCT at the 6 o'clock position, CCT and CV were significantly smaller in the torsional group compared to the longitudinal group at 1 day postoperatively $(P=0.002, P=0.025$ and $P=0.004$, respectively). All other changes in $C C T, C V$ and $P C T$ were not statistically significant between the two groups (all with $P>0.05$ ).
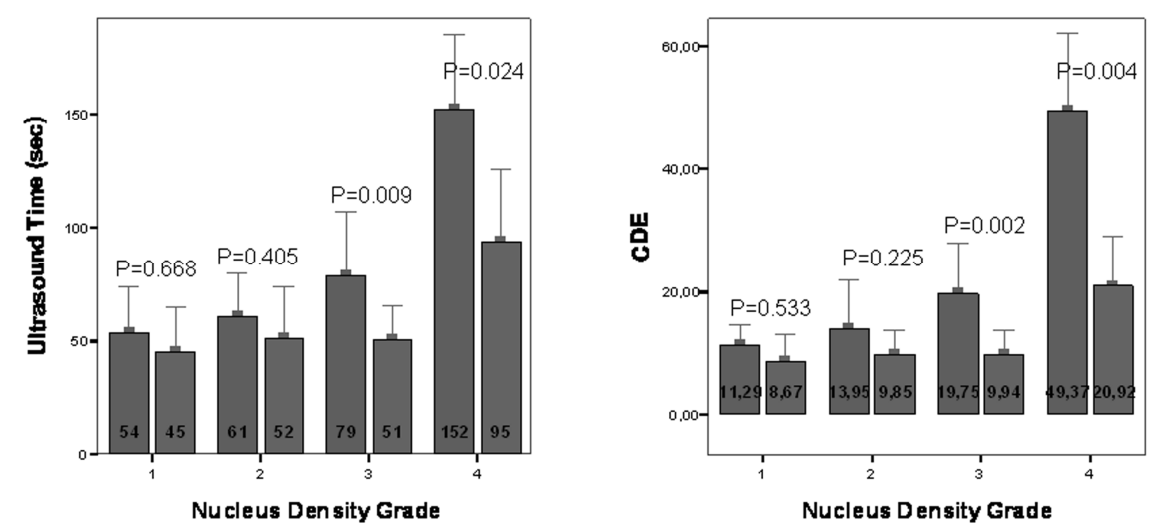

Figure 2. Ultrasound time (left) and Cumulative Dissipated Energy (CDE) (right) for each nucleus density grade, with longitudinal phacoemulsification in the left bars and torsional phacoemulsification in the right bars. P-values: independent sample $t$-test between the two groups.

Table 4. Postoperative Changes in Peripheral Corneal Thickness

\begin{tabular}{lcccc}
\hline Visit & $\begin{array}{c}\text { Change PCT 6 o'clock } \pm \text { Standard Deviation } \\
(\mu \mathrm{m})\end{array}$ & Change PCT 12 o'clock \pm Standard Deviation \\
& \multicolumn{1}{c}{ Torsional } & Longitudinal & Torsional & Longitudinal \\
\hline 1 Day & $44 \pm 35^{*}$ & $74 \pm 46^{*}$ & $180 \pm 85^{*}$ & $160 \pm 67^{*}$ \\
1 Week & $21 \pm 31^{*}$ & $27 \pm 30^{*}$ & $105 \pm 61^{*}$ & $89 \pm 49^{*}$ \\
1 Months & $12 \pm 29^{*}$ & $19 \pm 30^{*}$ & $57 \pm 61^{*}$ & $55 \pm 49^{*}$ \\
3 Months & $17 \pm 42^{\text {ns }}$ & $6 \pm 27^{\text {ns }}$ & $39 \pm 46^{*}$ & $33 \pm 39^{*}$ \\
6 Months & $14 \pm 21^{\text {ns }}$ & $11 \pm 21^{*}$ & $22 \pm 48^{*}$ & $30 \pm 35^{*}$ \\
\hline
\end{tabular}

PCT = peripheral corneal thickness

* Paired $t$-test comparing preoperative to postoperative values: all with $\mathrm{P}<0.032$

${ }^{n s}$ Paired $t$-test comparing preoperative to postoperative values not significant

\section{Changes in Visual Acuity}

\section{Within group results}

Figure 3 (bottom) visualizes BSCVA over the course of the study for both groups. BSCVA did not change between 1 month and 6 months after surgery with $P=0.139$ in the longitudinal and $P=0.704$ in the torsional group. Two eyes had CME with a 
BSCVA of 0.56 and $0.28 \log$ MAR at 3 months postoperatively, and 1 eye had macrophages on the IOL optic with a BSCVA of 0.94 logMAR (all in torsional group). When excluding these 3 eyes in the torsional group, the increase in BSCVA was even more significant at 1,3 and 6 months $(P=0.006 ; P=0.012 ; P=0.006$, respectively).
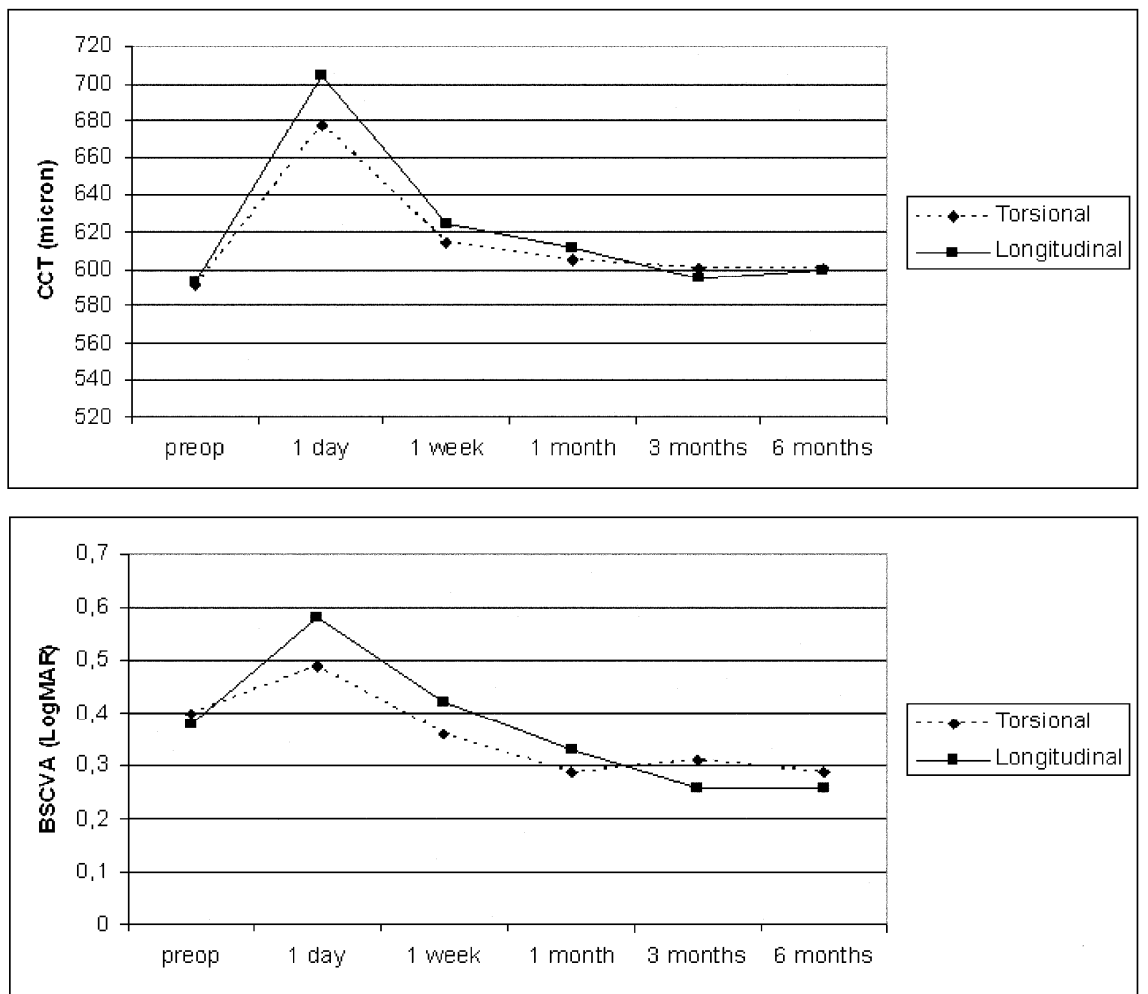

Figure 3. Central corneal thickness (CCT) (top) and best-spectacle corrected visual acuity (BSCVA) (bottom) at each follow-up visit for the longitudinal (full black line) and torsional (dotted black line) group.

\section{Between group results}

There were no significant differences in BSCVA between the two groups for all postoperative visits (all with $P>0.05$ ). A higher postoperative increase of CCT at 1 day was correlated to a lower BSCVA 1 day postoperatively in both groups, with a higher correlation in the torsional group $(r=0.522 \mathrm{P}=0.006)$ compared to the longitudinal group ( $r=0.365 \mathrm{P}=0.065)$.

\section{Correlation Preoperative Corneal Thickness and Other Outcome Parameters}

When evaluating both groups together, a higher preoperative CCT was associated with a more advanced stage of the Fuchs' disease $(r=0.427 ; P=0.002)$. Furthermore, 
a higher preoperative CCT was associated with a larger postoperative increase in CCT $(r=0.460 ; P=0.001$; Figure 4), PCT at incision site $(r=0.309 ; P=0.026), \mathrm{PCT}$ at 6 o'clock ( $r=0.356 ; P=0.010)$, and CV $(r=0.308 ; P=0.026)$ at 1 day postoperatively.

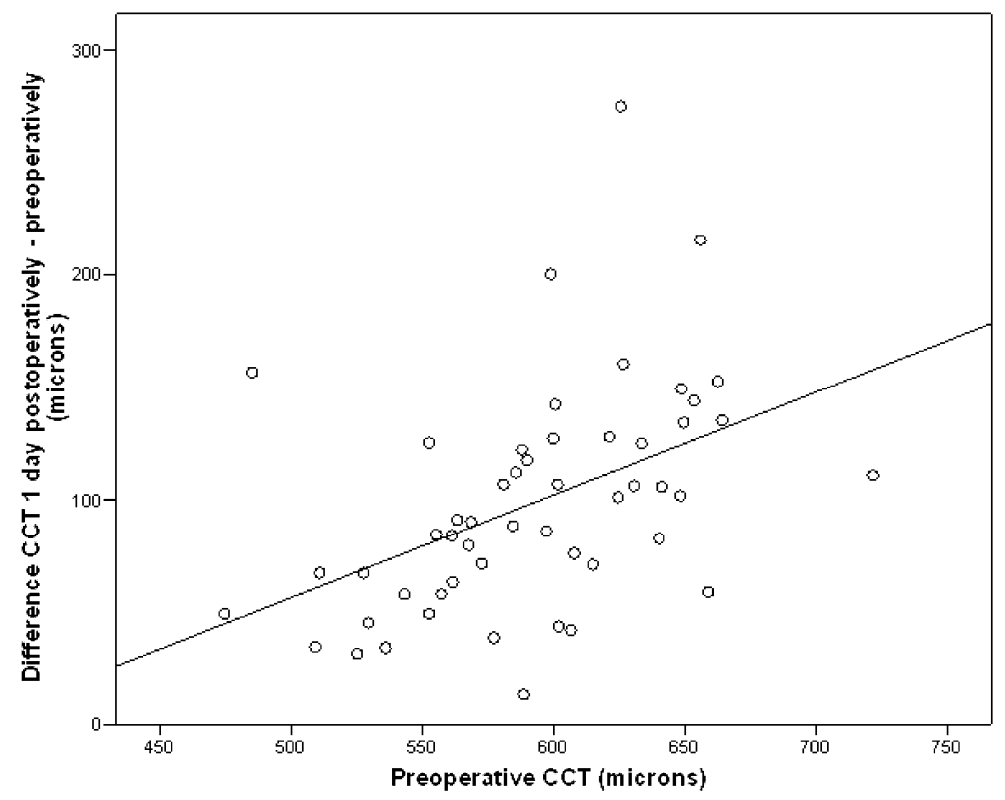

Figure 4. Scatterplot of relationship between preoperative central corneal thickness (CCT) and change in central corneal thickness between baseline and 1 day postoperatively (Pearson correlation coefficient $r=0.460 ; P=0.001$ ).

Preoperatively, there was no correlation between BSCVA and CCT. However, a higher preoperative CCT was correlated to a lower postoperative BSCVA at all follow-up visits (all with $r>0.344 ; P<0.015$; Figure 5 ).

There was no correlation between CV and stage of FED or any of the other outcome parameters.

\section{Risk Factors for Eventual DSAEK Surgery}

A total of 16 out of 50 eyes (30.8\%), 8 in the torsional and 8 in the longitudinal group, required DSAEK surgery due to corneal decompensation 6 months postoperatively. Figure 6 shows the distribution of eyes having DSAEK surgery as a function of their preoperative CCT. Mean preoperative CCT, PCT at 6 and 12 o'clock, and $\mathrm{CV}$ were significantly higher in the group that needed DSAEK surgery when compared to the group that did not need DSAEK surgery (Table 5; all with $P<0.022$ ). 
After logistic regression analysis, only preoperative CCT was a significant predictor of needing DSAEK surgery postoperatively $(P<0.001)$. An increase in preoperative CCT resulted in an increased risk of corneal decompensation postoperatively. All other preoperative and intraoperative parameters, including torsional and longitudinal phacoemulsification, did not significantly contribute to the risk of corneal decompensation postoperatively. Based on estimated coefficients, the following logistic regression equation was determined to estimate the probability $(P)$ of developing corneal decompensation in relation to preoperative corneal thickness: $P$ $($ DSAEK $)=1 /\left(1+\mathrm{e}^{-(-31.6+0.051 \text { (preCCT) }}\right)$. In this equation preoperative CCT is measured in units of 1 micron. The model predicts that for each 10 microns increase in preoperative CCT the probability of development of corneal decompensation increased with an odds ratio of 1.7 (95\% Cl 1.3-2.2; $P<0.001)$. A preoperative CCT of 620 microns corresponds to an odds ratio of 1 , meaning no increased risk of developing corneal decompensation.

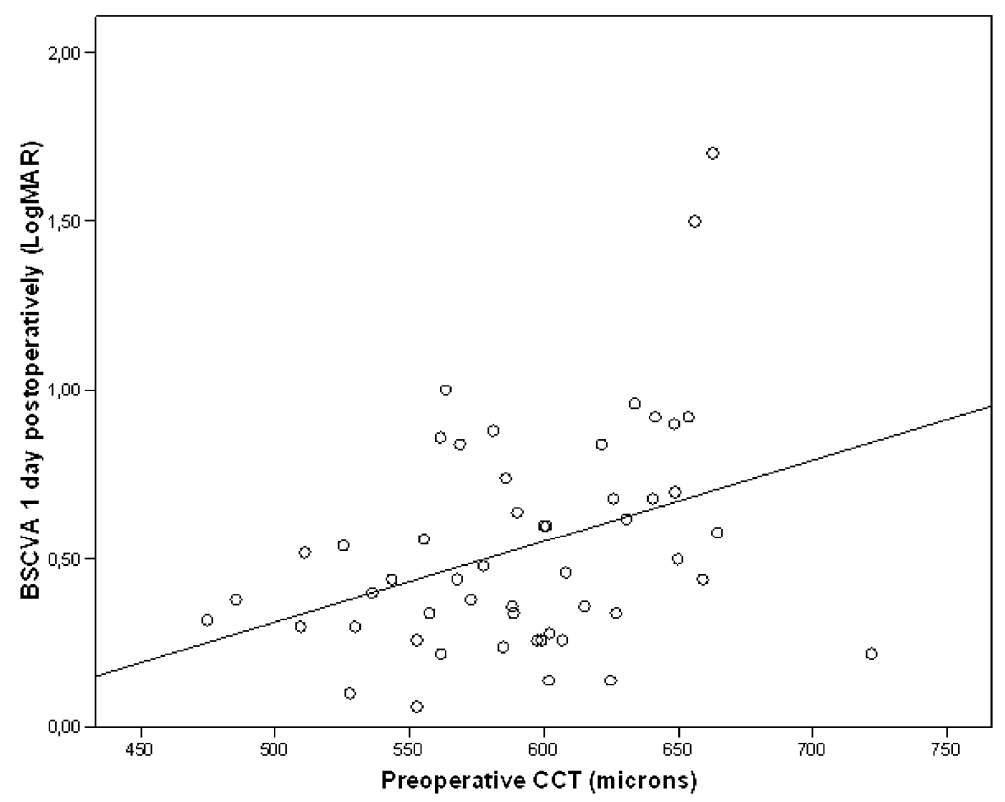

Figure 5. Scatterplot of relationship between preoperative central corneal thickness (CCT) and best spectacle corrected visual acuity (BSCVA) 1 day postoperatively (Pearson correlation coefficient $r=0.369$; $\mathrm{P}=0.007)$.

The model correctly identified 12 of the 16 eyes (75\% sensitivity) having DSAEK surgery, and identified 30 out of 34 eyes ( $88.2 \%$ specificity) not having DSAEK surgery, with an overall accuracy of the model of $84 \%$. 
Table 5. Preoperative Factors and Postoperative Corneal Decompensation

\begin{tabular}{|c|c|c|c|}
\hline \multirow[t]{2}{*}{ Preoperative Variable } & \multicolumn{2}{|c|}{ Corneal Decompensation } & \multirow[t]{2}{*}{ P-Value* } \\
\hline & Yes $(n=16)$ & No $(n=34)$ & \\
\hline BSCVA (LogMAR) & $0.45 \pm 0.20$ & $0.37 \pm 0.30$ & 0.332 \\
\hline CCT (microns) & $637 \pm 35$ & $569 \pm 42$ & $<0.001$ \\
\hline РCT 6 o'clock (microns) & $662 \pm 33$ & $624 \pm 45$ & 0.004 \\
\hline PCT 12 o'clock (microns) & $714 \pm 41$ & $675 \pm 60$ & 0.021 \\
\hline Corneal volume $\left(\mathrm{mm}^{3}\right)$ & $62.9 \pm 3.4$ & $59.3 \pm 4.8$ & 0.010 \\
\hline \multicolumn{4}{|c|}{ Data are mean values \pm standard deviation } \\
\hline \multicolumn{4}{|c|}{$\begin{array}{l}\text { BSCVA = best spectacle corrected visual acuity; } C C T=\text { central corneal thickness; } P C T=\text { peripheral corneal } \\
\text { thickness }\end{array}$} \\
\hline
\end{tabular}

\section{DISCUSSION}

This randomized controlled trial compared torsional and longitudinal phacoemulsification in patients with a compromised corneal endothelium (FED). Preoperative randomization ensured that age, nucleus density grade, and stage of the Fuchs' disease were not significantly different between the two groups. Contrary to the previously reported benefits of the torsional mode in healthy eyes ${ }^{15,16}$ we only found significant differences in corneal thickness and $\mathrm{CV}$ changes at 1 day postoperatively, in favour of the torsional group. However, stabilization of CCT occurred faster in the torsional group than the longitudinal. Furthermore, we found that during surgery both CDE and US time were reduced by $53 \%$ and $36 \%$ in the torsional group when compared to the longitudinal group, respectively. This is in accordance with previous reports comparing longitudinal and torsional phaco in healthy eyes. ${ }^{15}$ ${ }^{17}$ An explanation for the discrepancy between our results and previous studies could be in our sample size calculation. We used a standard deviation of 12 microns in CCT to calculate our sample size from the study of Zeng et al. performed in healthy corneas. ${ }^{16}$ Unfortunately, there were no data available for patients with a compromised corneal endothelium at the time of the start of this study. In our study, the standard deviation of the change in CCT 1 and 7 days postoperatively ranged from 27 to 58 micron, which is much larger than the 12 microns used for our sample size calculation. This might have resulted in a lower power than previously expected. However, we were not surprised to find a larger standard deviation in these FED patients, since we included a broad range of FED stages.

In longitudinal phaco, the phaco tip pushes the nucleus away during its forward stroke. This mechanism produces repulsion. Torsional phaco uses rotary oscillations of the phaco tip, which might reduce repulsion. The current study showed that PCT at the 6 o'clock position, which is opposite to the incision site, was significantly 
lower 1 day postoperatively in the torsional group. We believe this might be the result of less repulsion when using torsional phacoemulsification.

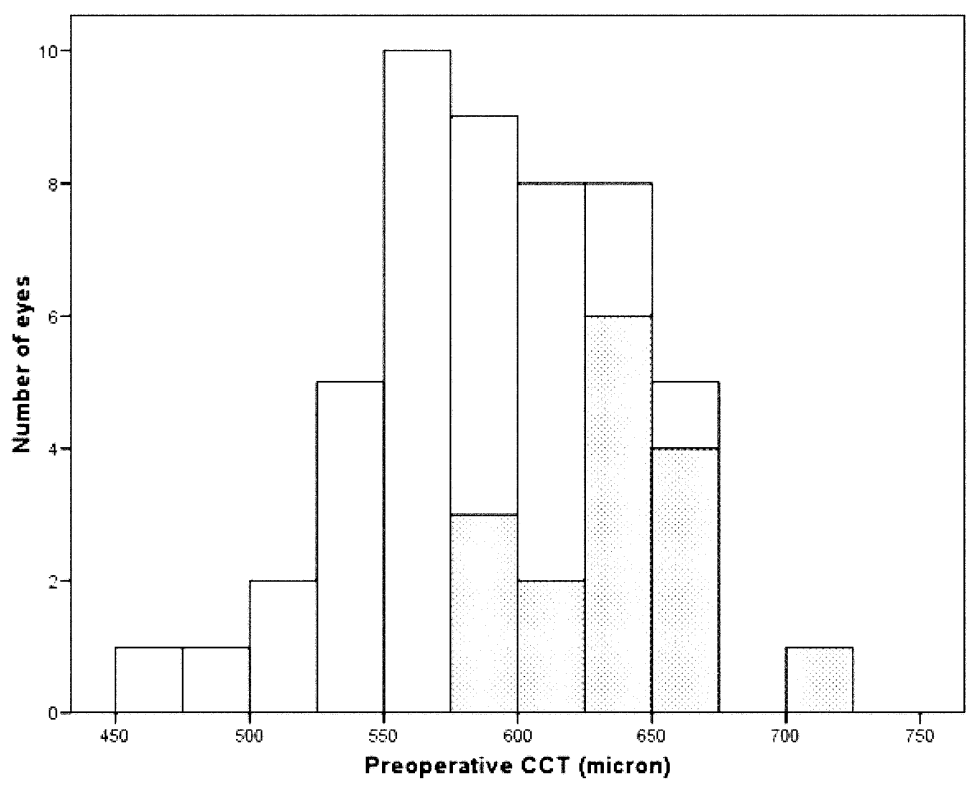

Figure 6. Histogram representing Fuchs endothelial dystrophy patients needing Descemet stripping automated endothelial keratoplasty (DSAEK) surgery after cataract extraction (gray boxes) versus patients not needing DSAEK surgery (white boxes), arranged according to their preoperative central corneal thickness (CCT).

Furthermore, we prospectively investigated the preoperative risk factors for postoperative corneal decompensation in patients with FED. As mentioned, a retrospective study by Seitzman et al. suggested a preoperative corneal thickness below $640 \mu \mathrm{m}$ as a safe thickness for considering careful phacoemulsification in many patients with FED and visually significant cataract. ${ }^{3}$ The presented prediction model in the current study demonstrated that a preoperative CCT over $620 \mu \mathrm{m}$ results in an increased risk of corneal decompensation needing DSAEK surgery 6 months after phacoemulsification. All values below 620 microns have no increased risk of corneal decompensation after phacoemulsification, according to our model. This model suggests that the previously described safety limit of $640 \mu \mathrm{m}$ might be too high for some patients. However, we measured CCT using AS-OCT, a non contact method, whereas Seitzman et al. measured CCT using ultrasound pachymetry, which is a contact method. ${ }^{3}$ Two recent studies found that CCT measurements using AS-OCT were consistently lower than ultrasound measurements, with mean differences of 
$16.5 \pm 11.7 \mu \mathrm{m}$ and $26.3 \pm 14.2 \mu \mathrm{m} .{ }^{21,22}$ These mean differences correspond to the difference in CCT found in our study compared to the study by Seitzman et al. ${ }^{3}$

Unfortunately, there is a lack of data on normal CCT values in patients with FED. Therefore, it is difficult to advise an absolute cut-off value of CCT for corneas at risk of decompensation. Our model found a cut-off point of $620 \mu \mathrm{m}$, which is quite similar to the previous study by Seitzman et al., when taking measurement differences into account. ${ }^{3}$ However, to increase the validity of the presented model, it should be applied to a second independent population for validation.

One of the limitations of a prediction model in general is the uncertainty of extrapolation of the data outside the ranges of the estimated values. Therefore, we included FED patients in all stages, to come up with a wide range in preoperative CCT and built a prediction model applicable to most FED patients. However, this did result in quite a large rate of eyes eventually having DSAEK surgery (30.8\%).

All important outcome parameters, i.e. BSCVA and CCT, remained stable 1 month after cataract extraction. Therefore, when patients are not satisfied with their visual acuity postoperatively, ophthalmologists can advise them to wait until their one month visit and then decide whether to perform corneal transplantation surgery. This decision does not have to be postponed to 3 or 6 months postoperatively.

In conclusion, torsional and longitudinal phaco show no long term clinically significant differences in postoperative CCT, PCT, CV and BSCVA. Only CCT stabilized faster in the torsional group when compared to the longitudinal group. The presented model calculates the risk for corneal decompensation after phacoemulsification in patients with FED using preoperative corneal thickness measured with ASOCT. Using AS-OCT, a CCT above 620 microns leads to an increased risk for corneal decompensation after phacoemulsification in patients with FED. This information can assist us in optimalisation of patient selection and counselling and prevent corneal decompensation after cataract surgery in FED patients. 


\section{REFERENCES}

1. Adamis AP, Filatov V, Tripathi BJ, Tripathi RC. Fuchs' endothelial dystrophy of the cornea. Surv Ophthalmol 1993;38(2):149-168.

2. Fuchs E. Dystrophia epithelialis corneae. Albrecht von Graefes Arch Klin Ophthalmol 1910;76:478 508.

3. Seitzman GD, Gottsch JD, Stark WJ. Cataract surgery in patients with Fuchs' corneal dystrophy: expanding recommendations for cataract surgery without simultaneous keratoplasty. Ophthalmology 2005(3);112:441-446.

4. Luo YH, Wong R. Cataract surgery and Fuchs' corneal dystrophy. Ophthalmology 2005;112(11):2054; author reply 2054-2055.

5. Ambrosio R, Jr., Netto MV, Wilson SE. Surgery in patients with Fuchs'. Ophthalmology 2006;113(3):503; author reply 504.

6. Ti SE, Chee SP. Cataract surgery in patients with Fuchs'. Ophthalmology 2006;113(10):1883-1884

7. Diaz-Valle D, Benitez del Castillo Sanchez JM, Castillo A, Sayagues O, Moriche M. Endothelial damage with cataract surgery techniques. J Cataract Refract Surg 1998;24(7):951-955.

8. Sandoval HP, de Castro LE, Vroman DT, Solomon KD. Randomized, double-masked clinical trial evaluating corneal endothelial cell loss after cataract extraction and intraocular lens implantation: Fluidbased system versus ultrasound phacoemulsification. Cornea 2006;25(9):1043-1045.

9. Alio JL, Mulet ME, Shalaby AM, Attia WH. Phacoemulsification in the anterior chamber. J Cataract Refract Surg 2002;28(1):67-75.

10. Walkow T, Anders N, Klebe S. Endothelial cell loss after phacoemulsification: relation to preoperative and intraoperative parameters. J Cataract Refract Surg 2000;26(5):727-732.

11. DeBry P, Olson RJ, Crandall AS. Comparison of energy required for phaco-chop and divide and conquer phacoemulsification. J Cataract Refract Surg 1998;24(5):689-692.

12. Vargas LG, Holzer MP, Solomon KD, Sandoval HP, Auffarth GU, Apple DJ. Endothelial cell integrity after phacoemulsification with 2 different handpieces. J Cataract Refract Surg 2004;30(2):478-482.

13. O'Brien PD, Fitzpatrick P, Kilmartin DJ, Beatty S. Risk factors for endothelial cell loss after phacoemulsification surgery by a junior resident. J Cataract Refract Surg 2004;30(4):839-843.

14. Packer M, Fishkind WJ, Fine IH, Seibel BS, Hoffman RS. The physics of phaco: a review. J Cataract Refract Surg 2005;31(2):424-431.

15. Liu Y, Zeng $M$, Liu X, et al. Torsional mode versus conventional ultrasound mode phacoemulsification: randomized comparative clinical study. J Cataract Refract Surg 2007;33(2):287-292.

16. Zeng $M$, Liu $Y$, Liu $X$, et al. Torsional ultrasound modality for hard nucleus Phacoemulsification cataract extraction. Br J Ophthalmol 2008;92(8):287-292.

17. Rekas M, Montés-Micó R, Krix-Jachym K, Klus A, Stankiewicz A, Ferrer-Blasco T. Comparison of torsional and longitudinal modes using phacoemulsification parameters. J Cataract Refract Surg 2009;35(10):1719-1724.

18. Chylack LT, Jr., Leske MC, McCarthy D, Khu P, Kashiwagi T, Sperduto R. Lens opacities classification system II (LOCS II). Arch Ophthalmol 1989;107(7):991-997.

19. Gimbel HV. Divide and conquer nucleofractis phacoemulsification: development and variations. J Cataract Refract Surg 1991;17(3):281-291.

20. Dupont WD, Plummer WD. PS power and sample size program available for free on the internet. Controlled Clinical Trials 1997;18(3):274-274.

21. Zhao PS, Wong TY, Wong WL, Saw SM, Aung T. Comparison of central corneal thickness measurements by visante anterior segment optical coherence tomography with ultrasound pachymetry. Am J Ophthalmol 2007;143(6):1047-1049.

22. Kim HY, Budenz DL, Lee PS, Feuer WJ, Barton K. Comparison of central corneal thickness using anterior segment optical coherence tomography vs ultrasound pachymetry. Am J Ophthalmol 2008;145(2):228-232. 

Chapter 10

General Discussion 


\section{GENERAL DISCUSSION}

Anterior segment imaging has become an important part of current ophthalmic practice. The greatest advantage of anterior segment optical coherence tomography (AS-OCT) is its non-contact technique, which enables us to examine the anterior segment with maximal patient comfort. This thesis describes several new possibilities of AS-OCT, particularly the Visante OCT, in refractive surgery, cataract surgery and corneal cross-linking (CXL). Most importantly, it shows the usefulness of this device in enhancing the safety of the aforementioned procedures.

The use of iris-fixated phakic intraocular lenses (pIOL) was first described in $1989,{ }^{1}$ with the first implantation in 1986. Numerous clinical studies have demonstrated that the visual results after iris-fixated plOL implantation with an Artisan or Artiflex lens are stable and predictable. ${ }^{2-4}$ However, the long-term effect of irisfixated pIOLs on the corneal endothelium remains a point of discussion. Several studies show that the endothelial cell loss is higher than the previously described natural yearly endothelial cell loss of $0.6 \%$ in virgin eyes. ${ }^{2,5-8}$ In 2008, a significant endothelial cell loss after Artisan implantation was reported, with a negative correlation between anterior chamber depth and endothelial cell loss; meaning that a shallower anterior chamber corresponds to a larger endothelial cell loss. During this period, some new concepts were introduced in the scene of iris-fixated plOL implantation. Terms like lens rise ${ }^{9}$ (the distance from the anterior surface of the crystalline lens to the horizontal line between the two angle recesses) and iris configuration became important patient selection criteria. These parameters are difficult to assess behind the slit-lamp, but can easily be visualized with an anterior segment imaging device. Furthermore, ophthalmologists became interested in the actual position of the iris-fixated $\mathrm{plOL}$ in the anterior chamber.

Several imaging techniques are currently available to visualize the anterior segment: Scheimpflug imaging, ultrasound biomicroscopy (UBM) and AS-OCT. Scheimpflug imaging can accurately measure anterior segment dimensions in a noncontact manner. ${ }^{10}$ It can visualize plOLs in the anterior chamber and measure distances from the crystalline lens and corneal endothelium. ${ }^{11}$ The new Pentacam software (Oculus, Wetzlar, Germany) even provides a plOL simulation programme for iris-fixated plOLs. However, this technique is based on a photography technique; it needs an optically clear cornea to visualize the anterior segment. Therefore, it can not be used in patients after corneal decompensation. UBM is a contact technique, which can be used through an opaque cornea. However, it has some disadvantages due to its contact method, like patient discomfort and risk of corneal abrasion. For imaging anterior segment dimensions, non-contact techniques have replaced UBM. Although, when there is a suspected problem behind the iris pigmented epithelium, 
it is the most reliable technique available, since Scheimpflug imaging and AS-OCT can not pass through the pigmented posterior layer of the iris. ${ }^{12}$

This thesis demonstrates the possibility of AS-OCT to visualize the iris-fixated pIOL in the anterior chamber, to measure distances from the pIOL to the endothelium and the crystalline lens, and to simulate the position of the iris-fixated pIOL preoperatively. Furthermore, the importance of these measurements for the clinical day-to-day practice is shown in several studies throughout this thesis.

The significance of measuring the edge distance (distance from the edge of the pIOL to the corneal endothelium) is clearly demonstrated, since a shorter edge distance was associated with a larger yearly endothelial cell loss. A model is described which can help the ophthalmologist to predict when a certain critical ECD count is reached after pIOL implantation, taking the edge distance into account. The pIOL simulation of the Visante OCT can be used to measure the edge distance, which can be valuable during patient selection and can be used in the presented model. This simulation program was capable of producing a reliable estimation of the actual postoperative $\mathrm{pIOL}$ position. The prediction model and $\mathrm{plOL}$ simulation can be used for counseling potential refractive surgery candidates. When the patient is not suitable for pIOL implantation due to a shallow anterior chamber with a small edge distance or a convex iris configuration, the ophthalmologist can show the anterior segment of the eye with the simulated $\mathrm{pIOL}$ in place. This gives the rejected patient a clear picture of the problem and therefore might prevent extensive health care shopping. Furthermore, the position of the iris-fixated pIOL should be monitored during long-term follow-up, since it is known that the anterior chamber shallows with increasing age due to changes in the crystalline lens, which leads to a decrease in edge distance. Future research should be aimed towards evaluating the effect of age-related changes of the natural lens on the edge distance, which could eventually lead to a new mathematical model with an accurate estimation of the decrease in edge distance over time.

This thesis also demonstrates the value of AS-OCT in patients with progressive keratoconus. CXL is the only available therapy to stabilize these patients, leading to a mechanical strengthening of the cornea. ${ }^{13}$ AS-OCT can visualize the stromal demarcation line, which represents the border between cross-linked and untreated corneal stroma. The depth of this demarcation line can be measured, and should be at $60 \%$ of the corneal depth. The currently used CXL technique is a time consuming operation, since it involves abrading the cornea, instilling riboflavine drops on the cornea for 30 minutes and performing ultraviolet-A (UVA) radiation for 30 minutes. Several research groups are currently evaluating the effects of different CXL techniques, for example without abrading the cornea, using different osmolarities of riboflavine solution with shorter instillation time, and irradiating the cornea for a shorter period of time but with higher UVA power. However, developers of the 
traditional CXL technique question if these modified techniques strengthen the deeper layers of the corneal stroma. In the future, the effects of these new methods can be demonstrated not only by evaluating the stability of clinical keratoconus parameters, but also by measuring demarcation line depth using AS-OCT.

Furthermore, the ability of AS-OCT to measure corneal thickness in patients with Fuchs' endothelial dystrophy needing cataract surgery is evaluated. Recent research indicates that monitoring central corneal thickness changes in Fuchs' endothelial dystrophy during follow-up could be a more sensitive measure of disease progression than slit lamp evaluation of corneal edema. ${ }^{14}$ Counselling patients with this disease before cataract surgery is extremely important, since corneal decompensation can occur postoperatively. Seitzman et al. suggested that most patients with Fuchs' dystrophy and a preoperative corneal thickness $<640$ micron can undergo cataract surgery without postoperative corneal decompensation. ${ }^{15}$ In their study, pachymetry measurements were performed using ultrasound pachymetry. However, AS-OCT can measure corneal thickness in a non-contact matter. Nowadays, many ophthalmologists use non-contact devices to measure corneal thickness. As demonstrated in several articles, contact and non-contact devices can not be used interchangeably. ${ }^{16-18}$ In this thesis, the cut-off value to safely perform cataract surgery in patients with Fuchs' dystrophy is 620 micron using the Visante OCT. For each 10 microns increase in preoperative corneal thickness, the odds of developing postoperative corneal decompensation are increased 1.7 times. Cataract surgeons are provided with the opportunity to calculate the risk for corneal decompensation prior to cataract surgery. This can be helpful in counselling patients preoperatively, giving them realistic expectations regarding their visual outcome. 


\section{REFERENCES}

1. Fechner PU, van der Heijde GL, Worst JG. The correction of myopia by lens implantation into phakic eyes. Am J Ophthalmol 1989;107(6):659-63.

2. Stulting RD, John ME, Maloney RK, et al. Three-year results of Artisan/Verisyse phakic intraocular lens implantation. Results of the United States Food And Drug Administration clinical trial. Ophthalmology 2008;115(3):464-72.e1.

3. Tahzib NG, Nuijts RM, Wu WY, Budo CJ. Long-term study of Artisan phakic intraocular lens implantation for the correction of moderate to high myopia: ten-year follow-up results. Ophthalmology 2007;114(6):1133-42.

4. Tehrani M, Dick HB. Short-term follow-up after implantation of a foldable iris-fixated intraocular lens in phakic eyes. Ophthalmology 2005;112(12):2189-95.

5. Benedetti S, Casamenti V, Benedetti M. Long-term endothelial changes in phakic eyes after Artisan intraocular lens implantation to correct myopia: five-year study. J Cataract Refract Surg 2007;33(5):784-90.

6. Bourne WM, Nelson LR, Hodge DO. Central corneal endothelial cell changes over a ten-year period. Invest Ophthalmol Vis Sci 1997;38(3):779-82.

7. Dick HB, Alio J, Bianchetti M, et al. Toric phakic intraocular lens: European multicenter study. Ophthalmology 2003;110(1):150-62.

8. Pop M, Payette Y. Initial results of endothelial cell counts after Artisan lens for phakic eyes: an evaluation of the United States Food and Drug Administration Ophtec Study. Ophthalmology 2004;111(2):309-17.

9. Baikoff G, Bourgeon G, Jodai HJ, et al. Pigment dispersion and Artisan phakic intraocular lenses: crystalline lens rise as a safety criterion. J Cataract Refract Surg 2005;31(4):674-80.

10. Espandar L, Meyer JJ, Moshirfar M. Phakic intraocular lenses. Curr Opin Ophthalmol 2008;19(4):34956.

11. Tehrani M, Dick HB. Scheimpflug biometry of the anterior segment after implantation of foldable irisfixated lenses. J Refract Surg 2006;22(3):243-6.

12. Bianciotto C, Shields CL, Guzman JM, et al. Assessment of anterior segment tumors with ultrasound biomicroscopy versus anterior segment optical coherence tomography in 200 cases. Ophthalmology 2011;118(7):1297-302.

13. Spoerl E, Huhle M, Seiler T. Induction of cross-links in corneal tissue. Exp Eye Res 1998;66(1):97-103.

14. Kopplin LJ, Przepyszny K, Schmotzer B. Relationship of Fuchs Endothelial Corneal Dystrophy Severity to Central Corneal Thickness. Arch Ophthalmol 2012;130(4):433-439.

15. Seitzman GD, Gottsch JD, Stark WJ. Cataract surgery in patients with Fuchs' corneal dystrophy: expanding recommendations for cataract surgery without simultaneous keratoplasty. Ophthalmology 2005;112(3):441-6.

16. Chakrabarti HS, Craig JP, Brahma A, et al. Comparison of corneal thickness measurements using ultrasound and Orbscan slit-scanning topography in normal and post-LASIK eyes. J Cataract Refract Surg 2001;27(11):1823-8.

17. Fujioka M, Nakamura M, Tatsumi $Y$, et al. Comparison of Pentacam Scheimpflug camera with ultrasound pachymetry and noncontact specular microscopy in measuring central corneal thickness. Curr Eye Res 2007;32(2):89-94.

18. Kim HY, Budenz DL, Lee PS, et al. Comparison of central corneal thickness using anterior segment optical coherence tomography vs ultrasound pachymetry. Am J Ophthalmol 2008;145(2):228-32. 

Summary

Samenvatting 


\section{SUMMARY}

Anterior segment optical coherence tomography (AS-OCT) is a rapidly evolving noncontact method for imaging the anterior segment of the eye. The aim of this thesis was to evaluate and explore the possibilities of AS-OCT (in particular the Visante $\mathrm{OCT}$ ) in the field of refractive surgery, cataract surgery and corneal cross-linking.

Chapter 1 summarizes the current research and practical applications of AS-OCT. Several biometry measurements can be performed, including a quantitative and qualitative assessment of the anterior chamber angle, corneal thickness, anterior chamber depth (ACD), angle-to-angle distance, crystalline lens rise and crystalline lens thickness. Furthermore, pathological changes in the anterior segment of the eye can be visualized, for example corneal opacities, uveitis and foreign bodies. LASIK-flap thickness, depth of intracorneal ring segments and safety distances of phakic intraocular lenses (pIOLs) can be measured. Finally, changes after corneal lamellar or penetrating keratoplasty can be easily demonstrated, even when the cornea is cloudy.

To study the reliability and agreement of central corneal thickness (CCT) and ACD measurements using AS-OCT, we compared them with a Scheimpflug device (Pentacam) and the Orbscan II (Chapter 2). The intraobserver reliability of AS-OCT is excellent for central corneal thickness (CCT) and anterior chamber depth (ACD) measurements. However, Pentacam, Orbscan II and AS-OCT measurements should not be used interchangeably for measurement of ACD and CCT in healthy subjects and patients after plOL implantation. Pair wise comparison of these imaging technologies show significant mean differences, with large $95 \%$ limits of agreement.

Chapter 3 evaluates the position of various iris-fixated pIOL models in the anterior chamber using AS-OCT and the effect of this position on the corneal endothelium. The distance from the edge of the plOL to the corneal endothelium is considered the shortest distance to the endothelium. It has already been established that yearly endothelial cell density (ECD) measurements prior to and after pIOL implantation are mandatory to monitor the long-term effect of the pIOL on the endothelium. We found that a shorter distance between the edge of the pIOL and the endothelium is associated with higher endothelial cell loss. Therefore, we believe that besides yearly ECD measurements, anterior chamber morphometrics should be carefully monitored during the follow-up of patient with pIOLs. Especially since the distance from the edge of the pIOL to the endothelium will decrease due to age-related changes of the crystalline lens. 
Chapter 4 investigates the precision of a new preoperative simulation program of the Visante OCT for iris-fixated pIOLs. It compares preoperative anterior chamber morphometrics to the actual postoperative position of the pIOL. Measured distances included: center of pIOL to endothelium, edge of pIOL to endothelium (nasal and temporal side) and back of pIOL to crystalline lens. Bland-Altman plots show small mean differences between the preoperative simulation and actual postoperative position. However, clinicians should be aware of the presented ranges of agreement between 0.24 and $0.29 \mathrm{~mm}$, which could be clinically relevant. One of the parameters responsible for this range is preoperative pupil size. The larger the pupil, the further the pIOL simulation model should be placed to the back of the iris tissue. Overall, the pIOL simulation program is a useful additional tool in the selection of patients considering pIOL implantation.

After demonstrating the importance of evaluating the edge distance before and after plOL implantation, Chapter 5 presents a linear model to assist ophthalmologists in patient selection and follow-up of pIOLs. This linear model predicts ECD counts during the follow-up of iris-fixated pIOL implantation in relation to the measured edge distance, patient age and preoperative ECD. Preoperative simulation is a useful tool in determining edge distance in the preoperative patient, which can be used in the presented model. However, as mentioned before, it is known that $A C D$ decreases with age, which might result in a decrease in the minimum edge distance over time. A longer follow-up with AS-OCT will be needed to evaluate the effect of age-related changes of the natural lens on the distance from the edge of the pIOL to the endothelium. We hope this leads to the development of an adequate mathematical description of the postoperative endothelial cell loss with an accurate estimation of the decrease in edge distance over time. Our suggestion would be to perform AS-OCT preoperatively and to use the pIOL simulation program to estimate edge distance, but also to continue the evaluation of this edge distance during long-term follow-up.

Chapter 6 describes a case series with a new late-onset complication after pIOL implantation: downward decentration due to progressive shifting of the haptics through the iris tissue. This complication can be discovered during standard slitlamp examination, and can be objectively monitored by regular measurements of the edge distances using AS-OCT. This downward decentration is associated with a decrease in iris tissue. In our case series it does not result in a distance from the edge of the pIOL to the endothelium smaller than the recommended safety distance of $1.5 \mathrm{~mm}$. A careful follow-up of these patients is necessary to decide whether timely refixation is indicated. 
Chapter 7 shows how AS-OCT is used as a tool for preoperative patient selection and postoperative evaluation of pIOL position in a large multicenter study evaluating the safety and effectiveness of a new foldable iris-fixated toric pIOL. It confirmes that the preoperative pIOL simulation program was quite reliable when compared to postoperative morphometrics. The study also shows that the Artiflex Toric plOL effectively and safely corrects myopia and astigmatism, with stable and predictable visual results. Strict inclusion criteria, correct surgical technique according to the manufacturer's specifications, and accurate postoperative examinations are required to achieve these results. Despite these precautions we did encounter non-pigment and pigment depositions on the Artiflex lens at different time points during the study. To limit these precipitates in the future, the investigators of the current study mention some of the most important patient selection criteria to be: $A C D \geq 3.2 \mathrm{~mm}$ (measured from epithelium), a flat iris and/or crystalline lens rise $<600$ microns, and an open chamber angle. The latter two criteria should preferably be evaluated using an anterior segment imaging device. Furthermore, subconjunctival steroids at the end of surgery and topical corticosteroids for at least 4 weeks are recommended. Overall, this lens can compete against the Toric Artisan pIOL, with the great benefit of the Artiflex Toric needing a smaller incision resulting in a faster visual recovery.

AS-OCT can also be used to evaluate the treatment depth of corneal collagen crosslinking $(C X L)$ in patients with progressive keratoconus. Chapter $\mathbf{8}$ demonstrates that the Visante OCT is able to visualize a stromal demarcation line after CXL. This line indicates the transition zone between the crosslinked anterior corneal stroma and the untreated posterior corneal stroma, and can be found within the first 3 months after the treatment, being most clearly visible 1 month postoperatively. The depth of the line can be accurately measured with AS-OCT. A deeper demarcation line depth is associated with a larger decrease in corneal thickness after the treatment. We believe that this decrease in corneal thickness implies a compacting process of corneal lamellae and a strengthening of collagen fibers. In terms of clinical outcome, all clinical keratoconus parameters remained stable from 3 to 12 months of follow-up after corneal cross-linking, thereby indicating a stabilization of keratoconus on the short term without the occurrence of clinically significant side effects. A longer follow-up will be needed to evaluate the long-term stabilizing effect of corneal cross-linking on the progression of keratoconus.

Chapter 9 presents the results of a prospective study investigating the preoperative risk factors for postoperative corneal decompensation after cataract surgery in patients with Fuchs endothelial dystrophy. After logistic regression analysis, only preoperative CCT measured with AS-OCT was a significant predictor of corneal decompensation. All other preoperative and intraoperative parameters did not significantly contribute. The presented prediction model demonstrates that a pre- 
operative CCT above 620 microns results in an increased risk of needing corneal transplantation. For each 10 microns increase in preoperative CCT, the odds of developing corneal decompensation increases 1.7 times. We believe this model may assist ophthalmologists in patient selection and preoperative counselling, with noncontact corneal thickness measurement using AS-OCT as a key parameter. In terms of comparing torsional versus longitudinal phacoemulsification in these Fuchs patients, torsional phacoemulsification results in a significantly lower cumulative dissipated energy (CDE) and a shorter total ultrasound time. However, on the long run and in the hands of an experienced surgeon, there are no significant differences. 



\section{SAMENVATTING}

Optical coherence tomography (OCT) van het voorsegment is een techniek die zich de laatste jaren erg snel ontwikkelt. Het betreffende apparaat visualiseert het voorsegment van het oog zonder ermee in contact te komen. Het doel van dit proefschrift was om de mogelijkheden van voorsegment-OCT, in het bijzonder de Visante OCT, te ontdekken en te evalueren met de nadruk op refractiechirurgie, cataractchirurgie en corneale cross-linking.

Hoofdstuk 1 vat de huidige mogelijkheden van de voorsegment-OCT voor onderzoek en praktijk samen in een review. Er kunnen verschillende biometriemetingen worden uitgevoerd, zoals een kwantitatieve en kwalitatieve evaluatie van de kamerhoek, het meten van de dikte van de cornea, de diepte van de voorste oogkamer (VOK), de afstand tussen de kamerhoeken, de lens rise en de dikte van de eigen lens. Ook pathologische veranderingen in het oog kunnen in beeld worden gebracht, bijvoorbeeld cornea-opaciteiten, cellen in de voorste oogkamer bij uveitis en intraoculaire corpora aliena. Na refractiechirurgie kan de dikte van een LASIKflap, de diepte van intracorneale ringsegmenten en de veiligheidsafstanden van een fake intraoculaire lens (IOL) worden gemeten. Tevens kunnen veranderingen in het voorsegment na lamellaire of penetrerende hoornvliestransplantaties in beeld worden gebracht, zelfs als het hoornvlies troebel is, bijvoorbeeld kort na de operatie.

Om de betrouwbaarheid van metingen met de Visante OCT te bepalen, worden deze in Hoofdstuk 2 vergeleken met de Pentacam (een Scheimpflug-apparaat) en de Orbscan II. Bij zowel gezonde vrijwilligers, als patiënten met een fake IOL is met behulp van deze 3 apparaten de centrale corneadikte (CCT) en de VOK-diepte bepaald. Om de reproduceerbaarheid van metingen met de Visante OCT te testen, worden er achtereenvolgens drie metingen uitgevoerd door dezelfde persoon. De reproduceerbaarheid van CCT en VOK-diepte metingen met de Visante OCT is goed, met kleine standaarddeviaties. Wanneer de meetwaarden echter vergeleken worden met de Pentacam en Orbscan II, zijn de verschillen dusdanig significant dat deze niet gewoonweg tegen elkaar uitgewisseld kunnen worden.

Hoofdstuk 3 evalueert de positie van verschillende typen iris-gefixeerde fake IOL's in de voorste oogkamer met behulp van de Visante OCT. Tevens wordt het effect van deze positie op het cornea-endotheel onderzocht. De afstand van de rand van het optiek van de fake IOL tot het cornea-endotheel (edge distance) wordt beschouwd als de kortste afstand tussen beide. In het verleden is reeds aangetoond dat jaarlijkse metingen van de endotheelceldichtheid (ECD) voor en na fake IOL implantatie verplicht zijn om het lange-termijn effect van deze lenzen op het 
endotheel te kunnen monitoren. Onze studie stelt vast dat een kortere edge distance geassocieerd is met een hoger endotheelcelverlies. Daarom vinden wij dat naast jaarlijkse ECD-metingen, ook voorste oogkamer morfometrie moet worden verricht gedurende de follow-up van patiënten met een fake IOL. Vooral omdat onderzoek heeft aangetoond dat de eigen lens met de leeftijd steeds verder naar voren komt, waardoor de edge distance met de tijd zal afnemen.

Hoofdstuk 4 onderzoekt de precisie van een nieuw preoperatief simulatieprogramma in de Visante OCT, speciaal ontworpen voor iris-gefixeerde fake IOL's. Het artikel vergelijkt de preoperatieve voorste oogkamer morfometrie met de daadwerkelijke postoperatieve positie van de fake IOL. De volgende afstanden zijn gemeten: centrum van IOL tot endotheel, rand van IOL tot endotheel (nasaal en temporaal) en achterkant van IOL tot eigen lens. Bland-Altman plots laten zien dat er kleine verschillen zijn tussen de gesimuleerde afstanden en de daadwerkelijke postoperatieve afstanden. Er wordt echter wel een behoorlijke spreiding in de getallen gevonden, tussen de $0.24 \mathrm{~mm}$ en $0.29 \mathrm{~mm}$, welke mogelijk klinisch relevant zijn. Eén van de parameters die verantwoordelijk is voor deze spreiding is de preoperatieve pupildiameter. Hoe groter de pupil op de preoperatieve scan, des te verder moet de gesimuleerde IOL naar de achterkant van het irisweefsel worden geplaatst. In zijn totaliteit is het fake IOL simulatieprogramma een zeer goed bruikbaar additioneel hulpmiddel gedurende het preoperatieve selectieproces van patiënten die een fake IOL zouden willen.

Nadat de voorgaande hoofdstukken het belang van het meten van de edge distance voor en na fake IOL implantatie hebben laten zien, presenteren wij in Hoofstuk $\mathbf{5}$ een lineair model welke oogartsen kan helpen bij de selectie en follow-up van patiënten. Dit lineaire model voorspelt ECD gedurende de follow-up van irisgefixeerde fake IOL's, waarbij de edge distance, de leeftijd van de patiënt en de preoperatieve ECD gebruikt wordt. De preoperatieve simulatie is hierin een gemakkelijk instrument om de edge distance te bepalen, welke gebruikt kan worden in het gepresenteerde model. We weten echter dat de VOK-diepte afneemt met de leeftijd. Dit kan resulteren in een afname van de edge distance. Een langere followup met voorsegment-OCT zal nodig zijn om het effect van de leeftijdsgerelateerde veranderingen in de eigen lens op de edge distance te bepalen. Wij hopen dat dit zal leiden tot de ontwikkeling van een adequate wiskundige beschrijving van het postoperatieve endotheelcelverlies met een nauwkeurige schatting van de afname van de edge distance in de tijd. Wij raden aan om preoperatief de fake IOL-simulatie van de voorsegment-OCT te gebruiken om de edge distance te kunnen inschatten en postoperatief deze afstand jaarlijks te blijven vervolgen samen met de ECD. 
Hoofdstuk 6 beschrijft een serie patiënten met een nieuwe complicatie na fake IOL implantatie die op de lange termijn kan optreden. Het betreft decentratie van de fake IOL door het zakken van de haptics (pootjes van de IOL) door het irisweefsel. Deze complicatie kan worden gezien bij spleetlamponderzoek en kan kwantitatief worden vervolgd door regelmatig voorste oogkamer morfometrie te verrichten. Het vóórkomen van decentratie is geassocieerd met een afname van irisweefsel. In onze serie resulteert het echter niet in een edge distance kleiner dan de in de literatuur geadviseerde afstand van $1.5 \mathrm{~mm}$. Deze patiënten moeten nauwkeurig worden vervolgd om tijdig te kunnen beslissen of refixatie geïndiceerd is, bijvoorbeeld door een sterke afname van de ECD en/of de edge distance.

Hoofdstuk 7 laat zien hoe de voorsegment-OCT gebruikt kan worden voor preoperatieve patiëntselectie en postoperatieve evaluatie van de fake IOL-positie. De veiligheid en effectiviteit van een nieuwe vouwbare iris-gefixeerde torische fake IOL wordt in een grote multicenter studie geëvalueerd. De studie bevestigt dat de preoperatieve fake IOL simulatie een betrouwbare voorspeller is van de daadwerkelijke postoperatieve metingen. Tevens wordt de Torische Artiflex fake IOL effectief en veilig bevonden in het corrigeren van myopie en astigmatisme, met stabiele en voorspelbare resultaten. Strenge inclusie-criteria, een correcte operatieve techniek zoals voorgeschreven door de fabrikant, en nauwkeurige postoperatieve onderzoeken zijn noodzakelijk om deze resultaten te behalen. Ondanks deze voorzorgsmaatregelen zagen wij deposities op de Artiflex lens gedurende de studie. Om deze deposities in de toekomst tot een minimum te beperken, noemen de onderzoekers van de studie een aantal belangrijke selectie-criteria: VOK diepte $\geq 3.2 \mathrm{~mm}$ (vanaf het epitheel gemeten), vlakke iris configuratie en/of lens rise $<600$ micron, en een open kamerhoek. De laatste twee criteria dienen bij voorkeur geëvalueerd te worden met behulp van een beeldvormende techniek voor het voorsegment, zoals de Visante OCT. Tevens wordt aanbevolen om steroïden aan het einde van de operatie subconjunctivaal achter te laten en topicale steroïden gedurende minstens 4 weken na de operatie voor te schrijven. Deze lens kan goed concurreren tegen de Torische Artisan fake IOL. Het grote voordeel van de vouwbare Torische Artiflex lens is de kleinere incisie, welke resulteert in een sneller visueel herstel.

Voorsegment-OCT kan ook worden gebruikt na corneale cross-linking (CXL) om de diepte van de behandeling te evalueren. Hoofdstuk 8 demonstreert de mogelijkheid om met de Visante OCT een stromale demarcatielijn na CXL te visualiseren. Deze lijn geeft de overgangszone tussen het behandelde anterieure corneale stroma en onbehandelde posterieure stroma weer. Deze kan worden gezien gedurende de eerste drie maanden na de behandeling en is het duidelijkst zichtbaar één maand postoperatief. De diepte van de demarcatielijn kan nauwkeurig worden gemeten met de Visante OCT. Een diepere demarcatielijn is geassocieerd met een grotere afname 
van corneadikte na de behandeling. Onze hypothese is dat deze afname van de corneadikte een gevolg is van het compacter worden van de cornea-lamellen met een versteviging van de collageenvezels. Wanneer we kijken naar de klinische uitkomstmaten zien we dat alle keratoconus-parameters stabiel blijven tussen 3 en 12 maanden na CXL. Dit wijst op een stabilisatie van de keratoconus tot 1 jaar na de behandeling zonder het optreden van klinisch significante bijwerkingen. Een langere follow-up is noodzakelijk om de effecten van CXL op de progressie van keratoconus op de lange termijn vast te kunnen stellen.

Hoofdstuk 9 presenteert de resultaten van een prospectieve studie bij patiënten met Fuchs' endotheeldystrofie en cataract. We gaan op zoek naar de preoperatieve risicofactoren van postoperatieve cornea-decompensatie na cataractchirurgie in deze kwetsbare patiëntengroep. Na logistische regressie analyse blijkt alleen preoperatieve CCT, gemeten met de Visante OCT, een significante voorspeller voor cornea-decompensatie. Alle andere preoperatieve en intraoperatieve parameters vertonen geen significante bijdrage. Er wordt een model gepresenteerd die demonstreert dat een preoperatieve CCT > 620 micron resulteert in een verhoogd risico op cornea-decompensatie. Voor elke 10 micron toename van de preoperatieve CCT, stijgt de kans op het ontwikkelen van cornea-decompensatie met 1.7 keer. Dit model kan oogartsen helpen tijdens het preoperatieve selectieproces en het gesprek met de patiënt ten aanzien van de postoperatieve prognose, waarbij de corneadikte gemeten met de Visante OCT op de voorgrond staat. 
Dankwoord

Curriculum Vitae

List of Publications 


\section{DANKWOORD}

Het schrijven van dit dankwoord maakt mij er extra van bewust dat dit proefschrift alleen maar tot stand heeft kunnen komen met de hulp van vele anderen. Niet alleen op wetenschappelijk vlak, maar ook voor wat ontspanning op z'n tijd, zodat ik mijn enthousiasme voor 'het onderzoek doen' niet verloor. Een aantal mensen zou ik graag persoonlijk willen bedanken.

Prof. dr. RMMA Nuijts. Beste Rudy, nadat jij tijdens mijn sollicitatie (als enige) onder de indruk bleek van mijn cijferlijst, had ik het geluk om aangenomen te worden als arts-onderzoeker. Onder het mom van 'we kijken wel hoe ver je komt in een jaar' begon ik mijn research traject. Ik had nooit gedacht dat ik er zoveel plezier aan zou beleven. Jouw eeuwige enthousiasme en creativiteit zorgden voor een prettige samenwerking. En tot op heden blijf ik geboeid door jouw drijfveren. Bedankt voor alle mogelijkheden die ik heb gekregen.

Prof. dr. CAB Webers. Beste Carroll, als mijn nieuwe opleider en promotor, wil ik u graag bedanken voor de faciliteiten die u mij heeft geboden om mijn onderzoek tot een goed einde te kunnen brengen. De extra tijd die ik kreeg om bijvoorbeeld naar congressen te kunnen gaan en mijn onderzoekspatiënten te kunnen vervolgen, ondanks de start van mijn opleiding, hebben mij erg geholpen. Ook Prof. dr. F. Hendrikse wil ik bedanken voor alle mogelijkheden in de tijd dat hij nog mijn opleider was.

Dr. T.T.J.M. Berendschot. Beste Tos, ik ging altijd zenuwachtig met mijn Excel- en SPSS-bestanden bij je naar binnen. De eerste maanden verliet ik vaak gedesillusioneerd je kamer. Maar na wat statistiekcursussen begon ik het steeds beter te begrijpen, en na een tijdje had ik zelfs het idee dat ik enige discussie met je kon voeren over de berekeningen. Bedankt voor al je hulp en nuttige tips bij het maken van de statistische modellen in dit proefschrift. Ook voor je altijd kritische blik op onze klinische onderzoeken. Je wist er altijd weer voor te zorgen dat wij met andere ogen naar de data gingen kijken, wat leidde tot verrassende uitkomsten.

De leden van de beoordelingscommissie, prof. dr. H.W.M. Steinbusch, dr. C.J. Budo, prof. dr. R.R.W.J. van der Hulst, prof. dr. N.M. Jansonius en prof. dr. G.P.M. Luyten voor de bereidheid om mijn proefschrift te beoordelen. Anders had ik hier nu niet gestaan.

De gehele afdeling Oogheelkunde, het secretariaat, Astrid Hacking en in het bijzonder Ellen Vrancken, voor alle hulp bij het afhandelen van de brieven en andere administatieve en organisatorische problemen. 
De 'onderzoekers'. In de afgelopen jaren is het aantal onderzoekers exponentieel gestegen. De meesten waar ik mijn onderzoekstijd mee begon zijn nu collega AIOS. Bedankt voor de vele lunches in de mensa van de Unversiteit, tea-time breaks, borrels en etentjes. Dit alles heeft mijn onderzoekstijd niet alleen leerzaam maar ook erg gezellig gemaakt!

Mijn paranimfen: Myrtille en Nienke. Myrt, de afgelopen 10 jaar hebben we veel meegemaakt samen. Van onze gezamenlijke ontgroening tot nu (eindelijk) mijn promotie. Je hebt me altijd met raad en daad bijgestaan. Jouw 'drive' en enthousiasme voor de geneeskunde verwonderen mij nog elke dag. Hopelijk gaat jouw promotie er ook snel van komen en kun je eindelijk aan die felbegeerde opleiding tot gynaecoloog beginnen! Nienke, de laatste jaren hebben we samen veel congressen in verschillende landen bezocht. Bedankt voor de gezellige tijd als kamergenootje, lunch-date, wijn- en bierproefmaatje, reisgenoot, en als fijne collega. Bedankt voor je hulp bij die lastige astigmatisme-berekeningen! Zonder jou was ik daar nu waarschijnlijk nog mee aan het worstelen.

De dames van Sterre, voor de nodige ontspanning op onze maandelijkse vrijdagavondborrels. En sinds kort voor de nuttige tips over spenen, rijstebloem en wipstoeltjes.

Mijn schoonfamilie, voor de interessante discussies, maar vooral ook voor de aanhoudende interesse die jullie toonden in de vorderingen van mijn promotie.

Pap en mam, bedankt voor jullie eeuwige vertrouwen. En voor de opbeurende telefoongesprekken op moeilijke momenten, die mij weer tot nieuwe inzichten brachten en de moed gaven om door te gaan.

Steef, voor je optimisme en enthousiasme. Hanna boft maar met zo'n tante! En samen met Ed, voor de fijne afleiding tijdens onze gezamenlijke vakanties.

Lieve Koen, bedankt voor al je liefde, vertrouwen, en steun, en natuurlijk voor onze dochter. Maar ook voor je creativiteit, en je taal- en spellingscorrecties. Op naar het volgende feestje op 4 oktober 2014, ik heb er zin in!

Lieve Hanna, eigenlijk heb jij het grootste gedeelte van mijn promotieonderzoek niet meegemaakt. De laatste maanden ervan, en dus de eerste maanden van jouw leven, heb ik iets te veel achter mijn computer gebivakkeerd (soms met jou slapend in de draagzak). Ik ben blij dat je er bent! Samen met papa gaan we nu genieten. 



\section{CURRICULUM VITAE}

Muriël Doors was born on March $7^{\text {th }} 1983$ in Eindhoven, The Netherlands. Between 1995 and 2001 she attended the Lorentz Casimir Lyceum in Eindhoven. Since she graduated with honours, she could start her medical study right away at the University of Maastricht. During her last year of college, she decided to take an elective internship in cardio-thoracic surgery at the Catharina Hospital in Eindhoven. In 2007 she received her medical degree with honours. Her interest in Ophthalmology became evident during an additional internship at the Catharina Hospital and in februari 2008 she started working as a researcher at the department of Ophthalmology, Maastricht University Medical Center. In april 2009 she started her residency in Ophthalmology in the same hospital and continued her research, which eventually lead to this thesis. She presented parts of this thesis at congresses of the American Society of Cataract and Refractive Surgeons (ASCRS 2009, 2010), the European Society of Cataract and Refractive Surgeons (ESCRS 2008, 2009, 2010, 2011), and several national meetings and congresses. 


\section{LIST OF PUBLICATIONS}

Doors M, Cals DW, Berendschot TTJM, de Brabander J, Hendrikse F, Webers CAB, Nuijts RMMA. Influence of anterior chamber morphometrics on endothelial cell changes after phakic intraocular lens implantation. J Cataract Refract Surg 2008;34:2110-2118.

Cruysberg LP, Doors M, Berendschot TTJM, de Brabander J, Webers CAB, Nuijts RMMA. Iris-fixated anterior chamber phakic intraocular lens for myopia moves posteriorly with mydriasis. J Refract Surg 2009;25:394-396.

Doors M, Berendschot TTJM, Hendrikse F, Webers CAB, Nuijts RMMA. Value of preoperative phakic intraocular lens simulation using optical coherence tomography. J Cataract Refract Surg 2009;35:438-443.

Doors M, Cruysberg LP, Berendschot TTJM, de Brabander J, Verbakel F, Webers CAB, Nuijts RMMA. Comparison of central corneal thickness and anterior chamber depth measurements using three imaging technologies in normal eyes and after phakic intraocular lens implantation. Graefes Arch Clin Exp Ophthalmol 2009;247:11391146.

Doors M, Eggink FA, Webers CAB, Nuijts RMMA. Late-onset decentration of irisfixated phakic intraocular lenses: a case series. Am J Ophthalmol 2009;147:9971003.

Doors M, Tahzib NG, Eggink FA, Berendschot TTJM, Webers CAB, Nuijts RMMA. Use of anterior segment optical coherence tomography to study corneal changes after collagen cross-linking. Am J Ophthalmol 2009;148:844-851.

Cruysberg LP, Doors M, Verbakel F, Berendschot TTJM, de Brabander J, Nuijts RMMA. Evaluation of the Lenstar LS 900 all-in-one non contact biometry meter. $\mathrm{Br} \mathrm{J}$ Ophthalmol 2010;94:106-110.

Doors M, Berendschot TTJM, Webers CAB, Nuijts RMMA. Model to predict endothelial cell loss after iris-fixated phakic intraocular lens implantation. Invest Ophthalmol Vis Sci. 2010;51:811-815.

Doors M, Berendschot TTJM, de Brabander J, Webers CAB, Nuijts RMMA. Value of optical coherence tomography for anterior segment surgery. J Cataract Refract Surg 2010;36:1213-1229. 
de Vries NE, Webers CAB, Verbakel F, de Brabander J, Berendschot TTJM, Cheng YY, Doors M, Nuijts RMMA. Visual outcome and patient satisfaction after multifocal intraocular lens implantation: aspheric versus spherical design. J Cataract Refract Surg 2010;36:1897-1904.

Paarlberg JC, Doors M, Webers CAB, Berendschot TTJM, van den Berg TJTP, Nuijts RMMA. The effect of iris-fixated foldable phakic intraocular lenses on retinal straylight. Am J Ophthalmol 2011; 152:969-975.

Doors M, Budo CJ, Christiaans BJ, Luger M, Marinho AA, Dick HB, Güell JJ, Nuijts RMMA. Artiflex Toric foldable phakic intraocular lens: short-term results of a prospective European multicenter study. Am J Ophthalmol 2012; 154:730-739.

Doors M, Berendschot TTJM, Touwslager W, Webers CAB, Nuijts RMMA. Phacopower modulation and the risk for postoperative corneal decompensation: a randomized trial of cataract surgery in Fuchs' endothelial dystrophy. JAMA Ophthalmol 2013; 131:1443-50. 